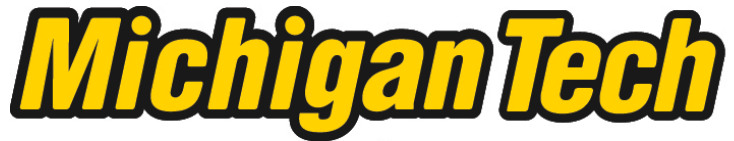 \\ Michigan Technological University Create the Future Digital Commons @ Michigan Tech
}

Dissertations, Master's Theses and Master's Reports - Open

Dissertations, Master's Theses and Master's

Reports

2011

\section{ATP modeling of internal transformer faults for relay performance testing}

Elizaveta O. Egorova

Michigan Technological University

Follow this and additional works at: https://digitalcommons.mtu.edu/etds

Part of the Electrical and Computer Engineering Commons

Copyright 2011 Elizaveta O. Egorova

\section{Recommended Citation}

Egorova, Elizaveta O., "ATP modeling of internal transformer faults for relay performance testing", Master's report, Michigan Technological University, 2011.

https://doi.org/10.37099/mtu.dc.etds/577

Follow this and additional works at: https://digitalcommons.mtu.edu/etds

Part of the Electrical and Computer Engineering Commons 


\title{
ATP MODELING OF INTERNAL TRANSFORMER FAULTS FOR RELAY PERFORMANCE TESTING
}

By

Elizaveta O. Egorova

\author{
A REPORT \\ Submitted in partial fulfillment of the requirements for the degree of \\ MASTER OF SCIENCE \\ Electrical Engineering \\ MICHIGAN TECHNOLOGICAL UNIVERSITY \\ 2011 \\ C2011 Elizaveta O. Egorova
}



This report, "ATP Modeling of Internal Transformer Faults for Relay Performance Testing," is hereby approved in partial fulfillment of the requirements for the Degree of MASTER OF SCIENCE IN ELECTRICAL ENGINEERING.

Department of Electrical and Computer Engineering

Signatures:

Report Advisor

Dr. Bruce A. Mork

Department Chair

Dr. Daniel R. Fuhrmann

Date 



\section{Acknowlegements}

I wish to express my deep gratitude to my advisor, Dr. Bruce A. Mork, for his support and encouragement during the time I spent working on my Master's degree.

My deep thanks are to John R. Drozynski of Doble, who loaned the F6150 Power System Simulator for my experiments, and to Jon Larson of SEL, who helped me to understand the settings of the SEL-487E relay.

I thank the Fulbright program which brought me to Michigan Tech and sponsored my MSEE education.

I thank the Electrical Machines Chair at Urals State University for my first steps in the Electrical Engineering world as well as specialists of the Hydrogenerator Department of former UETM Company in Yekaterinburg, Russia, with whom I worked for 6 years performing electromagnetic calculations and designing drawings for stator winding diagrams.

I thank N.N. Novikov and E.S. Elbert, people who have influenced me by being great examples of knowledge and commitment to the Electrical Engineering world.

My parents deserve the special gratitude for making me move further and further ahead, striving for something better than I have now.

My kind gratitudes are to my old friends in Russia and new friends whom I have met in the USA. 



\section{Table of Contents}

Acknowlegements...................................................................................................... V

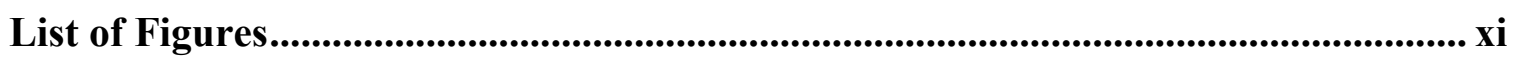

List of Tables ........................................................................................................................ xvii

Abstract.................................................................................................................... xix

CHAPTER 1 Introduction ................................................................................................. 1

CHAPTER 2 Background ................................................................................................... 3

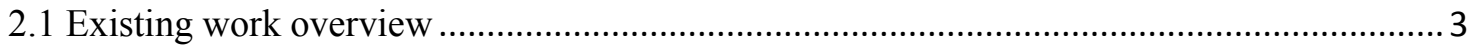

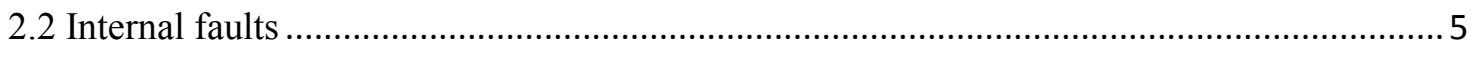

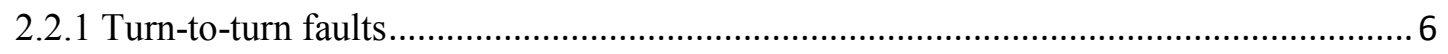

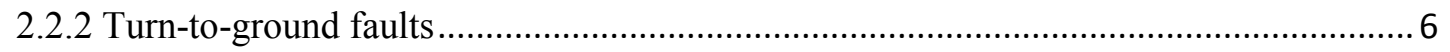

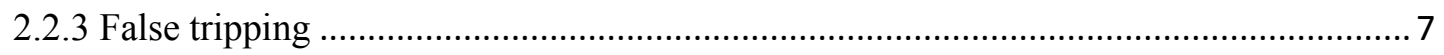

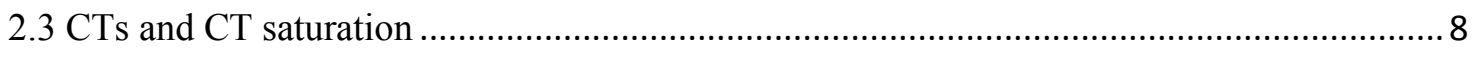

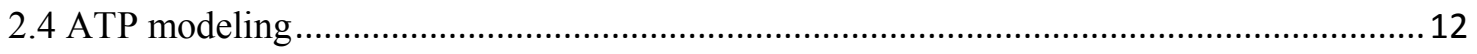

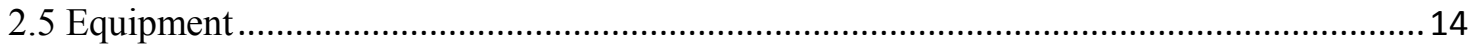

2.6 The SEL-487E transformer protection relay …………………………………………. 15

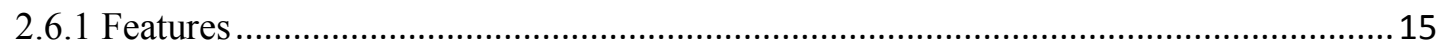

2.6.2 Phase percentage restraint differential element characteristics.....................................17

2.6.3 Negative-sequence percentage restraint differential element......................................... 18

2.6.4 Restricted earth-fault element .............................................................................. 20

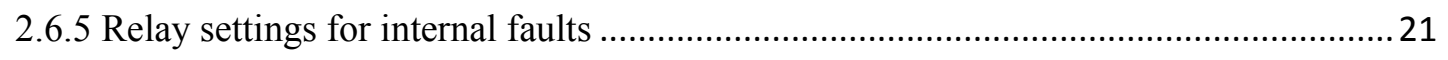

2.6.6 Event analysis and event report .............................................................................22

CHAPTER 3 Transformer Modeling for Internal Faults.............................................. 25

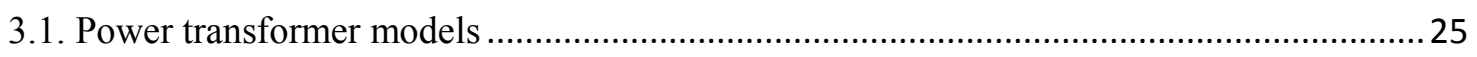

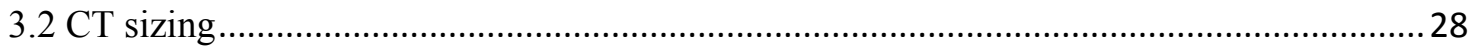

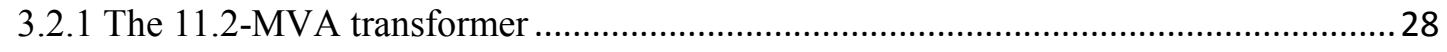

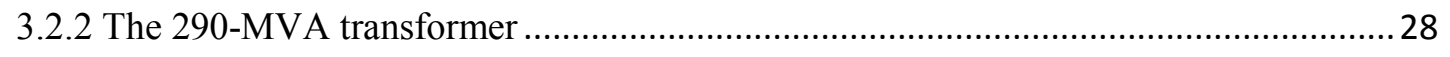

3.2.3 Summarized data about $\mathrm{CTs}$ used ........................................................................ 30

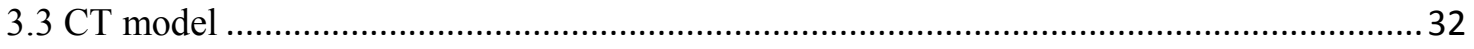




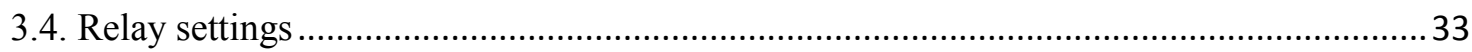

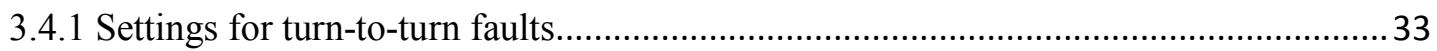

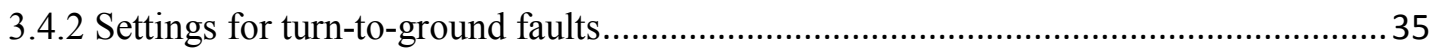

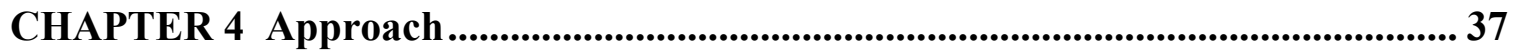

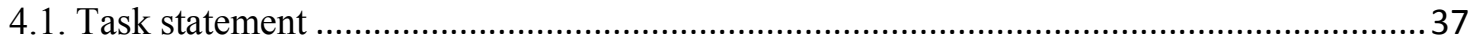

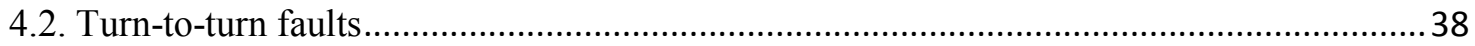

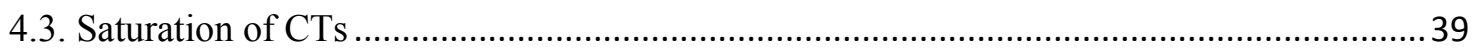

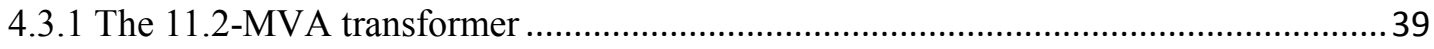

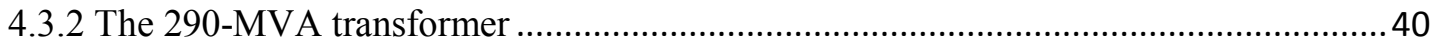

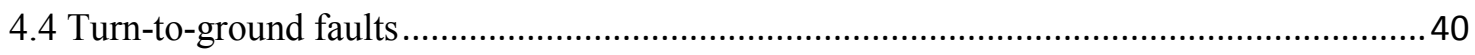

4.5 Test setups and application of waveforms ............................................................... 41

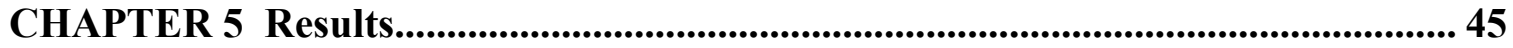

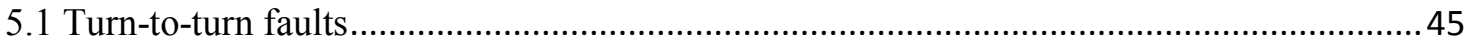

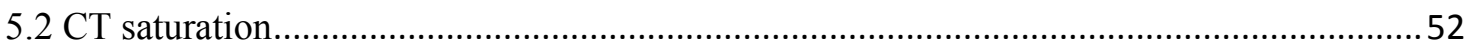

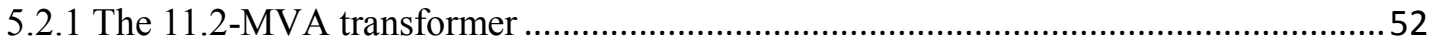

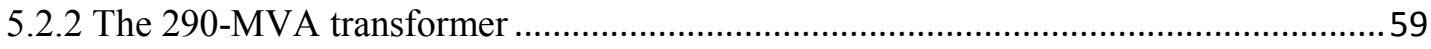

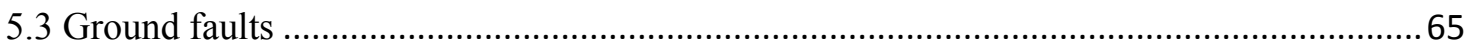

CHAPTER 6 Conclusions and Recommendations .............................................. 71

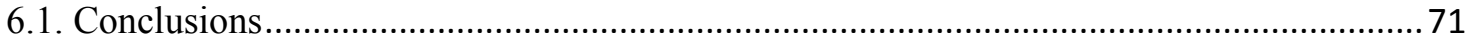

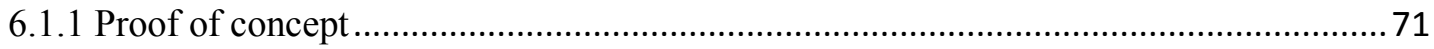

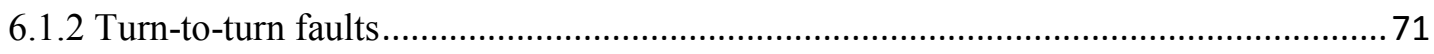

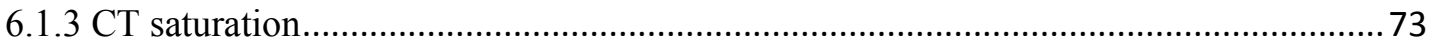

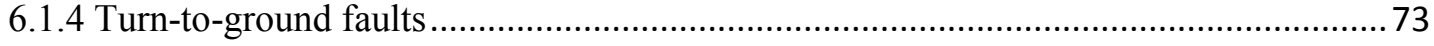

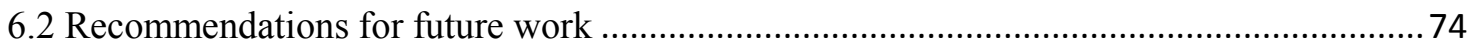

References...................................................................................................................... 75

Appendix A Transformer data ..................................................................................... 77

Appendix B Transformer ATP configurations ......................................................... 85

Appendix C Calculations................................................................................................... 97

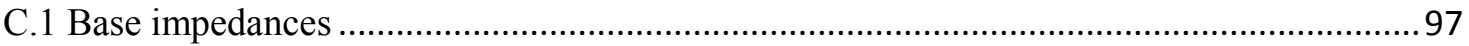

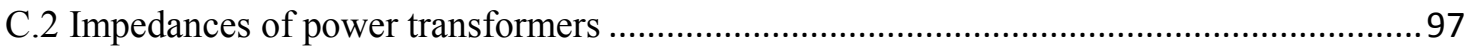

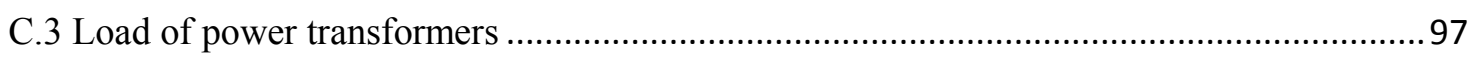




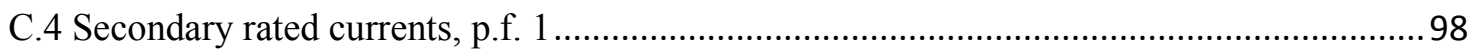

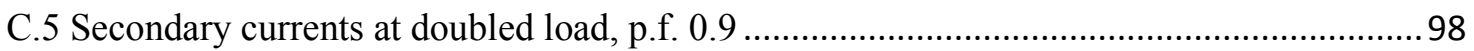

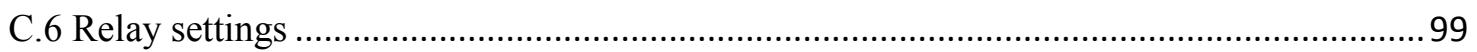

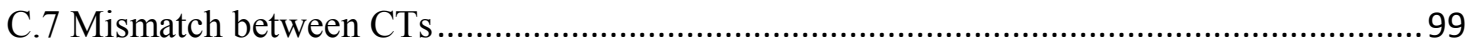

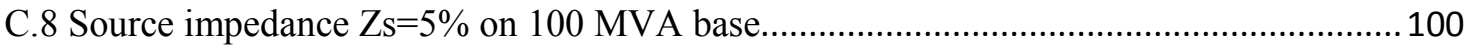

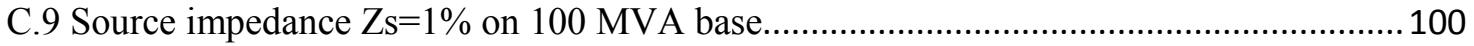

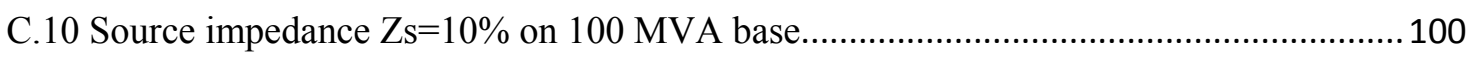

Appendix D $\lambda$-i characteristics of CTs used ............................................................. 101

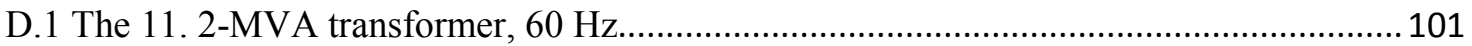

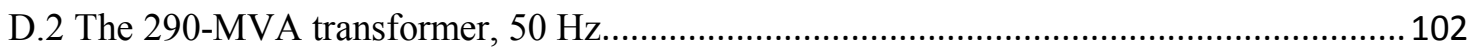

Appendix E Complete tables with results..................................................................... 103

E.1 Negative-sequence differential element sensititvity .................................................... 103

E.2 ATP results for turn-to-ground faults ...................................................................... 111

Appendix F Event reports ....................................................................................... 115

F.1 The 11.2-MVA transformer Event Report for turn-to-turn fault ..................................... 115

F.2 The 290-MVA transformer Event Report for turn-to-turn fault ....................................... 127

F.3 The 290-MVA transformer Event Report for turn-to-ground fault .................................. 139

Appendix G CT saturation results ................................................................. 149

G.1 The 11.2-MVA transformer, high-side 600:5 CTs tapped at 150:5 ............................... 149

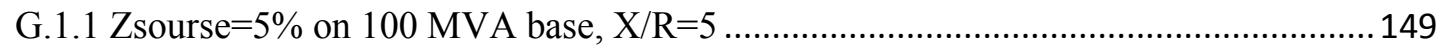

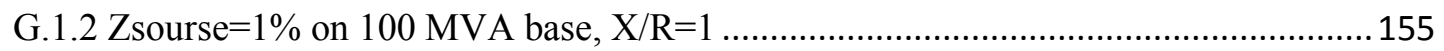

G.2 The 290-MVA transformer, high-side 1200:5 CTs tapped at 800:5 ............................... 162

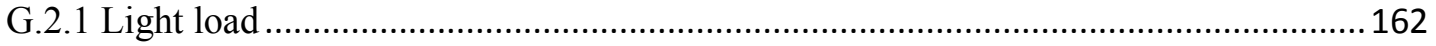

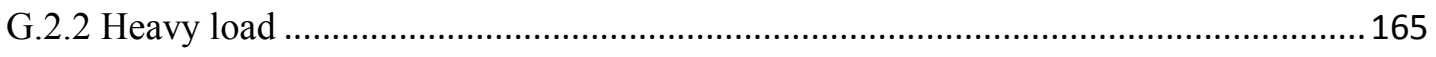

Appendix H Copyright permissions .............................................................................. 171 



\section{List of Figures}

1.1 Damaged transformer after the fire caused by an internal fault (reproduced from [1] with permission) ..................................................................

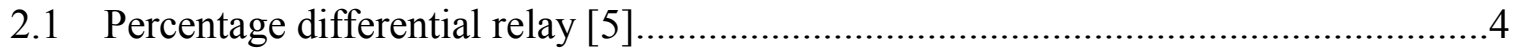

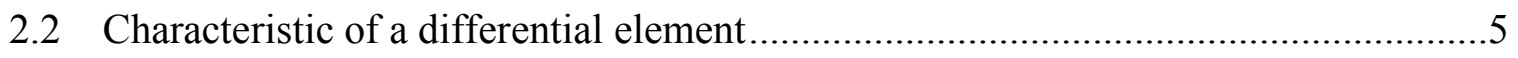

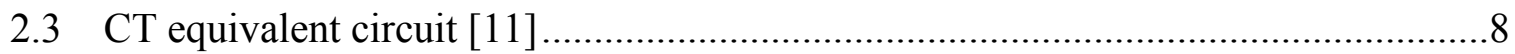

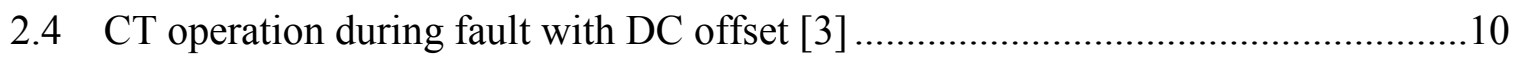

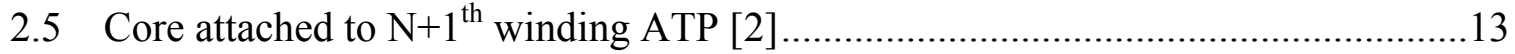

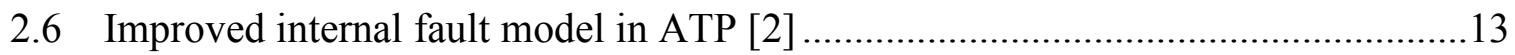

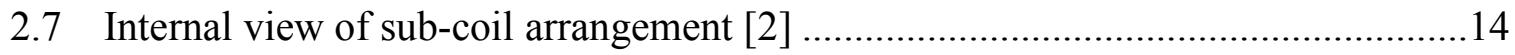

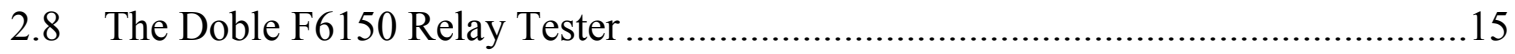

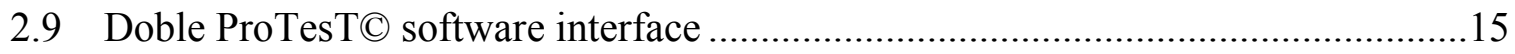

2.10 The SEL-487E transformer protection relay (reproduced from [15]

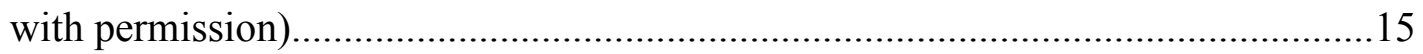

2.11 The AcSELerator QuickSet SEL-5030 software interface ………………..............16

2.12 Differential element characteristic (reproduced from [7] with permission) .............17

2.13 Sensitivity comparison of the phase-differential element and the negative-sequence differential element (reproduced from [7] with permission) ....................................19

2.14 REF application on wye-connected winding of a delta-wye transformer (reproduced from [7] with permission) ...............................................................2

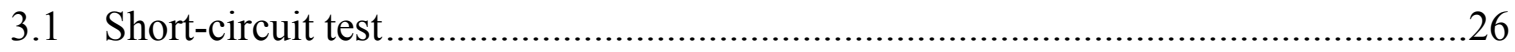

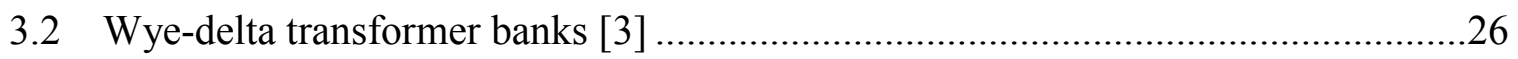

3.3 Differential relay connections for the delta-wye 11.2-MVA transformer [3] ..........27

3.4 Differential relay connections for the wye-delta 290-MVA transformer .................27

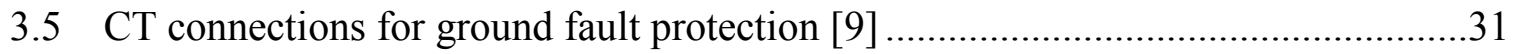

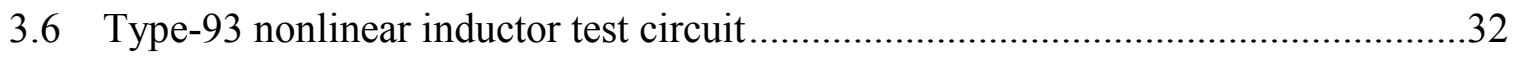

3.7 Current in Type-93 element at voltages above the saturation point ………..............33

3.8 CT model in ATP with Type-93 nonlinear inductor..................................................33

4.1 The Doble Tester-Relay test setup for turn-to-turn fault tests ...................................41

4.2 The Doble Tester-Relay test setup for turn-to-ground fault tests ..............................42

4.3 ProTesT@ current outputs for turn-to-turn fault experiments ...................................43

4.4 ProTesTC current outputs for turn-to-ground fault experiments .............................43

4.5 Currents from CTs in TRANS macro for a turn-to-turn fault experiment..................44

4.6 Analog tab settings in TRANS macro for a turn-to-turn fault experiments ..............44 
5.1 High security mode of the SEL-487E relay during turning on the Doble Tester .....46

5.2 Line currents and active digitals recorded by the relay for turn-to-turn fault in

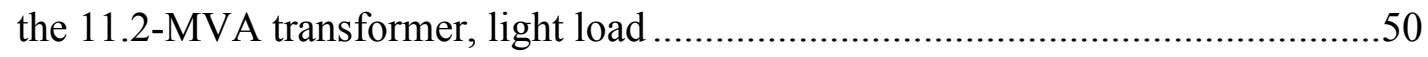

5.3 Line currents and active digitals recorded by the relay for turn-to-turn fault in

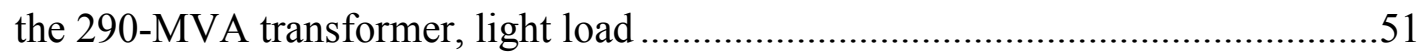

$5.411 .2 \mathrm{MVA}, \mathrm{Zs}_{\mathrm{s}}=5 \%$, light load, $\mathrm{R}_{\mathrm{TOT}}=0.256 \Omega$ : Phase-A CT currents......................53

5.5 11.2 MVA, Zs $=5 \%$, light load, $\mathrm{R}_{\mathrm{TOT}}=0.676 \Omega$ : Phase-A CT currents......................53

5.6 11.2 MVA, Zs=5\%, light load, $\mathrm{R}_{\mathrm{TOT}}=1.396 \Omega$ : Phase-A CT currents......................53

5.711 .2 MVA, $Z s=5 \%$, heavy load, $\mathrm{R}_{\mathrm{TOT}}=0.256 \Omega$ : Phase-A CT currents ...................54

$5.811 .2 \mathrm{MVA}, \mathrm{Zs}_{\mathrm{s}}=5 \%$, heavy load, $\mathrm{R}_{\mathrm{TOT}}=0.676 \Omega$ : Phase-A CT currents ...................54

$5.911 .2 \mathrm{MVA}, \mathrm{Zs}_{\mathrm{s}}=5 \%$, heavy load, $\mathrm{R}_{\mathrm{TOT}}=1.396 \Omega$ : Phase-A CT currents ...................54

$5.1011 .2 \mathrm{MVA}, \mathrm{Zs}_{\mathrm{s}}=1 \%$, light load, $\mathrm{R}_{\mathrm{TOT}}=0.256 \Omega$ : Phase-A CT currents......................55

5.11 11.2 MVA, Zs $=1 \%$, light load, $\mathrm{R}_{\mathrm{TOT}}=0.676 \Omega$ : Phase-A CT currents......................55

5.1211 .2 MVA, Zs=1\%, light load, $\mathrm{R}_{\mathrm{TOT}}=1.396 \Omega$ : Phase-A CT currents......................55

5.1311 .2 MVA, Zs=1\%, heavy load, $\mathrm{R}_{\mathrm{TOT}}=0.256 \Omega$ : Phase-A CT currents ...................56

5.1411 .2 MVA, $Z_{s}=1 \%$, heavy load, $\mathrm{R}_{\mathrm{TOT}}=0.676 \Omega$ : Phase-A CT currents ...................56

5.1511 .2 MVA, Zs=1\%, heavy load, $\mathrm{R}_{\text {Tот }}=1.396 \Omega$ : Phase-A CT currents ...................56

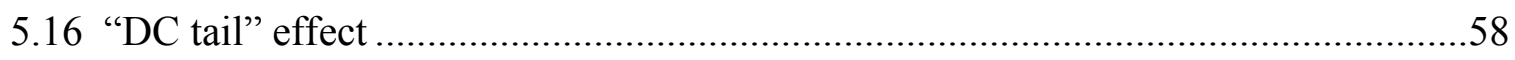

5.17 Primary current and distorted CT secondary current during fault ...........................58

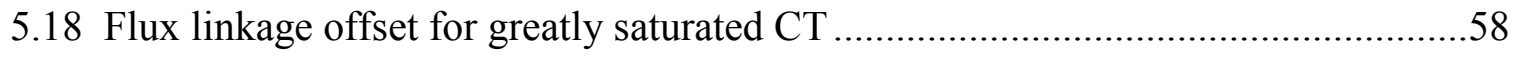

5.19 The 290-MVA transformer, three-phase through fault........................................59

5.20 290 MVA, three-phase through fault and 90\% turn-to-turn fault at phase A, light load.

5.21 290 MVA, three-phase through fault and 90\% turn-to-turn fault at phase $A$, heavy load 60

$5.22290 \mathrm{MVA}, \mathrm{Zs}=10^{-8} \Omega$, light load, $\mathrm{R}_{\mathrm{TOT}}=0.512 \Omega$ : Phase-A CT currents.................61

$5.23290 \mathrm{MVA}, \mathrm{Zs}_{\mathrm{s}}=10^{-8} \Omega$, light load, $\mathrm{R}_{\mathrm{TOT}}=0.932 \Omega$ : Phase-A CT currents.................61

$5.24290 \mathrm{MVA}, \mathrm{Zs}_{\mathrm{s}}=10^{-8} \Omega$, light load, $\mathrm{R}_{\mathrm{TOT}}=1.652 \Omega$ : Phase-A CT currents.................62

$5.25290 \mathrm{MVA}, \mathrm{Zs}_{\mathrm{s}}=10^{-8} \Omega$, heavy load, $\mathrm{R}_{\mathrm{TOT}}=0.512 \Omega$ : Phase-A CT currents...............62

$5.26290 \mathrm{MVA}, \mathrm{Zs}_{\mathrm{s}}=10^{-8} \Omega$, heavy load, $\mathrm{R}_{\mathrm{TOT}}=0.932 \Omega$ : Phase-A CT currents...............62

$5.27290 \mathrm{MVA}, \mathrm{Zs}_{\mathrm{s}}=10^{-8} \Omega$, heavy load, $\mathrm{R}_{\mathrm{TOT}}=1.652 \Omega$ : Phase-A CT currents...............63

5.28 Line currents and active digitals recordered by the relay for external three-phase fault on the 290-MVA transformer .................................65

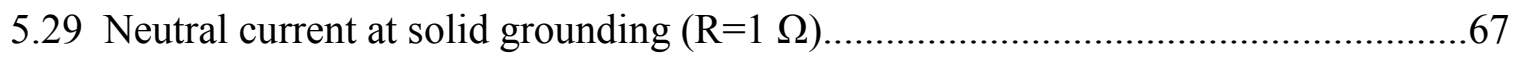

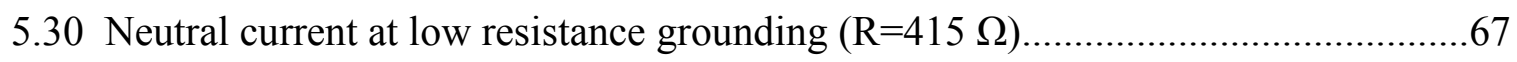

5.31 Line currents and active digitals recorded by the relay for turn-to-ground fault on the 290-MVA transformer 


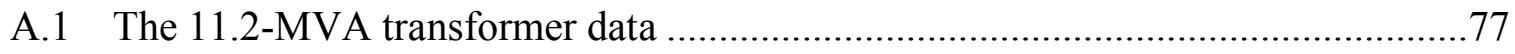

A.2 Magnetizing curve of $600: 5 \mathrm{CT}$ tapped at $150: 5$ ratio ............................................ 80

A.3 Magnetizing curve of $600: 5 \mathrm{CT}$ tapped at 400:5 ratio ..........................................81

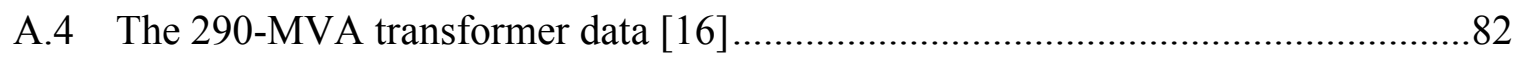

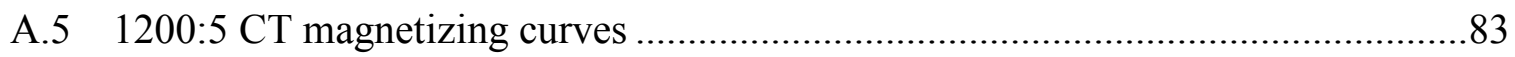

B.1 ATP configuration of the 11.2-MVA transformer for turn-to-turn faults,

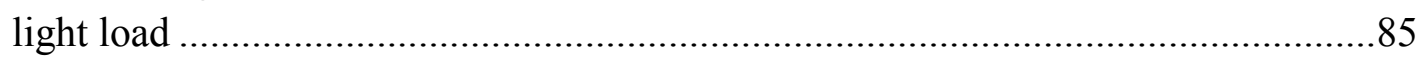

B.2 ATP configuration of the 11.2-MVA transformer for turn-to-turn faults,

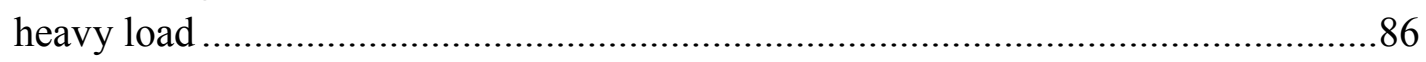

B.3 ATP configuration of the 290-MVA transformer for turn-to-turn faults,

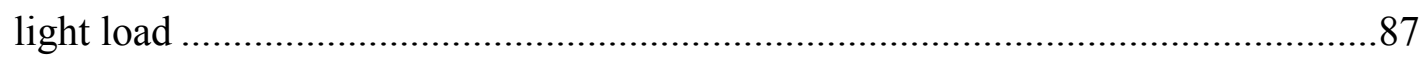

B.4 ATP configuration of the 290-MVA transformer for turn-to-turn faults, heavy load

B.5 ATP configuration of the 290-MVA transformer for turn-to-ground faults, solid grounding, light load

B.6 ATP configuration of the 290-MVA transformer for turn-to-ground faults, solid grounding, heavy load

B.7 ATP configuration of the 290-MVA transformer for turn-to-ground faults, low-resistance grounding, light load.

B.8 ATP configuration of the 290-MVA transformer for turn-to-ground faults, low-resistance grounding, heavy load.

B.9 ATP configuration of the 11.2-MVA transformer for CT saturation experiments, light load

B.10 ATP configuration of the 11.2-MVA transformer for CT saturation experiments, heavy load.

B.11 ATP configuration of the 290-MVA transformer for CT saturation experiments, light load

B.12 ATP configuration of the 290-MVA transformer for CT saturation experiments, heavy load.

F.1 Phasors screenshot for the 11.2-MVA transformer for turn-to-turn fault

F.2 Winding S Fundamental Metering for the 11.2-MVA transformer for turn-to-turn fault.

F.3 Currents from CTs in TRANS macro for the 11.2-MVA transformer for turn-to-turn fault.

F.4 ATP currents supplied to the SEL-487E relay from high-side CTs of the 11.2-MVA transformer for turn-to-turn fault

F.5 ATP currents supplied to the SEL-487E relay from low-side CTs of the 11.2-MVA transformer for turn-to-turn fault 
F.6 Phasors screenshot for the 290-MVA transformer for turn-to-turn fault 135

F.7 Winding S Fundamental Metering for the 290-MVA transformer for turn-to-turn fault 136

F.8 Currents from CTs in TRANS macro for the 290-MVA transformer for turn-to-turn fault .137

F.9 ATP currents supplied to the SEL-487E relay from high-side CTs of the 290-MVA transformer for turn-to-turn fault 138

F.10 ATP currents supplied to the SEL-487E relay from low-side CTs of the 290-MVA transformer for turn-to-turn fault 138

F.11 Phasors screenshot for the 290-MVA transformer for turn-to-ground fault. 146

F.12 Winding S Fundamental Metering for the 290-MVA transformer for turn-to-ground fault

F.13 Currents from CTs in TRANS macro for the 290-MVA transformer

for turn-to-ground fault .148

F.14 ATP currents supplied to the SEL-487E relay from high-side and neutral CTs of the 290-MVA transformer for turn-to-ground fault... .148

G.1 11.2 MVA, Zs=5\%, light load, $\mathrm{R}_{\mathrm{TOT}}=0.256 \Omega$ : Phase-A CT currents 149

G.2 11.2 MVA, $Z_{s}=5 \%$, light load, $\mathrm{R}_{\mathrm{TOT}}=0.256 \Omega$ : Phase-B CT currents

G.3 11.2 MVA, $Z_{s}=5 \%$, light load, $\mathrm{R}_{\mathrm{TOT}}=0.256 \Omega$ : Phase-C CT currents 150

G.4 11.2 MVA, Zs=5\%, light load, $\mathrm{R}_{\mathrm{TOT}}=0.676 \Omega$ : Phase-A CT currents 150

G.5 11.2 MVA, Zs $=5 \%$, light load, $\mathrm{R}_{\mathrm{TOT}}=0.676 \Omega$ : Phase-B CT currents 150

G.6 11.2 MVA, Zs=5\%, light load, $\mathrm{R}_{\mathrm{TOT}}=0.676 \Omega$ : Phase-C CT currents 151

G.7 11.2 MVA, Zs=5\%, light load, $\mathrm{R}_{\mathrm{TOT}}=1.396 \Omega$ : Phase-A CT currents 151

G.8 11.2 MVA, $Z_{\mathrm{s}}=5 \%$, light load, $\mathrm{R}_{\mathrm{TOT}}=1.396 \Omega$ : Phase-B CT currents ....................151

G.9 11.2 MVA, Zs $=5 \%$, light load, $\mathrm{R}_{\mathrm{TOT}}=1.396 \Omega$ : Phase-C CT currents .152

G.10 11.2 MVA, Zs $=5 \%$, heavy load, $\mathrm{R}_{\mathrm{TOT}}=0.256 \Omega$ : Phase-A CT currents..................152

G.11 11.2 MVA, Zs=5\%, heavy load, $\mathrm{R}_{\mathrm{TOT}}=0.256 \Omega$ : Phase-B CT currents ..................152

G.12 11.2 MVA, Zs $=5 \%$, heavy load, $\mathrm{R}_{\mathrm{TOT}}=0.256 \Omega$ : Phase-C CT currents ...................153

G.13 11.2 MVA, Zs=5\%, heavy load, $\mathrm{R}_{\mathrm{TOT}}=0.676 \Omega$ : Phase-A CT currents...................153

G.14 11.2 MVA, $Z_{s}=5 \%$, heavy load, $\mathrm{R}_{\text {TOT }}=0.676 \Omega$ : Phase-B CT currents ...................153

G.15 11.2 MVA, Zs=5\%, heavy load, $\mathrm{R}_{\mathrm{TOT}}=0.676 \Omega$ : Phase-C CT currents ..................154

G.16 11.2 MVA, Zs=5\%, heavy load, $\mathrm{R}_{\mathrm{TOT}}=1.396 \Omega$ : Phase-A CT currents..................154

G.17 11.2 MVA, Zs=5\%, heavy load, $\mathrm{R}_{\mathrm{TOT}}=1.396 \Omega$ : Phase-B CT currents ..................154

G.18 11.2 MVA, Zs $=5 \%$, heavy load, $\mathrm{R}_{\mathrm{TOT}}=1.396 \Omega$ : Phase-C CT currents ...................155

G.19 11.2 MVA, $Z_{s}=1 \%$, light load, $\mathrm{R}_{\mathrm{TOT}}=0.256 \Omega$ : Phase-A CT currents .....................155

G.20 11.2 MVA, Zs=1\%, light load, $\mathrm{R}_{\mathrm{TOT}}=0.256 \Omega$ : Phase-B CT currents ....................155

G.21 11.2 MVA, Zs=1\%, light load, $\mathrm{R}_{\mathrm{TOT}}=0.256 \Omega$ : Phase-C CT currents ....................156

G.22 11.2 MVA, Zs=1\%, light load, $\mathrm{R}_{\mathrm{TOT}}=0.676 \Omega$ : Phase-A CT currents .....................156

G.23 11.2 MVA, Zs=1\%, light load, $\mathrm{R}_{\mathrm{TOT}}=0.676 \Omega$ : Phase-B CT currents ....................156 
G.24 11.2 MVA, Zs=1\%, light load, $\mathrm{R}_{\mathrm{TOT}}=0.676 \Omega$ : Phase-C CT currents 157

G.25 11.2 MVA, Zs=1\%, light load, $\mathrm{R}_{\mathrm{TOT}}=1.396 \Omega$ : Phase-A CT currents .157

G.26 11.2 MVA, $Z s=1 \%$, light load, $\mathrm{R}_{\mathrm{TOT}}=1.396 \Omega$ : Phase-B CT currents 157

G.27 11.2 MVA, $Z s=1 \%$, light load, $\mathrm{R}_{\text {TOT }}=1.396 \Omega$ : Phase-C CT currents 158

G.28 11.2 MVA, Zs=1\%, heavy load, $\mathrm{R}_{\mathrm{TOT}}=0.256 \Omega$ : Phase-A CT currents...................158

G.29 11.2 MVA, $Z s=1 \%$, heavy load, $\mathrm{R}_{\mathrm{TOT}}=0.256 \Omega$ : Phase-B CT currents...................158

G.30 11.2 MVA, Zs=1\%, heavy load, $\mathrm{R}_{\mathrm{TOT}}=0.256 \Omega$ : Phase-C CT currents...................159

G.31 11.2 MVA, Zs=1\%, heavy load, $\mathrm{R}_{\mathrm{TOT}}=0.676 \Omega$ : Phase-A CT currents...................159

G.32 11.2 MVA, Zs=1\%, heavy load, $\mathrm{R}_{\mathrm{TOT}}=0.676 \Omega$ : Phase-B CT currents..................159

G.33 11.2 MVA, Zs=1\%, heavy load, $\mathrm{R}_{\mathrm{TOT}}=0.676 \Omega$ : Phase-C CT currents...................160

G.34 11.2 MVA, Zs=1\%, heavy load, $\mathrm{R}_{\mathrm{TOT}}=1.396 \Omega$ : Phase-A CT currents...................160

G.35 11.2 MVA, Zs=1\%, heavy load, $\mathrm{R}_{\mathrm{TOT}}=1.396 \Omega$ : Phase-B CT currents....................160

G.36 11.2 MVA, Zs=1\%, heavy load, $\mathrm{R}_{\mathrm{TOT}}=1.396 \Omega$ : Phase-C CT currents...................161

G.37 11.2 MVA, $Z s=5 \%$, heavy load, $\mathrm{R}_{\mathrm{TOT}}=1.396 \Omega$ : magnetizing

current of phase-A CT

G.38 11.2 MVA, $Z_{s}=5 \%$, heavy load, $\mathrm{R}_{\mathrm{TOT}}=1.396 \Omega$ : magnetizing current of phase-B CT.

G.39 11.2 MVA, Zs=5\%, heavy load, $\mathrm{R}_{\mathrm{TOT}}=1.396 \Omega$ : magnetizing current of phase-C CT. 162

G.40 290 MVA, Zs $=10^{-8} \Omega$, light load, $\mathrm{R}_{\mathrm{TOT}}=0.512 \Omega$ : Phase-A CT currents.................162

G.41 290 MVA, $Z s=10^{-8} \Omega$, light load, $\mathrm{R}_{\mathrm{TOT}}=0.512 \Omega$ : Phase-B CT currents .................163

G.42 290 MVA, $Z s=10^{-8} \Omega$, light load, $\mathrm{R}_{\mathrm{TOT}}=0.512 \Omega$ : Phase-C CT currents .................163

G.43 290 MVA, $Z s=10^{-8} \Omega$, light load, $\mathrm{R}_{\text {TOT }}=0.932 \Omega$ : Phase-A CT currents.................163

G.44 290 MVA, Zs $=10^{-8} \Omega$, light load, $\mathrm{R}_{\mathrm{TOT}}=0.932 \Omega$ : Phase-B CT currents .................164

G.45 290 MVA, $Z s=10^{-8} \Omega$, light load, $\mathrm{R}_{\mathrm{TOT}}=0.932 \Omega$ : Phase-C CT currents .................164

G.46 290 MVA, $Z s=10^{-8} \Omega$, light load, $\mathrm{R}_{\mathrm{TOT}}=1.652 \Omega$ : Phase-A CT currents.................164

G.47 290 MVA, Zs=10-8 $\Omega$, light load, $\mathrm{R}_{\mathrm{TOT}}=1.652 \Omega$ : Phase-B CT currents .................165

G.48 290 MVA, $Z s=10^{-8} \Omega$, light load, $\mathrm{R}_{\text {TOT }}=1.652 \Omega$ : Phase-C CT currents .................165

G.49 290 MVA, $Z s=10^{-8} \Omega$, heavy load, $\mathrm{R}_{\mathrm{TOT}}=0.512 \Omega$ : Phase-A CT currents...............165

G.50 290 MVA, $Z s=10^{-8} \Omega$, heavy load, $\mathrm{R}_{\mathrm{TOT}}=0.512 \Omega$ : Phase-B CT currents ...............166

G.51 290 MVA, $Z s=10^{-8} \Omega$, heavy load, $\mathrm{R}_{\mathrm{TOT}}=0.512 \Omega$ : Phase-C CT currents ...............166

G.52 290 MVA, $Z s=10^{-8} \Omega$, heavy load, $\mathrm{R}_{\text {TOT }}=0.932 \Omega$ : Phase-A CT currents................166

G.53 290 MVA, $Z s=10^{-8} \Omega$, heavy load, $\mathrm{R}_{\mathrm{TOT}}=0.932 \Omega$ : Phase-B CT currents ..............167

G.54 290 MVA, Zs $=10^{-8} \Omega$, heavy load, $\mathrm{R}_{\text {TOT }}=0.932 \Omega$ : Phase-C CT currents...............167

G.55 290 MVA, Zs $=10^{-8} \Omega$, heavy load, $\mathrm{R}_{\mathrm{TOT}}=1.652 \Omega$ : Phase-A CT currents...............167

G.56 $290 \mathrm{MVA}, \mathrm{Zs}=10^{-8} \Omega$, heavy load, $\mathrm{R}_{\mathrm{TOT}}=1.652 \Omega$ : Phase-B CT currents...............168

G.57 290 MVA, $Z s=10^{-8} \Omega$, heavy load, $\mathrm{R}_{\text {TOT }}=1.652 \Omega$ : Phase-C CT currents...............168

G.58 $290 \mathrm{MVA}, \mathrm{Zs}=10^{-8} \Omega$, heavy load, $\mathrm{R}_{\mathrm{TOT}}=1.652 \Omega$ : magnetizing

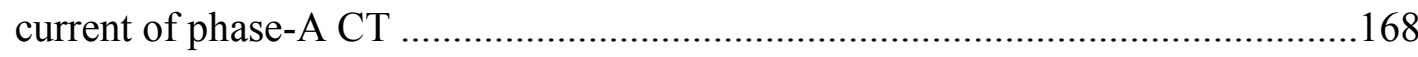


G.59 $290 \mathrm{MVA}, \mathrm{Zs}=10^{-8} \Omega$, heavy load, $\mathrm{R}_{\mathrm{TOT}}=1.652 \Omega$ : magnetizing

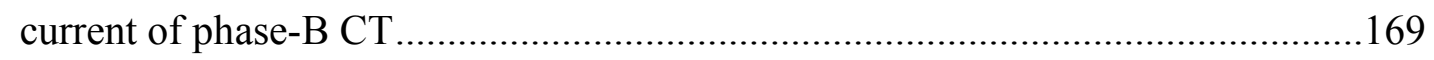
G.60 290 MVA, Zs $=10^{-8} \Omega$, heavy load, $\mathrm{R}_{\mathrm{TO}}=1.652 \Omega$ : magnetizing

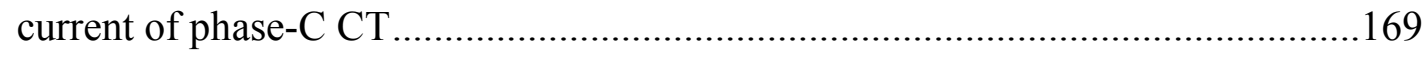




\section{List of Tables}

3.1 Short circuit test parameters

3.2 Short circuit test data verification for Hybrid Model and internal fault model ...........26

3.3 MVA values for different transformer ratings, 290 MVA...........................................29

3.4 Recalculation of magnetizing curve from $60 \mathrm{~Hz}$ to $50 \mathrm{~Hz}$

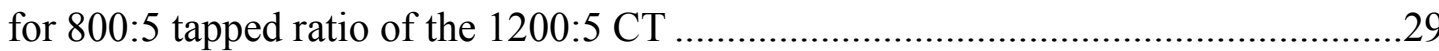

3.5 Recalculation of magnetizing curve from $60 \mathrm{~Hz}$ to $50 \mathrm{~Hz}$

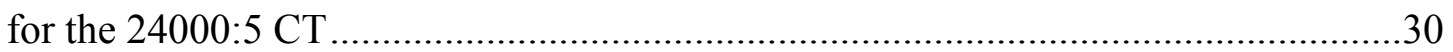

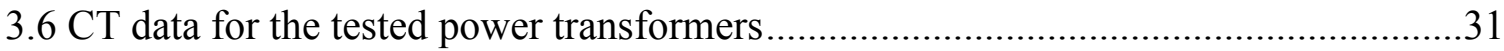

3.7 The SEL-487E relay settings for turn-to-turn faults .....................................................

3.8 The SEL-487E relay settings for turn-to-ground faults ..............................................36

4.1 Calculated and simulated currents for light load and heavy load conditions ...............38

4.2 Variation of burdens of CTs on high side of both power transformers ........................39

5.1 Negative-sequence differential element sensitivity for the 11.2-MVA transformer ...47 5.2 Negative-sequence differential element sensitivity for the 290-MVA transformer ....48

5.3 Primary fault current max amplitudes for the 11.2-MVA transformer........................52

5.4 Primary fault current max amplitudes for phase-A 90\% turn-to-turn fault in the 290-MVA transformer .59

5.5 Primary fault current max amplitudes for combination of three-phase through fault and phase-A 90\% turn-to-turn fault in the 290-MVA transformer ......................60

5.6 Neutral and fault currents at solid grounding and low-resistance grounding ..............66

5.7 REF element sensitivity at solidly grounded neutral ................................................68

5.8 SEL-487E relay sensitivity results at different neutral resistances..............................70

A.1 Load losses, impedance and total losses for the 11.2-MVA transformer ...................78

A.2 CT ratios, polarity and DC resistance tests for CTs of the 11.2-MVA transformer ...79

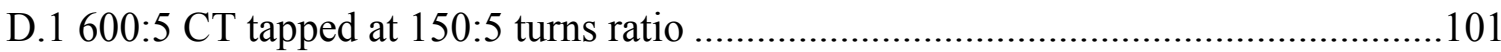

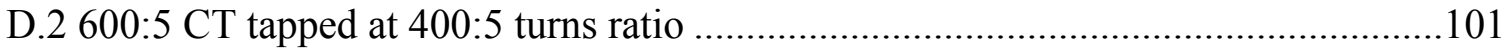

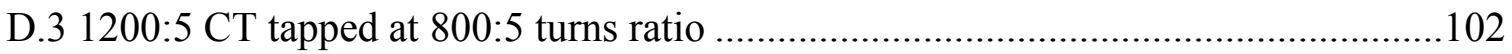

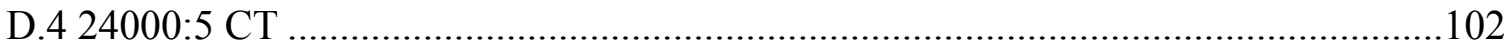

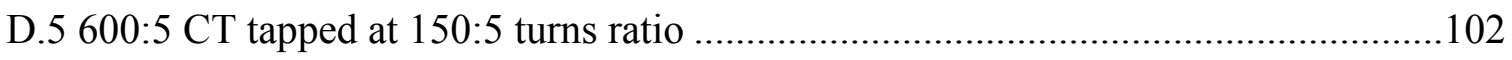

E.1 Negative-sequence differential element sensitivity for

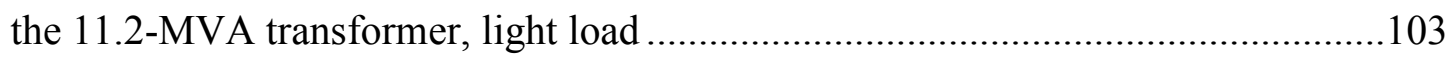

E.2 Negative-sequence differential element sensitivity for the 290-MVA transformer, light load 
E.3 Negative-sequence differential element sensitivity for

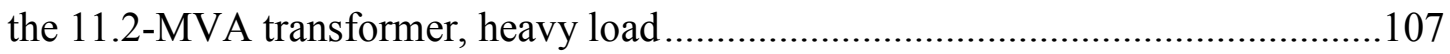

E.4 Negative-sequence differential element sensitivity for

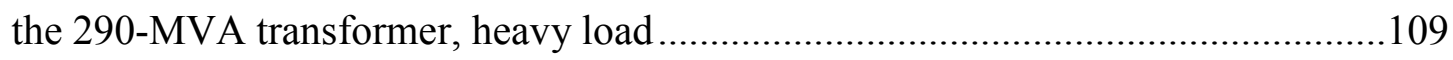

E.5 Turn-to-ground fault results for solidly grounded neutral $(\mathrm{R}=1 \Omega)$, light load .........111

E.6 Turn-to-ground fault results for low-resistance grounded neutral $(\mathrm{R}=415 \Omega)$, light load

E.7 Turn-to-ground fault results for solidly grounded neutral $(\mathrm{R}=1 \Omega)$, heavy load.......113

E. 8 Turn-to-ground fault results for low-resistance grounded neutral $(\mathrm{R}=415 \Omega)$, heavy load 


\section{Abstract}

Transformers are very important elements of any power system. Unfortunately, they are subjected to through-faults and abnormal operating conditions which can affect not only the transformer itself but also other equipment connected to the transformer. Thus, it is essential to provide sufficient protection for transformers as well as the best possible selectivity and sensitivity of the protection. Nowadays microprocessor-based relays are widely used to protect power equipment. Current differential and voltage protection strategies are used in transformer protection applications and provide fast and sensitive multi-level protection and monitoring.

The elements responsible for detecting turn-to-turn and turn-to-ground faults are the negative-sequence percentage differential element and restricted earth-fault (REF) element, respectively. During severe internal faults current transformers can saturate and slow down the speed of relay operation which affects the degree of equipment damage.

The scope of this work is to develop a modeling methodology to perform simulations and laboratory tests for internal faults such as turn-to-turn and turn-to-ground for two stepdown power transformers with capacity ratings of 11.2 MVA and 290 MVA. The simulated current waveforms are injected to a microprocessor relay to check its sensitivity for these internal faults. Saturation of current transformers is also studied in this work.

All simulations are performed with the Alternative Transients Program (ATP) utilizing the internal fault model for three-phase two-winding transformers. The tested microprocessor relay is the SEL-487E current differential and voltage protection relay.

The results showed that the ATP internal fault model can be used for testing microprocessor relays for any percentage of turns involved in an internal fault. An interesting observation from the experiments was that the SEL-487E relay is more sensitive to turn-to-turn faults than advertized for the transformers studied. The sensitivity of the restricted earth-fault element was confirmed. CT saturation cases showed that low accuracy CTs can be saturated with a high percentage of turn-to-turn faults, where the CT burden will affect the extent of saturation.

Recommendations for future work include more accurate simulation of internal faults, transformer energization inrush, and other scenarios involving core saturation, using the newest version of the internal fault model. The SEL-487E relay or other microprocessor relays should again be tested for performance. Also, application of a grounding bank to the delta-connected side of a transformer will increase the zone of protection and relay performance can be tested for internal ground faults on both sides of a transformer. 



\section{CHAPTER 1 Introduction}

The main objective of transformer protection is to provide a sensitive detection of faults within the zone of protection along with sufficient selectivity to avoid false trips. This protection should have immunity to inrush currents and overexcitation cases. This type of transformer protection is defined as differential protection which provides good protection against phase and ground faults in grounded systems without high-impedance grounding. Figure 1.1 shows an example of a power station transformer which was damaged due to an internal fault followed by a fire (see Appendix $\mathrm{H}$ for documentation of permission to republish the material).

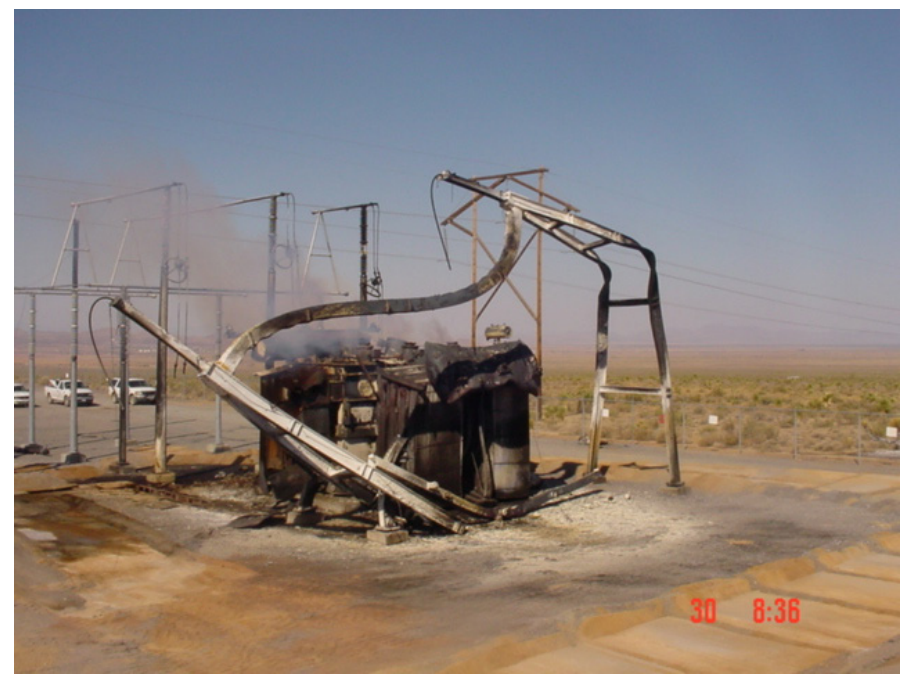

Figure 1.1: Damaged transformer after the fire caused by an internal fault [1].

In a laboratory, the performance of protection equipment can be studied if simulated currents are injected into a relay using a relay tester. There are several models of transformers which could be used to simulate internal faults, i.e., values of currents and voltages at different severity of faults. It is impossible to create one universal model which can be utilized for all the transformers for all the possible condition simulations. Each model pursues a number of goals only.

The model to be used here is the internal fault model which was created recently by Alejandro Avendaño, Michigan Technological University, for simulation of internal faults in the ATP program [2].

Different percentages of turns involved in turn-to-turn and turn-to-ground faults are studied in simulations for two step-down transformers rated at 11.2 MVA and 290 MVA. 
The SEL-487E microprocessor transformer differential relay is tested for its sensitivity to internal faults in these transformers. The .pl4 files obtained from the ATP simulations are transferred to the ProTesT(C) software of the Doble F6150 Relay Tester which injects currents into the high-voltage, low-voltage and neutral inputs of the relay.

The report is organized in six chapters.

Chapter 2 describes transformer differential protection and its purpose. As current transformers (CTs) affect operation of protective relays, CT saturation problem is introduced with some details. Chapter 2 also introduces the ATP internal fault model which was utilized in simulations of internal faults for both power transformers. Such elements of the SEL-487E relay as phase percentage restraint differential and negativesequence percentage restraint differential as well as restricted earth-fault (REF) are described with some details.

Chapter 3 provides information on development of the ATP model of the power transformers utilizing the internal fault model as well as modeling of CTs. Parameters of both power transformers and their CTs are introduced in the beginning of this chapter. Settings for the relay are given in this chapter as well.

Chapter 4 documents the systematic approach to the work performed. It introduces internal fault conditions and shows burdens of the CTs used in experiments with saturation of CTs. Equipment test setups for the experiments and the current waveform injection procedure are given in this chapter as well.

Chapter 5 shows the relay sensitivity results obtained for turn-to-turn and turn-to-ground faults with the use of several settings options. Also, Chapter 5 provides CT saturation plots from the ATP models for internal faults with different values of total burden applied to the CTs. The SEL-487E relay operation for an external fault is shown here as well.

Chapter 6 provides conclusions and recommendations for future work. 


\section{CHAPTER 2 \\ Background}

The differential protection of power transformers is explained in this chapter. General information about detecting turn-to-turn and turn-to-ground faults is given. Current transformers (CTs) can affect operation of a protective relay. The CT equivalent circuit and CT saturation issues are explained here with some details. To simulate internal faults, the ATP internal fault model for three-phase two-winding transformers was utilized in this work. Thus, information about the model itself and its creator is presented. Information about equipment used for the lab tests is given here. The particular relay used in this work is discussed, with detailed information on the elements responsible for sensitive protection against internal faults and their general settings. Event reports as an important source of information about operating conditions of a power system and for post fault analysis are introduced in this chapter.

\subsection{Existing work overview}

A power transformer is one of the key elements of any power system and it is expensive to manufacture and repair it after heavy damage. Transformer internal faults can cause fire and damage a transformer to an unrepairable degree. To protect this costly equipment, microprocessor relays are widely used. They provide high-speed multi-level protection and monitoring of a transformer and trip circuit breakers responsible for isolating this transformer. Protection should be provided against different faults and abnormal operation. According to [3], differential protection is the most reliable scheme, but it is typically used for transformers rated above 10 MVA. Transformers with lower ratings are protected with overcurrent protection or fuses. The cost of differential protection for transformers less than 10 MVA can be justified if they are important for a particular interconnection or load.

In general, transformers are exposed to internal and external faults. Protection equipment consisting of CTs and relays defines the zone of protection. Faults inside this zone are termed as internal, and outside of this zone as external. It is essential that differential protection operates for internal faults only; otherwise in case of false operation for an external "through fault" the healthy power transformer would be unnecessarily taken out of service for several days of tests to check for internal damage.

From [3], the examples of abnormal conditions are overvoltage, overexcitation, and overload. For these cases a transformer is protected with the set of different relays (if 
electro-mechanical relays) or multiple choice of different elements in one relay (if a microprocessor relay).

Reference [4] points out that internal faults often involve low-magnitude currents which are quite small compared to the rated transformer current. This defines the main purpose of transformer protection as a detection of internal faults with high sensitivity. Speed of detection is also of great importance as induced forces within and between the coils during faults can cause severe damages within a few cycles.

A simple differential scheme is the scheme with an instantaneous overcurrent relay. An internal fault creates a difference between the currents entering and exiting the protected zone. Thus, a protective relay will be subjected to a difference of currents in the secondary windings of CTs. If the operating current exceeds the relay pickup value, the relay will trip the circuit breakers. This differential (operating) current approaches zero during normal operation or external faults. According to [5], the overcurrent relay in the differential scheme is very sensitive to saturation error of CTs and magnetizing inrush currents, tripping for non-fault conditions. To overcome these drawbacks, percentage differential relays were developed (see Figure 2.1).

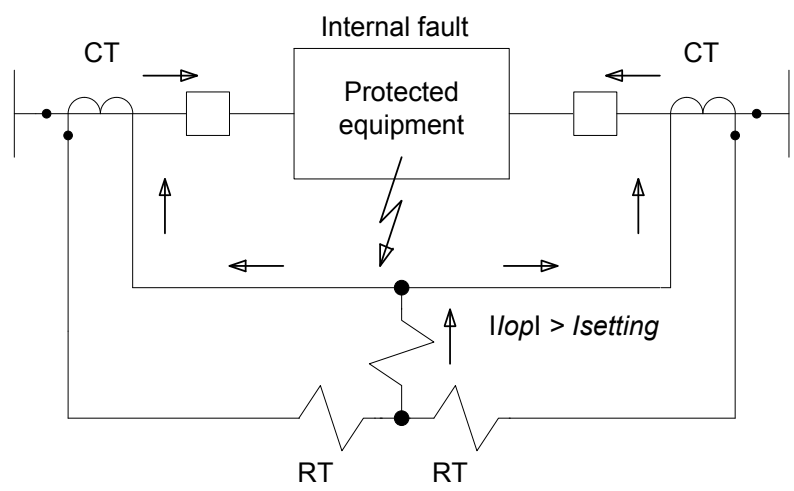

Figure 2.1: Percentage differential relay [5].

These relays should trip if the differential (operating) current exceeds a predetermined percentage of the through (restraint) current. Commonly, relays calculate these currents according to Equations (1) and (2).

$$
\begin{aligned}
& \left|\overline{\mathrm{I}_{\mathrm{OP}}}\right|=\left|\overline{\mathrm{I}_{\mathrm{S}}}+\overline{\mathrm{I}_{\mathrm{R}}}\right| \\
& \left|\overline{\mathrm{I}_{\mathrm{RT}}}\right|=\frac{\left|\overline{\mathrm{I}_{\mathrm{S}}}\right|+\left|\overline{\mathrm{I}_{\mathrm{R}}}\right|}{2}
\end{aligned}
$$

Where:

$\mathrm{I}_{\mathrm{OP}}$ is operating current,

$I_{S}$ is secondary current from sending end,

$I_{R}$ is secondary current from receiving end, and

$\mathrm{I}_{\mathrm{RT}}$ is restraint current. 
Figure 2.2 shows the generic characteristic of a differential element of a microprocessor relay. The comparison algorithm of the operating and restraint currents is running all the time. When the operating current $\mathrm{I}_{\mathrm{OP}}$ exceeds the trip threshold $\mathrm{I}_{\mathrm{PICKUP}}$ of the relay, based on the region where the comparsion calculation falls, the relay trips or restrains operation of a circuit breaker. When the restraint current $I_{R T}$ is zero or has some small value, the differential element operates as an overcurrent relay. When $\mathrm{I}_{\mathrm{OP}}$ increases, $\mathrm{I}_{\mathrm{RT}}$ also increases depending on the differential slope.

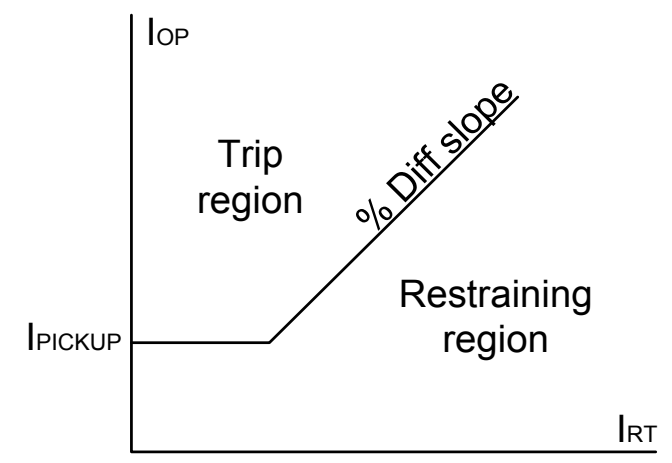

Figure 2.2: Characteristic of a differential element.

The percentage restrained differential relays are very insensitive to external faults with CT errors. Even so, the sensitivity for internal faults is not sacrificed significantly, because the restraining current is smaller for internal faults [5].

From reference [4], the percentage difference can be fixed or variable (i.e. dual slope characteristic). There is also the minimum differential current pickup value to trip circuit breakers, without regard the restraint current. This value is called the unrestrained setting and relay operation on it momentarily protects the transformer from high fault currents.

References $[3,6]$ indicate that percentage differential protection provides reliable protection from most internal faults (phase and ground faults), except in ungrounded systems and systems with high-impedance grounding. The differential element is not sensitive enough for single-phase-to-ground faults close to the grounding point in solidly grounded transformers [6,7].

\subsection{Internal faults}

Common transformer internal faults are turn-to-turn and ground faults. Variations of both are phase-to-phase, layer-to-layer, phase-to-ground, turn-to-ground (core or tank), layerto-ground [8]. The most challenging fault to detect is a fault that initially involves one or only a few turns. 


\subsubsection{Turn-to-turn faults}

Reference [4] provides information about mechanical detection of turn-to-turn faults. A turn-to-turn fault does not create a considerable difference in line currents, but only causes a high current in a shorted portion of the winding. This high current creates arcing and heat, which in turn generates combustible gases. A sudden-pressure relay is used to detect sudden changes in tank pressure. Another type is a gas accumulator relay. The most popular relay of this type is the Buchholz relay, which is used for transformers with conservator and without gas space inside the tank. After accumulating gas over some period of time, the relay will produce an alarm.

In order to sensitively detect turn-to-turn faults, a microprocessor relay uses the negativesequence differential element, for example, the SEL-487E relay is able to detect turn-toturn faults during heavy load conditions involving as little as $2 \%$ of the total winding [7]. The speed of the relay operation is of high importance as it can greatly reduce damage on a transformer. High-speed microprocessor relays can respond to internal fault conditions in less than 1.5 cycles.

Reference [6] describes the interesting nature of the phase-differential element: its sensitivity greatly depends on transformer loading, i.e., if the transformer load is light, the phase-differential and negative-sequence differential elements have almost the same sensitivity. However, if the transformer load increases, the sensititvity of the phasedifferential element decreases, while the negative-sequence differential element retains its sensitivity unchanged. More explanation on this issue shall be given in Sections 2.6.2 and 2.6.3.

\subsubsection{Turn-to-ground faults}

If not detected by the relay, a turn-to-turn fault eventually evolves into a ground fault. Reference [9] explains restrictive earth-fault (REF) transformer protection. REF protection can be used to complement the differential protection. Large current in the neutral conductor provides fast and sensitive operation of the REF protection. Microprocessor relays have the REF element which provides protection for ground faults close to neutral for grounded wye-connected transformer windings. Additional CT should be installed in the neutral path. The REF element provides protection for faults occurring between the phase and neutral CTs from the wye-side of the winding.

According to [9], REF protection can be of two types: high-impedance and lowimpedance. Previously only high-impedance REF protection was available because electromechanical relays have high impedance. Presently with new technology, a lowimpedance REF protection is available with microprocessor relays. Both of these options 
have advantages and limitations which should be considered before protection application. For example, high-impedance REF protection has immunity to CT saturation for external faults, but the line CTs and neutral CT should have the same ratio. Lowimpedance REF protection does not have stability against CT saturation, but its main advantage is that the neutral CT does not need to be of the same ratio as line CTs. The microprocessor relay internally compensates for different ratio of the neutral CT.

Another issue which is of high importance for protection against ground faults is the option of transformer grounding. In general, transformers can be solidly grounded, highresistance grounded or low-resistance grounded. According to [10], systems with voltages $115 \mathrm{kV}$ or higher should be solidly grounded or grounded through low resistance. Grounding is necessary to reduce overvoltage during ground faults to the maximum value of the phase-to-ground voltage. Resistance in the neutral has the goal of reducing the damaging current during ground faults. However, in this case a question about the relay sensitivity for faults close to the neutral point arises. At a solidly grounded neutral, the current during a fault is very high even starting from the first turn and can be easily detected by the neutral CT. With some big value of resistance in the neutral, its current is small in case of faults close to the neutral point, and this current may be not sufficient to operate the relay [9].

\subsubsection{False tripping}

According to [4], inrush current and overexcitation are two main cases for which a transformer differential relay can produce false tripping. To avoid misoperation, microprocessor differential relays have both harmonic restraint and harmonic blocking functions. To block or restrain a relay during inrush conditions, second and forth harmonics are used, and to block the relay during overexcitation, the fifth harmonic is utilized.

References [4] and [11] indicate that CT saturation also generates harmonics which can delay operation of differential relays with harmonic restraint function. Due to CT saturation, the current waveform will contain both odd and even harmonics, with even harmonics having lower magnitudes. Thus, proper settings for inrush harmonics magnitudes will restrain the relay regardless of the amount of inrush and provide highspeed operation if an internal fault occurs during energization or other types of inrush current. 


\subsection{CTs and CT saturation}

According to [3] and [11], CTs are used in power systems to reduce the magnitudes of currents from power lines down to a standardized $5 \mathrm{~A}$ or $1 \mathrm{~A}$. These values are used as rated inputs in protective relays to make them relatively small and inexpensive.

The simplified equivalent circuit of a CT is shown in Figure 2.3.

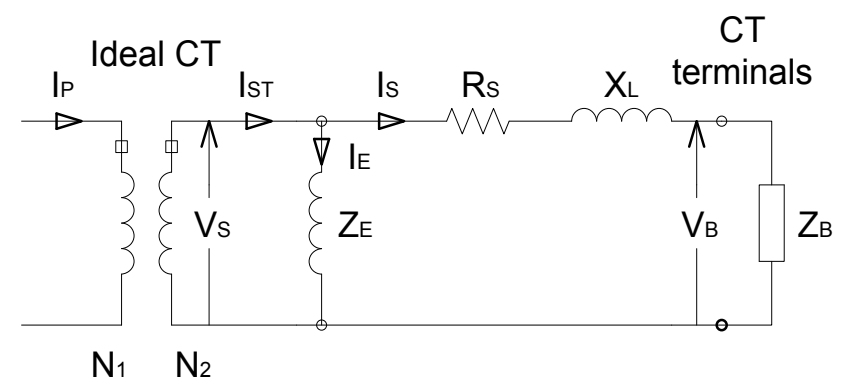

Figure 2.3: CT equivalent circuit [11].

From [11], the leakage impedance and related winding reactance of primary and secondary windings are negligible for calculations and are usually neglected. The symbols used in Figure 2.3 are:

$\mathrm{V}_{\mathrm{S}}$ is secondary exciting voltage,

$\mathrm{V}_{\mathrm{B}}$ is CT terminal voltage across external burden,

$I_{P}$ is primary current,

$\mathrm{I}_{\mathrm{ST}}$ is total secondary current,

$\mathrm{I}_{\mathrm{S}}$ is secondary load current,

$\mathrm{I}_{\mathrm{E}}$ is exciting current,

$Z_{\mathrm{E}}$ is exciting impedance (linearized to point of operation),

$\mathrm{R}_{\mathrm{S}}$ is secondary resistance,

$\mathrm{X}_{\mathrm{L}}$ is leakage reactance (negligible in Class C CTs),

$\mathrm{Z}_{\mathrm{B}}$ is burden impedance (includes secondary device and leads), and

$\mathrm{N} 1 / \mathrm{N} 2$ is $\mathrm{CT}$ turns ratio.

During steady-state operation, current in the secondary side of a CT does not exceed the rated value. However, high fault currents can be up to 20 times the rated current and may cause CT saturation which greatly affects accuracy. Increase in voltage across the CT secondary winding can happen due to either the current increase or CT burden increase. Increase in voltage makes flux in the $\mathrm{CT}$ core increase, creating a disproportional increase in the exciting current. After entering the magnetically saturated region, CT operation will be affected with increased ratio error and distorted current waveforms on the secondary side. The small burden of modern microprocessor relays keeps the error small. 
An important characteristic of any CT is its accuracy. According to [11], "accuracy is the extent to which the current in the secondary circuit reproduces the current in the primary circuit in the proportion stated by the marked ratio and represents the phase relationship of the primary current".

IEEE relay accuracy classes are determined by a letter designation and a secondary terminal voltage rating. Designation letters are C, K, T, H, L. Almost all the CTs used for protective relaying belong to $\mathrm{C}$ or $\mathrm{K}$ classification [11].

Class $\mathrm{C}$ indicates that the leakage flux is negligible and the excitation characteristics can be used directly to determine performance, and CT ratio error can be calculated. "It is assumed that the burden and excitation currents are in phase and the secondary winding is distributed uniformly" [11]. According to [12], the ratio correction factor is defined as $\mathrm{I}_{\mathrm{E}} / \mathrm{I}_{\mathrm{S}}$.

Class $\mathrm{K}$ is the same as the $\mathrm{C}$ class, "but the knee-point voltage must be at least $70 \%$ of the secondary terminal voltage rating" [11].

For Class T CTs, ratio error must be determined by a test. CTs of T class have a nonnegligible core flux leakage effect which contributes to appreciable ratio error [11].

Classes H, L are old ANSI classifcations. "There were two accuracy classes used $-2.5 \%$ and $10 \%$. CTs were specified in the following manner - $10 \mathrm{~L} 200,2.5 \mathrm{H} 400$, etc. The first number indicated the accuracy class and the last number indicated the secondary voltage class. L class CTs were rated at the specified burden and at 20 times the normal current. $\mathrm{H}$ class CTs were rated at any combination of burden from 5 times to 20 times the normal current. These ratings are applicable only to old CTs mostly manufactured before 1954" [11].

The number after the designating class letter is the secondary terminal voltage rating that the CT will supply when it is connected to the secondary burden at 20 times the rated secondary current, without exceeding a $10 \%$ ratio error.

As an example, a CT of the C800 class should be understood as follows: $\mathrm{C}$ is the accuracy class and $800 \mathrm{~V}$ can be delivered to the CT burden at 20 times the rated current with no more than $10 \%$ error due to the exciting current; the older version of this designation was $10 \mathrm{C} 800$.

However, if the CT is of a multi-ratio type, each used tap will give a voltage capability directly proportional to the ratio between the turns used and the full winding capability. This is accurate for the condition if the windings of a CT are fully distributed around the core. 
Reference [11] considers asymmetrical primary current. The worst fault in the primary winding will be an asymmetrical one having a decaying DC component. When DC offset is at a maximum, the $\mathrm{CT}$ flux increases approximately to $1+\mathrm{X} / \mathrm{R}$ times the flux resulting from the non-offset component. $\mathrm{X}$ and $\mathrm{R}$ are components of thevenin impedance of the primary circuit at the fault point. The decaying DC offset can saturate the iron of a CT and reproduction of the primary current can be greatly distorted. Figure 2.4 shows a comparison of CT operation for low and high resistive burdens at 20 times the rated full offset current (see Appendix $\mathrm{H}$ for documentation of permission to republish the material).

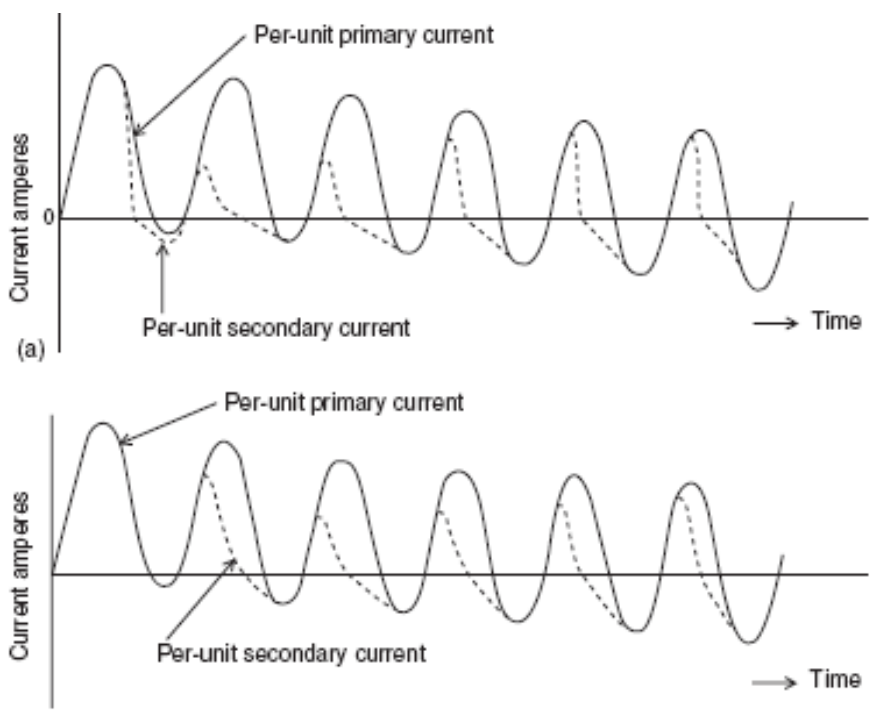

(b)

Figure 2.4: CT operation during fault with DC offset:

(a) large resistive burden, (b) small resistive burden [3].

However, after the DC component decays, the CT recovers and with each subsequent cycle the secondary current reproduces the primary one with increasing accuracy. When the DC component fully dies out, the primary current is reproduced with rated accuracy [3]. As seen from Figure 2.4, saturation does not occur instantly, and the time before saturation appears is called the time-to-saturation. Usually CTs are accurate from one to two cycles before the core starts operation in its saturated region $[3,11]$. The time-tosaturation of a CT depends on the following parameters: degree of fault current offset, fault current magnitude, remanent flux in the $\mathrm{CT}$ core, secondary circuit impedance, saturation voltage, and CT turns ratio. A combination of such effects as more EMF per unit of flux and lower secondary current will give a decrease of the core flux and increase in turns ratio. This in turn will produce higher voltage at which saturation occurs and time-to-saturation will be increased [11].

From [11], in order to avoid the effects of saturation, CT sizing should be used. It gives the knee-point voltage above that required for the maximum expected fault current and 
CT secondary burden. If the primary winding has a DC component and the burden is purely resistive, the required secondary saturation voltage $\left(V_{X}\right)$ is given in Equation (3):

$$
V_{X}>I_{S} \times Z_{S} \times\left(1+\frac{X}{R}\right)
$$

Where:

$\mathrm{I}_{\mathrm{S}}$ is primary current divided by turns ratio,

$Z_{\mathrm{S}}$ is total secondary burden,

$\mathrm{X}$ and $\mathrm{R}$ are components of primary system thevenin impedance at the point of fault.

However, these requirements make CTs impractical. As a rule of thumb from [11], CT performance will be satisfactory if the $\mathrm{CT}$ secondary maximum symmetrical internal fault current multiplied by the total secondary burden is less than half the C-class voltage rating of the CT. Another way to avoid saturation is the use of high-speed relays that can operate before saturation occurs, or low-burden relays (typical of microprocessor relays).

CT operation can also be affected by remanence. The remanent flux in a CT core depends on the flux in the core immediately before primary current interruption [11]. The magnitude of this flux depends on the value of symmetrical primary current, DC offset, and secondary circuit impedance. There are some tests on transformers that require DC current to flow in the transformer winding, which of course will give remanence in the CT cores. And once it is established, dissipation will be very slow under normal load conditions. The time-to-saturation will be less in a transformer with remanent flux. With high remanent flux the total burden capability of a CT will be less and since the resistance of the CT secondary is a part of the total burden, the burden of a relay should be reduced in order to minimize the possibility of fast CT saturation [11]. There is a possibility for severe saturation on internal faults, particularly in the presence of a DC offset, which could prevent or delay differential relay operation.

Another case when proper replication of primary currents cannot be obtained is when CTs of a power transformer have unequal saturation. This can be a consequence of unequal transient DC component in each phase. To minimize incorrect indication caused by this case, CTs with similar excitation characteristics and burdens in all phases should be used. However, since percentage differential relays have a rising pickup characteristic, the relay is protected against improper operation [3].

Mismatch is an issue related to selection of CT ratios. Mismatch between CTs on the high-voltage and low-voltage sides of a power transformer can cause operating current in the relay. Mismatch can result from different CT ratios or a load tap changer. Thus, the pickup current of the relay should be set above the values which appear in the operating coil due to these reasons $[3,11]$. 


\subsection{ATP modeling}

Internal faults will be simulated for two oil-immersed step-down power transformers. Detection sensitivity of the differential relay shall be determined for these faults. The transformers have the following ratings:

- $\quad 11.20 \mathrm{MVA}, 72.00 \Delta / 25.00 \mathrm{GY} \mathrm{kV}, 60 \mathrm{~Hz}$

- $290 \mathrm{MVA}, 432 \mathrm{GY} / 16 \Delta \mathrm{kV}, 50 \mathrm{~Hz}$

Internal faults such as turn-to-turn and turn-to-ground faults involving different percentage of the high-voltage phase-A winding were simulated in the Alternative Transients Program (ATP) utilizing the transformer model developed specially for these purposes by Alejandro Avendaño at Michigan Technological University under the supervision of Dr. Bruce A. Mork. The complete description of the internal fault model is in [2]. This model was developed using only short-circuit impedance obtained through laboratory measurements or given in a factory test report. This method can be applied to transformers of different sizes and configurations [2].

The internal fault model used for this project can be found in [13] and ATP figures for this project are shown in Appendix B, some explanation of this model shall also be given in Section 4.2 of this report.

The version of the internal fault model to be used for this project consists of two parts: ATP model and Matlab library component. Each phase of the high-voltage side of the transformer winding in the ATP model is divided into three sections to allow performing turn-to-turn and turn-to-ground faults. The ATP model also allows performing any connections of the windings. All the necessary information for a power transformer concerning MVA rating, line-to-line voltages, winding resistance and inductance, power frequency and percentage of each section in split high-side winding for all the phases are contained in the Matlab library component. This information is used to create the winding resistance and leakage inductance matrices in AR notation (" $A$ " is the $[\mathrm{L}]^{-1}$-matrix (matrix description of the transformer leakage effects) and " $R$ " is the [R]-matrix) [14]. This version of the internal fault model does not include core saturation, thus internal faults during energization inrush cannot be studied. Also, the utilized version of the internal fault model does not consider all of the changes in self and mutual impedances of a transformer coil according to internal fault location, resulting in imprecise currents being simulated.

The internal fault model from [2] is an improved version of the model utilized for this work and addresses the issues mentioned above. Figures $2.5-2.7$ show details of the improved internal fault model. The core representation is depicted in Figure 2.5. " $\mathrm{Z}_{1}$ and 
$\mathrm{Z}_{\mathrm{y}}$ represent the nonlinear limbs and yokes respectively, and $\mathrm{L}_{4}$ represents the zerosequence path through the tank. The attachment of the core to the leakage model was created through ideal transformers of unity-turns ratio representing the $\alpha, \beta, \gamma$ terminals of an infinitely-thin $\mathrm{N}+1^{\text {th }}$ "coil" at the surface of the core leg" [2].

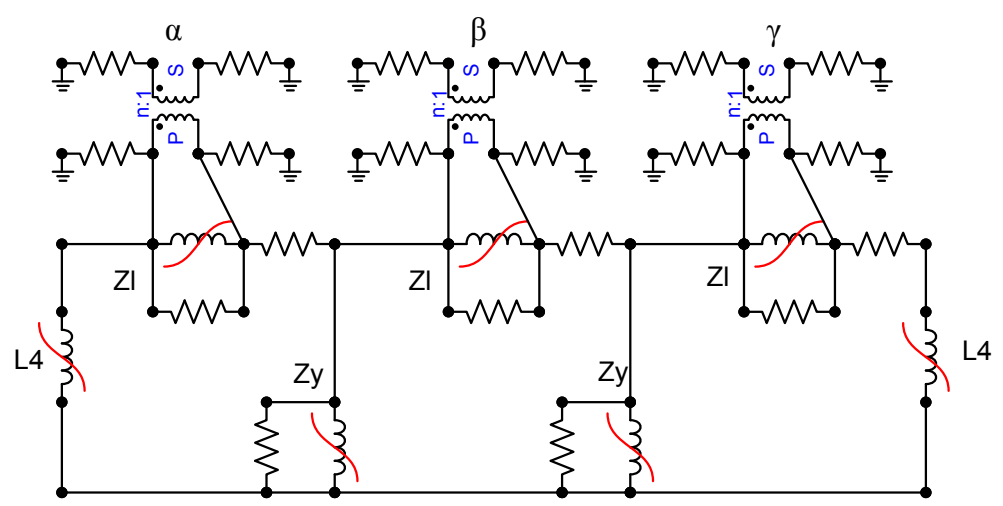

Figure 2.5: Core attached to $\mathrm{N}+1^{\text {th }}$ winding ATP [2].

Figure 2.6 depicts the complete model with a turn-to-ground fault in phase A of the highvoltage winding while the low-voltage winding is short circuited. "The high-voltage side is divided into three sections to allow simulation of turn-to-turn and turn-to-ground faults in transformer winding. The connection between the fictitious winding and dualityderived core model was made by referencing the $\alpha, \beta, \gamma$ nodes of the ideal transformers" from Figure 2.5 [2]. Except for the fault resistance, resistances shown are $1 \mathrm{E}^{-8} \Omega$, which provide for current measurements.

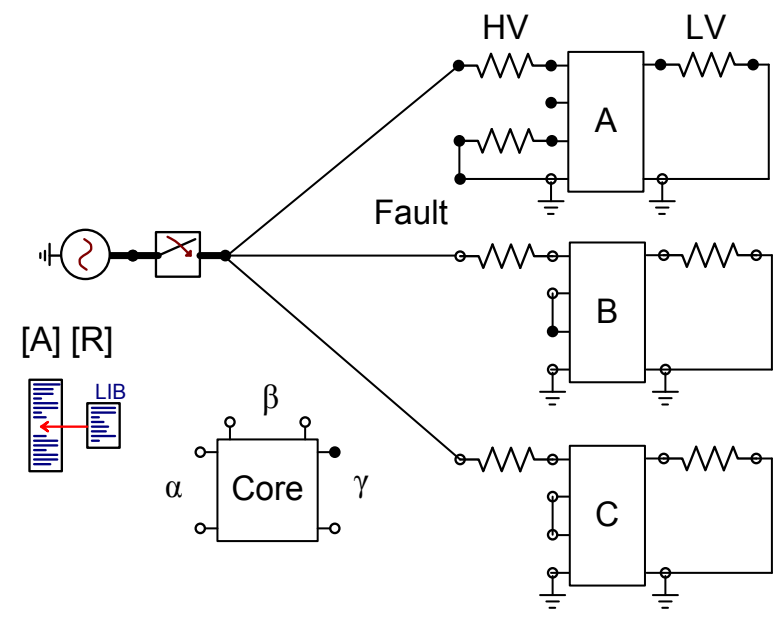

Figure 2.6: Improved internal fault model in ATP [2].

Division of each coil into three sections is shown in Figure 2.7. "Those sections are connected internally for one of the phases. The connection points between sections $\mathrm{H}, \mathrm{M}$, and $\mathrm{T}$ of the $\mathrm{HV}$ coils were brought out to simulate the faults. Ideal transformers of unity turns-ratio were used to make the top and bottom terminals available for each coil 
included in the A-matrix. The resistances shown in this figure have large values $\left(1 \mathrm{E}^{4}-1 \mathrm{E}^{8}\right.$ $\Omega$ ) and were added to avoid singularity problems in the solution process of ATP caused by the ideal transformers "[2].

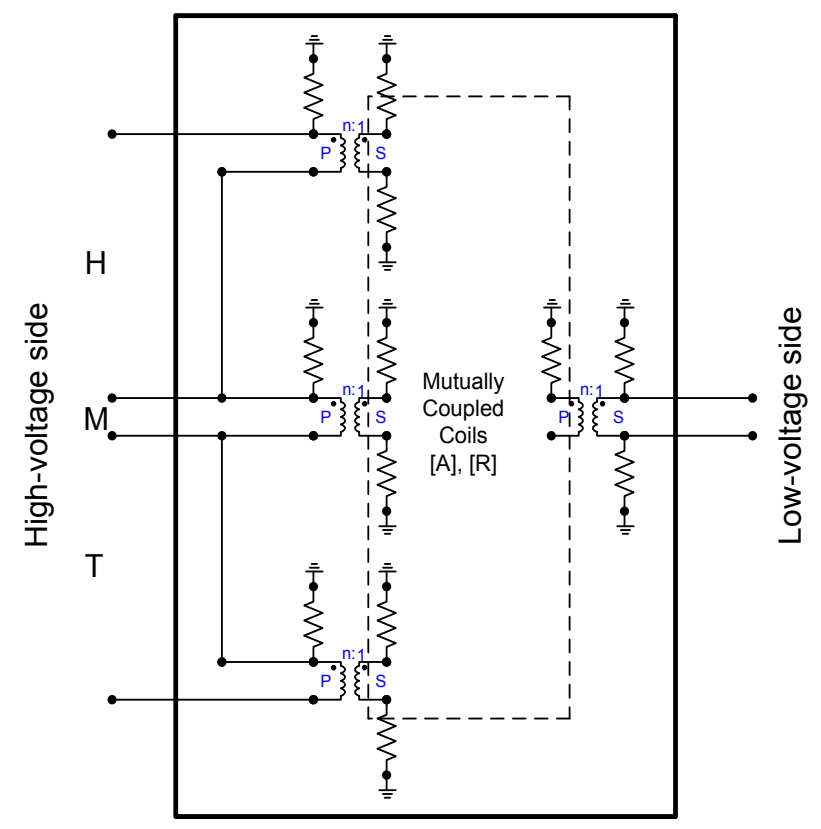

Figure 2.7: Internal view of sub-coil arrangement [2].

\subsection{Equipment}

The following lab equipment and its software were utilized to perform the lab tests:

- The SEL-487E Current Differential and Voltage Protection Relay

- The AcSELerator QuickSet SEL-5030 software

- The Doble F6150 Power System Simulator

- The Doble ProTesTC software, version 2.08

Necessary relay information to perform the tests shall be given with additional details in Section 2.6.

One of the ways to communicate with a transformer protection relay from a PC is by utilizing specially developed programs. For these purposes, the AcSELerator QuickSet SEL-5030 software was developed for the SEL relay family. It is used for creating and managing relay settings online and offline, analyzing events, monitoring in real-time and relay stored data, and controlling relays. This software has a library and stores settings which can be modified later and uploaded to the relay [7].

The Doble ProTesTC software and Doble F6150 Power System Simulator (the Doble Tester later in the text) allow controlling the values of currents and voltages that can be 
applied to any relay. The Doble Tester has six current sources and six convertible V/I sources. The F6150 allows two sets of three-phase currents to be applied as the highvoltage side and low-voltage side currents to the relay: there are 6 current outputs, each of $15 \mathrm{~A}_{\mathrm{RMS}}$ in normal mode and $30 \mathrm{~A}_{\mathrm{RMS}}$ in transient mode. Number of current sources can be from one up to six. If only three current sources are used, then their ratings are 30 $A_{R M S}$ in normal mode and $60 \mathrm{~A}_{\mathrm{RMS}}$ in transient mode for each source. The humanmachine interface (HMI) of the Doble F6150 Tester is shown in Figure 2.8. The Doble ProTesT@ software interface is given in Figure 2.9.

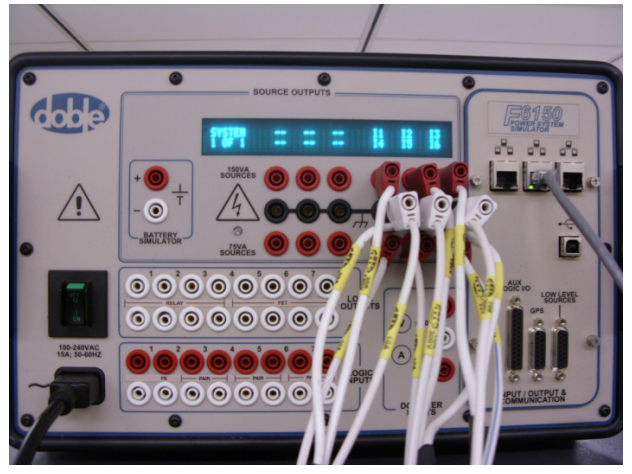

Figure 2.8: The Doble F6150 Relay Tester.

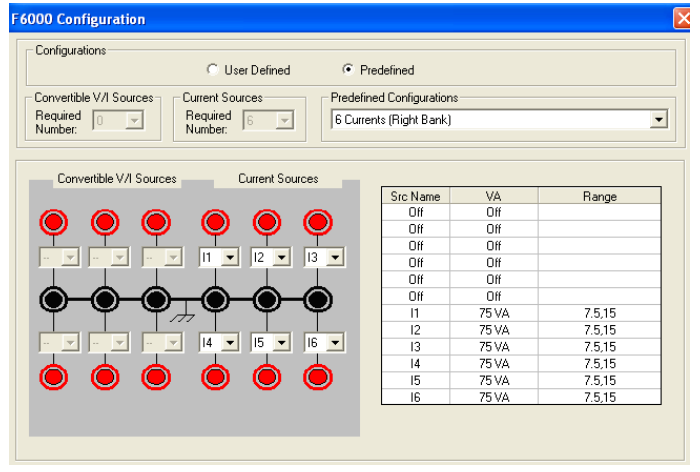

Figure 2.9: Doble ProTesT@ software interface.

\subsection{The SEL-487E transformer protection relay}

\subsubsection{Features}

The SEL-487E relay manufactured by Schweitzer Engineering Laboratories, Inc. is a relay for comprehensive transformer protection. The relay can protect and monitor most of the transformer behaviors, providing a suite of current and voltage elements [7]. The HMI of the relay is shown in Figure 2.10 (see Appendix $\mathrm{H}$ for documentation of permission to republish the material).

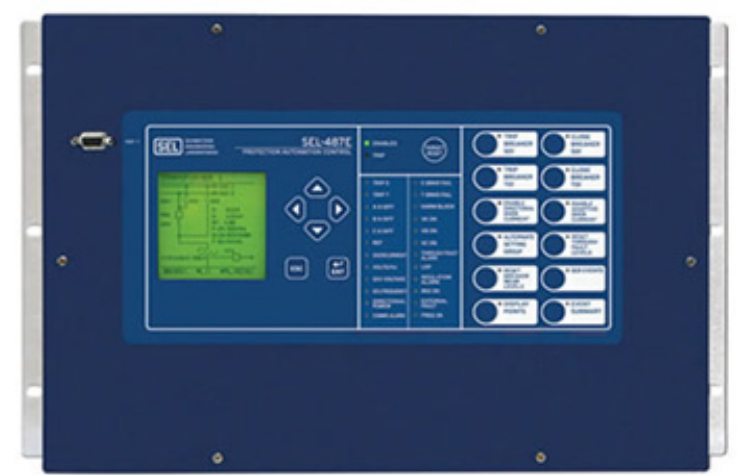

Figure 2.10: The SEL-487E transformer protection relay [15].

(C)Schweitzer Engineering Laboratories, Inc. 2010 
This relay can be applied for two-, three-, four-, and five-winding power transformers. Modern microprocessor protection relays contain a combination of protection elements. The SEL-487E relay utilizes the following elements to perform main protection for power transformers:

- an adaptive-slope phase percentage restraint differential element,

- an unrestraint differential element,

- a negative-sequence percentage restraint differential element,

- programmable restricted earth-fault elements,

- breaker failure protection for each winding, and

- several voltage polarized directional and non-directional phase, negativesequence and zero-sequence definite-time and inverse-time overcurrent elements [7].

The delta-wye transformer requires two sets of three-phase current inputs to apply the differential protection and one single phase current input for the restricted earth-fault protection. The rest of the current inputs are available for other protection functions [7].

Figure 2.11 shows the AcSELerator QuickSet SEL-5030 software interface. This window is designated for entering the power transformer parameters.

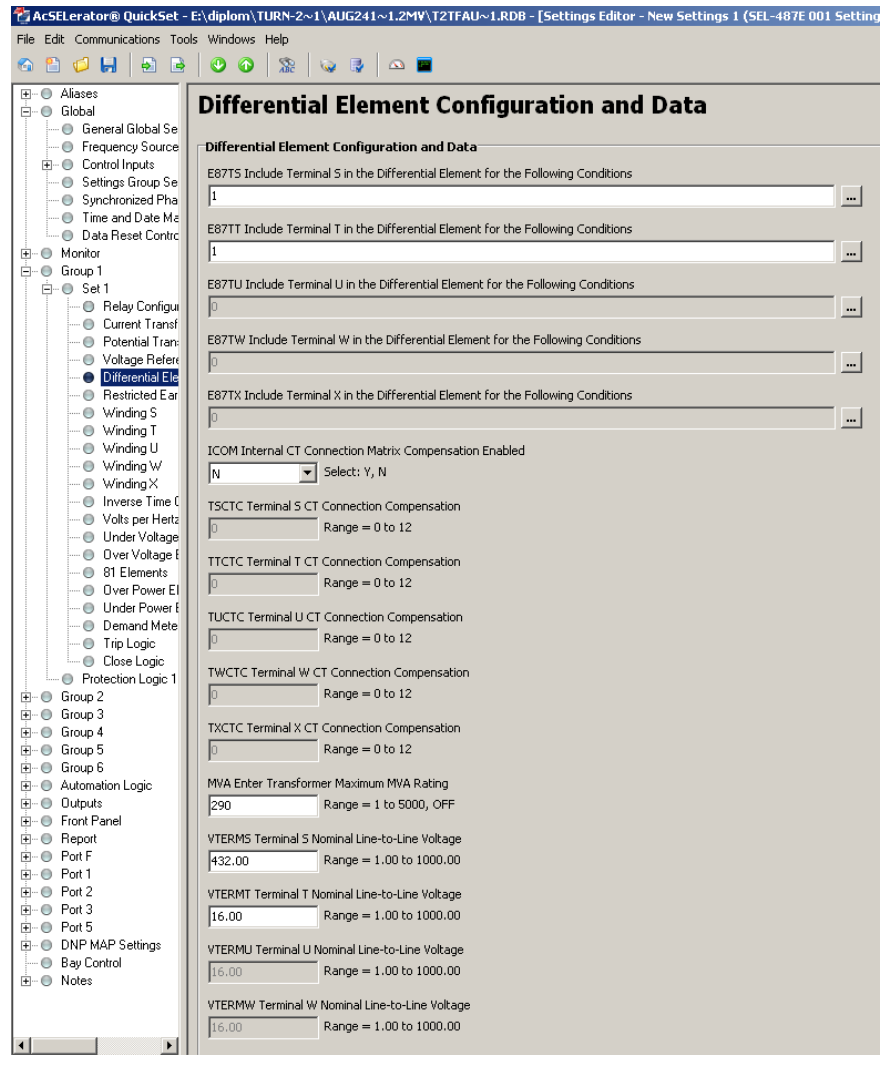

Figure 2.11: The AcSELerator QuickSet SEL-5030 software interface. 


\subsubsection{Phase percentage restraint differential element characteristics}

Equation (4) and Figure 2.12 describe the adaptive-slope phase percentage restraint differential element. In general, the characteristic of the differential element is a straight line through the origin [7]:

$$
I O P F A=k \times S L P C \times I R T F A
$$

Where:

O87P is minimum IOP level required for operation,

IOPFA is operating current of phase A,

IRTFA is restraint current of phase A,

SLPc is slope 1 (normal operation) or 2 (high-security mode for through faults), and $\mathrm{k}=1$.

For operating quantities (IOPFA) which exceed the threshold level O87P and fall in the operate region of Figure 2.12, the filtered differential element issues an output [7] (see Appendix $\mathrm{H}$ for documentation of permission to republish the material).

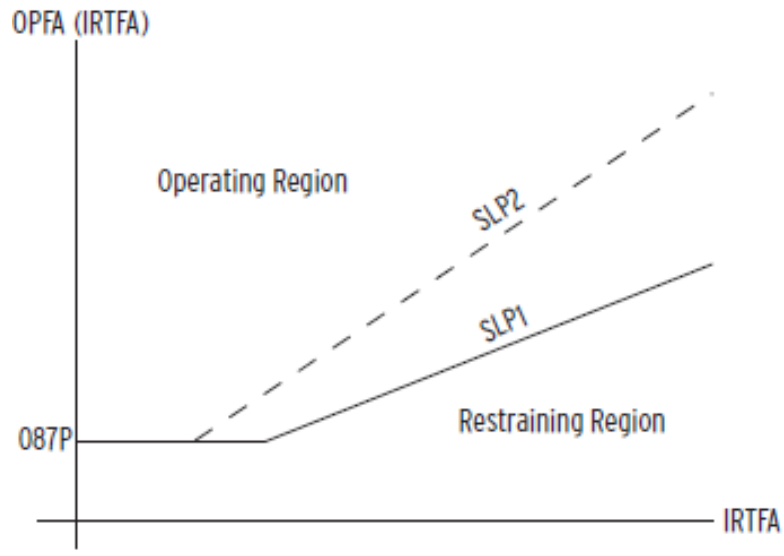

Figure 2.12: Differential element characteristic [7].

CSchweitzer Engineering Laboratories, Inc. 2010

The differential element of the relay should trip for internal faults only and remain stable during external faults causing saturation of CTs. At normal conditions the relay operates at Slope 1, and after detecting a through-fault it automatically switches to Slope 2 to prevent false tripping. The principle of discrimination used is that operating and restraint currents increase simultaneously for internal faults, but only the restraint current increases for external faults, if there is no CT saturation [7]. The relay compares changes in operating current with changes in restraint current. Equations (5) and (6) are used in the relay logic for operating and restraint currents: 


$$
\begin{aligned}
& I O P R A=|\Sigma I A k M C| \\
& I R T R A=\Sigma|I A k M C|
\end{aligned}
$$

Where:

IAkMC is instantaneous pu current of phase $\mathrm{A}$, and $\mathrm{k}$ is transformer winding: $\mathrm{S}, \mathrm{T}, \mathrm{U}, \mathrm{W}, \mathrm{X}$.

The relay logic for harmonic filtering, internal and external fault detection, and filtered differential element can be found in [7].

The adaptive differential element responds to most internal fault conditions in less than 1.5 cycles [15].

In Section 2.2.1 it was mentioned that transformer loading defines sensitivity of the phase-differential element, and if a transformer is heavily loaded, the negative-sequence element is much more sensitive for fault detection. References [6] and [7] explain this innate characteristic with the fact that the differential element operates with the sum of positive- and negative-sequence currents (see Equations (5) and (6)). This means that if transformer loading increases, the positive-sequence and the through (restraint) currents increase, making the phase-differential element less sensitive for internal faults.

If an unbalanced fault occurs inside a transformer zone, eg. a turn-to-turn or an interwinding fault, the negative-sequence current flows towards the fault point [6]. Because the amount of load does not affect negative-sequence currents in a balanced system, the negative-sequence percentage differential element provides sensitive protection for internal faults in transformer windings.

\subsubsection{Negative-sequence percentage restraint differential element}

According to [7], an internal fault which shorts only a few turns of a transformer winding creates a small change in a phase current which can be lower than the pickup current value, while at the same time the current in the faulted area can be of high magnitude. The negative-sequence differential element is the main tool to detect turn-to-turn faults that involve few turns. Reference [7] also stresses that a fault that shorts as little as $2 \%$ of the total transformer winding can be detected with the negative-sequence element of the SEL-487E relay. Sensitivity of this element is important as it prevents evolution into more severe faults, thus reducing time and cost of transformer repair.

For this element the relay calculates the operating current IOP87Q by summing the $3 \mathrm{I}_{2}$ vectors from each compensated winding input (see Equation (8)), and the restraint current RST87Q represents the maximum $3 \mathrm{I}_{2}$ magnitude of the compensated winding inputs (see Equation (9)). Then the relay plots operating current versus restraint current and 
compares this result against the slope characteristic which defines relay operation or restraining. The relay uses Equation (7) to calculate the negative-sequence currents (ABC rotation):

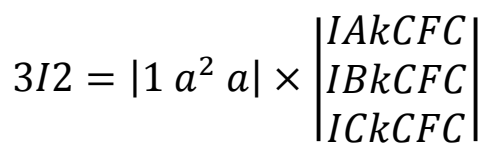

Where:

$$
\begin{aligned}
& a=e^{j 120}, \\
& a^{2}=e^{j 240}, \text { and }
\end{aligned}
$$

IAkCFC is phase-A filtered pu current ( $\mathrm{k}=\mathrm{S}, \mathrm{T}, \mathrm{U}, \mathrm{W}, \mathrm{X} ; \mathrm{k}$ is transformer winding).

$$
\begin{aligned}
& I O P 87 Q=\left|\sum 3 I 2 k C\right| \\
& R S T 87 Q=\max (|3 I 2 k C|)
\end{aligned}
$$

Figure 2.13 shows a comparison of sensitive operation of the negative-sequence element versus the phase-differential element. The path of circles in this figure is a trajectory of a fault that shorts out $2 \%$ of the phase-A winding in a three-phase transformer operating at full load. On the left, the phase-differential element operates when the operating current reaches $0.43 \mathrm{pu}$ On the right, the same fault is shown for the negative-sequence element. Because balanced load does not affect negative-sequence currents, the negative-sequence element operates when the operating current reaches $0.1 \mathrm{pu}$ [7] (see Appendix $\mathrm{H}$ for documentation of permission to republish the material).
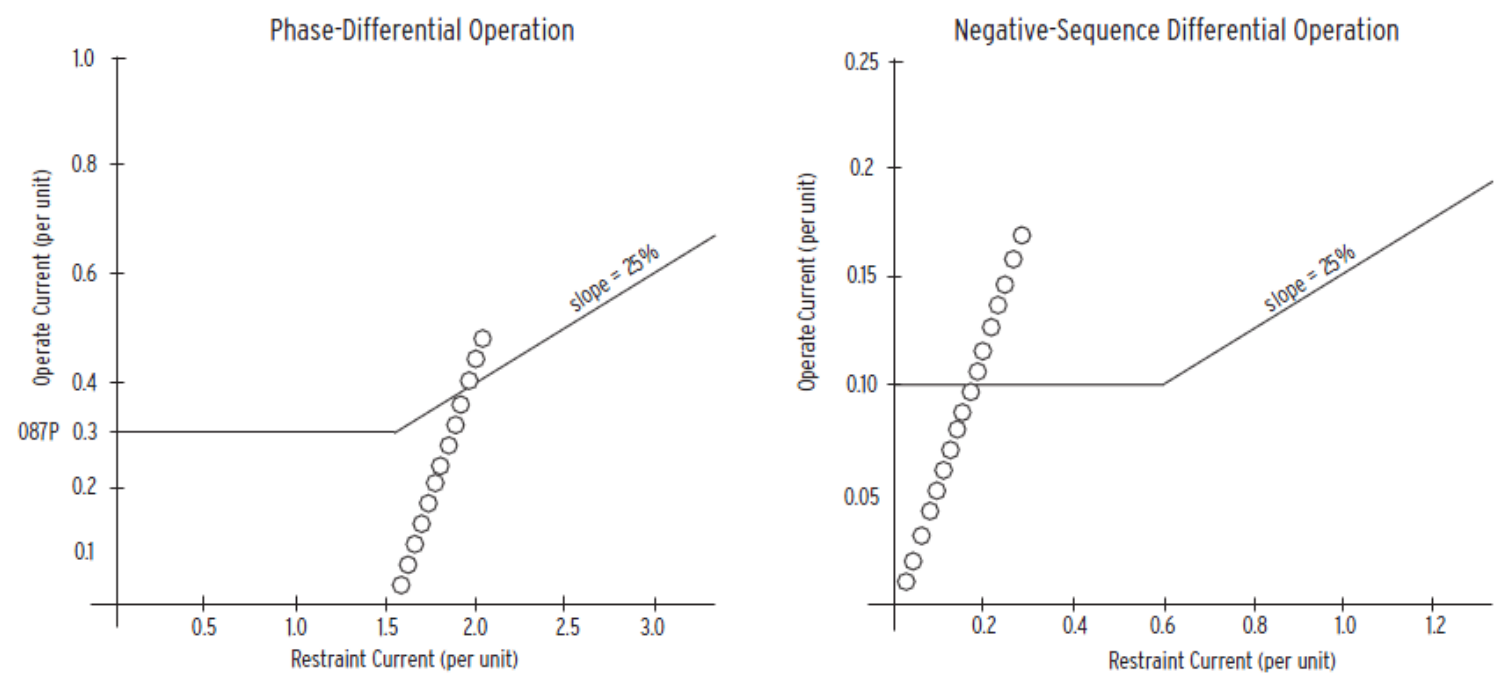

Figure 2.13: Sensitivity comparison of the phase-differential element (a) and the negative-sequence differential element (b) [7]. CSchweitzer Engineering Laboratories, Inc. 2010

The negative-sequence differential relay logic can be viewed in [7]. 


\subsubsection{Restricted earth-fault element}

The REF element is intended to provide sensitive ground fault detection in wyeconnected transformer windings where the neutral is solidly or impedance grounded. It compares the zero-sequence current from the wye-connected CTs on the wye-connected winding of a transformer $\left(3 \mathrm{I}_{0}=\mathrm{I}_{\mathrm{A}}+\mathrm{I}_{\mathrm{B}}+\mathrm{I}_{\mathrm{C}}\right)$ to the current detected in the neutral connection of the transformer $\left(\mathrm{I}_{\mathrm{N}}=\mathrm{I}_{\mathrm{A}}+\mathrm{I}_{\mathrm{B}}+\mathrm{I}_{\mathrm{C}}\right)$ as well as their directions. The delta side of the transformer should have wye-connected CTs also. In this case the transformer phase shift in CTs can be compensated through compensation settings in the relay which are represented with 12 three-by-three matrices. The effect of the compensation is to create phase shift and to remove zero-sequence components [7]. Figure 2.14 depicts application of the REF element in the SEL-487E relay (see Appendix $\mathrm{H}$ for documentation of permission to republish the material).

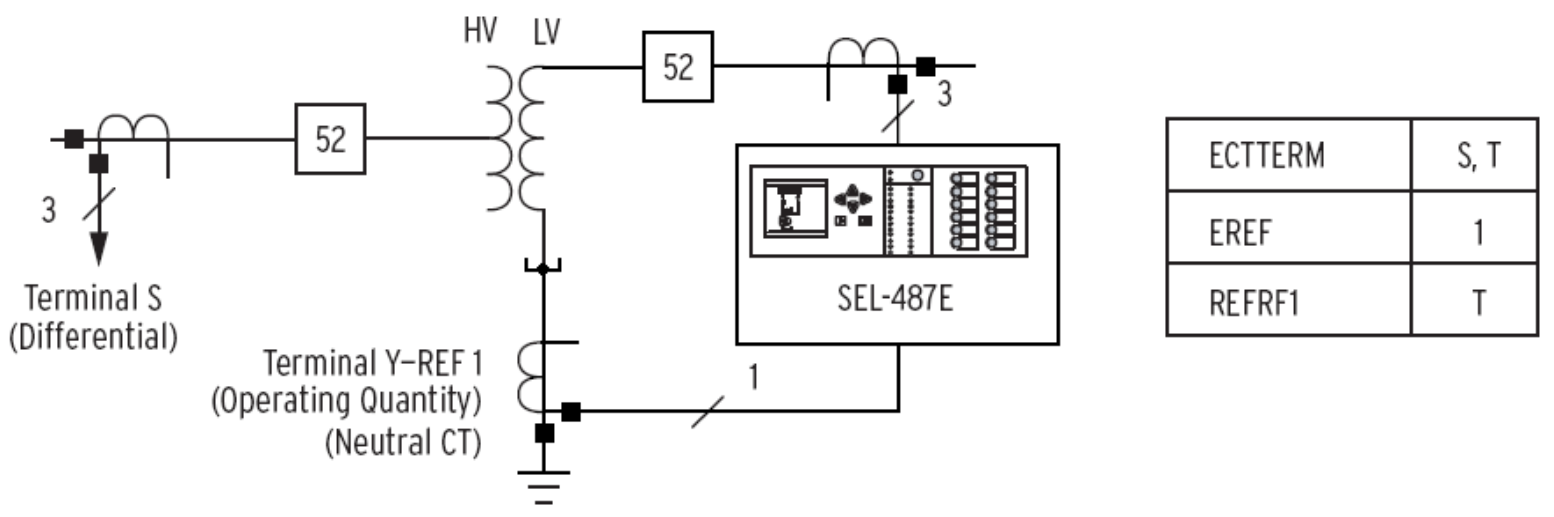

Figure 2.14: REF application on wye-connected winding of a delta-wye transformer [7].

(C)Schweitzer Engineering Laboratories, Inc. 2010

Operating (residual) current is the current from the neutral CT, and the reference (restraint) current is the current from the line CTs. The logic diagram, algorithm that performs the directional calculations, and REF element trip output are shown in [7].

The REF algorithm determines direction of the fault current by calculating the real part of the product of the reference quantity and the conjugate of the operating quantity [7]. If this value is positive, the fault is forward or internal. If this value is negative, the fault is reverse or external. Or, in other words, the fault is internal if both the operating and restraint currents are in phase and external if those currents are 180 degrees out of phase. However, the internal turn-to-ground fault should persist for at least 1.5 cycles before the REFF1 Word bit asserts, constituting an internal ground fault.

The phase CTs and the neutral CT can be mismatched by a ratio of 25:1 [7]. 
The REF element in the SEL-487E microprocessor relay represents a low-impedance REF protection.

\subsubsection{Relay settings for internal faults}

The relay settings can be entered into the relay from the AcSELerator QuickSet SEL5030 software. The settings tree will appear on a PC screen, from which settings mostly under the Group 1, Set 1 were changed for this work, and namely for phase-differential element, negative-sequence element and restricted earth-fault element (refer to Figure 2.11). According to Equation (10), the relay automatically calculates tap values for both $\mathrm{S}$ - and T-windings, where S-terminals are designated for the high-voltage side and $\mathrm{T}$ for the low-voltage side of a power transformer [7].

$$
T A P=\frac{M V A \times 1000}{\sqrt{3} \times V T E R M \times C T R} \times C
$$

Where:

MVA is transformer maximum MVA,

VTERM is terminal line-to-line voltage of a winding in $\mathrm{kV}$,

CTR is CT turns ratio,

$\mathrm{C}$ is 1 if CTs are connected in wye, and

$\mathrm{C}$ is $\sqrt{3}$ is CTs are connected in delta.

The restrained element operating current pickup is defined by Equation (11):

$$
087 P \geq \frac{0.1 \times I_{\text {nom }}}{T_{A P_{k}}}
$$

Where $\mathrm{I}_{\text {nom }}$ is nominal current of CT.

The general differential element tap pickup is available from the range $(0.1-32.0) \times$

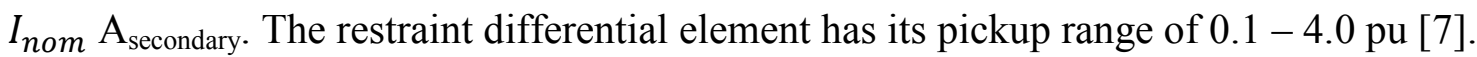

High line currents which cause distortion in the CT secondary current can be created with faults internal or external to the protected zone. For internal faults differential relays are designed and applied such that they will operate despite the presence of distorted waveforms, or prior to their onset [11]. For detection of a turn-to-turn fault the negativesequence differential element can be sensitive from 0.05 to 1 pu tap with the slope chosen from 5 to $100 \%$, and the accuracy of pickup is $\pm 5 \%$ of the user setting. The negativesequence differential element delay setting programs the relay to assert tripping according to the number of cycles set by the user. The default delay is 5 cycles.

From [7], the SEL-487E relay is equipped with harmonic restraint and harmonic blocking elements which are set to percent values of particular harmonics. However, harmonics 
appear not only in inrush currents, but also at CT saturation. In this case operation on severe internal faults can be delayed, and in order to minimize such chances, the relay is also equipped with unrestrained overcurrent element to operate instantly on high values of currents. For the SEL-487E relay the unrestrained pickup setting can be chosen from the range of $(1.0-20.0) \times T A P$.

Three independent REF elements can be assigned at the same time in the SEL-487E relay to protect equipment. The restraint quantity should be assigned to the winding which is electrically connected to the winding earmarked for REF protection. The number of terminals used for the REF protection should be specified as well in the AcSELerator. There is a choice to enable either instantaneous/definite time-overcurrent element (50) or adaptive time-overcurrent element (51); otherwise both 50 and 51 elements can be enabled to provide sufficient protection against ground faults. The REF neutral element instantaneous overcurrent (50) pickup has the range between 0.25 and $100 \mathrm{~A}_{\text {secondary }}$ for 5 A nominal CT current.

\subsubsection{Event analysis and event report}

According to [7], the AcSELerator Quickset software is also a tool for event analysis. The SEL-487E relay provides a feature of recording of operating conditions in a power system. Information about currents, voltages, settings used, and elements that operated in the relay is very valuable for analysis of the fault conditions, outage analysis and settings coordination.

The HMI feature of the AcSELerator software allows observing different parameters while performing experiments. For experiments performed in this work, the following functions of HMI used for observation were:

- Phasors,

- Differential Metering,

- Fundamental Metering Winding S, and

- RMS Metering Winding S.

The Phasors screen shows phasors diagram as well as fundamental current and voltage metering quantities. The Fundamental Metering screen shows the negative-sequence values.

The relay measures voltages and currents with the maximum rate of 8000 samples per second and minimum rate of 1000 samples per second. The relay automatically starts recording event data according to settings programmed by a user. In order to initiate data capture, it is necessary to add triggering conditions in the SELogic control equation ER in the Trip Logic settings under the Group 1 category. Later the event report can be pulled 
up with the command "EVE No" entered through the terminal window. This command displays the full length report stored in the relay memory. The user can choose the length of the event report and number of samples per cycle. The differential report can be a part of the analog section if user specified. The full length event report consists of 4 main parts:

- Report header and analog section,

- Digital section,

- Summary section, and

- Settings section. 



\section{CHAPTER 3 \\ Transformer Modeling for Internal Faults}

This chapter introduces parameters of two power transformers used in this work as well as data on verification of short circuit tests performed for both power transformers utilizing the Hybrid Model and the internal fault model. CT parameters and the ATP model of a CT are also given in this chapter. Detailed relay settings for the negativesequence and REF elements are developed.

\subsection{Power transformer models}

As mentioned earlier, two three-phase step-down power transformers were used in this project for simulation of faults and relay sensitivity testing:

- $\quad$ 11.2 MVA,72.00 $\Delta / 25.00 \mathrm{GY} \mathrm{kV,60} \mathrm{Hz}$

- $290 \mathrm{MVA}, 432 \mathrm{GY} / 16 \Delta \mathrm{kV}, 50 \mathrm{~Hz}$

The first transformer has a factory test report (see Appendix A); parameters of the second were obtained from Example 16 of the Users' Manual for ATPDraw version 5.6 [16] (see Figure A.4 in Appendix A). The data obtained from the test report were used to create the Hybrid Model for the 11.2-MVA transformer and perform short circuit and open circuit tests for verification with the test report data. The Hybrid Model of the 290-MVA transformer was available from [16]. Parameters for the short circuit tests are given in Table 3.1.

Table 3.1: Short circuit test parameters.

\begin{tabular}{|c|c|c|}
\hline & 11.2-MVA transformer & 290-MVA transformer \\
\hline Rated $\mathrm{V}_{\mathrm{pri}}, \% /$ Volts & $100 / 72$ & $100 / 432$ \\
\hline $\mathrm{Z}_{\mathrm{sc}}, \%$ & 8.676 & 14.6 \\
\hline $\mathrm{R} / \mathrm{X}, \%$ & $0.425 / 8.666$ & $0.24 / 14.598$ \\
\hline $\mathrm{V}_{\mathrm{sc}}, \% /$ Volts & $\begin{array}{c}8.676 / 6247(6255 \text { from the test } \\
\text { report })\end{array}$ & $14.6 / 63072$ \\
\hline
\end{tabular}

Figure 3.1 depicts the Hybrid Models for short circuit tests performed for the 11.2-MVA and 290-MVA transformers. All the resistances in this figure have low values $\left(1 \mathrm{E}^{-6} \Omega\right)$. The resistance between each source and transformer is used for current measuring purposes, and the resistance from transformer to ground both imitates a short circuit and serves as a current meter. In ATP, the grounding element cannot be connected directly to primary or secondary terminals of the transformer. 


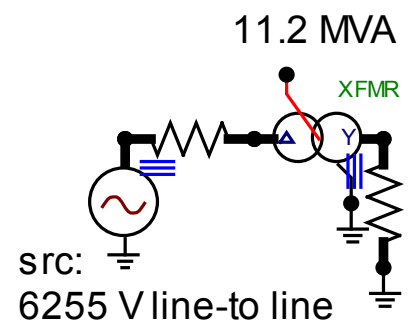

(a)

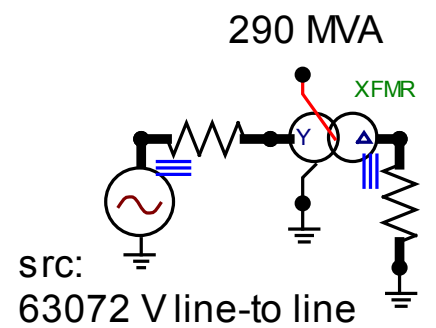

(b)

Figure 3.1: Short-circuit test: (a) 11.2-MVA transformer, (b) 290-MVA transformer.

For the next step, the internal fault model was created for each transformer. These power transformers are the IEEE standard transformers, which means that the high-voltage positive-sequence phase angle leads the low-voltage side by $30^{\circ}$ [17]. Thus, different connections for the delta side are required for each transformer. Figure 3.2 shows the detailed connections.
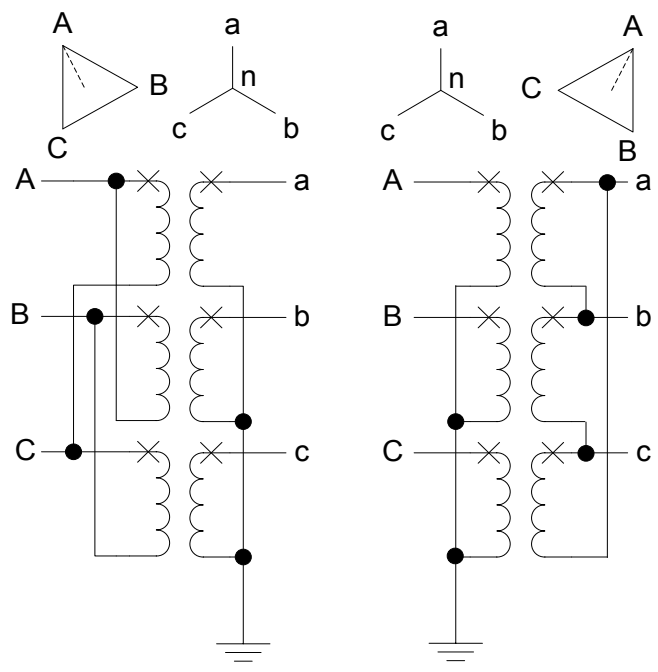

Figure 3.2: Wye-delta transformer banks: (a) delta-connected bank leads the wye connected side by $30^{\circ}$, (b) delta-connected side lags the wye connected side by $30^{\circ}[3]$.

For both power transformers the proper $30^{\circ}$ phase shift was verified for the internal fault model, and short circuit tests were also performed to see if the currents for both Hybrid and internal fault models were the same. Table 3.2 provides verification information.

Table 3.2: Short circuit test data verification for Hybrid Model and internal fault model.

\begin{tabular}{|c|c|c|c|c|}
\hline & \multicolumn{2}{|c|}{ 11.2-MVA transformer } & \multicolumn{2}{c|}{ 290-MVA transformer } \\
\cline { 2 - 5 } & Hybrid Model & $\begin{array}{c}\text { Internal fault } \\
\text { model }\end{array}$ & Hybrid Model & $\begin{array}{c}\text { Internal fault } \\
\text { model }\end{array}$ \\
\hline $\begin{array}{c}\text { High-side current, } \\
\mathrm{A}_{\text {peak pri }}\end{array}$ & 127.22 & 127.18 & 548.11 & 548.13 \\
\hline $\begin{array}{c}\text { Low-side current, } \\
\mathrm{A}_{\text {peak pri }}\end{array}$ & 366.27 & 366.26 & 14799 & 14799 \\
\hline
\end{tabular}


High-voltage side and low-voltage side rated currents calculations for both transformers are given in Appendix C. Figures 3.3 and 3.4 show connections of windings for both power transformers as well as $\mathrm{CT}$ and relay connections.

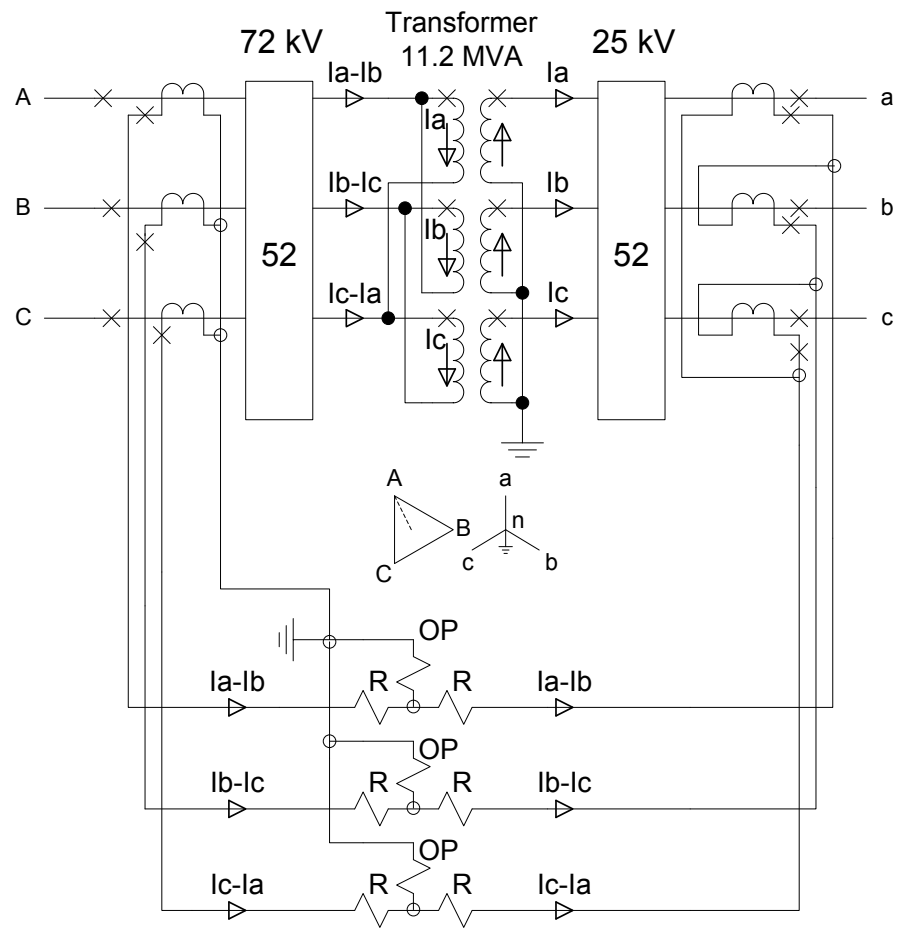

Figure 3.3: Differential relay connections for the delta-wye 11.2-MVA transformer [3].

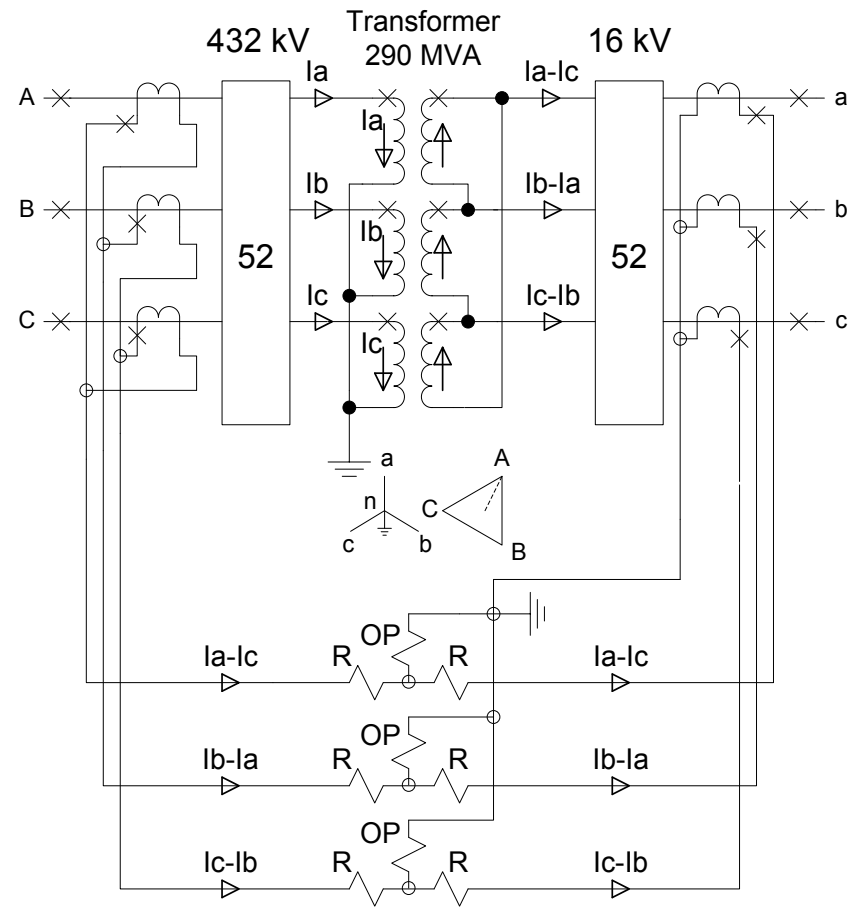

Figure 3.4: Differential relay connections for the wye-delta 290-MVA transformer. 


\subsection{CT sizing}

As mentioned in Section 2.3, in order to avoid saturation of CTs, they should be chosen with a $\mathrm{C}$-voltage rating at least twice that required for the maximum symmetrical fault current at its steady-state. However, the purpose of the CT saturation experiments in this project is to achieve saturation and see the curves from the CT primary and secondary windings. Thus, the recommended CT sizing was not performed. CT sizing was performed for the maximum load of each power transformer.

\subsubsection{The 11.2-MVA transformer}

The test report for the 11.2-MVA transformer provides data for its current transformers. All six CTs are bushing 600:5 CTs of C800 accuracy class with multi-ratio winding.

The CTs should be sized for maximum load according to the design capabilities. From the test report, the ONAF mode is 14 MVA. According to [17], ONAF stands for Oil Natural Air Forced (FA in old abbreaviation, meaning fan cooled through radiator, oil moves by convection). Thus, the tap ratio of the CTs for the high-voltage side of the 11.2-MVA transformer should be chosen considering primary current value calculated as $I_{\text {pri HS }}=\frac{14000 \mathrm{kVA}}{\sqrt{3} \times 72 \mathrm{kV}}=112.26 \mathrm{~A}$, and the tap ratio of the CTs for the low-voltage side of this transformer is chosen for its primary current $I_{\text {pri LS }}=\frac{14000 \mathrm{kVA}}{\sqrt{3} \times 25 \mathrm{kV}}=323.32 \mathrm{~A}$.

From the standard turns ratio (see Appendix A, Table A.2), CTs for the high-voltage side of the 11.2-MVA transformer will have 30 turns; and CTs for the low-voltage side will have 80 turns, which gives ratios of 150:5 and 400:5 respectively. As mentioned in Section 2.3, at partial use of multi-ratio CTs, accuracy should be recalculated:

For CTs on high side, $\frac{30 \times 5}{600} \times 800=200 \mathrm{~V}$. Thus, accuracy is approximately C200.

For CTs on low side, $\frac{80 \times 5}{600} \times 800=533.33 \mathrm{~V}$. Thus, accuracy is approximately C500.

This gives the maximum secondary exciting voltages for the CTs of the 11.2-MVA transformer of $200 \mathrm{~V}$ and $500 \mathrm{~V}$, respectively. However, looking at the excitation curves (see Appendix A, Figures A.2 and A.3), the linear region is up to about $150 \mathrm{~V}$ and $450 \mathrm{~V}$, respectively.

\subsubsection{The 290-MVA transformer}

Sizing of the CTs for the 290-MVA transformer was performed also considering the maximum amount of MVA (see Table 3.3). 
Table 3.3: MVA values for different transformer ratings, 290 MVA.

\begin{tabular}{|c|c|c|c|c|}
\hline MVA multiplier & 3 & 4 & 5 & Temperature rise \\
\hline 1 & $290 \mathrm{MVA}$ & $386.7 \mathrm{MVA}$ & $483.3 \mathrm{MVA}$ & $55^{\circ} \mathrm{C}$ \\
\hline 1.125 & $326.25 \mathrm{MVA}$ & $435 \mathrm{MVA}$ & $543.7 \mathrm{MVA}$ & $65^{\circ} \mathrm{C}$ \\
\hline
\end{tabular}

The maximum power rating of the 290-MVA transformer is 543.7 MVA which is related to OFAF regime (Oil Forced Air Forced). Thus, CTs for the high-voltage side of the 290MVA transformer should be chosen considering primary current value calculated as $I_{\text {pri HS }}=\frac{543700 \mathrm{kVA}}{\sqrt{3} \times 432 \mathrm{kV}}=726.63 \mathrm{~A}$, and CTs for the low-voltage side of this transformer $I_{\text {pri LS }}=\frac{543700 \mathrm{kVA}}{\sqrt{3} \times 16 \mathrm{kV}}=19619.08 \mathrm{~A}$. CTs for the 290-MVA power transformer were not provided. Available standard 1200:5 multi-ratio CTs of accuracy 10C800, tapped at 800:5, were chosen for the high-voltage side of the power transformer (see magnetizing curves in Figure A.5, Appendix A). For the low-voltage side of this power transformer, single ratio 24000:5 CTs of C800 accuracy class were chosen. However, the V-I data are provided for $60 \mathrm{~Hz}$ frequency, and the power transformer considered is of $50 \mathrm{~Hz}$. Taking this into consideration, magnetizing characteristics can be recalculated. From the chain of formulas $E=4.44 B A f N, B=\frac{\Phi}{A}, \Phi=\frac{N I}{\mathcal{R}}$, it is seen that the decrease in frequency is proportional to the rise in flux density $\mathrm{B}$, which in turn is proportional to the rise in the magnetizing current. The frequency-decrease-flux-density-increase percentage is $17 \%$. The recalculated magnetizing curve for the 800:5 ratio is given in Table 3.4.

Table 3.4: Recalculation of magnetizing curve from $60 \mathrm{~Hz}$ to $50 \mathrm{~Hz}$ for 800:5 tapped ratio of the 1200:5 CT.

\begin{tabular}{|c|c|c|}
\hline Voltage, $\mathrm{V}_{\mathrm{RMS}}$ & $\mathrm{I}_{\mathrm{E} 60}, \mathrm{~A}_{\mathrm{RMS}}$ & $\mathrm{I}_{\mathrm{E} 50}, \mathrm{~A}_{\mathrm{RMS}}$ \\
\hline 0.25 & 0.0010 & 0.0012 \\
\hline 100 & 0.0650 & 0.0761 \\
\hline 250 & 0.1300 & 0.1521 \\
\hline 300 & 0.1450 & 0.1697 \\
\hline 350 & 0.1750 & 0.2048 \\
\hline 500 & 0.3000 & 0.3510 \\
\hline 525 & 0.3500 & 0.4095 \\
\hline 550 & 0.4500 & 0.5265 \\
\hline 575 & 0.6000 & 0.7020 \\
\hline 600 & 1.0000 & 1.1700 \\
\hline 625 & 2.5000 & 2.9250 \\
\hline 650 & 5.0000 & 5.8500 \\
\hline 700 & 20.0000 & 23.4000 \\
\hline
\end{tabular}

Accuracy of the 1200:5 CT tapped at 800:5 should be also recalculated: $\frac{160 \times 5}{1200} \times 800=$ $533.33 \mathrm{~V}$. Thus, accuracy is approximately C500. According to Figure A.5, CT secondary winding resistance for $800: 5$ ratio is $0.0027 \Omega /$ turn $\times 160=0.432 \Omega$. 
Table 3.5: Recalculation of magnetizing curve from $60 \mathrm{~Hz}$ to $50 \mathrm{~Hz}$ for the 24000:5 CT.

\begin{tabular}{|c|c|c|}
\hline Voltage, $\mathrm{V}_{\mathrm{RMS}}$ & $\mathrm{I}_{\mathrm{E} 60}, \mathrm{~A}_{\mathrm{RMS}}$ & $\mathrm{I}_{\mathrm{E} 50}, \mathrm{~A}_{\mathrm{RMS}}$ \\
\hline 400 & 3.3000 & 3.8610 \\
\hline 800 & 5.8000 & 6.7860 \\
\hline 1200 & 13.9000 & 16.2630 \\
\hline 1400 & 38.2000 & 44.6940 \\
\hline
\end{tabular}

Magnetizing curve for the low-side CTs was obtained in Table 3.5 for $60 \mathrm{~Hz}$, showing original information and recalculated currents.

The secondary winding resistance for the 24000:5 CT was approximately defined utilizing resistance of the C800 3000:5 CT. The 24000-A CT uses a core which is about half the cross sectional area of the 3000-A CT. And increase in turns can be compensated by multiplying by 8 . Taking $0.002 \Omega /$ turn for the 3000-A CT, $R_{S 3000}=0.002 \times 600=$ $1.2 \Omega$. Then $R_{S} 24000=\frac{1.2}{\sqrt{2}} \times 8=6.788 \Omega$.

\subsubsection{Summarized data about CTs used}

The CT voltage developed across the secondary winding at high fault currents will depend on the total burden (see Figure 2.3):

$$
R_{T O T}=R_{S}+R_{w}+R_{B}
$$

Where:

$\mathrm{R}_{\mathrm{S}}$ is secondary resistance of CT,

$\mathrm{R}_{\mathrm{W}}$ is leads resistance, and

$\mathrm{R}_{\mathrm{B}}$ is relay burden.

Values of $R_{S}$ are available from the test report and calculations above, and given as the summarized data in Table 3.6 below. $\mathrm{R}_{\mathrm{W}}$ was changed during experiments performed to explore the effect of the burden on saturation of the CTs. $R_{B}$ is purely resistive, taken from the relay specification: $\leq 0.5 \mathrm{VA}$ at $5 \mathrm{~A}[7]$, or $0.02 \Omega$.

In order to compensate for delta-wye and wye-delta connections of the power transformers, their CTs were connected in the opposite order (see Figures 3.3 and 3.4).

Due to different turns ratios of the CTs on the high-voltage and low-voltage sides of the power transformers, there is a small current flowing in the operating coil of the relay. To provide safety margins for anticipated performance errors, the percentage mismatch should be low and can be calculated according to Equation (13), taken from [3]:

$$
M=100 \times \frac{\frac{I_{H}}{I_{L}}-\frac{T_{H}}{T_{L}}}{S}
$$


Where:

$\mathrm{I}_{\mathrm{H}}$ and $\mathrm{T}_{\mathrm{H}}$ are secondary current and relay tap related to high-side winding, $\mathrm{I}_{\mathrm{L}}$ and $\mathrm{T}_{\mathrm{L}}$ are secondary current and relay tap related to low-side winding, and $\mathrm{S}$ is smallest of current or tap ratios.

Mismatch between CTs of the 11.2-MVA transformer is $0.06 \%$ and between CTs of the 290-MVA transformer is $0.24 \%$. This is a very good match for both power transformers (see calculations in Appendix C).

For turn-to-ground fault experiments, the neutral CT for solidly grounded neutral is of 600:5 multi-ratio tapped at 150:5, and for low-resistance grounded neutral, the neutral CT has the same ratio of 150:5. The scheme of CT connections for using the REF element in the SEL-487E relay is shown in Figure 3.5. Also this figure shows directions of currents during internal ground fault on the wye-connected winding.

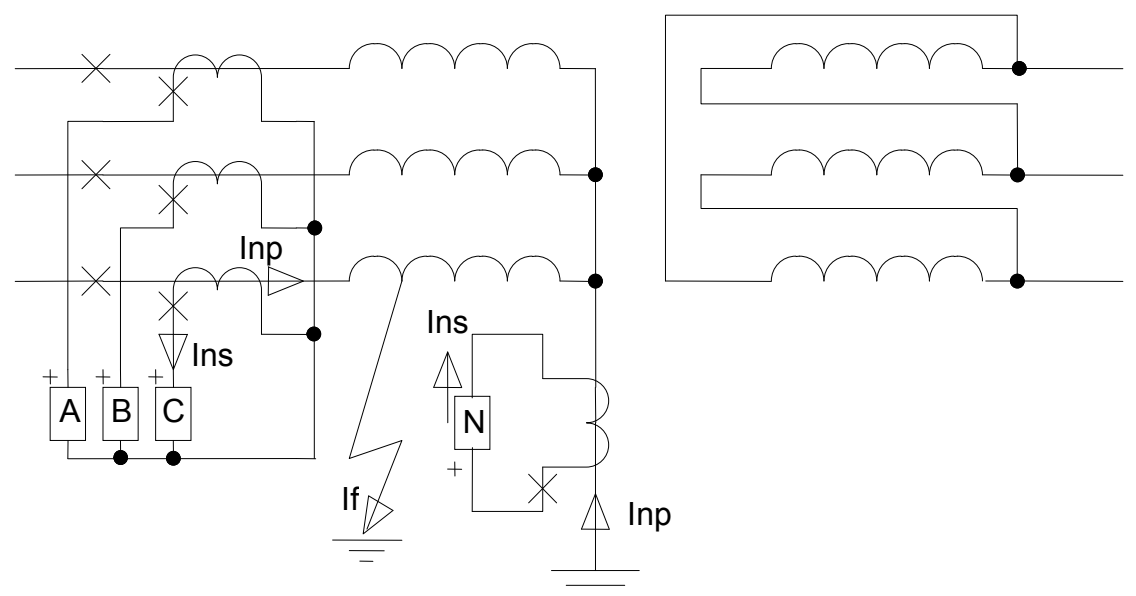

Figure 3.5: CT connections for ground fault protection [9].

The summarized CT data for both power transformers is given in Table 3.6.

Table 3.6: CT data for the tested power transformers.

\begin{tabular}{|c|c|c|c|c|c|}
\hline \multicolumn{2}{|c|}{} & \multirow{2}{*}{ High-side CT } & Low-side CT & \multicolumn{2}{c|}{ Neutral CT } \\
\cline { 3 - 6 } & & & $\begin{array}{c}\text { Solid } \\
\text { grounding }\end{array}$ & $\begin{array}{c}\text { Low- } \\
\text { resistance } \\
\text { grounding }\end{array}$ \\
\hline \multirow{3}{*}{11.2 MVA } & CT & $600: 5$ & $600: 5$ & \multirow{2}{*}{ No tests performed } \\
\cline { 2 - 6 } & CT ratio & $150: 5$ & $400: 5$ & $600: 5$ & $600: 5$ \\
\cline { 2 - 6 } & $\mathrm{R}_{\mathrm{S}}, \Omega$ & 0.176 & 0.253 & $150: 5$ & $150: 5$ \\
\hline \multirow{3}{*}{290 MVA } & $\mathrm{CT}$ & $1200: 5$ & $24000: 5$ & 0.176 & 0.176 \\
\cline { 2 - 6 } & $\mathrm{CT}$ ratio & $800: 5$ & $24000: 5$ & & \\
\cline { 2 - 6 } & $\mathrm{R}_{\mathrm{S}}, \Omega$ & 0.432 & 6.788 & & \\
\hline
\end{tabular}




\subsection{CT model}

A current transformer can be modeled in ATP in different ways. One is using the saturable transformer component [18]. Another method, which was used for this work, utilizes two components: an ideal transformer and a nonlinear inductor. Nonlinear inductances have two main representations in ATP: Types 93 and 98. Nonlinear elements have several potential numerical problems at the transient simulation process.

For the saturable inductor representation, Type-93 nonlinear inductor is a more attractive choice due to its "true" L-i characteristic. "True" in this case means that in every time step, an iterative process is applied in order to get a very close solution to a piece-wise characteristic. However, there is a risk that at large current changes divergence will occur. For Type-98 nonlinear inductor, inductance is adjusted in one integration step for the next one. The smaller $\Delta t$, the closer to characteristic, without nonconvergence problems, but with numerical-oscillation latency. Thus, the core of each CT was represented with the Type-93 nonlinear inductor.

The V-I data were taken from the test report and Tables 3.4 and 3.5 to enter $\lambda$-i characteristics into the Type-93 elements. The V-I curve data are given in RMS values, and $\lambda$-i curve should be entered as peak values. The $\lambda$-i characteristics for all the CTs are given in Appendix D.

Necessary ATP tests were performed to benchmark data of the CT core models created in ATP with the data provided. For this, a simple circuit was created (see Figure 3.6) and different voltages from the V-I curves were applied.

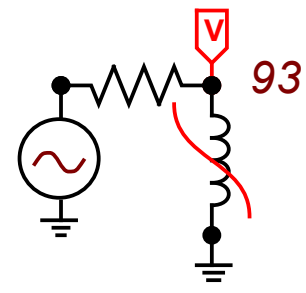

Figure 3.6: Type-93 nonlinear inductor test circuit.

The resistance between the source and nonlinear element is an arbitrarily small resistance, here $\mathrm{R}=0.01 \Omega$. For voltages much below the knee-point voltage, currents have a pure sine wave and values are very close to the provided data. In the region of high saturation the currents of the nonlinear inductors have the shapes depicted in Figure 3.7 . 


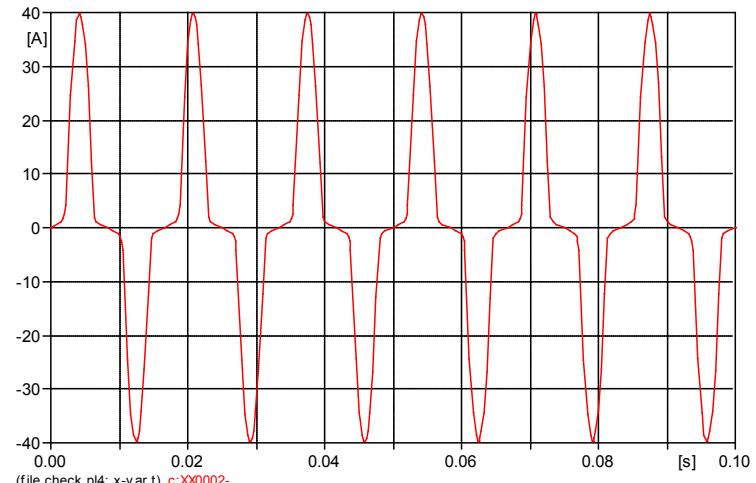

(a)

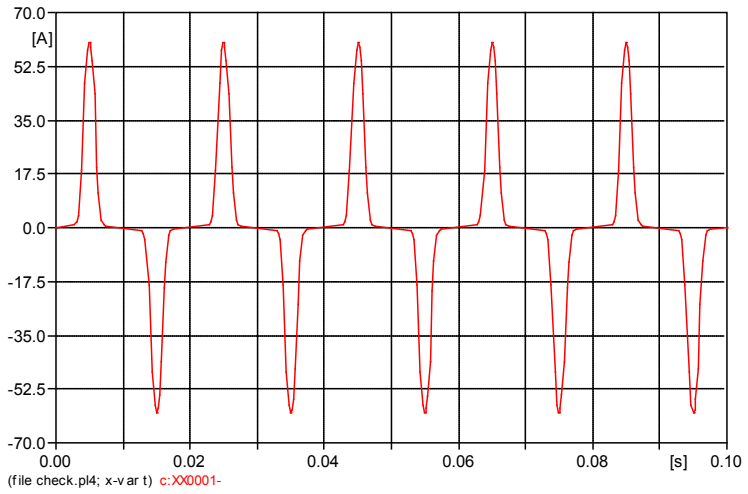

(b)

Figure 3.7: Current in Type-93 element at voltages above the saturation point:

(a) for 600:5 CT tapped at 150:5 $\left(\lambda_{\mathrm{p}}=1.13 \mathrm{~Wb}-\mathrm{T}\right)$, (b) for 1200:5 CT tapped at 800:5 $\left(\lambda_{\mathrm{p}}=3.15 \mathrm{~Wb}-\mathrm{T}\right)$.

The CT model in ATP is shown in Figure 3.8.

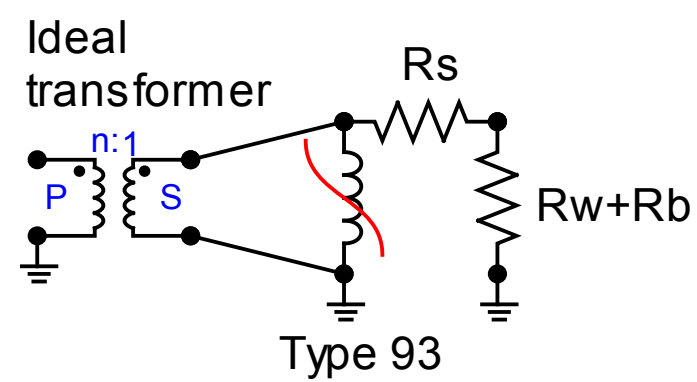

Figure 3.8: CT model in ATP with Type-93 nonlinear inductor.

The leakage impedance for CTs of class C is negligible and omitted here.

The ATP internal fault models for both power transformers for turn-to-turn and turn-toground fault experiments are shown in Appendix B. These figures also contain ATP models of each CT.

\subsection{Relay settings}

\subsubsection{Settings for turn-to-turn faults}

To operate for turn-to-turn faults, the SEL-487E relay uses the negative-sequence percentage restrained differential element which is designated as $87 \mathrm{Q}$ in the relay. All other relay elements, except the phase-differential and definite time overcurrent elements, during experiments for this part of the work were disabled. For this purpose the TRXFMR SELogic control equation (in the Trip Logic settings under the Group 1 category) had the following setting: $87 \mathrm{R}$ OR $87 \mathrm{Q}$, where $87 \mathrm{R}$ is responsible for phasedifferential element operation and $87 \mathrm{Q}$ for negative-sequence differential element operation. Settings for turn-to-turn faults detection are given in Table 3.7. 
Table 3.7: The SEL-487E relay settings for turn-to-turn faults.

\begin{tabular}{|c|c|c|c|c|}
\hline \multicolumn{3}{|r|}{ Categories } & \multirow{2}{*}{$\begin{array}{c}11.2 \\
\text { MVA } \\
60\end{array}$} & \multirow{2}{*}{$\begin{array}{c}290 \text { MVA } \\
50\end{array}$} \\
\hline Global & $\begin{array}{l}\text { General Global } \\
\text { Settings }\end{array}$ & Frequency, $\mathrm{Hz}$ & & \\
\hline \multirow{36}{*}{$\begin{array}{c}\text { Group } 1 \\
\text { Set } 1\end{array}$} & \multirow{3}{*}{$\begin{array}{c}\text { Relay } \\
\text { Configuration }\end{array}$} & ECTTERM Enable the following current terminals & \multicolumn{2}{|c|}{$\mathrm{S}, \mathrm{T}$} \\
\hline & & $\begin{array}{l}\text { E87 Include the following terminals in the differential } \\
\text { element }\end{array}$ & \multicolumn{2}{|c|}{$\mathrm{S}, \mathrm{T}$} \\
\hline & & $\begin{array}{l}\text { E50 Enable Definite time overcurrent element for the } \\
\text { following terminals }\end{array}$ & \multicolumn{2}{|c|}{$\mathrm{S}$} \\
\hline & \multirow{4}{*}{$\begin{array}{c}\text { Current } \\
\text { Transformers }\end{array}$} & CTRS Current transformer ratio for Terminal S & 30 & 160 \\
\hline & & $\begin{array}{l}\text { CTCONS Current transformer connection for Terminal } \\
\text { S }\end{array}$ & $\mathrm{Y}$ & $\mathrm{D}$ \\
\hline & & CTRT Current transformer ratio for Terminal T & 80 & 4800 \\
\hline & & $\begin{array}{l}\text { CTCONT Current transformer connection for Terminal } \\
\mathrm{T}\end{array}$ & $\mathrm{D}$ & $\mathrm{Y}$ \\
\hline & \multirow{15}{*}{$\begin{array}{c}\text { Differential } \\
\text { Element } \\
\text { Configuration and } \\
\text { Data }\end{array}$} & $\begin{array}{l}\text { E87TS Include Terminal S in the differential element } \\
\text { for the following conditions }\end{array}$ & \multicolumn{2}{|c|}{1} \\
\hline & & $\begin{array}{l}\text { E87T Include Terminal } \mathrm{T} \text { in the differential element for } \\
\text { the following conditions }\end{array}$ & \multicolumn{2}{|c|}{1} \\
\hline & & $\begin{array}{l}\text { ICOM Internal CT connection matrix compensation } \\
\text { enabled }\end{array}$ & \multicolumn{2}{|c|}{$\mathrm{N}$} \\
\hline & & MVA Enter transformer maximum MVA rating & 11.2 & 290 \\
\hline & & VTERMS Terminal S nominal line-to-line voltage & 72 & 432 \\
\hline & & VTERMT Terminal T nominal line-to-line voltage & 25 & 16 \\
\hline & & O87P Differential element operating current pickup & 0.18 & 0.23 \\
\hline & & SLP1 Slope 1 setting & \multicolumn{2}{|c|}{35} \\
\hline & & SLP2 Slope 2 setting & \multicolumn{2}{|c|}{75} \\
\hline & & U87P Unrestrained element current pickup & \multicolumn{2}{|c|}{8} \\
\hline & & DIOPR Incremental operate current pickup & \multicolumn{2}{|c|}{1.2} \\
\hline & & DIRTR Incremental restraint current pickup & \multicolumn{2}{|c|}{1.2} \\
\hline & & $\begin{array}{l}\text { 87QP Negative sequence differential element operating } \\
\text { current pickup }\end{array}$ & \multicolumn{2}{|c|}{$0.05-1$} \\
\hline & & SLPQ1 Negative sequence differential slope & \multicolumn{2}{|c|}{$5-100$} \\
\hline & & 87QD Negative sequence differential element delay & \multicolumn{2}{|c|}{5} \\
\hline & \multirow{5}{*}{ Winding S } & $\begin{array}{l}\text { E50S Enable the Type of Overcurrent Elements for } \\
\text { Terminal S }\end{array}$ & \multicolumn{2}{|c|}{$\mathrm{P}, \mathrm{Q}$} \\
\hline & & $\begin{array}{l}\text { 50SP1P Phase Instantaneous Overcurrent Pickup } \\
\text { Level1 }\end{array}$ & \multicolumn{2}{|c|}{0.25} \\
\hline & & $\begin{array}{l}\text { 67SP1TC Phase Instantaneous Overcurrent Level1 } \\
\text { Torque Control }\end{array}$ & \multicolumn{2}{|c|}{1} \\
\hline & & $\begin{array}{l}\text { 50SQ1P Negative Sequence Instantaneous Overcurrent } \\
\text { Pickup Level1 }\end{array}$ & \multicolumn{2}{|c|}{0.25} \\
\hline & & $\begin{array}{l}\text { 67SQ1TC Negative Sequence Instantaneous } \\
\text { Overcurrent Level1 Torque Control }\end{array}$ & \multicolumn{2}{|c|}{1} \\
\hline & \multirow{9}{*}{ Trip Logic } & TRXFMR Trip conditions for transformer terminals & 871 & R 87Q \\
\hline & & $\begin{array}{l}\text { ULTXFMR Unlatch trip conditions for transformer } \\
\text { terminals }\end{array}$ & & TR \\
\hline & & TRS Trip conditions for Terminal S & & \\
\hline & & ULTRS Unlatch trip conditions for Terminal S & & TR \\
\hline & & TRT Trip conditions for Terminal T & & \\
\hline & & ULTRT Unlatch trip conditions for Terminal T & & TR \\
\hline & & TDURD Minimum trip duration & & \\
\hline & & ER Conditions for triggering event reports & 50SP & 50SQ1 \\
\hline & & FAULT Conditions for asserting FAULT Bit & & \\
\hline
\end{tabular}


The relay automatically calculates the tap values for the high-voltage and low-voltage sides, and O87P values were defined according to Equation (11). These calculations are given in Appendix C.

In the SEL-487E relay, the high-voltage side winding is designated as the S-winding, and the low-voltage side winding as the T-winding. From the relay calculations, the 11.2MVA transformer has S-winding tap of $2.94 \mathrm{~A}$, and the 290-MVA transformer has Swinding tap of 4.2 A. Different slope percentages and operating current pickup settings for the negative-sequence element were used later in the experiments. All other settings shown in Table 3.7 are the default settings.

All the necessary settings are located under the Group 1 category in the AcSELerator software. However, to choose the power frequency for each transformer, the Global category settings needed to be changed.

\subsubsection{Settings for turn-to-ground faults}

To define turn-to-ground faults, the SEL-487E relay uses the REF element designated with the REFF1 Word bit. REFRF1 was set to $\mathrm{S}$ as terminal $\mathrm{S}$ is electrically connected to the winding earmarked for REF protection, i.e., the wye-connected winding of the 290MVA transformer is protected against ground faults.

The Restricted Earth Fault Element section has the pickup settings for instantaneous overcurrent (50) and adaptive time-overcurrent (51) elements. The 51 element provides additional security in REF applications; however, for faster tripping the instantaneous overcurrent element can be used only. Thus, the REF front panel Target LED was indentified with the instantaneous overcurrent element (50): T6_LED = REFF1, which gives the red light on whenever the ground fault is tripped with the instantaneous overcurrent element.

According to the logic diagrams from [7], the input current from the neutral CT is compared against REF50G1setting (residual current sensitivity pickup). For security purposes, this comparison is made in three comparators. If the pickup threshold is exceeded, the logic performs directional calculations, which determine whether the fault is internal or external. After the logic indicates the internal fault, it should persist for at least 1.5 cycles, and only after that delay the internal ground fault will be detected by assertion of the REFF1 Relay Word bit.

During turn-to-ground experiments, residual current pickup settings for the REF element 1 (REF50G1) were changed. Relay settings for turn-to-ground faults detection are given in Table 3.8 . 
Table 3.8: The SEL-487E relay settings for turn-to-ground faults.

\begin{tabular}{|c|c|c|c|}
\hline \multicolumn{3}{|r|}{ Categories } & \multirow{2}{*}{$\begin{array}{c}290 \mathrm{MVA} \\
50\end{array}$} \\
\hline Global & $\begin{array}{l}\text { General Global } \\
\text { Settings }\end{array}$ & Frequency, $\mathrm{Hz}$ & \\
\hline \multirow{25}{*}{$\begin{array}{c}\text { Group } 1 \\
\text { Set } 1\end{array}$} & \multirow{5}{*}{$\begin{array}{l}\text { Relay } \\
\text { Configuration }\end{array}$} & ECTTERM Enable the following current terminals & $\mathrm{S}$ \\
\hline & & E87 Include the following terminals in the differential element & OFF \\
\hline & & $\begin{array}{l}\text { EREF Enable the following number of restricted earth fault } \\
\text { elements }\end{array}$ & 1 \\
\hline & & REFRF1 Select the restraint quantity for REF element 1 & $\mathrm{~S}$ \\
\hline & & $\begin{array}{l}\text { E50 Enable Definite time overcurrent element for the following } \\
\text { terminals }\end{array}$ & $\mathrm{S}$ \\
\hline & \multirow{3}{*}{$\begin{array}{c}\text { Current } \\
\text { Transformers }\end{array}$} & CTRS Current transformer ratio for Terminal S & 160 \\
\hline & & CTCONS Current transformer connection for Terminal S & $\mathrm{Y}$ \\
\hline & & CTRY Current transformer ratio for Terminal Y, channel 1 & 30 \\
\hline & \multirow{5}{*}{$\begin{array}{l}\text { Restricted Earth } \\
\text { Fault Elements }\end{array}$} & REF50G1 Residual current pickup for REF element 1 & $0.25-3$ \\
\hline & & TCREF1 Torque control for REF element 1 & 1 \\
\hline & & $\begin{array}{l}\text { REF50P1 REF(50P) Operate current instantaneous overcurrent } 1 \\
\text { pickup }\end{array}$ & 0.25 \\
\hline & & REF50D1 REF Instantaneous overcurrent element 1 time delay & 60 \\
\hline & & $\begin{array}{l}\text { REF51P1 REF(51P) Operate current inverse time overcirrent } \\
\text { element } 1 \text { pickup }\end{array}$ & OFF \\
\hline & \multirow{5}{*}{ Winding S } & Overcurrent Terminal S & $\mathrm{P}, \mathrm{Q}$ \\
\hline & & 50SP1P Phase Instantaneous Overcurrent Pickup Level1 & 0.25 \\
\hline & & 67SP1TC Phase Instantaneous Overcurrent Level1 Torque Control & 1 \\
\hline & & $\begin{array}{l}\text { 50SQ1P Negative Sequence Instantaneous Overcurrent Pickup } \\
\text { Level1 }\end{array}$ & 0.25 \\
\hline & & $\begin{array}{l}\text { 67SQ1TC Negative Sequence Instantaneous Overcurrent Level1 } \\
\text { Torque Control }\end{array}$ & 1 \\
\hline & \multirow{7}{*}{ Trip Logic } & TRXFMR Trip conditions for transformer terminals & REFF1 \\
\hline & & ULTXFMR Unlatch trip conditions for transformer terminals & TRGTR \\
\hline & & TRS Trip conditions for Terminal S & 0 \\
\hline & & ULTRS Unlatch trip conditions for Terminal S & TRGTR \\
\hline & & TDURD Minimum trip duration & 5 \\
\hline & & ER Conditions for triggering event reports & $\begin{array}{c}\text { REF501 OR } \\
\text { 50SP1 OR } \\
\text { 50SQ1 }\end{array}$ \\
\hline & & FAULT Conditions for asserting FAULT Bit & REFF1 \\
\hline $\begin{array}{l}\text { Front } \\
\text { Panel }\end{array}$ & Target LEDs & T6_LED Target LED 6 (SELogic) & REFF1 \\
\hline
\end{tabular}




\section{CHAPTER 4 \\ Approach}

This chapter introduces conditions for simulation of turn-to-turn and turn-to ground faults as well as conditions for simulation of cases with saturation of CTs. Laboratory test setups for relay operation and information about application of waveforms obtained from the ATP simulations for turn-to-turn and turn-to-ground faults are explained here as well.

\subsection{Task statement}

For comparison each set of experiments (turn-to-turn, CT saturation cases, and turn-toground) were performed for two types of load:

- faults with resistive load on power transformers at rated conditions, later in the text designated as light load,

- faults with inductive load on power transformers at heavy load conditions, later in the text designated as heavy load.

Light load: the resistive load $\mathrm{R}_{\text {load }}$ for rated conditions was calculated for both power transformers (see Appendix C).

Heavy load: according to Table 7 from [19], the maximum short-time loading for power transformers can be $200 \%$ of the nameplate rating. Considering 0.9 p.f. for the $200 \%$ load, values of $\mathrm{R}_{\text {load }}$ and $\mathrm{X}_{\text {load }}$ were calculated for both power transformers (see Appendix C).

The internal fault models with the external connections corresponding to each case are shown in Appendix B. According to the ATP model, the high-voltage side of each phase was split into three sections, the second section was shorted to perform turn-to-turn short circuits, and the third section was shorted to perform turn-to-ground short circuits. All the experiments were performed on phase A. Necessary changes were made in the Matlab library component each time the percentage of the shorted winding portion was changed. The simulated internal faults had no fault resistance.

Comparison of calculated and simulated currents in the Hybrid Model and internal fault model for both types of load is given in Table 4.1. All the calculations for this table are given in Appendix C.

The values from the column "Loading total" are the sum of the transformer impedance and the actual load on the secondary side for each power transformer. 
Table 4.1: Calculated and simulated currents for light load and heavy load conditions.

\begin{tabular}{|c|c|c|c|c|c|c|}
\hline \multirow{2}{*}{ Transformer } & \multirow{2}{*}{ Loading total, $\Omega$} & \multirow{2}{*}{$\begin{array}{c}\text { Transformer } \\
\text { impedance, } \Omega\end{array}$} & \multirow{2}{*}{$\begin{array}{c}\text { Actual load on } \\
\text { transformer } \\
\text { secondary, } \Omega\end{array}$} & \multirow{2}{*}{$\begin{array}{l}\text { ATP } \\
\text { model }\end{array}$} & \multicolumn{2}{|c|}{ Load current, $A_{\text {peak pri }}$} \\
\hline & & & & & Simulation & Calculation \\
\hline \multirow[b]{2}{*}{ 11.2 MVA } & \multirow[b]{2}{*}{$\begin{array}{l}\text { Light } \\
55.8+\mathrm{j} 4.836\end{array}$} & \multirow[b]{2}{*}{$0.237+\mathrm{j} 4.836$} & \multirow[b]{2}{*}{55.563} & $\begin{array}{l}\text { Hybrid } \\
\text { Model }\end{array}$ & 364.45 & \multirow[b]{2}{*}{364.45} \\
\hline & & & & $\begin{array}{c}\text { Internal } \\
\text { fault } \\
\text { model }\end{array}$ & 366.7 & \\
\hline \multirow[b]{2}{*}{$\begin{array}{c}11.2 \mathrm{MVA} \\
\times 2\end{array}$} & \multirow[b]{2}{*}{$\begin{array}{c}\text { Heavy } \\
25.17+\mathrm{j} 12.276\end{array}$} & \multirow[b]{2}{*}{$0.237+\mathrm{j} 4.836$} & \multirow[b]{2}{*}{$24.933+\mathrm{j} 7.44$} & $\begin{array}{l}\text { Hybrid } \\
\text { Model }\end{array}$ & 728.91 & \multirow[b]{2}{*}{728.89} \\
\hline & & & & $\begin{array}{c}\text { Internal } \\
\text { fault } \\
\text { model }\end{array}$ & 767.39 & \\
\hline \multirow[b]{2}{*}{290 MVA } & \multirow[b]{2}{*}{$\begin{array}{c}\text { Light } \\
0.8827+\mathrm{j} 0.12914\end{array}$} & \multirow[b]{2}{*}{$0.00212+\mathrm{j} 0.129$} & \multirow[b]{2}{*}{0.88058} & $\begin{array}{l}\text { Hybrid } \\
\text { Model }\end{array}$ & 14642 & \multirow[b]{2}{*}{14644} \\
\hline & & & & $\begin{array}{l}\text { Internal } \\
\text { fault } \\
\text { model }\end{array}$ & 14645 & \\
\hline \multirow[b]{2}{*}{$\begin{array}{c}290 \text { MVA } \\
\times 2\end{array}$} & \multirow[b]{2}{*}{$\begin{array}{c}\text { Heavy } \\
0.401+\mathrm{j} 0.1955\end{array}$} & \multirow[b]{2}{*}{$0.00212+\mathrm{j} 0.129$} & \multirow[b]{2}{*}{$0.3989+\mathrm{j} 0.0665$} & $\begin{array}{c}\text { Hybrid } \\
\text { Model }\end{array}$ & 29280 & \multirow[b]{2}{*}{29288} \\
\hline & & & & $\begin{array}{l}\text { Internal } \\
\text { fault } \\
\text { model }\end{array}$ & 29286 & \\
\hline
\end{tabular}

\subsection{Turn-to-turn faults}

In a real transformer, location of a turn-to-turn fault along the winding height affects the self and mutual impedances between the windings, creating the unique case of self and mutual impedance interactions for each turn-to-turn fault. The newly configured self and mutual impedances of the windings affect the value of a current in the faulted portion of the winding and correspondingly currents in the lines. The internal fault model used for simulations in this project is the older version, which does not have a feature to account for difference in self and mutual impedances between the newly configured winding due to the turn-to-turn fault location and the rest of the windings. Thus, it did not matter at what location along the winding height the faults were simulated. However, this information is available: the turn-to-turn faults for the 11.2-MVA transformer were performed so that the healthy section from the bottom was always kept at $80 \%$ of the phase-A winding, the middle section had a fault, and percentage of the healthy top section was changed depending on the amount of fault percentage. The same idea is used for the 290-MVA transformer, but the healthy bottom section was always kept at $50 \%$ of the phase-A winding.

For simulation of turn-to-turn faults, the CT burdens are purely resistive for both power transformers, with length of leads from CTs to the relay being $400 \mathrm{ft}$ (see Table 4.2). 


\subsection{Saturation of CTs}

Only the CTs on the high-voltage sides of both power transformers were expected to have saturation issues as turn-to-turn faults were performed on the high-voltage side of the power transformers. Saturation experiments were performed when power transformers had light load and heavy load, according to the task statement. The ATP models for each case of CT saturation are given in Appendix B.

As mentioned in Section 3.2.3, the total burden on a CT is $R_{T O T}=R_{S}+R_{w}+R_{B}$. Leads which connect each CT to a relay can be long or short which affects the winding resistance value. For experiments with saturation of CTs, Table 4.2 provides values of winding resistances used depending on the lead's length as well as total burden values. It was considered that the leads from the CTs to the relay are \#10 AWG stranded wires with capacity of $30 \mathrm{~A}$.

There was curiosity also to check how the $\mathrm{X} / \mathrm{R}$ ratio affects fault currents, DC offset decay, and $\mathrm{CT}$ saturation. The value of the $\mathrm{X} / \mathrm{R}$ ratio depends on the voltage level. For 72 $\mathrm{kV}$ level, it is approximately in the range $1-5$, and for $432 \mathrm{kV}$ level, it is $5-10$. The upper and lower values of these ranges were taken for the experiments. The source impedance was also changed. Calculations of the source impedance values are given in Appendix C.

Table 4.2: Variation of burdens of CTs on high side of both power transformers.

\begin{tabular}{|c|c|c|c|c|c|}
\hline \multirow{2}{*}{ Transformer } & $\begin{array}{c}\text { Distance from } \\
\text { CT to relay }\end{array}$ & $\mathrm{R}_{\mathrm{CT}}, \Omega$ & $\mathrm{R}_{\text {LEADS }}, \Omega$ & $\mathrm{R}_{\text {RELAY }}, \Omega$ & $\mathrm{R}_{\text {TOT }}, \Omega$ \\
\hline \multirow{3}{*}{11.2 MVA } & $50 \mathrm{ft}$ & 0.176 & 0.06 & 0.02 & 0.256 \\
\cline { 2 - 6 } & $400 \mathrm{ft}$ & 0.176 & 0.48 & 0.02 & 0.676 \\
\cline { 2 - 6 } & $1000 \mathrm{ft}$ & 0.176 & 1.2 & 0.02 & 1.396 \\
\hline \multirow{3}{*}{290 MVA } & $50 \mathrm{ft}$ & 0.432 & 0.06 & 0.02 & 0.512 \\
\cline { 2 - 6 } & $400 \mathrm{ft}$ & 0.432 & 0.48 & 0.02 & 0.932 \\
\cline { 2 - 6 } & $1000 \mathrm{ft}$ & 0.432 & 1.2 & 0.02 & 1.652 \\
\hline
\end{tabular}

\subsubsection{The 11.2-MVA transformer}

To see signs of saturation of the high-side CTs, the secondary exciting voltage should be about $200 \mathrm{~V}_{\text {rms }}$ (see calculations in Section 3.2.1 and V-I characteristic in Figure A.2, Appendix A).

1) $\mathrm{R}_{\mathrm{TOT}}=0.256 \Omega$. This gives the total secondary current of $\frac{200}{0.256}=781.25 A_{r m s}$, which gives the primary line current value of $781.25 \times 30=23437.5 \mathrm{~A}_{\text {rms }}$ or $33145.6 \mathrm{~A}_{\text {peak }}$. 
2) $\mathrm{R}_{\mathrm{TOT}}=0.676 \Omega$. This gives the total secondary current of $\frac{200}{0.676}=295.86 A_{r m s}$, which gives the primary line current value of $295.86 \times 30=8875.8 A_{\text {rms }}$ or $12552.3 \mathrm{~A}_{\text {peak }}$.

3) $\mathrm{R}_{\mathrm{TOT}}=1.396 \Omega$. This gives the total secondary current of $\frac{200}{1.396}=143.27 A_{\text {rms }}$, which gives the primary line current value of $143.27 \times 30=4298.1 A_{\text {rms }}$ or $6078.4 \mathrm{~A}_{\text {peak }}$.

\subsubsection{The 290-MVA transformer}

To see signs of saturation of the high-side CTs, the secondary exciting voltage should be about $500 \mathrm{~V}_{\text {rms }}$ (see calculations in section 3.2.2 and V-I characteristic for the 800:5 ratio in Figure A.5, Appendix A).

1) $\mathrm{R}_{\mathrm{TOT}}=0.512 \Omega$. This gives the total secondary current of $\frac{500}{0.512}=976.56 A_{\text {rms }}$, which gives the primary line current value of $976.56 \times 160 / \sqrt{3}=$ $90210.7 A_{\text {rms }}$ or $127577.2 \mathrm{~A}_{\text {peak }}$.

2) $\mathrm{R}_{\mathrm{TOT}}=0.932 \Omega$. This gives the total secondary current of $\frac{500}{0.932}=536.48 A_{\text {rms }}$, which gives the primary line current value of $536.48 \times 160 / \sqrt{3}=$ $49557.9 A_{\text {rms }}$ or $70085.5 \mathrm{~A}_{\text {peak }}$.

3) $\mathrm{R}_{\mathrm{TOT}}=1.652 \Omega$. This gives the total secondary current of $\frac{500}{1.652}=302.67 A_{\text {rms }}$, which gives the primary line current value of $302.67 \times 160 / \sqrt{3}=$ $27959.5 A_{r m s}$ or $39540.7 \mathrm{~A}_{\text {peak }}$.

\subsection{Turn-to-ground faults}

Since the older version of the internal fault model used for this work allows performing simulations of faults on the high-voltage side and the REF element operates on the grounded wye side, the 290-MVA transformer only can be tested for turn-to-ground faults. As mentioned earlier, for the REF element to operate, current information from the neutral CT and transformer's wye-side CTs connected in wye is needed. Thus, the ATP schemes different from the turn-to-turn or $\mathrm{CT}$ saturation cases are used for the ground faults experiments (see Appendix B).

Sensitivity of the REF element was compared for light load and heavy load as well, for two cases:

- solidly grounded neutral,

- low-resistance grounded neutral. 
Solidly grounded neutrals with grounding made of steel bars, cables and steel structures have some value of resistance. With a solidly grounded neutral, this value is expected to be as low as possible. According to [20], multiple rods in parallel yield lower resistance to ground and the value of 1-5 $\Omega$ is generally found suitable for industrial plant substations and building, and large commercial installations. Thus, the resistance value of $1 \Omega$ is considered for simulations with solidly grounded neutral.

The low-resistance grounding limits the neutral current during a fault to a value approximately from 50 to $600 \mathrm{~A}$ [3]. The grounding resistor is applied directly in the transformer neutral of the wye connected winding. Assuming the maximum expected neutral current during fault conditions of $600 \mathrm{~A}$ for the 290-MVA transformer, the resistance value is $R=\frac{V_{L N}}{I}=\frac{432000}{\sqrt{3} \times 600}=415 \Omega$.

For simulation of turn-to-ground faults, the $\mathrm{CT}$ burdens are purely resistive, with length of leads from CTs to the relay being $400 \mathrm{ft}$ (see Table 4.2); the neutral CT has a burden of $R_{B}=0.176+0.48+0.02=0.676 \Omega$.

\subsection{Test setups and application of waveforms}

The SEL-487E relay is connected to a PC through Port F on its front side. The Doble Tester supplies currents into the relay. S-winding and T-winding should be enabled in AcSELerator settings to allow operation of the phase-differential and negative-sequence differential elements. Connections for windings on the low-voltage side (terminals $\mathrm{T}$ on the relay) of the power transformers need to have the polarity reversed. This is explained by the fact that currents should be removed rather than injected into the relay [21]. Figure 4.1 shows connection of the Doble Tester and the SEL-487E relay for the turn-to-turn fault tests. The sources I1, I2, I3 are related to the high-voltage side of the power transformers, and sources I4, I5, I6 are related to the low-voltage side.

Doble Test Set

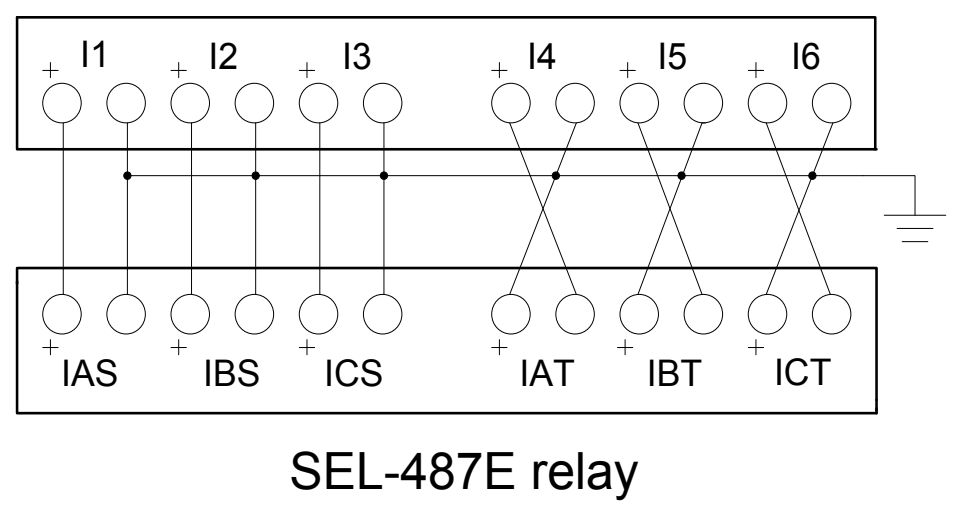

Figure 4.1: The Doble Tester-Relay test setup for turn-to-turn fault tests. 
Figure 4.2 shows current sources for the S-terminals and one additional current source (IN) which supplies current from the neutral of the 290-MVA transformer to the SEL487E relay for the turn-to-ground fault tests. The T-winding is disabled for these tests.

Doble Test Set

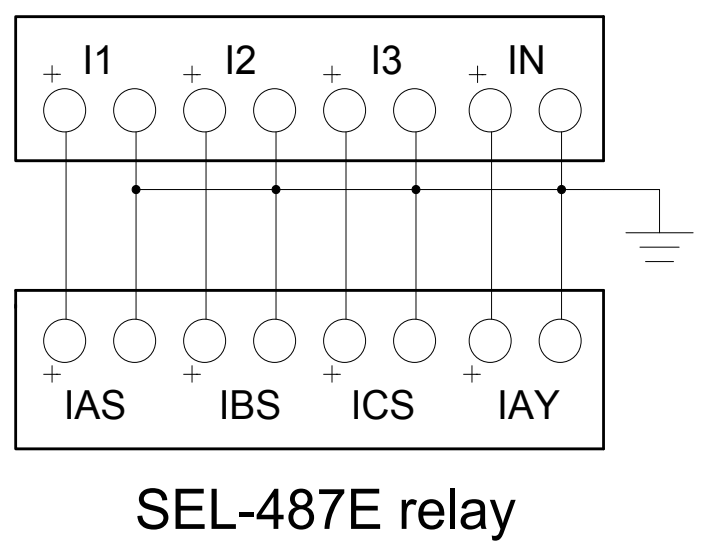

Figure 4.2: The Doble Tester-Relay test setup for turn-to-ground fault tests.

Four currents were supplied from four current sources of the Doble Tester. In this case the outputs of the current sources were as follows: two current outputs had $30 A_{\text {RMS }}$ in normal mode and $60 \mathrm{~A}_{\mathrm{RMS}}$ in transient mode, and other two current outputs had $15 \mathrm{~A}_{\mathrm{RMS}}$ in normal mode and $30 \mathrm{~A}_{\mathrm{RMS}}$ in transient mode.

Each simulation in ATP produces a pl4 binary waveform file which is readable by the Doble ProTesTC software. Time step $\Delta \mathrm{t}$ in each simulation was $5 \mu$ s. Data saved in .pl4 files corresponds to currents in the relay burden of each CT. To import .p14 files into the ProTesT(C) software, the TRANS macro should be created and proper channels need to be selected. Choosing the Run Continuously button does not stop the currents after the relay trips, which is useful to observe data from HMI Meter and Control of the AcSELerator software as well as capture screenshots. As mentioned in Section 2.6.6, for experiments in this work the following functions of HMI were used for observations: Phasors, Differential Metering, Fundamental Metering Winding S, and RMS Metering Winding S.

Figure 4.3 depicts the configuration of the ProTesT@ current outputs for the turn-to-turn fault experiments. The maximum values of current sources in normal mode are shown here in the right window.

Figure 4.4 shows the configuration of the ProTesTC current outputs for the turn-toground fault experiments with their limits in normal mode. 


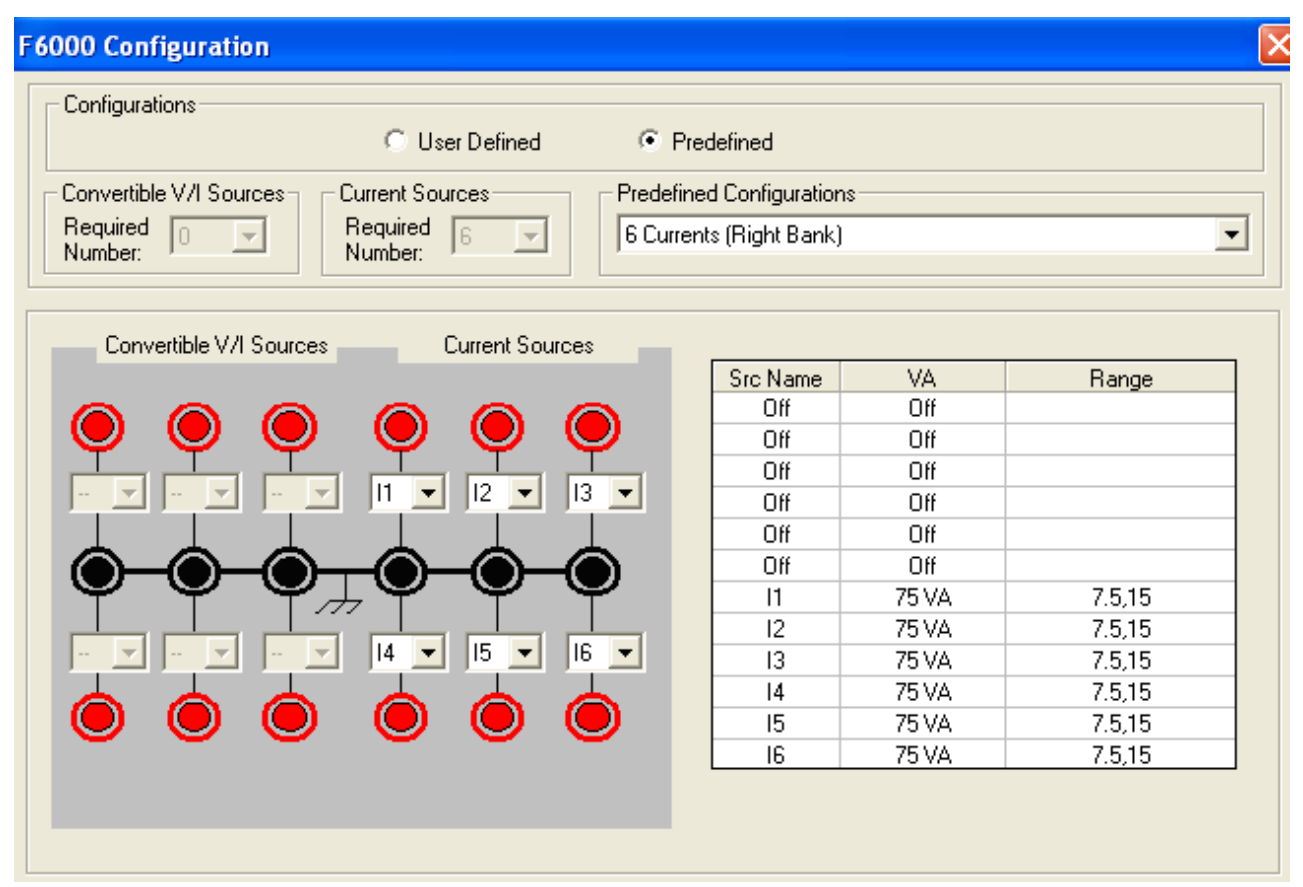

Figure 4.3: ProTesT $\odot$ current outputs for turn-to-turn fault experiments.
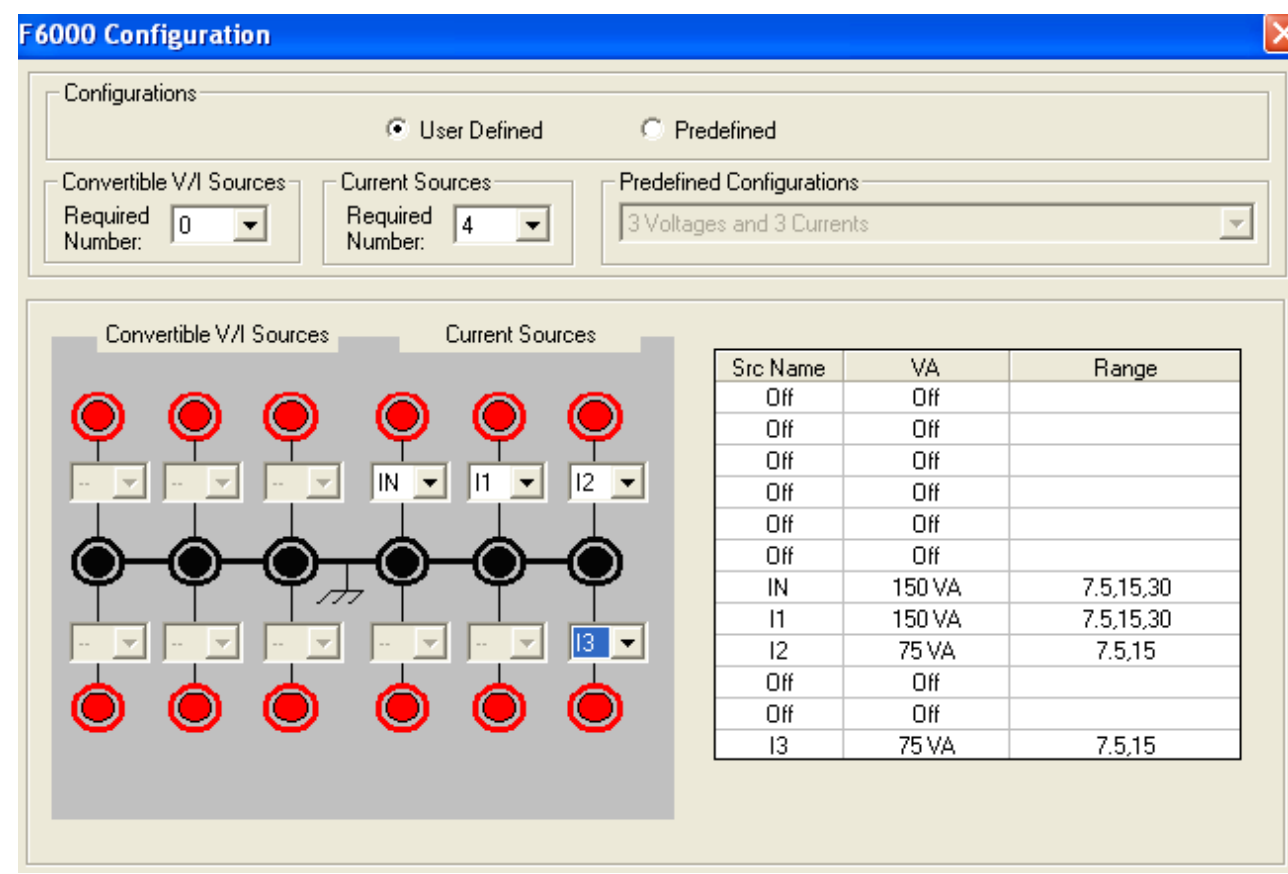

Figure 4.4: ProTesT $\odot$ current outputs for turn-to-ground fault experiments.

Figures 4.5 and 4.6 show screenshots from the ProTesT(C) software for one of the turn-toturn experiments: waveforms from the .p14 file and analog tab settings of the TRANS macro, respectively. 


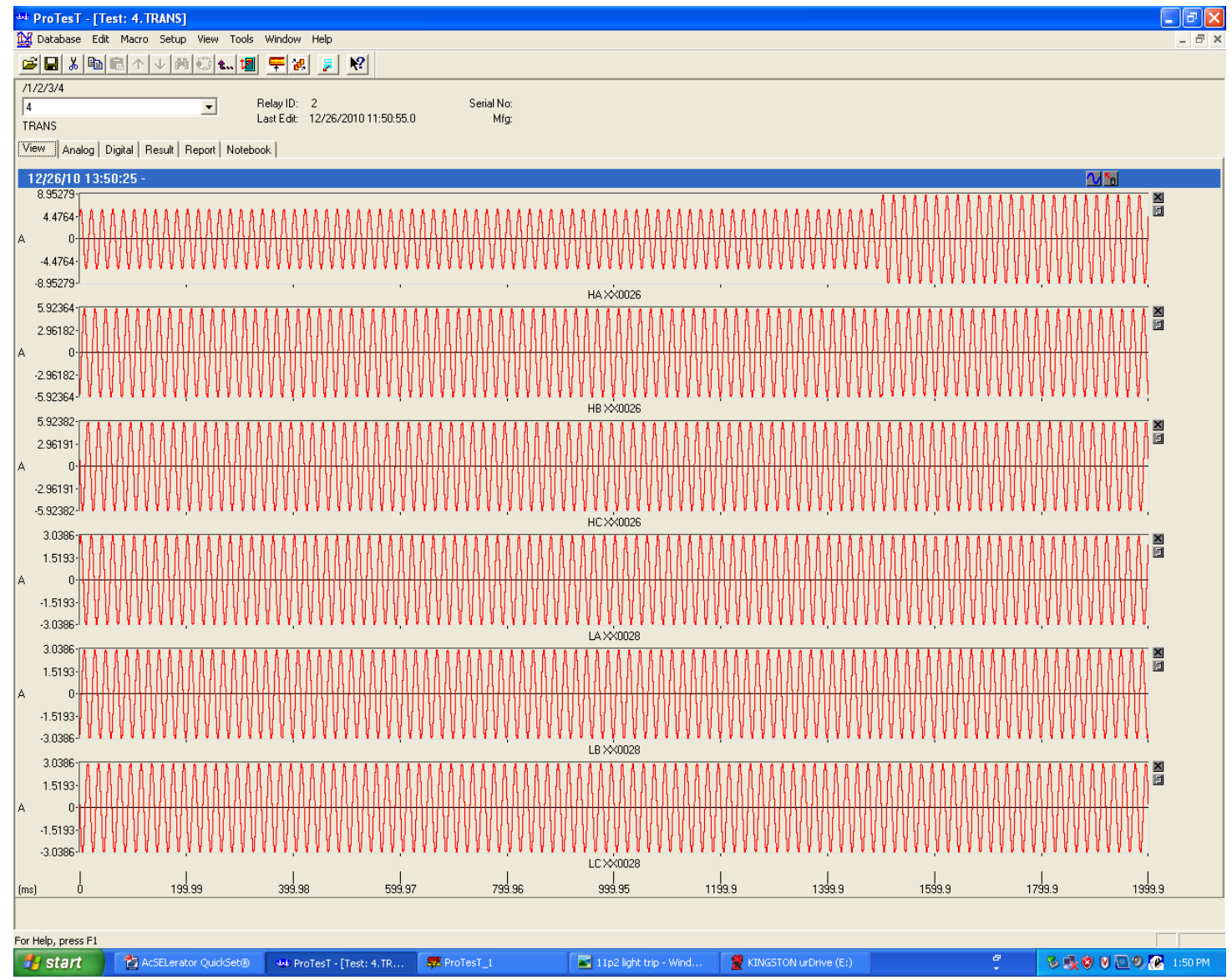

Figure 4.5: Currents from CTs in TRANS macro for one of the turn-to-turn fault experiments.

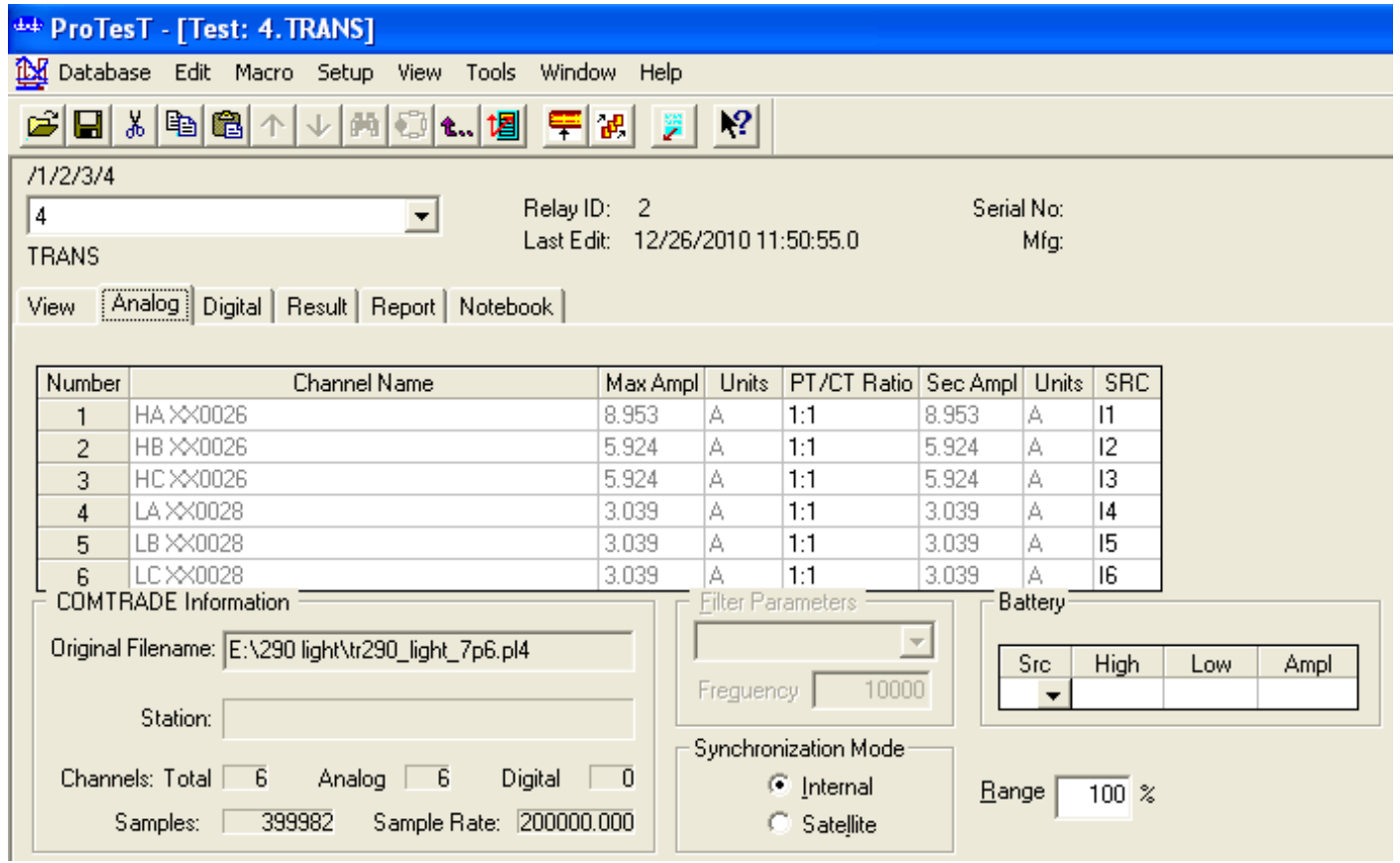

Figure 4.6: Analog tab settings in TRANS macro for one of the turn-to-turn fault experiments. 


\section{CHAPTER 5 \\ Results}

This chapter presents sensitivity results of the negative-sequence and REF elements of the SEL-487E relay. CT saturation curves obtained from the ATP simulations for different values of resistive burden are shown here as well.

\subsection{Turn-to-turn faults}

Originally all the ATP files sent to the relay were of $0.1 \mathrm{~s}$ length, however, the relay was indicating external faults by lighting the external fault LED on the front panel. Turning on the currents from the Doble Tester is causing the SEL-487E relay to go into its high security mode (the CON Word bit asserts). Once CON asserts, it latches in for a maximum time of 60 cycles. This means that $\mathrm{CON}$ is deasserted after 60 cycles which required extending each experiment time up to 120 cycles, where 90 cycles were prefault conditions and 30 cycles of fault. This allowed CON to deassert before the turn-to-turn fault occurs.

Figure 5.1 below shows that while turning the Doble Tester on, 3IRT increases while 3IOP does not increase between the solid and dashed vertical lines. The solid vertical line is three samples prior to the CONA and CONC Word bits asserting. The increase in 3IRT current occurs when the Doble Tester starts to send out currents, and this causes the CON Word bits to assert, as restraint current is increased and operating current is not increased according to the differential relay logic for an external fault.

The relay Word bits indicated in Figure 5.1 mean the following:

$87 \mathrm{QB}$ is blocking negative- and zero-sequence directional elements,

$87 \mathrm{Q}$ is negative-sequence differential element (internal fault detected),

$87 \mathrm{R}$ is restrained differential element operated,

87RA, 87RB, 87RC define 87R Word bit related to phases $\mathrm{A}, \mathrm{B}$, and $\mathrm{C}$,

$\mathrm{CON}$ is fault outside of transformer differential zone,

CONA, CONB, CONC define CON Word bit related to phases A, B, and C.

The thick blue solid lines opposite those Word bits mean asserting.

The complete tables with results of experiments for turn-to-turn faults for the 11.2-MVA transformer and the 290-MVA transformer with light load are given in Appendix E, Tables E.1 and E.2, respectively. The results of experiments for heavy load conditions for 
the 11.2-MVA transformer and the 290-MVA transformer are given in Appendix E, Tables E. 3 and E.4, respectively.

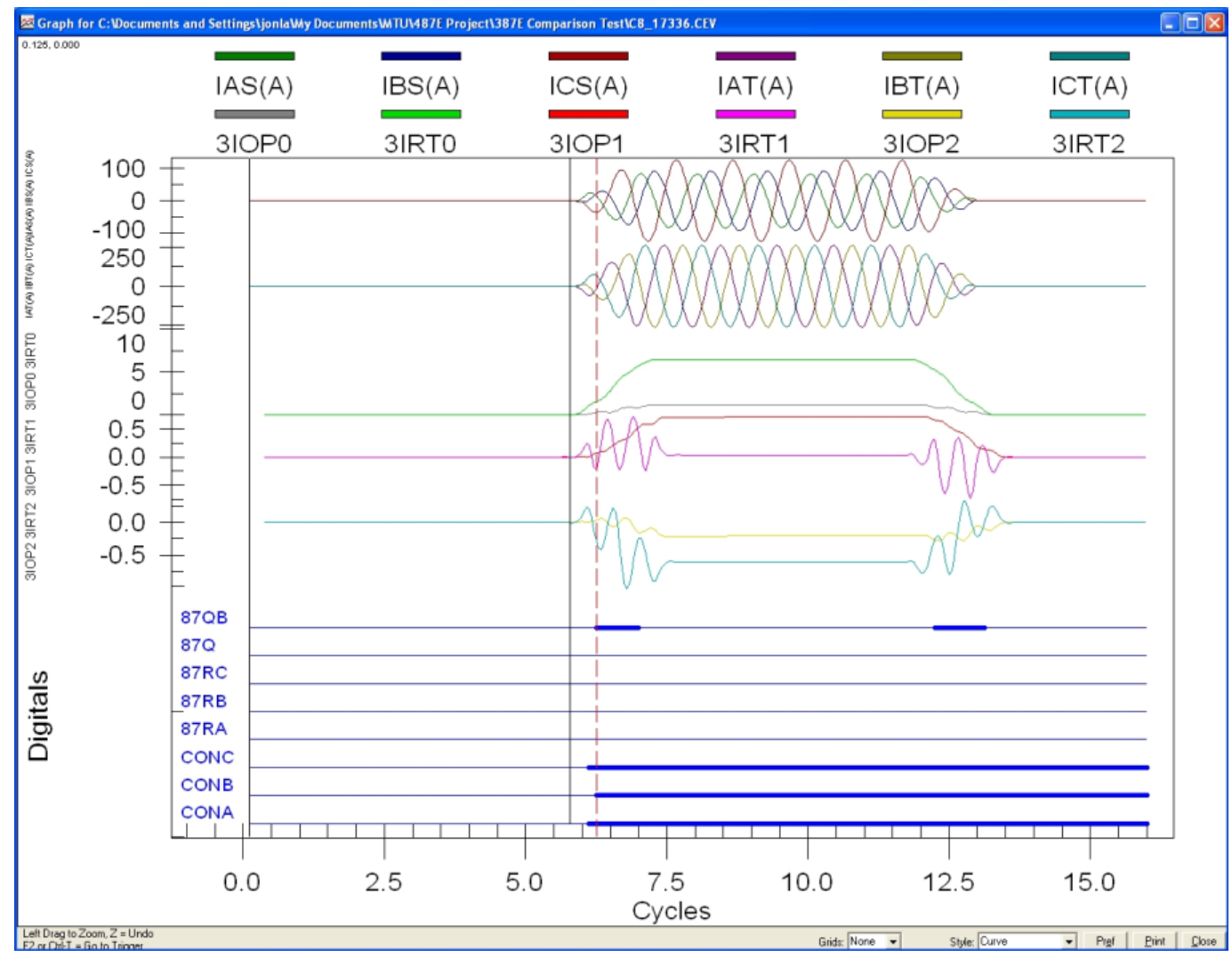

Figure 5.1: High security mode of the SEL-487E relay during turning on the Doble Tester.

Tables 5.1 and 5.2 represent the most interesting excerpts from Tables E.1 and E.3, E.2 and E.4 correspondingly: results for the highest sensitivity settings, default settings and settings when the relay trips at $2 \%$ of turns involved in the turn-to-turn fault.

As expected, the results show that the negative-sequence differential element operation was not affected by the amount of balanced load, i.e., for the balanced load either light or heavy, the negative-sequence differential element asserted for the same amount of shorted winding percentage with the corresponding settings. However, phase-differential element sensitivity was decreased about twice for heavy load for both transformers.

The relay has its highest sensitivity at $87 \mathrm{QP}=0.05 \mathrm{pu}$ tap and $87 \mathrm{QPSLP}=5 \%$. The operating region gradually decreases when the slope percentage is increased and when the $87 \mathrm{QP}$ setting is set higher. The relay user does not want the relay to trip for phase current unbalance which often exists due to load difference in phases. From the performed experiments, it is seen that at any $87 \mathrm{QP}$ pickup setting and with slope of $100 \%$ the negative-sequence element does not detect faults, mandating that the phase- 
differential element must pick up turn-to-turn faults. The negative-sequence element pickup and slope settings can be chosen by the relay user according to the allowed current unbalances in the particular system.

Table 5.1: Negative-sequence differential element sensitivity for the 11.2-MVA transformer.

\begin{tabular}{|c|c|c|c|c|c|}
\hline Transformer & 87QP, pu tap & 87QP slope, \% & $\begin{array}{l}\text { Shorted winding } \\
\text { percentage, } \%\end{array}$ & $\begin{array}{l}\text { Element } \\
\text { asserted }\end{array}$ & $\begin{array}{c}3 \mathrm{I}_{2}, \mathrm{~A}_{\mathrm{RMS} \text { pri }} \mathrm{S} \text {-winding } \\
\text { (calculated from Event } \\
\text { Summary data) }\end{array}$ \\
\hline \multicolumn{6}{|c|}{ Light load } \\
\hline \multirow{24}{*}{ 11.2 MVA } & \multirow{9}{*}{0.05} & 5 & 0.3 & $87 Q$ & \multirow{5}{*}{$5.409 @-75.95^{\circ}$} \\
\hline & & 25 & 0.3 & $87 Q$ & \\
\hline & & 50 & 0.3 & $87 Q$ & \\
\hline & & 75 & 0.3 & $87 Q$ & \\
\hline & & 80 & 0.3 & $87 Q$ & \\
\hline & & 85 & 0.4 & $87 Q$ & \multirow{2}{*}{ 9.258@-73.22 } \\
\hline & & 90 & 0.4 & $87 \mathrm{Q}$ & \\
\hline & & 95 & 0.6 & $87 \mathrm{Q}$ & 19.004@-83.41ํ․ \\
\hline & & 100 & 2.3 & 87RA & $130.972 @-81.56^{\circ}$ \\
\hline & \multirow{10}{*}{0.1} & 5 & 0.4 & $87 Q$ & \multirow{8}{*}{ 9.258@-73.22 } \\
\hline & & 15 & 0.4 & $87 \mathrm{Q}$ & \\
\hline & & 25 & 0.4 & $87 Q$ & \\
\hline & & 50 & 0.4 & $87 Q$ & \\
\hline & & 75 & 0.4 & $87 \mathrm{Q}$ & \\
\hline & & 80 & 0.4 & $87 \mathrm{Q}$ & \\
\hline & & 85 & 0.4 & $87 \mathrm{Q}$ & \\
\hline & & 90 & 0.4 & $87 \mathrm{Q}$ & \\
\hline & & 95 & 0.6 & $87 \mathrm{Q}$ & 19.004@-83.41ํ․ \\
\hline & & 100 & 2.3 & 87RA & $130.972 @-81.56^{\circ}$ \\
\hline & \multirow{4}{*}{1.0} & 97 & 1.7 & $87 Q$ & \multirow{2}{*}{ 90.446@-87.15 } \\
\hline & & 98 & 1.7 & $87 \mathrm{Q}$ & \\
\hline & & 99 & 1.8 & $87 Q$ & 96.953@-85.74 \\
\hline & & 100 & 2.3 & 87RA & $130.972 @-81.56^{\circ}$ \\
\hline & disabled & N/A & 2.3 & 87RA & $130.972 @-81.56^{\circ}$ \\
\hline \multicolumn{6}{|c|}{ Heavy load } \\
\hline \multirow{24}{*}{ 11.2 MVA } & \multirow{9}{*}{0.05} & 5 & 0.3 & $87 \mathrm{Q}$ & \multirow{5}{*}{$5.904 @-56.3^{\circ}$} \\
\hline & & 25 & 0.3 & $87 \mathrm{Q}$ & \\
\hline & & 50 & 0.3 & $87 Q$ & \\
\hline & & 75 & 0.3 & $87 \mathrm{Q}$ & \\
\hline & & 80 & 0.3 & $87 Q$ & \\
\hline & & 85 & 0.4 & $87 \mathrm{Q}$ & \multirow{2}{*}{ 9.679@-61.15 } \\
\hline & & 90 & 0.4 & $87 Q$ & \\
\hline & & 95 & 0.6 & $87 \mathrm{Q}$ & 19.839@-68.13 \\
\hline & & 100 & 4.5 & 87RA & $282.533 @-76.13^{\circ}$ \\
\hline & \multirow{10}{*}{0.1} & 5 & 0.4 & $87 Q$ & \multirow{8}{*}{ 9.679@-61.15 } \\
\hline & & 15 & 0.4 & $87 \mathrm{Q}$ & \\
\hline & & 25 & 0.4 & $87 Q$ & \\
\hline & & 50 & 0.4 & $87 Q$ & \\
\hline & & 75 & 0.4 & $87 Q$ & \\
\hline & & 80 & 0.4 & $87 Q$ & \\
\hline & & 85 & 0.4 & $87 Q$ & \\
\hline & & 90 & 0.4 & $87 \mathrm{Q}$ & \\
\hline & & 95 & 0.6 & $87 \mathrm{Q}$ & $19.839 @-68.13^{\circ}$ \\
\hline & & 100 & 4.5 & 87RA & 282.533@-76.13 \\
\hline & \multirow{4}{*}{1.0} & 97 & 1.7 & $87 Q$ & \multirow{2}{*}{ 90.658@-84.15 } \\
\hline & & 98 & 1.7 & $87 Q$ & \\
\hline & & 99 & 1.8 & $87 \mathrm{Q}$ & $97.845 @-84.62^{\circ}$ \\
\hline & & 100 & 4.5 & 87RA & $282.533 @-76.13^{\circ}$ \\
\hline & disabled & N/A & 4.5 & 87RA & 282.533@-76.13 \\
\hline
\end{tabular}


Table 5.2: Negative-sequence differential element sensitivity for the 290-MVA transformer

\begin{tabular}{|c|c|c|c|c|c|}
\hline Transformer & 87QP, pu tap & 87QP slope, \% & $\begin{array}{l}\text { Shorted winding } \\
\text { percentage, } \%\end{array}$ & $\begin{array}{l}\text { Element } \\
\text { asserted }\end{array}$ & $\begin{array}{c}3 \mathrm{I}_{2}, \mathrm{~A}_{\mathrm{RMS} \text { pri }} \mathrm{S} \text {-winding } \\
\text { (calculated from Event } \\
\text { Summary data) }\end{array}$ \\
\hline \multicolumn{6}{|c|}{ Light load } \\
\hline \multirow{23}{*}{290 MVA } & \multirow{9}{*}{0.05} & 5 & 0.4 & $87 Q$ & \multirow{5}{*}{ 21.717@-22.43 } \\
\hline & & 25 & 0.4 & $87 Q$ & \\
\hline & & 50 & 0.4 & $87 Q$ & \\
\hline & & 75 & 0.4 & $87 Q$ & \\
\hline & & 80 & 0.4 & $87 Q$ & \\
\hline & & 85 & 0.6 & $87 Q$ & $32.704 @-19.15^{\circ}$ \\
\hline & & 90 & 0.8 & $87 Q$ & $42.872 @-18.62^{\circ}$ \\
\hline & & 95 & 1.6 & $87 Q$ & $85.847 @-16.06^{\circ}$ \\
\hline & & 100 & 7.6 & $87 \mathrm{RB}$ & 437.302@-1.21 \\
\hline & \multirow{10}{*}{0.1} & 5 & 0.8 & $87 Q$ & \multirow{8}{*}{ 42.872@-18.62 } \\
\hline & & 15 & 0.8 & $87 Q$ & \\
\hline & & 25 & 0.8 & 87Q & \\
\hline & & 50 & 0.8 & $87 Q$ & \\
\hline & & 75 & 0.8 & $87 Q$ & \\
\hline & & 80 & 0.8 & $87 Q$ & \\
\hline & & 85 & 0.8 & $87 Q$ & \\
\hline & & 90 & 0.8 & $87 Q$ & \\
\hline & & 95 & 1.6 & $87 Q$ & $85.847 @-16.06^{\circ}$ \\
\hline & & 100 & 7.6 & $87 \mathrm{RB}$ & 437.302@-1.21이․ \\
\hline & \multirow{3}{*}{0.27} & 5 & 2.0 & $87 Q$ & \multirow{2}{*}{$108.365 @-14.59^{\circ}$} \\
\hline & & 95 & 2.0 & $87 Q$ & \\
\hline & & 100 & 7.6 & $87 \mathrm{RB}$ & 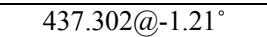 \\
\hline & disabled & N/A & 7.6 & $87 \mathrm{RB}$ & 437.302@-1.21임 \\
\hline \multicolumn{6}{|c|}{ Heavy load } \\
\hline \multirow{23}{*}{290 MVA } & \multirow{9}{*}{0.05} & 5 & 0.4 & $87 Q$ & \multirow{5}{*}{ 22.271@-5.65 } \\
\hline & & 25 & 0.4 & $87 Q$ & \\
\hline & & 50 & 0.4 & $87 Q$ & \\
\hline & & 75 & 0.4 & $87 Q$ & \\
\hline & & 80 & 0.4 & $87 Q$ & \\
\hline & & 85 & 0.6 & $87 Q$ & 31.918@-3.93 \\
\hline & & 90 & 0.8 & $87 Q$ & $42.588 @-2.93^{\circ}$ \\
\hline & & 95 & 1.6 & $87 Q$ & 87.640@-1.98 \\
\hline & & 100 & 15.1 & $87 \mathrm{RB}$ & 943.554@10.44 \\
\hline & \multirow{10}{*}{0.1} & 5 & 0.8 & $87 Q$ & \multirow{8}{*}{ 42.588@-2.93․ } \\
\hline & & 15 & 0.8 & $87 Q$ & \\
\hline & & 25 & 0.8 & $87 \mathrm{Q}$ & \\
\hline & & 50 & 0.8 & $87 \mathrm{Q}$ & \\
\hline & & 75 & 0.8 & $87 \mathrm{Q}$ & \\
\hline & & 80 & 0.8 & $87 Q$ & \\
\hline & & 85 & 0.8 & $87 Q$ & \\
\hline & & 90 & 0.8 & $87 Q$ & \\
\hline & & 95 & 1.6 & $87 Q$ & 87.640@-1.98 \\
\hline & & 100 & 15.1 & $87 \mathrm{RB}$ & 943.554@10.44 \\
\hline & \multirow{3}{*}{0.27} & 5 & 2.0 & $87 Q$ & \multirow{2}{*}{ 108.837@-1.45 } \\
\hline & & 95 & 2.0 & $87 Q$ & \\
\hline & & 100 & 15.1 & $87 \mathrm{RB}$ & $943.554 @ 10.44^{\circ}$ \\
\hline & disabled & $\mathrm{N} / \mathrm{A}$ & 15.1 & $87 \mathrm{RB}$ & 943.554@10.44 \\
\hline
\end{tabular}

The relay manufacturer has default settings for the negative-sequence element: $87 \mathrm{QP}=0.1$ pu tap and $87 \mathrm{QPSLP}=25 \%$. Tables 5.1 and 5.2 show high sensitivity pickup for these settings: $0.4 \%$ for the 11.2 -MVA transformer and $0.8 \%$ for the 290 -MVA transformer. The default settings resulted in the relay operation at twice the minimum detectable faulted percentage for the 290-MVA transformer. However, this is still more sensitive than the advertised $2 \%$ of turns involved in a turn-to-turn fault at heavy load, assuming 
that the advertisement performance was based on the default settings. At the setting $87 \mathrm{QP}=0.27 \mathrm{pu}$ tap, the relay detected a turn-to-turn fault involving $2 \%$ of the phase-A winding on the high-voltage side of the 290-MVA transformer. Higher 87QP thresholds increased this percentage (see Tables E.2 and E.4 in Appendix E).

For the 11.2-MVA transformer, the default settings resulted in relay operation at about 1.3 times the minimum detectable faulted percentage. With all the possible combinations of the $87 \mathrm{QP}$ and $87 \mathrm{QPSLP}$ (below 100\%) settings, the relay tripped for turn-to-turn faults before they could reach $2 \%$ of the high-voltage side phase-A winding. This proves that the SEL-487E relay is more sensitive for smaller transformers. This sensitivity comes from the fact that the $3 I_{2}$ currents for a smaller transformer are less than for a bigger transformer for the same pickup settings of the negative-sequence differential element (see Tables 5.1 and 5.2). The negative-sequence differential element uses a pickup setting as pu tap, and tap settings for each transformer are different. For a smaller transformer, tap settings are smaller (see Appendix C).

The sensitivity results obtained for the tested power transformers are in agreement with reference [6] which states that "the negative-sequence differential element is sensitive enough to detect turn-to-turn faults involving less than $2 \%$ of the winding".

Sensitivity of the phase-differential element was affected by an increase in transformer load. In Tables 5.1 and 5.2, the rows marked "disabled" mean that the negative-sequence element was disabled and the phase-differential element was enabled to trip for turn-toturn faults. It is seen that its sensititvity degraded about twice when the load was changed from the minimum to the maximum.

The culmination of relay operation is information contained in the event report. The SEL$487 \mathrm{E}$ relay records the filtered power system data that the relay uses in protection and automation processing. Filtered information is presented in the event report, event summary, and event history. However, to view transient conditions in the power system, raw data oscillography can be used. An example can be seen in Appendix F. Event reports were pulled up with the command "EVE No", where No is the number of the event. In the event report, the relay marks the trigger row with a $>$ character. This is the dividing point between the prefault and fault data. The row that the relay uses for the currents in the event summary section of the event report is the row marked with an asterisk (*). This is 1.25 cycles afther the event trigger point. The relay elements asserted for the fault are indicated in the digital section of the event report with an asterisk $\left(^{*}\right)$ as well. 
Two of the event reports given in Appendix $\mathrm{F}$ belong to the cases with light load and default settings $(87 \mathrm{QP}=0.1 \mathrm{pu}$ tap, $\mathrm{SLPQ} 1=25 \%$, typed in bold in Tables 5.1, 5.2, E.1, and E.2). These event reports have been captured with 4-samples/cycle sampling. Also, for the same cases, Appendix F contains screenshots of Phasors, Fundamental Metering Winding S, Doble currents in TRANS macro and ATP currents from CTs supplied to the SEL-487E relay.

Figures 5.2 and 5.3 show waveforms of the line currents from the high-voltage and lowvoltage sides, captured by the relay for each power transformer, where CON is asserted during turning the Doble Tester on and deasserted 60 cylces later. The 50SQ1 Word bit is asserted when the relay detects a turn-to-turn internal fault and 5 cycles later (according to the settings) the $87 \mathrm{Q}$ Word bit is asserted indicating the turn-to-turn fault. These figures also belong to the cases typed in bold in Tables 5.1 and 5.2.

Waveform

Event Time: 12/28/2010 02:54:01.567

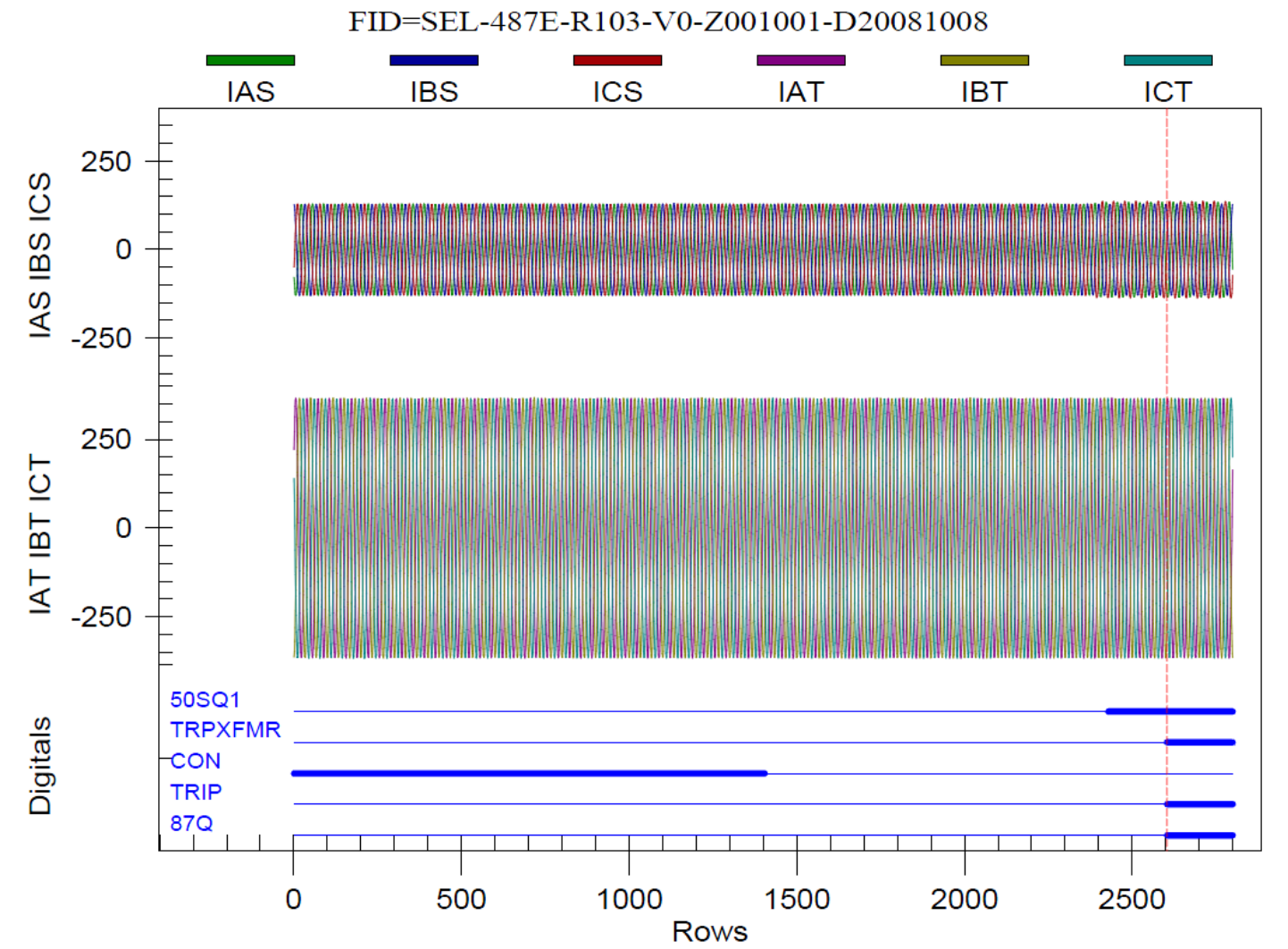

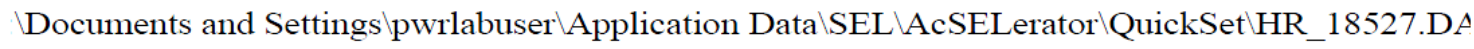

Figure 5.2: Line currents and active digitals recorded by the relay for turn-to-turn fault in the 11.2-MVA transformer, light load. 

$\mathrm{FID}=\mathrm{SEL}-487 \mathrm{E}-\mathrm{R} 103-\mathrm{V0}-\mathrm{Z} 001001-\mathrm{D} 20081008$

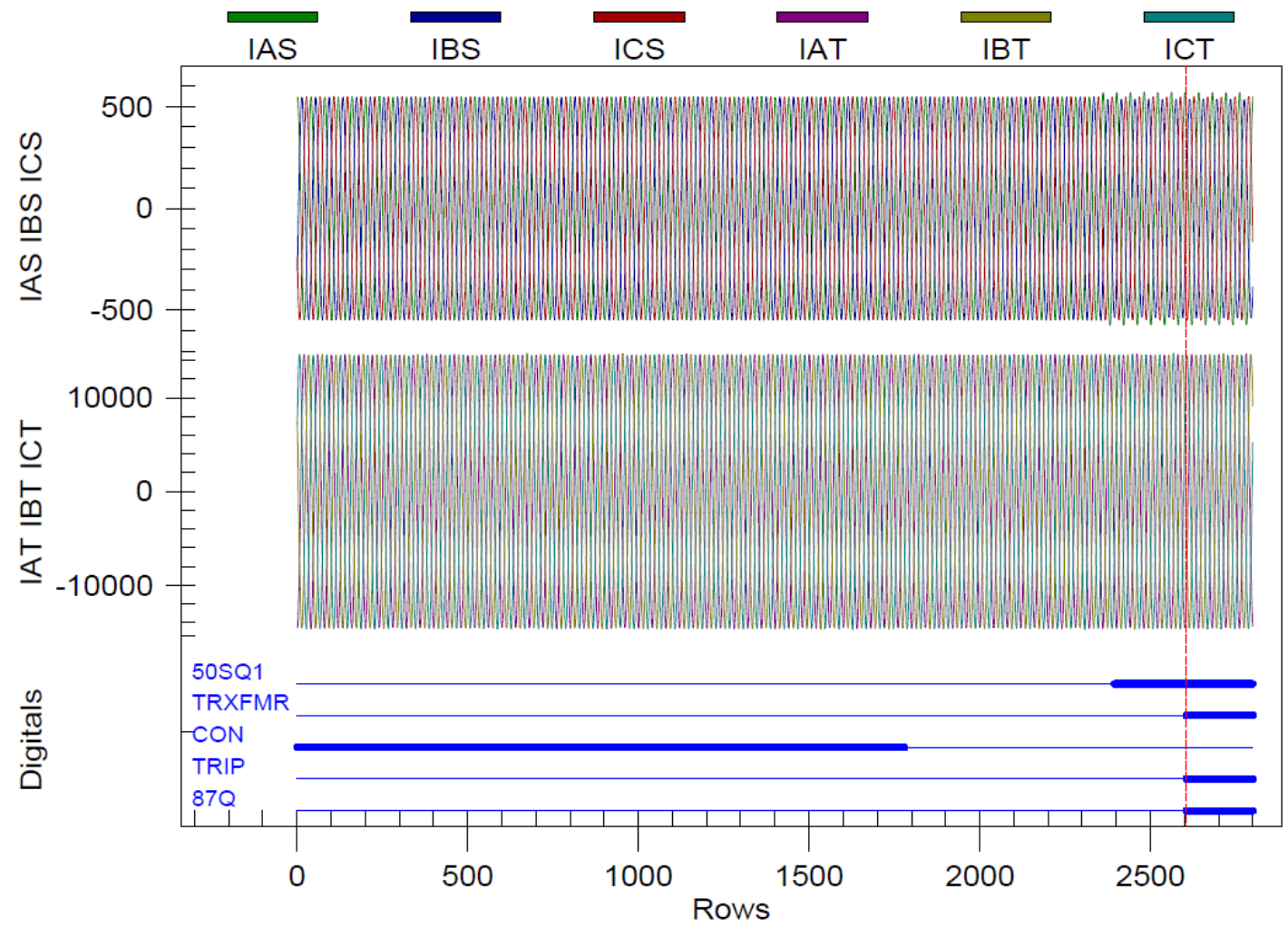

$\backslash$ Documents and Settings $\backslash$ pwrlabuser $\backslash A p p l i c a t i o n ~ D a t a \backslash S E L \backslash A c S E L e r a t o r \backslash Q u i c k S e t \backslash H R \quad$ 18532.DA

Figure 5.3: Line currents and active digitals recorded by the relay for turn-to-turn fault in the 290-MVA transformer, light load.

The indicated relay Word bits in these figures mean the following:

50SQ1 is negative-sequence definite time element 1, terminal S, TRPXFMR is transformer trip output asserted, $\mathrm{CON}$ is fault outside of transformer differential zone, TRIP is transformer or terminal trip signal asserted, $87 \mathrm{Q}$ is negative-sequence differential element (internal fault detected).

For Tables E.1, E.2, E.3, and E.4, if the 87QP setting was increased by 0.01 pu tap, the detectable shorted percentage on the high-side phase-A winding was also increased:

- for the 11.2-MVA transformer, the increase was about $0.1 \%$ of turns after several subsequent changes of the $87 \mathrm{QP}$ setting;

- for the 290-MVA transformer the increase was about $0.1 \%$ of turns after each subsequent change of the $87 \mathrm{QP}$ setting up to $87 \mathrm{QP}=0.15$ pu tap and in average about $0.6 \%$ of turns after $87 \mathrm{QP}=0.15$ pu tap. 


\subsection{CT saturation}

The experiments are performed for the high-voltage side CTs. The complete set of the ATP plots is placed in Appendix G. The ATP models for CT saturation experiments are shown in Appendix B. From the simulations performed, CT saturation is obtained due to changes in the value of CT total burden.

\subsubsection{The 11.2-MVA transformer}

If some large portion of turns will be shorted in one phase, the primary line current will be sufficient to saturate the CTs. The shorting of $90 \%$ of the turns in the phase-A winding gives a high primary current (see Section 4.3.1) for the case of $\mathrm{Zs}_{\mathrm{s}}=1 \%$. For the case of $\mathrm{Zs}=5 \%$ this value is lower. Table 5.3 shows the maximum amplitudes of primary currents. These currents were obtained applying 90\% turn-to-turn fault on the highvoltage side of the phase-A winding at time $\mathrm{t}=0.05 \mathrm{~s}$, i.e., after 3 cycles, for all the cases. At time $\mathrm{t}=0.2 \mathrm{~s}$, the source was disconnected. The voltage source has its peak value $\frac{72 \times \sqrt{2}}{\sqrt{3}} \mathrm{kV}$ at the time 0 .

The effect of the source impedance as well as $\mathrm{X} / \mathrm{R}$ ratio on primary current $\mathrm{DC}$ offset can be seen from figures shown here, but for the full picture, see Figures G.1-G.36 in Appendix G. Different values of burden used for the simulations are shown in Table 4.2. In this section the primary and secondary currents of the CTs in the phase-A winding are shown only. For each figure, a red curve is the line current and a green curve is the current seen by the CT secondary side.

Table 5.3: Primary fault current max amplitudes for the 11.2-MVA transformer.

\begin{tabular}{|c|c|c|c|c|c|c|c|c|c|c|c|c|}
\hline & \multicolumn{12}{|c|}{ Primary fault current max amplitude } \\
\hline & \multicolumn{6}{|c|}{$\mathrm{Zs}=5 \%$ on $100 \mathrm{MVA}$} & \multicolumn{6}{|c|}{$\mathrm{Zs}=1 \%$ on $100 \mathrm{MVA}$} \\
\hline & \multicolumn{3}{|c|}{ Light load } & \multicolumn{3}{|c|}{ Heavy load } & \multicolumn{3}{|c|}{ Light load } & \multicolumn{3}{|c|}{ Heavy load } \\
\hline $\begin{array}{l}\text { Time of } \\
\text { closing }\end{array}$ & $\begin{array}{c}\mathrm{I}_{\mathrm{A}}, \\
\mathrm{A}_{\text {peak }}\end{array}$ & $\begin{array}{c}\mathrm{I}_{\mathrm{B}}, \\
\mathrm{A}_{\text {peak }}\end{array}$ & $\begin{array}{c}\mathrm{I}_{\mathrm{C}}, \\
\mathrm{A}_{\text {peak }} \\
\end{array}$ & $\begin{array}{c}\mathrm{I}_{\mathrm{A}}, \\
\mathrm{A}_{\text {peak }}\end{array}$ & $\begin{array}{c}\mathrm{I}_{\mathrm{B}}, \\
\mathrm{A}_{\text {peak }}\end{array}$ & $\begin{array}{c}\mathrm{I}_{\mathrm{C}} \\
\mathrm{A}_{\text {peak }}\end{array}$ & $\begin{array}{c}\mathrm{I}_{\mathrm{A}}, \\
\mathrm{A}_{\text {peak }}\end{array}$ & $\begin{array}{c}\mathrm{I}_{\mathrm{B}}, \\
\mathrm{A}_{\text {peak }}\end{array}$ & $\begin{array}{c}\mathrm{I}_{\mathrm{C}}, \\
\mathrm{A}_{\text {peak }}\end{array}$ & $\begin{array}{c}\mathrm{I}_{\mathrm{A}}, \\
\mathrm{A}_{\text {peak }}\end{array}$ & $\begin{array}{c}\mathrm{I}_{\mathrm{B}}, \\
\mathrm{A}_{\text {peak }}\end{array}$ & $\begin{array}{c}\mathrm{I}_{\mathrm{C}}, \\
\mathrm{A}_{\text {peak }}\end{array}$ \\
\hline $\begin{array}{l}3 \text { cycles } \\
=0.05 \mathrm{~s}\end{array}$ & 17429 & 129.07 & 17554 & 17411 & 266.62 & 17638 & 37773 & 129.14 & 37894 & 37783 & 267.68 & 37993 \\
\hline
\end{tabular}




\subsubsection{1 $\mathrm{Zs}=5 \%$ on $100 \mathrm{MVA}$ base, $\mathrm{X} / \mathrm{R}=5$, light load}

1) $\mathrm{R}_{\mathrm{TOT}}=0.256 \Omega$

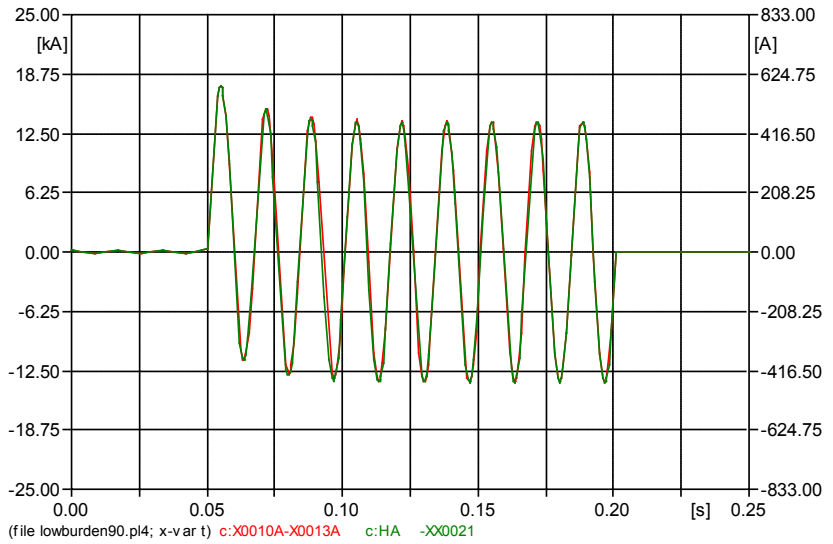

Figure 5.4: $11.2 \mathrm{MVA}, \mathrm{Zs}=5 \%$, light load, $\mathrm{R}_{\mathrm{TOT}}=0.256 \Omega$ : Phase-A pri and sec $\mathrm{CT}$ currents.

2) $\mathrm{R}_{\mathrm{TOT}}=0.676 \Omega$

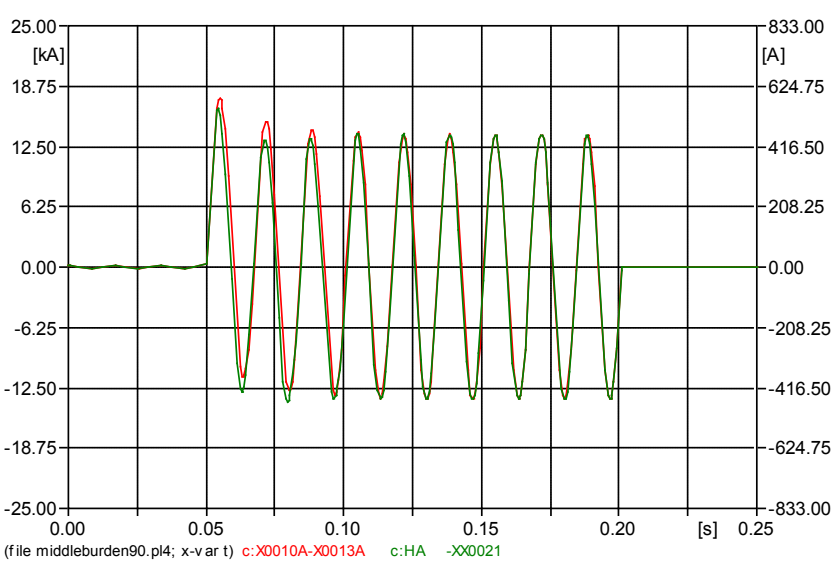

Figure 5.5: $11.2 \mathrm{MVA}, \mathrm{Zs}=5 \%$, light load, $\mathrm{R}_{\mathrm{TOT}}=0.676 \Omega$ : Phase-A pri and sec $\mathrm{CT}$ currents.

3) $\mathrm{R}_{\mathrm{TOT}}=1.396 \Omega$

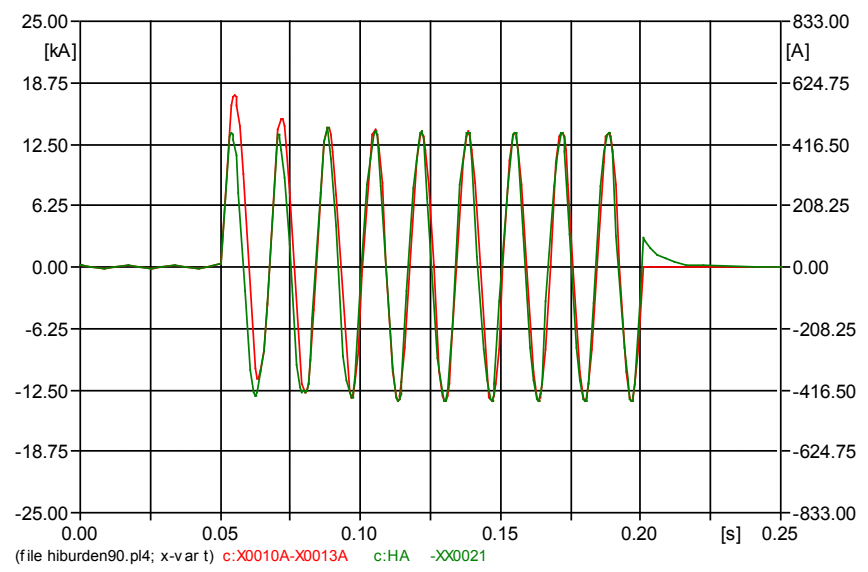

Figure 5.6: $11.2 \mathrm{MVA}, \mathrm{Zs}=5 \%$, light load, $\mathrm{R}_{\mathrm{TOT}}=1.396 \Omega$ : Phase-A pri and sec $\mathrm{CT}$ currents. 


\subsubsection{2 $\mathrm{Zs}=5 \%$ on $100 \mathrm{MVA}$ base, $\mathrm{X} / \mathrm{R}=5$, heavy load}

1) $\mathrm{R}_{\mathrm{TOT}}=0.256 \Omega$

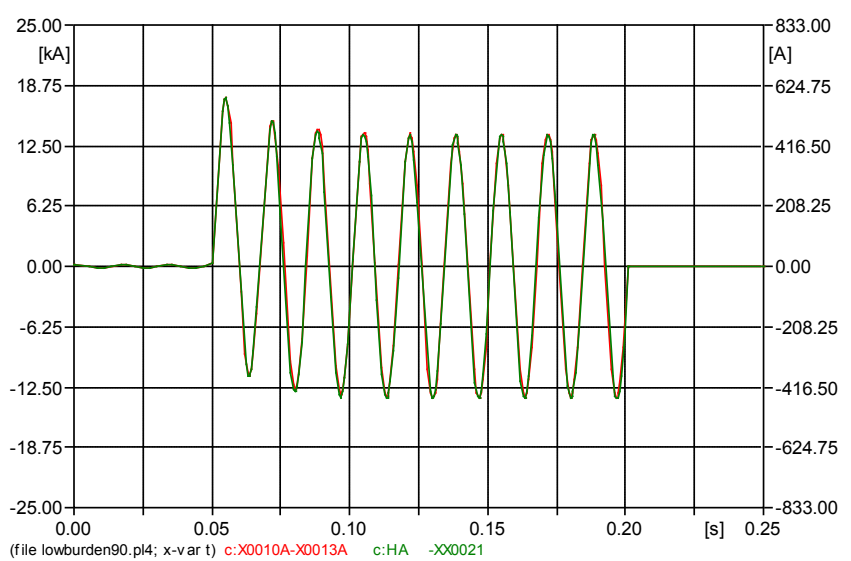

Figure 5.7: $11.2 \mathrm{MVA}, \mathrm{Zs}_{\mathrm{s}}=5 \%$, heavy load, $\mathrm{R}_{\mathrm{TOT}}=0.256 \Omega$ : Phase-A pri and sec $\mathrm{CT}$ currents.

2) $\mathrm{R}_{\mathrm{TOT}}=0.676 \Omega$

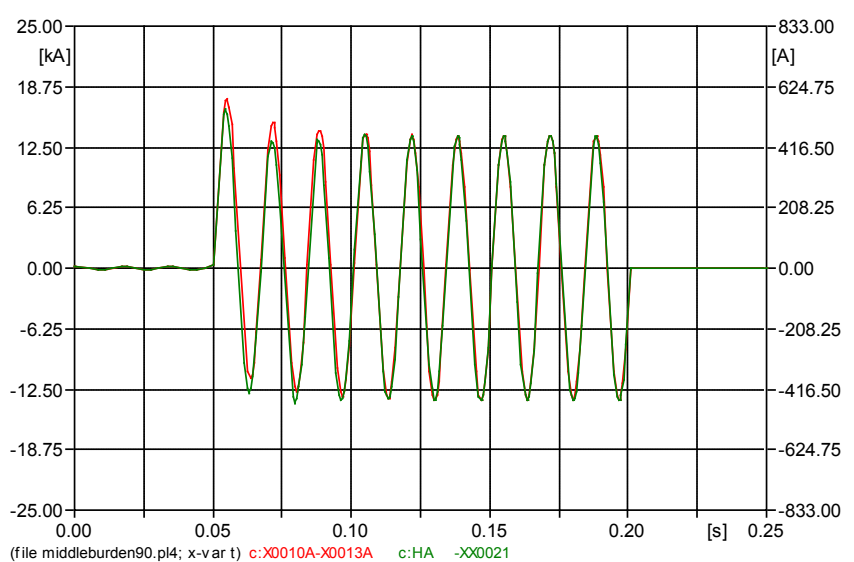

Figure 5.8: $11.2 \mathrm{MVA}, \mathrm{Zs}=5 \%$, heavy load, $\mathrm{R}_{\mathrm{TOT}}=0.676 \Omega$ : Phase-A pri and sec $\mathrm{CT}$ currents.

3) $\mathrm{R}_{\mathrm{TOT}}=1.396 \Omega$

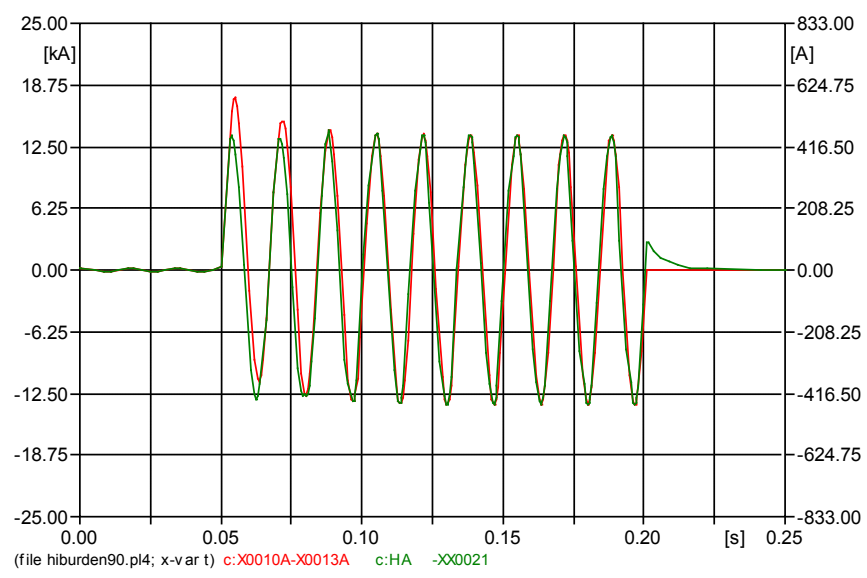

Figure 5.9: 11.2 MVA, $Z_{s}=5 \%$, heavy load, $R_{T O T}=1.396 \Omega$ : Phase-A pri and sec $C T$ currents. 


\subsubsection{3 $\mathrm{Zs}=1 \%$ on $100 \mathrm{MVA}$ base, $\mathrm{X} / \mathrm{R}=1$, light load}

1) $\mathrm{R}_{\mathrm{TOT}}=0.256 \Omega$

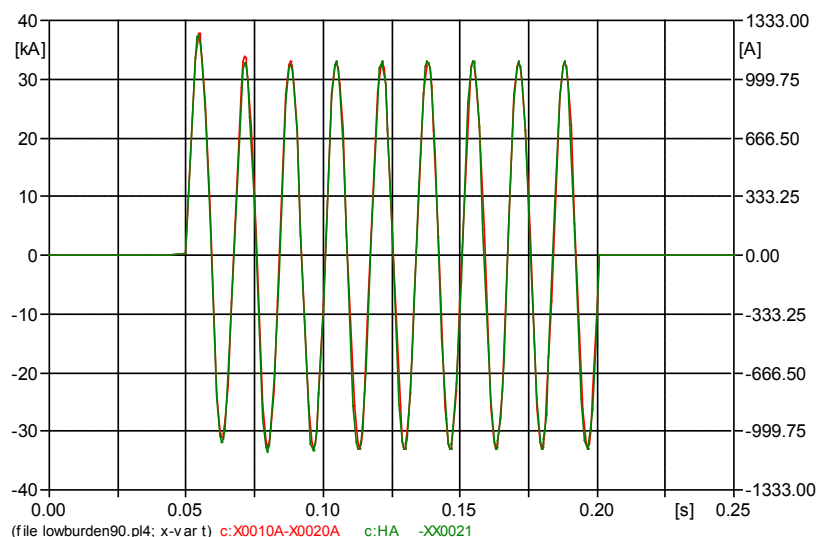

Figure 5.10: $11.2 \mathrm{MVA}, \mathrm{Zs}_{\mathrm{s}}=1 \%$, light load, $\mathrm{R}_{\mathrm{TOT}}=0.256 \Omega$ : Phase-A pri and sec CT currents.

2) $\mathrm{R}_{\mathrm{TOT}}=0.676 \Omega$

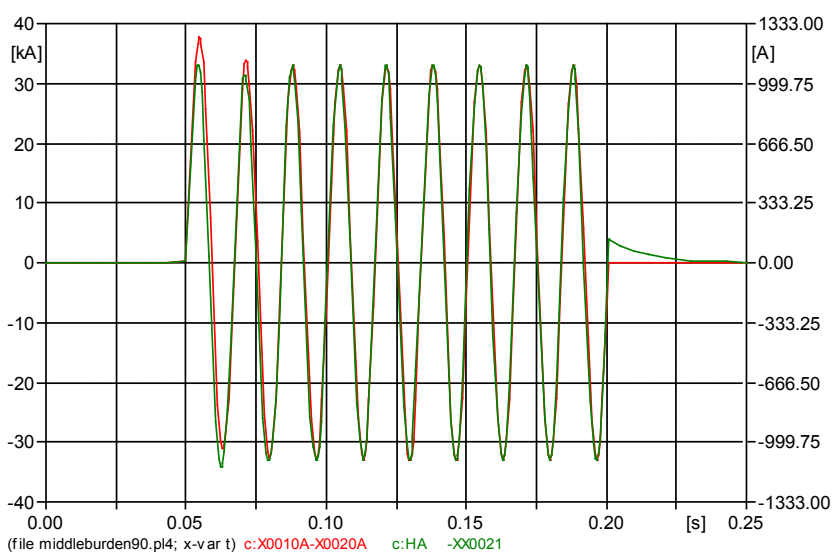

Figure 5.11: $11.2 \mathrm{MVA}, \mathrm{Zs}_{\mathrm{s}}=1 \%$, light load, $\mathrm{R}_{\mathrm{TOT}}=0.676 \Omega$ : Phase-A pri and sec CT currents.

3) $\mathrm{R}_{\mathrm{TOT}}=1.396 \Omega$

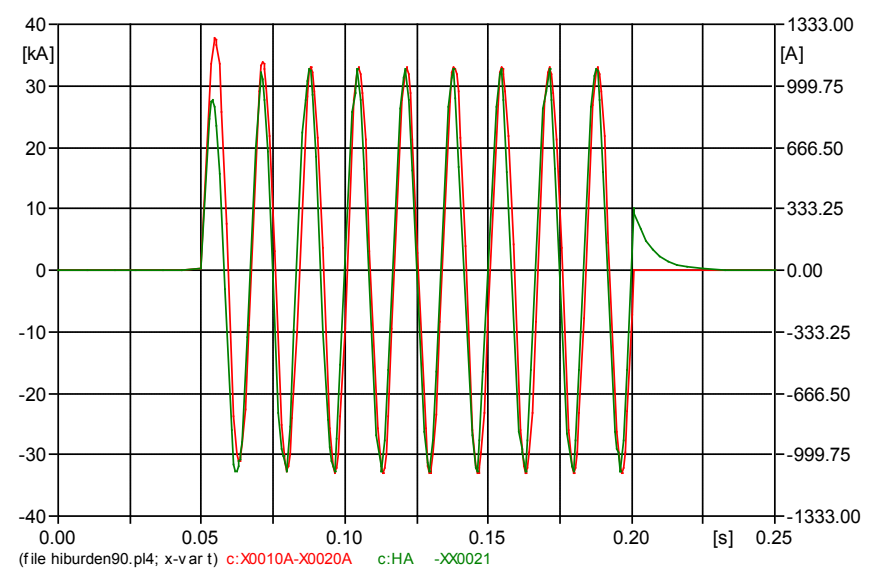

Figure 5.12: $11.2 \mathrm{MVA}, \mathrm{Zs}_{\mathrm{s}}=1 \%$, light load, $\mathrm{R}_{\mathrm{TOT}}=1.396 \Omega$ : Phase-A pri and sec CT currents. 


\subsubsection{Zs $=1 \%$ on 100 MVA base, $\mathrm{X} / \mathrm{R}=1$, heavy load}

1) $\mathrm{R}_{\mathrm{TOT}}=0.256 \Omega$

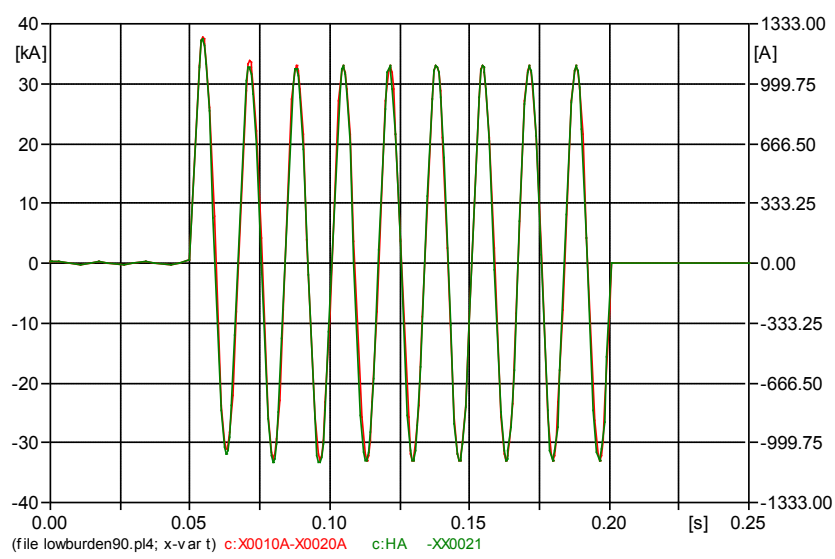

Figure 5.13: $11.2 \mathrm{MVA}, \mathrm{Zs}_{\mathrm{s}}=1 \%$, heavy load, $\mathrm{R}_{\mathrm{TOT}}=0.256 \Omega$ : Phase-A pri and sec CT currents.

2) $\mathrm{R}_{\mathrm{TOT}}=0.676 \Omega$

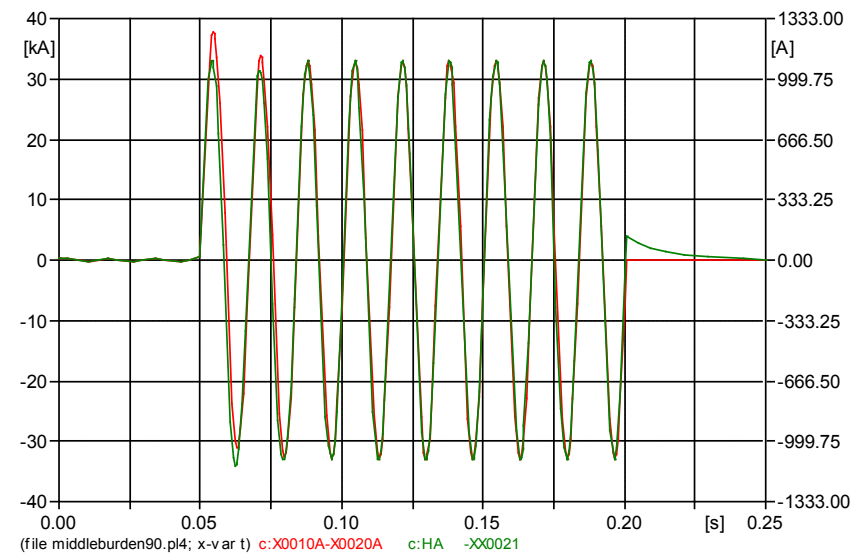

Figure 5.14: $11.2 \mathrm{MVA}, \mathrm{Zs}=1 \%$, heavy load, $\mathrm{R}_{\mathrm{TOT}}=0.676 \Omega$ : Phase-A pri and sec $\mathrm{CT}$ currents.

3) $\mathrm{R}_{\mathrm{TOT}}=1.396 \Omega$

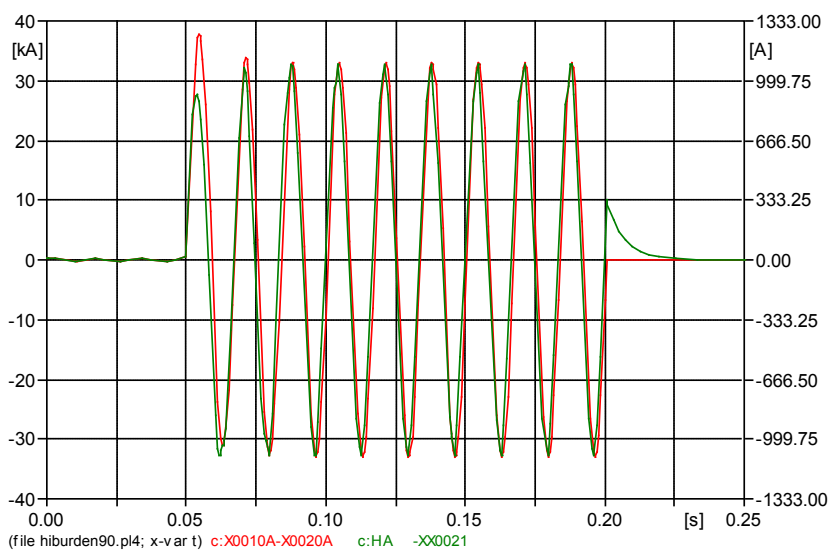

Figure 5.15: $11.2 \mathrm{MVA}, \mathrm{Zs}=1 \%$, heavy load, $\mathrm{R}_{\mathrm{TOT}}=1.396 \Omega$ : Phase-A pri and sec $\mathrm{CT}$ currents. 
In the figures above and Appendix G (see Figures G.1-G.36), the ATP simulations show mild CT saturation in phases A and C. Primary line current in phase B of the 11.2-MVA transformer is unchanged due to the wye connection of the CTs. The phase-B CT replicates the line current accurately, showing no signs of saturation.

DC offset decay in the primary current depends on the $\mathrm{X} / \mathrm{R}$ coefficient of the system. From the figures obtained, it is seen that it decays faster with $\mathrm{X} / \mathrm{R}=1$. With higher source impedance, the fault current is less by about 2.2 times which can be a big advantage.

Cases "light load" and "heavy load" for the same amount of source impedance have approximately the same value of fault current, which says that the amount of the power transformer's balanced load does not affect the fault current magnitude.

Generally, the source impedance affects the CT saturation through the effect on the value of the CT primary current. However, for the performed experiments, the change in source impedance from $\mathrm{Zs}=5 \%$ to $\mathrm{Zs}=1 \%$ did not affect the primary current enough to see the difference in the shape of the secondary currents of the CTs.

Another observation is that at a high CT burden, the CT operates as a DC filter. Decay rate of a transient $\mathrm{DC}$ decaying component in the $\mathrm{CT}$ secondary current is accelerated by the resistance of the CT secondary winding. However, at low CT burden, the CT replicates the primary current with much less error.

In many figures for these experiments, a "DC tail" is present. This "tail" appears after fault interruption as a CT decaying current when the primary current is zero. Reference [22] gives insight into this effect. When the CT saturates due to the primary current, the secondary current may not be zero when a circuit breaker opens contacts. The non-zero CT current results in a decaying DC offset, which is called the "DC tail", see Figure 5.16. It decays as a function of $\mathrm{L} / \mathrm{R}$ of the $\mathrm{CT}$ secondary winding. For the differential relay, this effect is not harmful; however, relays that coordinate on current dropout can misoperate.

For comparison with the figures above where mild CT saturation is present, the greatly distorted CT secondary current is shown in Figure 5.17. This distorted CT current was obtained at the $90 \%$ turn-to-turn fault and $5 \Omega$ total CT burden. Distortion appears about $1.6 \mathrm{~ms}$ after the fault begins. 


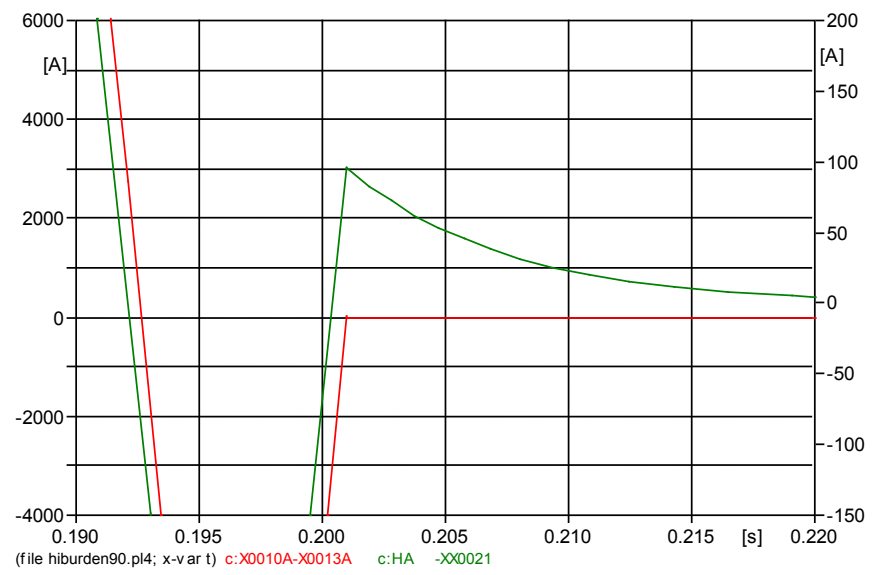

Figure 5.16: "DC tail" effect.

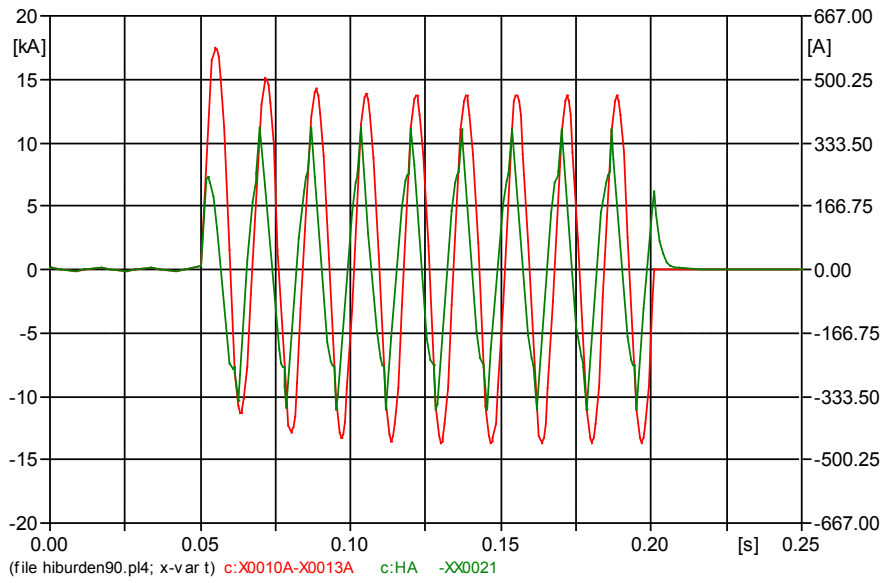

Figure 5.17: Primary current and distorted CT secondary current during fault.

Figure 5.18 shows the flux linkage offset for the same case.

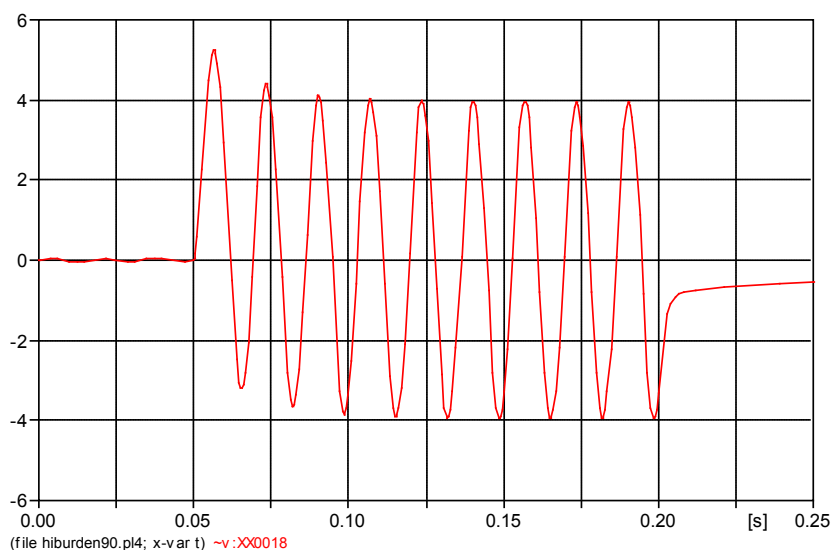

Figure 5.18: Flux linkage offset for greatly saturated CT. 


\subsubsection{The 290-MVA transformer}

Simulations of the $90 \%$ turn-to-turn fault on the phase-A winding gave small primary currents, not enough to saturate the CTs. Depending on the source impedance, the first peak of the fault current was obtained for each case, as shown in Table 5.4.

Table 5.4: Primary fault current max amplitudes for phase-A $90 \%$ turn-to-turn fault in the 290-MVA transformer.

\begin{tabular}{|c|c|c|c|c|c|c|c|c|c|c|c|c|}
\hline & \multicolumn{12}{|c|}{ Primary fault current max amplitude } \\
\hline & \multicolumn{6}{|c|}{$\mathrm{Zs}=10 \%$ on $100 \mathrm{MVA}$} & \multicolumn{6}{|c|}{$\mathrm{Zs}=5 \%$ on $100 \mathrm{MVA}$} \\
\hline & \multicolumn{3}{|c|}{ Light load } & \multicolumn{3}{|c|}{ Heavy load } & \multicolumn{3}{|c|}{ Light load } & \multicolumn{3}{|c|}{ Heavy load } \\
\hline $\begin{array}{c}\text { Time } \\
\text { of } \\
\text { closing }\end{array}$ & $\begin{array}{c}\mathrm{I}_{\mathrm{A}} \\
\mathrm{A}_{\text {peak }}\end{array}$ & $\begin{array}{c}\mathrm{I}_{\mathrm{B}}, \\
\mathrm{A}_{\text {peak }}\end{array}$ & $\begin{array}{c}\mathrm{I}_{\mathrm{C}} \\
\mathrm{A}_{\text {peak }}\end{array}$ & $\begin{array}{c}\mathrm{I}_{\mathrm{A}}, \\
\mathrm{A}_{\text {peak }}\end{array}$ & $\begin{array}{c}\mathrm{I}_{\mathrm{B}}, \\
\mathrm{A}_{\text {peak }}\end{array}$ & $\begin{array}{c}\mathrm{I}_{\mathrm{C}}, \\
\mathrm{A}_{\text {peak }}\end{array}$ & $\begin{array}{c}\mathrm{I}_{\mathrm{A}}, \\
\mathrm{A}_{\text {peak }}\end{array}$ & $\begin{array}{c}\mathrm{I}_{\mathrm{B}} \\
\mathrm{A}_{\text {peak }}\end{array}$ & $\begin{array}{c}\mathrm{I}_{\mathrm{C}} \\
\mathrm{A}_{\text {peak }}\end{array}$ & $\begin{array}{c}\mathrm{I}_{\mathrm{A}}, \\
\mathrm{A}_{\text {peak }}\end{array}$ & $\begin{array}{c}\mathrm{I}_{\mathrm{B}} \\
\mathrm{A}_{\text {peak }}\end{array}$ & $\begin{array}{c}\mathrm{I}_{\mathrm{C}} \\
\mathrm{A}_{\text {peak }}\end{array}$ \\
\hline $\begin{array}{c}3 \\
\text { cycles } \\
=0.05 \mathrm{~s}\end{array}$ & 2049.5 & 313.78 & 1004.6 & 2123.1 & 473.54 & 1190.2 & 3391.4 & 330.64 & 1167.6 & 4891.5 & 1019.1 & 1763.4 \\
\hline
\end{tabular}

Simulation of the three-phase through fault gave higher primary currents; however, they were still small to saturate CTs on the high-voltage side of the 290-MVA transformer (see Figure 5.19).

To obtain at least one primary current high enough to saturate the CTs, the $90 \%$ turn-toturn fault was applied 3 cycles after the three-phase through fault initiation. To reach a high value of the total fault current, the source impedance was kept very small for all the cases, $\mathrm{Zs}=10^{-8} \Omega$. The fault current first peak values are shown in Table 5.5. Thus, the effect of the source impedance or system $\mathrm{X} / \mathrm{R}$ ratio on a fault current was not possible to explore here and the goal for CT saturation of the 290-MVA transformer shifted to just obtain sings of saturation in the high-voltage side CTs.

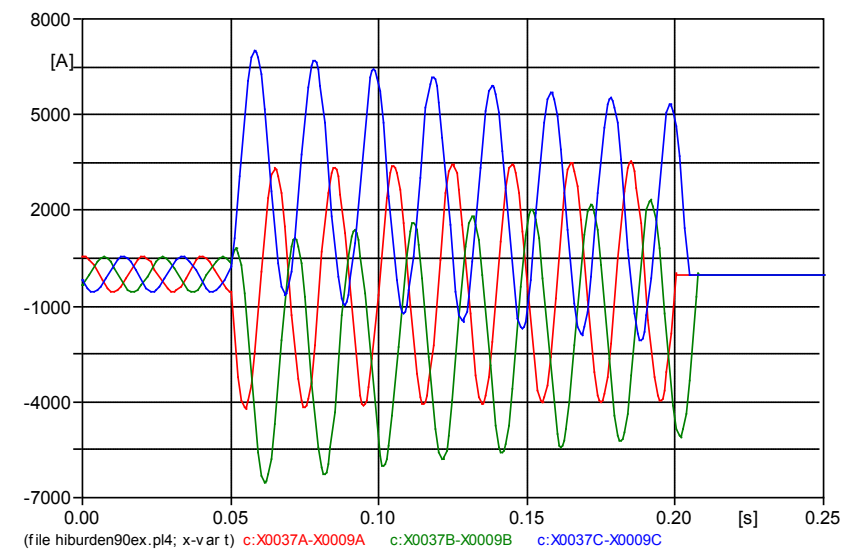

Figure 5.19: The 290-MVA transformer, three-phase through fault. 
Table 5.5: Primary fault current max amplitudes for combination of three-phase through fault and phase-A 90\% turn-to-turn fault in the 290-MVA transformer.

\begin{tabular}{|c|c|c|c|c|c|c|c|}
\hline & \multirow{3}{*}{$\begin{array}{l}\text { Time of } \\
\text { closing }\end{array}$} & \multicolumn{6}{|c|}{ Primary fault current max amplitude } \\
\hline & & \multicolumn{3}{|c|}{ Light load } & \multicolumn{3}{|c|}{ Heavy load } \\
\hline & & $\mathrm{I}_{\mathrm{A}}, \mathrm{A}_{\text {peak }}$ & $\mathrm{I}_{\mathrm{B}}, \mathrm{A}_{\text {peal }}$ & $\mathrm{I}_{\mathrm{C}}, \mathrm{A}_{\text {peak }}$ & $\mathrm{I}_{\mathrm{A}}, \mathrm{A}_{\text {peak }}$ & $\mathrm{I}_{\mathrm{B}}, \mathrm{A}_{\text {peak }}$ & $\mathrm{I}_{\mathrm{C}}, \mathrm{A}_{\text {peak }}$ \\
\hline $\begin{array}{c}\text { 3ph through } \\
\text { fault }\end{array}$ & $\begin{array}{l}3 \text { cycles } \\
=0.05 \mathrm{~s}\end{array}$ & 4208.8 & 6533.5 & 7028.8 & 4637.1 & 6003.9 & 6910.9 \\
\hline $\begin{array}{l}\text { Turn-to-turn } \\
\text { fault }\end{array}$ & $\begin{array}{c}6 \text { cycles } \\
=0.1 \mathrm{~s}\end{array}$ & 69843 & 1608 & 6156 & 69512 & 2017 & 6069.5 \\
\hline
\end{tabular}

Comparing the values from Table 5.5 with the data from Section 4.3.2, it is seen that for the smallest value of $\mathrm{R}_{\mathrm{TOT}}=0.512 \Omega$ current in the primary winding is not enough to saturate CTs, but for other cases of total CT burden, the CT saturation should be visible.

Figure 5.20 shows primary currents for light load, and Figure 5.21 shows primary currents for heavy load. It is clearly seen that the three-phase through fault current for both cases has comparatively small amplitude at the time interval from $0.05 \mathrm{~s}$ till $0.1 \mathrm{~s}$. Application of $90 \%$ turn-to-turn fault gives a considerable rise to the current in the faulted phase.

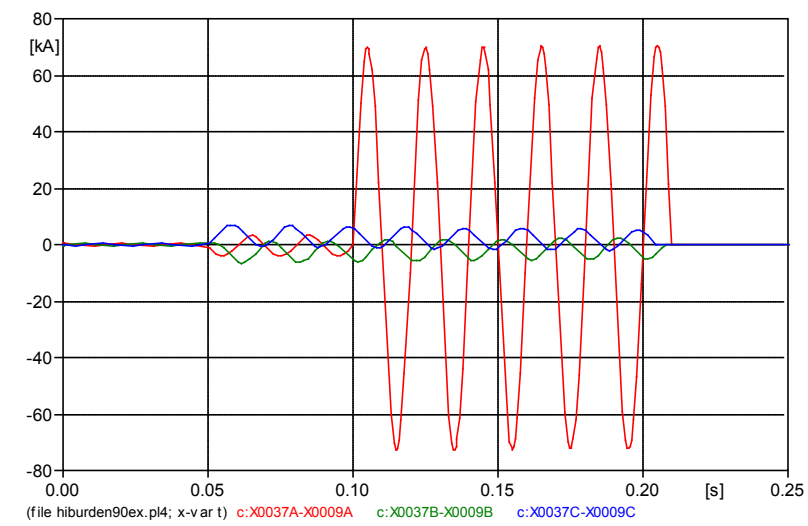

Figure 5.20: 290 MVA, three-phase through fault and 90\% turn-to-turn fault at phase A, light load.

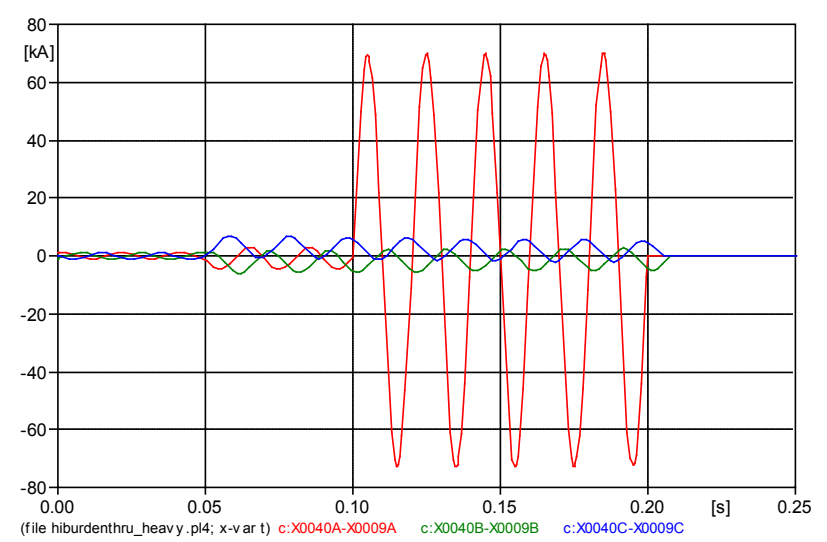

Figure 5.21: 290 MVA, three-phase through fault and 90\% turn-to-turn fault at phase A, heavy load. 
When the through fault was applied, high currents were present in the low-voltage side of the power transformer which affected the low-voltage side CTs. However, the goal was to check saturation issues in the high-voltage side CTs.

Only the phase-A currents are again shown in this section. The whole set of ATP plots for the 290-MVA transformer is given in Appendix G (see Figures G.40-G.57). For each figure, a red curve is the line current and a green curve is the current seen by the CT secondary side.

\subsubsection{Light load}

1) $\mathrm{R}_{\mathrm{TOT}}=0.512 \Omega$

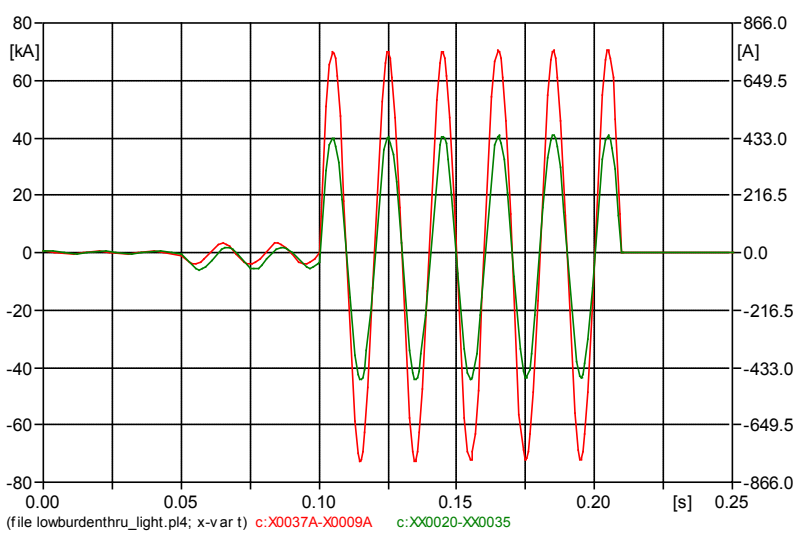

Figure 5.22: $290 \mathrm{MVA}, \mathrm{Zs}=10^{-8} \Omega$, light load, $\mathrm{R}_{\mathrm{TOT}}=0.512 \Omega$ : Phase-A pri and sec $\mathrm{CT}$ currents.

2) $\mathrm{R}_{\mathrm{TOT}}=0.932 \Omega$

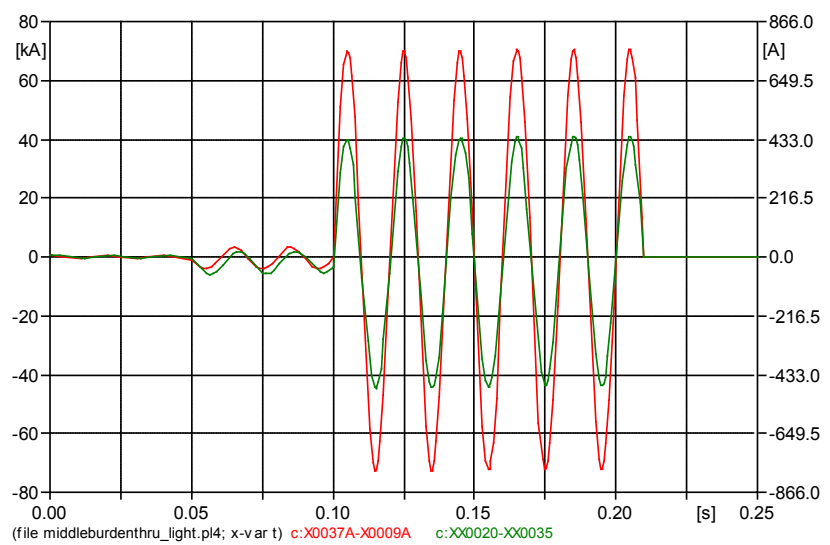

Figure 5.23: 290 MVA, $Z_{s}=10^{-8} \Omega$, light load, $\mathrm{R}_{\mathrm{TOT}}=0.932 \Omega$ : Phase-A pri and sec $\mathrm{CT}$ currents. 
3) $R_{\text {TOT }}=1.652 \Omega$.

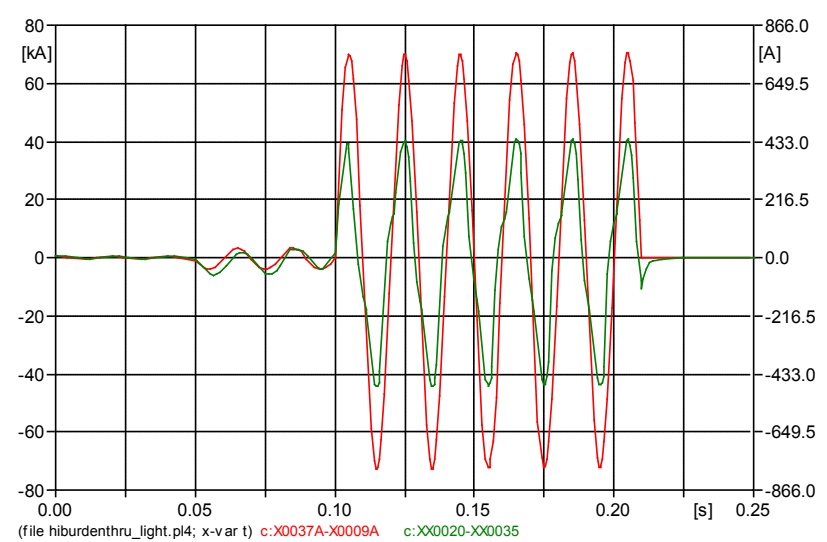

Figure 5.24: $290 \mathrm{MVA}, \mathrm{Zs}=10^{-8} \Omega$, light load, $\mathrm{R}_{\mathrm{TOT}}=1.652 \Omega$ : Phase-A pri and sec $\mathrm{CT}$ currents.

\subsubsection{Heavy load}

1) $\mathrm{R}_{\mathrm{TOT}}=0.512 \Omega$

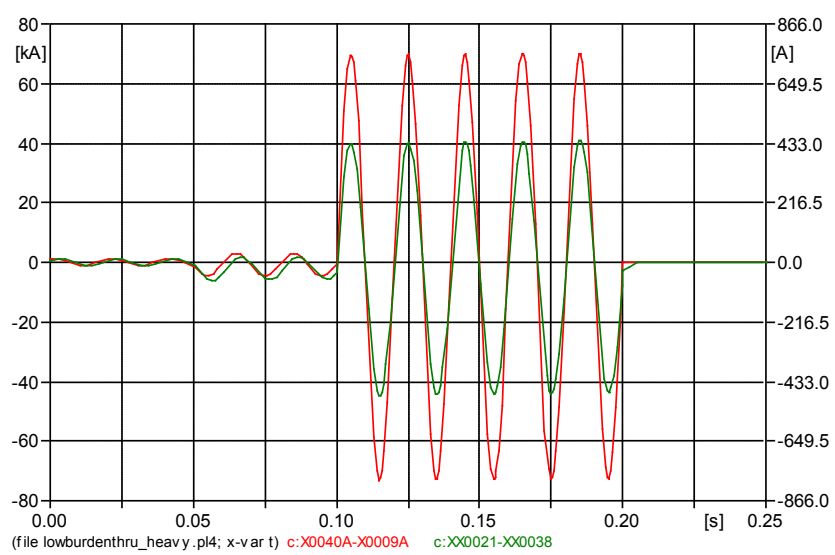

Figure 5.25: $290 \mathrm{MVA}, \mathrm{Zs}=10^{-8} \Omega$, heavy load, $\mathrm{R}_{\mathrm{TOT}}=0.512 \Omega$ : Phase-A pri and sec $\mathrm{CT}$ currents.

2) $\mathrm{R}_{\mathrm{TOT}}=0.932 \Omega$

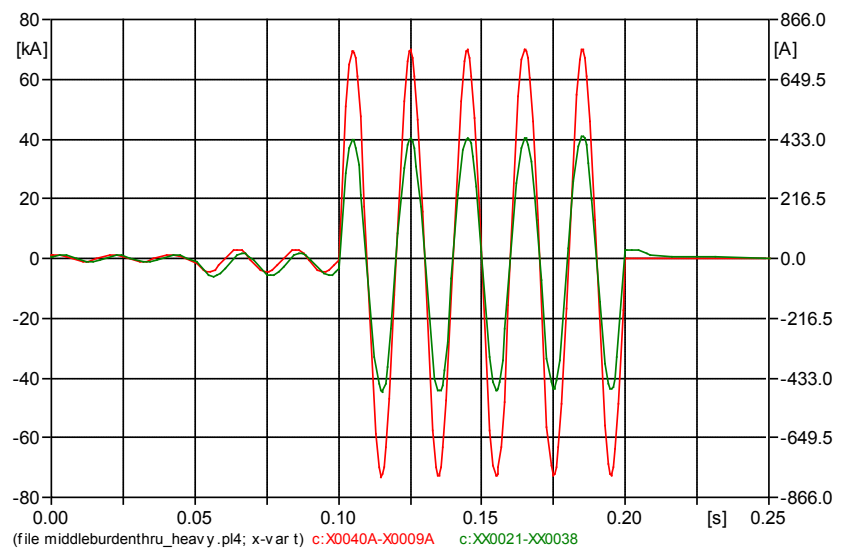

Figure 5.26: $290 \mathrm{MVA}, \mathrm{Zs}_{\mathrm{s}}=10^{-8} \Omega$, heavy load, $\mathrm{R}_{\mathrm{TOT}}=0.932 \Omega$ : Phase-A pri and sec CT currents. 
3) $\mathrm{R}_{\mathrm{TOT}}=1.652 \Omega$

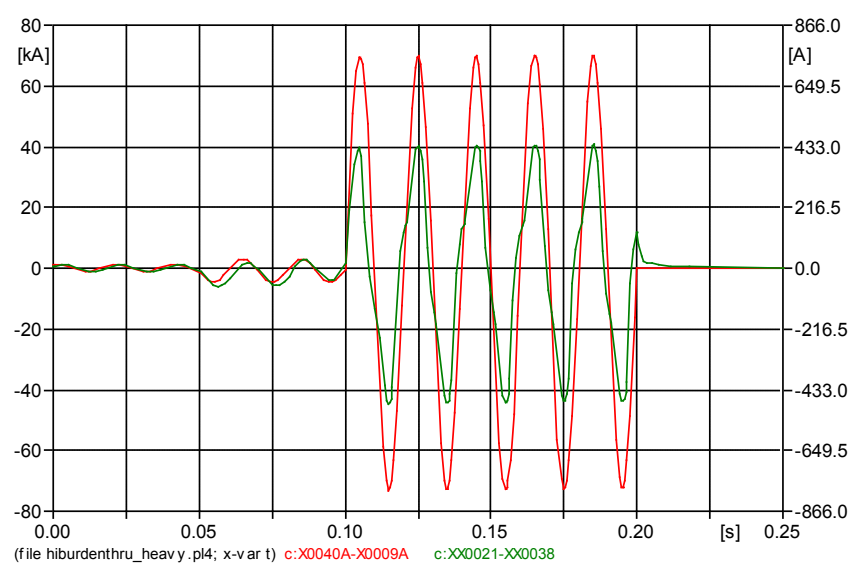

Figure 5.27: $290 \mathrm{MVA}, \mathrm{Zs}=10^{-8} \Omega$, heavy load, $\mathrm{R}_{\mathrm{TOT}}=1.652 \Omega$ : Phase-A pri and sec CT currents.

From the figures above and Appendix G (see Figures G.40-G.57), the phase-A CT shows mild saturation for the cases with $\mathrm{R}_{\mathrm{TOT}}=0.512 \Omega$ and $\mathrm{R}_{\mathrm{TOT}}=0.932 \Omega$, and the case with highest burden resistance $\left(\mathrm{R}_{\mathrm{TOT}}=1.652 \Omega\right)$ shows stronger phase-A CT saturation.

The secondary current (green) is from a delta-connected CT and so lags the primary current (red) by $30^{\circ}$. Relay settings provided compensation for this phase shift. When the $90 \%$ turn-to-turn fault is applied, there is, in addition to a $30^{\circ}$ phase shift, current measurement error due to CT saturation.

For low burden $\left(\mathrm{R}_{\mathrm{TOT}}=0.512 \Omega\right)$, the phase-C CT secondary current was not influenced by the $90 \%$ turn-to-turn fault on the phase-A winding, thus, the phase-C CT secondary current is a replication of the phase-C primary current (shifted by $30^{\circ}$ ) during the threephase through fault (see Figures G.42 and G.51). However, when the burden is increased, there is a big distortion in the phase-C CT secondary current after the $90 \%$ turn-to-turn fault application (see Figures G.45, G.48, G.54, and G.57).

Some detailed analysis of the CT primary and secondary currents during the through-fault is as follows:

1) The phase-A CT primary current has a very small and slowly decaying DC offset (see Figures 5.22-5.27), however the CT secondary current has a more visible DC offset which decays very slowly with $\mathrm{R}_{\text {TOT }}=0.512 \Omega$ (see Figures 5.22 and 5.25) and $\mathrm{R}_{\mathrm{TOT}}=0.932 \Omega$ (see Figures 5.23 and 5.26), and much faster with $\mathrm{R}_{\mathrm{TOT}}=1.652$ $\Omega$ (see Figures 5.24 and 5.27). 
2) The phase-B CT primary current has a more visible decaying DC offset due to the time of the through-fault application (see Figures G.41, G.44, G.47, G.50, G.53, and G.56); the CT secondary current decays equally slow for all the values of $\mathrm{R}_{\text {TOT. }}$

3) Both phase-C CT primary and secondary currents have visible decaying DC offset (see Figures G.42, G.45, G.48, G.51, G.54, and G.57).

As in the case with the 11.2-MVA power transformer, amount of balanced load (light or heavy) on the 290-MVA transformer did not affect the fault current magnitude considerably.

For the cases with CT saturation, theory and tests show that CTs are very good DC filters, meaning the DC component of the primary current causes an offset in flux linked but is not transferred to the secondary side current; the decay rate of a transient DC decaying component in the secondary of a CT is greatly accelerated with a higher CT burden. However, the main goal is to keep the $\mathrm{CT}$ burden low to avoid improper replication of the $\mathrm{CT}$ primary current and as a consequence the relay misoperation. The higher the accuracy of the $\mathrm{CT}$, the more difficult it is to saturate it.

Unfortunately, the cases with CT saturation require currents from the Doble Tester up to $500 \mathrm{~A}$. These cases cannot be tested due to the current outputs limitation of $30 \mathrm{~A}_{\mathrm{RMS}}$ in transient mode if all the six current sources are involved. However, the through-fault case can be tested and was done for the 290-MVA transformer when the three-phase fault was applied at the low-voltage side of the transformer at the time of $1.5 \mathrm{~s}$. As in the cases with turn-to-turn faults, CON was asserted during turning the Doble Tester on and was deasserted 60 cycles later. Figure 5.28 shows the high-voltage side and low-voltage side line currents. The indicated relay Word bits in this figure mean the following:

50SQ1 is negative-sequence definite time element 1, terminal S,

$87 \mathrm{QB}$ is blocking negative- and zero-sequence directional elements,

$\mathrm{CON}$ is fault outside of transformer differential zone,

CONA, CONB, CONC define CON Word bit related to phases A, B, and C.

When the 50SQ1 Word bit was asserted, 5 cycles after the 87Q Word bit should assert indicating internal fault if the negative-sequence differential element would not be blocked. Blocking of the negative-sequence element is shown by assertion of the $87 \mathrm{QB}$ Word bit. Thus, asserting the CON and 87QB Word bits the SEL-487E relay indicates an external fault and goes into its high security mode - slope 2 in Figure 2.12 


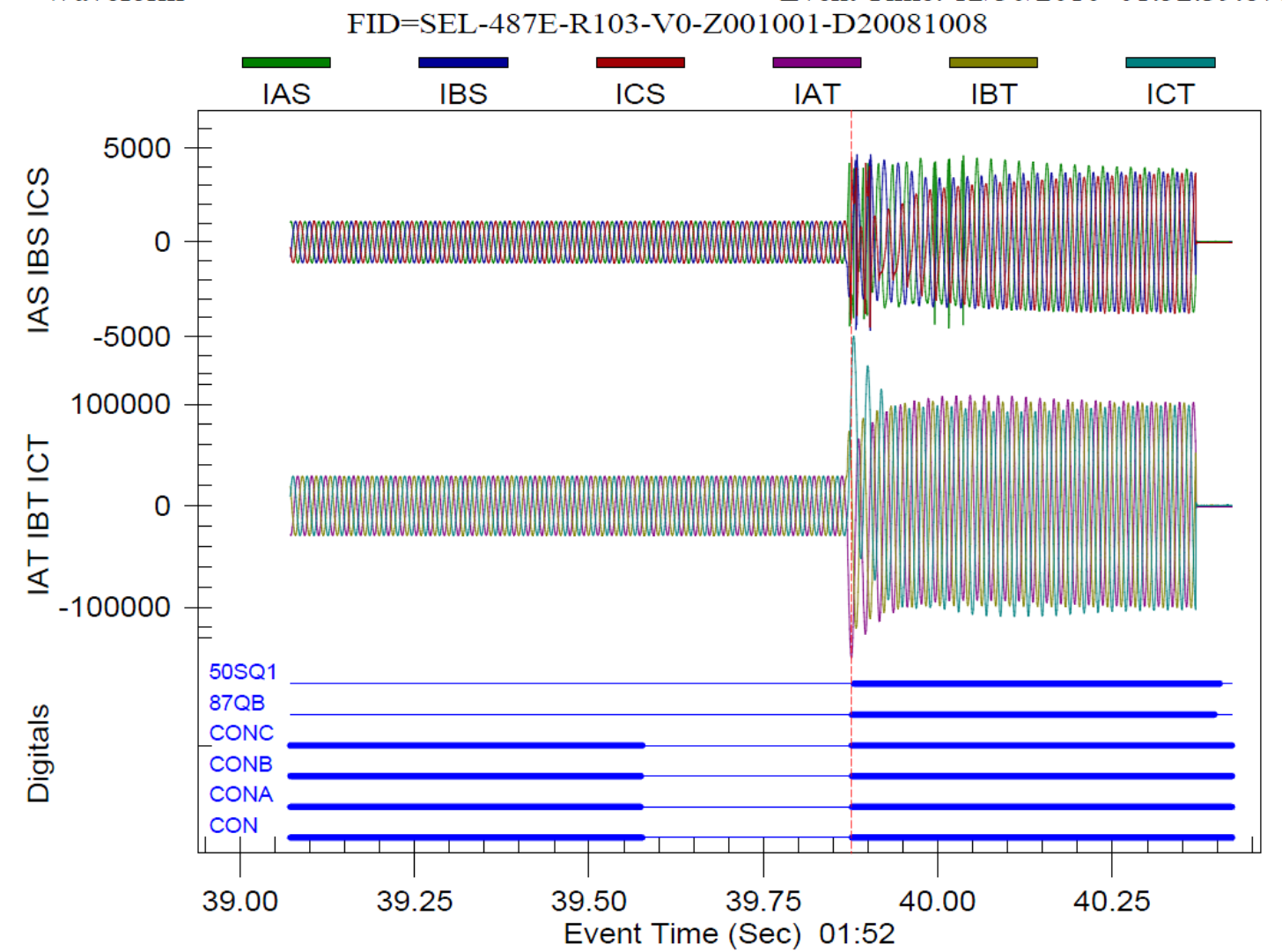

$\backslash$ Documents and Settings $\backslash$ pwrlabuser $\backslash A$ pplication Data $\backslash S E L \backslash A c S E L e r a t o r \backslash Q u i c k S e t \backslash H R \_18544$.DA

Figure 5.28: Line currents and active digitals recordered by the relay for external three-phase fault on the 290-MVA transformer.

\subsection{Ground faults}

The results of the ATP experiments for the 290-MVA transformer with light load for solidly grounded neutral are given in Appendix E, Table E.5, and for low-resistance grounded neutral are given in Table E.6. The results of the ATP experiments for the 290MVA transformer with heavy load for solidly grounded neutral are given in Table E.7, and for low-resistance grounded neutral are given in Table E.8. In these tables $\mathrm{I}_{\mathrm{A}}, \mathrm{I}_{\mathrm{B}}, \mathrm{I}_{\mathrm{C}}$ are the high-voltage side currents, $\mathrm{I}_{\mathrm{a}}, \mathrm{I}_{\mathrm{b}}, \mathrm{I}_{\mathrm{c}}$ are the low-voltage side currents, $\mathrm{I}_{\mathrm{N}}$ is the neutral current, and $\mathrm{I}_{\text {fault }}$ is the ground fault current.

Comparing neutral currents from these four tables, it is an expected result that the neutral currents from Tables E.5 and E.7 are the same as well as from Tables E.6 and E.8. The amount of balanced load does not affect the fault current and neutral current magnitudes.

Information in Table 5.6 compares the neutral and fault currents at solid grounding with the same currents at low-resistance grounding. 
Table 5.6: Neutral and fault currents at solid grounding and low-resistance grounding.

\begin{tabular}{|c|c|c|c|c|}
\hline \multirow{2}{*}{$\begin{array}{l}\text { Shorted winding } \\
\text { percentage, } \%\end{array}$} & \multicolumn{2}{|c|}{ Solid grounding ( $1 \Omega$ ) } & \multicolumn{2}{|c|}{$\begin{array}{c}\text { Low-resistance grounding } \\
(415 \Omega)\end{array}$} \\
\hline & $\mathrm{I}_{\mathrm{N}}, \mathrm{A}_{\text {peak pri }}$ & $\mathrm{I}_{\text {fault }}, \mathrm{A}_{\text {peak pri }}$ & $\mathrm{I}_{\mathrm{N}}, \mathrm{A}_{\text {peak pri }}$ & $\mathrm{I}_{\text {fault }}, \mathrm{A}_{\text {peak pri }}$ \\
\hline Rated load & 0 & N/A & 0 & $\mathrm{~N} / \mathrm{A}$ \\
\hline 1 & 3159.6 & 3195 & 8.457 & 113.67 \\
\hline 2 & 5072.6 & 5181.5 & 16.83 & 228.51 \\
\hline 3 & 6045.7 & 6239.3 & 25.12 & 344.59 \\
\hline 4 & 6553.8 & 6834.1 & 33.328 & 461.95 \\
\hline 5 & 6840.5 & 7208.2 & 41.456 & 580.66 \\
\hline 6 & 7015 & 7470.8 & 49.505 & 700.77 \\
\hline 7 & 7127.7 & 7673.1 & 57.475 & 822.34 \\
\hline 8 & 7205.9 & 7840.8 & 65.368 & 945.44 \\
\hline 9 & 7261.1 & 7987.8 & 73.185 & 1070.1 \\
\hline 10 & 7301.9 & 8121.9 & 80.927 & 1196.5 \\
\hline 15 & 7404.2 & 8720.1 & 118.55 & 1855.8 \\
\hline 20 & 7443.2 & 9313.8 & 154.45 & 2568.9 \\
\hline 25 & 7462.4 & 9960.4 & 188.74 & 3348.4 \\
\hline 30 & 7473.4 & 10687 & 221.52 & 4210.7 \\
\hline 35 & 7480.5 & 11520 & 252.89 & 5176.7 \\
\hline 40 & 7485.2 & 12488 & 282.93 & 6274.3 \\
\hline 45 & 7488.6 & 13630 & 311.74 & 7541.5 \\
\hline 50 & 7491.2 & 14998 & 339.37 & 9031 \\
\hline 55 & 7493.1 & 16669 & 365.91 & 10819 \\
\hline 60 & 7494.7 & 18756 & 391.41 & 13020 \\
\hline 65 & 7495.9 & 21439 & 415.93 & 15811 \\
\hline 70 & 7497 & 25016 & 439.53 & 13493 \\
\hline 75 & 7497.8 & 30022 & 462.25 & 24601 \\
\hline 80 & 7498.6 & 37532 & 484.15 & 32209 \\
\hline 85 & 7499.2 & 50046 & 505.27 & 44818 \\
\hline 90 & 7499.6 & 75075 & 525.64 & 69938 \\
\hline 95 & 7500.2 & 150160 & 545.32 & 145110 \\
\hline
\end{tabular}

On the basis of pairs of Tables E.5 and E.7, E.6 and E.8, the change in the neutral current was plotted as a function of a distance from the neutral point (see Figures 5.29 and 5.30). From Figure 5.29 it can be seen that the neutral current at solid grounding always has a high value which is enough for the relay to detect a ground fault even if a few turns are involved.

Figure 5.30 gives a clear picture of the fact that at low number of turns involved in the ground fault close to the neutral point in a transformer with low-resistance grounding, the relay will not be able to sense this fault. 


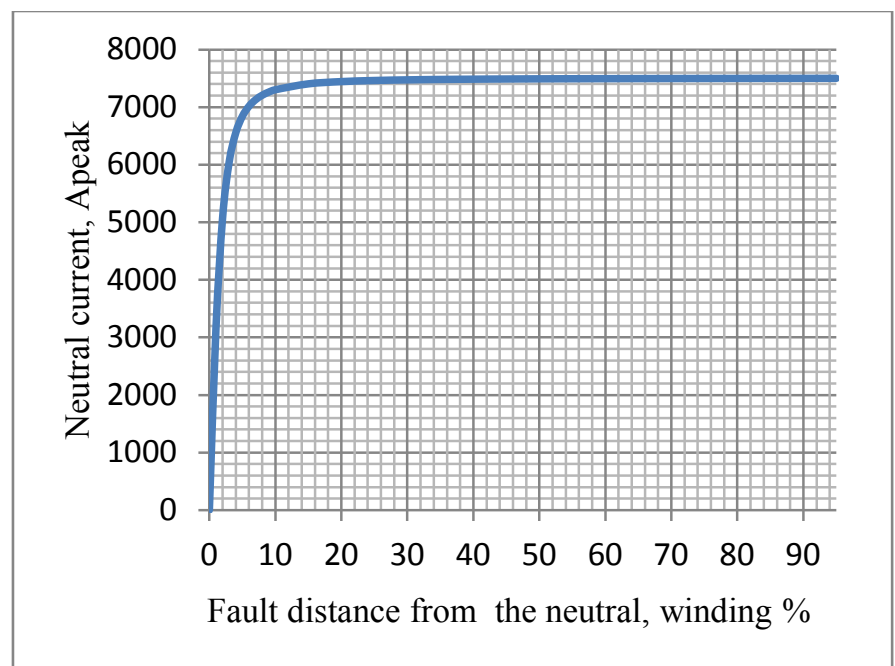

Figure 5.29: Neutral current at solid grounding $(\mathrm{R}=1 \Omega)$.

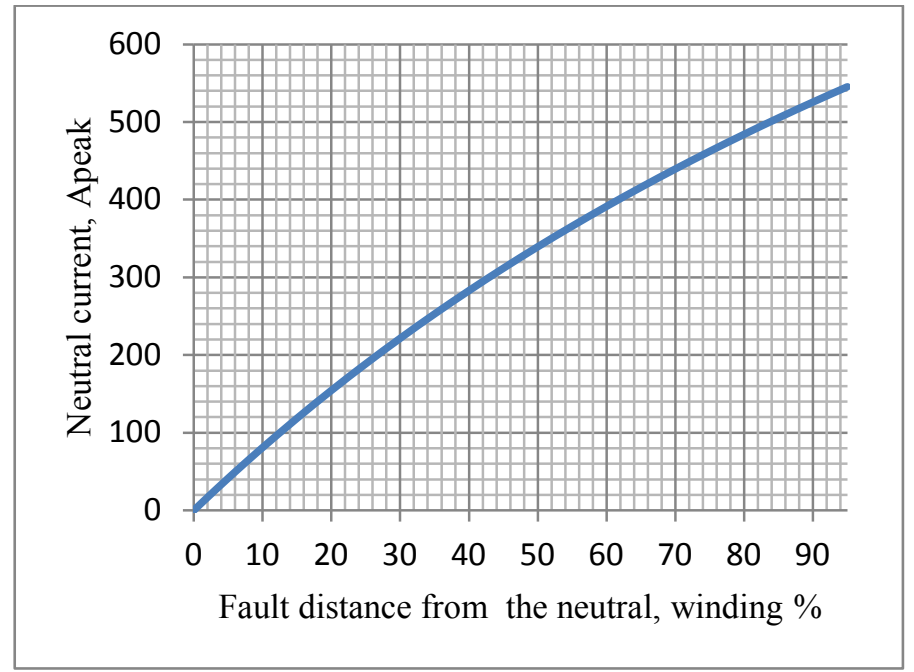

Figure 5.30: Neutral current at low-resistance grounding $(\mathrm{R}=415 \Omega)$.

The relay sensitivity for the 290-MVA transformer at solid grounding was tested with the settings indicated in Table 3.8, where the REF50G1 value was changed during the experiments.

Lab experiments with the relay showed that for the solid grounding cases it tripped when faults involved $0.1 \%$ of the phase-A winding starting from the neutral point (see Table 5.7) at the most sensitive settings. Tripping at this value can be considered as sensitive enough. For example, if high side of a transformer has 1000 turns, than $0.1 \%$ will be 1 turn.

At solid grounding, current in the neutral path at ground fault is always high, which explains high sensitivity of microprocessor relays for ground faults. 
One of the event reports given in Appendix F belongs to the case with light load, solidly grounded neutral and default settings (REF50G1=1.0 $\mathrm{A}_{\mathrm{sec}}$, typed in bold in Table 5.7) Also, the Phasors and Fundamental Metering Winding S screenshots, Doble currents in TRANS macro and ATP currents from CTs supplied to the SEL-487E relay for the same turn-to-ground fault are given there.

The transformer's high-voltage side and neutral primary currents and the relay digitals for the same case from Table 5.7 are shown in Figure 5.31. The vertical red dashed line indicates that the relay detected exceeding of the settings and assertion of the REFF1 Word bit indicates internal gound fault.

From this figure it is seen that the relay tripped after the ground fault persisted for about 1.5 cycles which is in accordance with the relay logic for ground faults programmed that a ground fault should persist at least 1.5 cycles to be tripped by the relay [7].

Table 5.7: REF element sensitivity at solidly grounded neutral.

\begin{tabular}{|c|c|c|c|c|c|}
\hline \multirow[t]{2}{*}{ REF50G1, $\mathrm{A}_{\mathrm{sec}}$} & \multicolumn{2}{|c|}{ 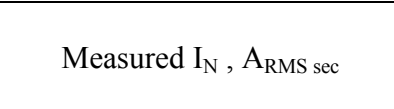 } & \multicolumn{2}{|c|}{$\begin{array}{c}3 \mathrm{I}_{0}, \mathrm{~A}_{\mathrm{RMS}} \mathrm{sec} \\
\text { (calculated from Event Summary } \\
\text { data) }\end{array}$} & \multirow{2}{*}{$\begin{array}{c}\text { Shorted } \\
\text { winding } \\
\text { percentage, \% }\end{array}$} \\
\hline & Light load & Heavy load & Light load & Heavy load & \\
\hline 0.25 & \multirow{15}{*}{$8.27 @ 6.1^{\circ}$} & \multirow{15}{*}{$8.27 @ 23.7^{\circ}$} & \multirow{15}{*}{$8.79 @-82.42^{\circ}$} & \multirow{15}{*}{$8.16 @-63.14^{\circ}$} & \multirow{15}{*}{0.1} \\
\hline 0.3 & & & & & \\
\hline 0.4 & & & & & \\
\hline 0.5 & & & & & \\
\hline 0.6 & & & & & \\
\hline 0.7 & & & & & \\
\hline 0.8 & & & & & \\
\hline 0.9 & & & & & \\
\hline 1.0 & & & & & \\
\hline 1.1 & & & & & \\
\hline 1.2 & & & & & \\
\hline 1.3 & & & & & \\
\hline 1.4 & & & & & \\
\hline 1.5 & & & & & \\
\hline 1.6 & & & & & \\
\hline 1.7 & \multirow{14}{*}{$16.47 @ 3.8^{\circ}$} & \multirow{14}{*}{$16.47 @ 21.2^{\circ}$} & \multirow{14}{*}{ 16.38@-81.77 } & \multirow{14}{*}{ 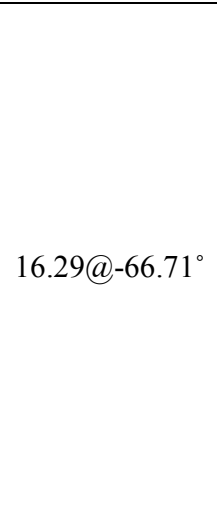 } & \multirow{14}{*}{0.2} \\
\hline 1.8 & & & & & \\
\hline 1.9 & & & & & \\
\hline 2.0 & & & & & \\
\hline 2.1 & & & & & \\
\hline 2.2 & & & & & \\
\hline 2.3 & & & & & \\
\hline 2.4 & & & & & \\
\hline 2.5 & & & & & \\
\hline 2.6 & & & & & \\
\hline 2.7 & & & & & \\
\hline 2.8 & & & & & \\
\hline 2.9 & & & & & \\
\hline 3.0 & & & & & \\
\hline
\end{tabular}




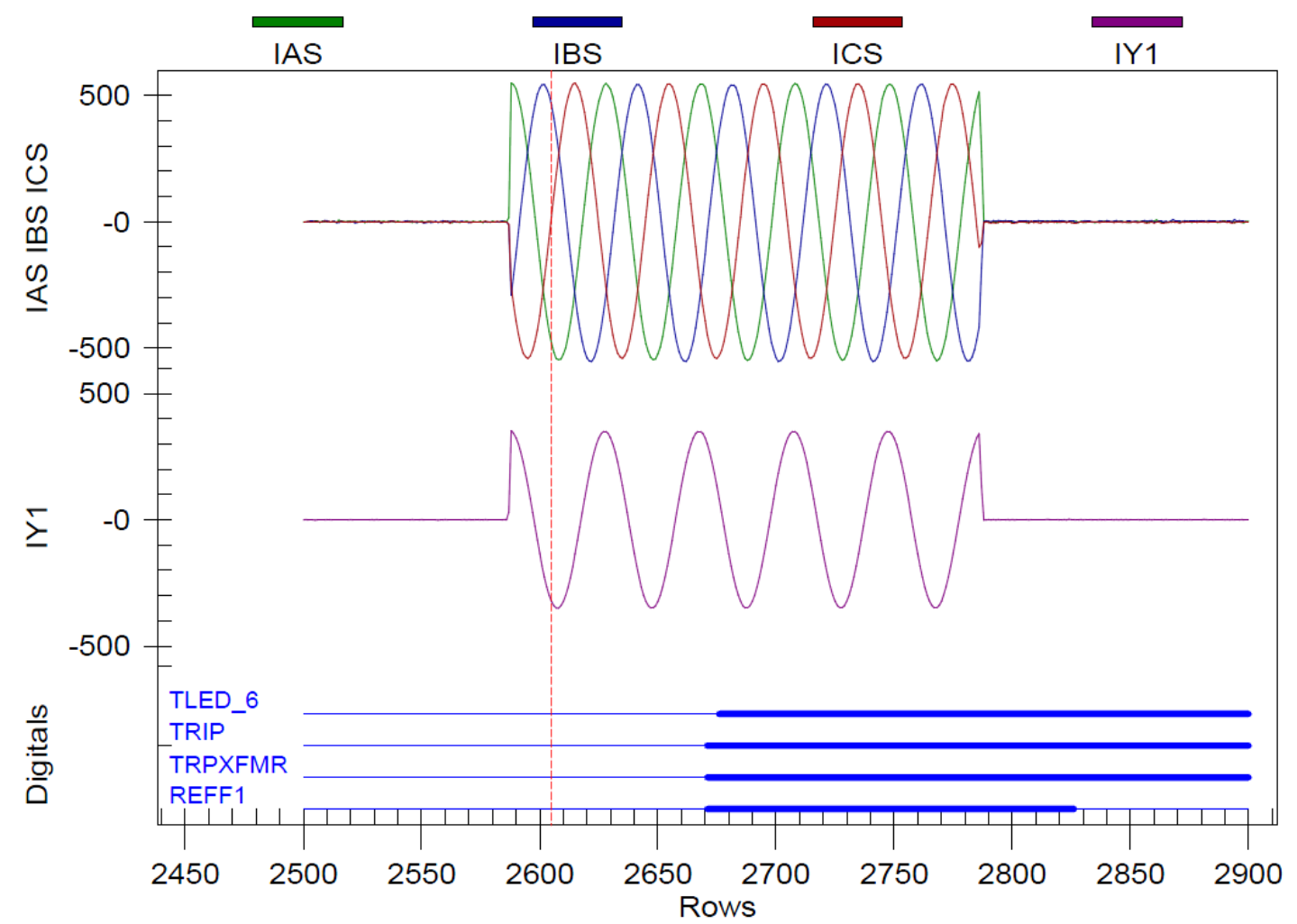

Documents and Settings $\backslash$ pwrlabuser $\backslash$ Application Data $\backslash$ SEL $\backslash A c S E L e r a t o r \backslash Q u i c k S e t \backslash H R \_18518$.DA

Figure 5.31: Line currents and active digitals recorded by the relay for turn-to-ground fault on the 290-MVA transformer.

The indicated relay Word bits in this figure mean the following:

TRLED_6 is target LED6 on relay front panel,

TRIP is transformer or terminal trip signal asserted,

TRPXFMR is transformer trip output asserted,

REFF1 is earth fault inside restricted zone 1.

The relay sensitivity for the 290-MVA transformer at low-resistance grounding (415 $\Omega$ ) was tested with the same settings indicated in Table 3.8. In this case the neutral CT had ratio 150:5 as well. Due to the Doble Tester's current limitation in transient mode of 60 $A_{R M S}$ for two out of four utilized current sources and $30 A_{R M S}$ for other two current sources for the turn-to-ground test setup, the .p14 files with maximum $60 \%$ of turns involved in the ground fault can be applied. The results showed that the relay did not trip for any turn-to-ground fault with the neutral resistance of $415 \Omega$.

Next arbitrary values of the neutral resistance were taken: $300 \Omega, 200 \Omega, 150 \Omega, 100 \Omega$, $50 \Omega$, and $10 \Omega$. Table 5.8 shows sensitivity results for the cases with these resistances in 
the neutral. At the resistance of $10 \Omega$, the relay tripped when the ground fault involved $0.4 \%$ of the winding close to the neutral point. This small resistance value gives high sensitivity to ground faults and limits fault currents.

Table 5.8: The SEL-487E relay sensitivity results at different neutral resistances.

\begin{tabular}{|c|c|c|c|}
\hline Neutral resistance, $\Omega$ & Tested percentage, $\%$ & Max $_{\mathrm{N}}, \mathrm{A}_{\text {peak pri }} / \mathrm{A}_{\text {RMS pri }}$ & REFF1 operation \\
\hline 415 & 60 & $391.41 / 276.77$ & No trip \\
\hline 300 & 60 & $540.59 / 382.25$ & No trip \\
\hline 200 & 60 & $807.78 / 571.19$ & No trip \\
\hline 150 & 60 & $1071.6 / 757.74$ & No trip \\
\hline 100 & 60 & $1585.6 / 1121.19$ & Trip \\
\hline 50 & 30 & $1780.5 / 1259$ & Trip \\
\hline 10 & 0.4 & $140.73 / 99.51$ & Trip \\
\hline
\end{tabular}

Thus, even low-resistance grounding significantly affects the SEL-487E relay sensitivity, implying that one should either utilize solidly grounded neutral or use a value of the neutral resistance which reduces the neutral current during an internal ground fault down to the value sensed by the relay. For any particular case, the reasonable value of a neutral resistance can be found utilizing the ATP internal fault model which was used for this project and described in Section 2.4 and [13] as well as the improved internal fault model from [2]. 


\section{CHAPTER 6 \\ Conclusions and Recommendations}

\subsection{Conclusions}

The following conclusions from the performed work can be drawn based on the analysis of the results:

\subsubsection{Proof of concept}

The goal of this work was to develop a modeling methodology to perform simulations and laboratory tests of internal faults for the 11.2-MVA and 290-MVA transformers. Simulations were carried out utilizing the ATP internal fault model and laboratory tests involved performance verification of the SEL-487E current differential and voltage protection microprocessor relay.

Correctness of the results of the tested relay depends on the accuracy of the ATP internal fault model used to produce current waveforms supplied to the relay. The utilized internal fault model did not include the core saturation and did not consider all the changes in mutual and self impedances during transients. Lack of core saturation in the model did not allow performing cases involving energization inrush. Lack of consideration of all of the changes in impedances due to fault location along the winding height means that the currents calculated during internal faults are not strongly accurate [2]. However, each internal fault is unique because self and mutual impedances created in the faulted transformer depend on the fault location along the height of the winding and this in turn affects the current in the faulted portion as well as line currents.

The improved internal fault model [2], not yet available when this work was done, takes into consideration both facts mentioned above.

\subsubsection{Turn-to-turn faults}

- The relay has its highest sensitivity at $87 \mathrm{QP}=0.05 \mathrm{pu}$ tap and $87 \mathrm{QPSLP}=5 \%$. The operating region gradually decreases when the slope percentage is increased and when the $87 \mathrm{QP}$ threshold is set higher.

- At the highest sensitivity the relay started to trip in case of the 11.2-MVA transformer - at $0.3 \%$ of turns involved in the turn-to-turn fault on the high-side phase-A winding; in case of the 290-MVA transformer - at $0.4 \%$. 
- The relay manufacturer has default settings for the negative-sequence element: $87 \mathrm{QP}=0.1 \mathrm{pu}$ tap and $87 \mathrm{QPSLP}=25 \%$. Results show high sensitivity pickup for these settings: $0.4 \%$ for the 11.2-MVA transformer and $0.8 \%$ for the 290-MVA transformer for either light or heavy load.

- The default settings resulted in the relay operation at about twice the minimum detectable faulted percentage for the 290-MVA transformer. However, this is still more sensitive than the advertised $2 \%$ of turns involved in a turn-to-turn fault at heavy load, assuming that the advertisement statement was based on the default settings. At the setting $87 \mathrm{QP}=0.27 \mathrm{pu}$ tap, the relay detected the turn-to-turn fault involving $2 \%$ of the phase-A winding on the high-voltage side of the 290-MVA transformer. Higher $87 \mathrm{QP}$ settings increased this percentage.

- For the 11.2-MVA transformer, with all the possible combinations of the $87 \mathrm{QP}$ and 87 QPSLP (below 100\%) settings, the relay tripped for turn-to-turn faults before they could reach $2 \%$ of the high-side phase-A winding. This proves that the sensitivity of the negative-sequence element of the SEL-487E relay is higher for smaller transformers.

- The sensitivity results obtained for the tested power transformers are in agreement with reference [6] which states that "the negative-sequence differential element is sensitive enough to detect turn-to-turn faults involving less than $2 \%$ of the winding".

- At any $87 \mathrm{QP}$ pickup setting and $87 \mathrm{QPSLP}=100 \%$, the negative-sequence differential element does not detect turn-to-turn faults; they are tripped by the phase-differential element

- The amount of balanced load, either light or heavy, did not affect the sensitivity of the negative-sequence differential element.

- The amount of balanced load did affect the sensitivity of the phase-differential element: in case of the 11.2 MVA-transformer the phase-differential element asserted for the light load case at shorting $2.3 \%$ of the high-side phase-A winding, and for the heavy load case at $4.5 \%$; in case of the 290-MVA transformer the phase-differential element asserted for the light load case at shorting $7.6 \%$ of the high-side phase-A winding, and for the heavy load case at $15.1 \%$. Thus, 
sensitivity of the phase-differential element degraded about twice for the heavy load cases.

- If the $87 \mathrm{QP}$ setting was increased by $0.01 \mathrm{pu}$ tap, the detectable shorted percentage on the high-side phase-A winding was also increased: for the 11.2MVA transformer, the increase was about $0.1 \%$ of turns after several subsequent changes of the 87QP setting; for the 290-MVA transformer the increase was about $0.1 \%$ of turns after each subsequent change of the $87 \mathrm{QP}$ setting up to $87 \mathrm{QP}=0.15$ pu tap and in average about $0.6 \%$ of turns after.

- Settings for the negative-sequence percentage differential element should be set considering the allowed unbalance in the system.

\subsubsection{CT saturation}

- The higher accuracy a CT has, the more difficult it is to saturate it. It is vital to choose adequate $\mathrm{CT}$ s for transformer differential protection.

- CT sizing should be used to minimize the risk of CT saturation, the more common rule from [11]: a C-voltage rating of a CT should be at least twice that required for the maximum symmetrical fault current at its steady-state.

- A value of a CT burden affects the ability of the CT to saturate, thus, the value of the CT burden should be kept as low as possible which is easily achievable with modern microprocessor relays.

\subsubsection{Turn-to-ground faults}

- Turn-to-ground faults at solid grounding are detectable by the SEL-487E relay when the number of turns involved into the fault is $0.1 \%$ of the high-voltage side phase-A winding starting from the neutral point for the 290-MVA transformer.

- Low-resistance grounding should be applied carefully because it greatly affects the relay sensitivity for turn-to-ground faults. The best sensitivity achieved with low-resistance grounding for the 290-MVA transformer was with the $10 \Omega$ resistor in the transformer neutral - the relay started to trip when the ground fault involved $0.4 \%$ of turns starting from the neutral point. 
- Values of the current in the neutral path at turn-to-ground faults can be found utilizing the ATP internal fault model, and thus, the appropriate value of the neutral resistance can be found from this analysis.

- Settings for the REF element should be chosen considering the allowed unbalance in the system; however, it was discovered that the relay is very sensitive for all the operating current settings (REF50G1): from 0.25 to $1.6 \mathrm{~A}_{\text {secondary }}$ ground faults were detected at shorting $0.1 \%$ of the phase-A winding starting from the neutral point and from 1.7 to $3 \mathrm{~A}_{\text {secondary }}$ ground faults were detected at shorting $0.2 \%$.

\subsection{Recommendations for future work}

- A new set of experiments similar to those in this project can be performed utilizing the developed modeling methodology and improved internal fault model to obtain more accurate results.

- Simulation of energization inrush and internal faults involving core saturation can now be performed. Also, the improved internal fault model can be used to simulate internal faults on either side of a transformer with more than two windings. Thus, operation of the SEL-487E relay can now be studied for internal faults during energization inrush for any type or configuration of a power transformer.

- Dependence of a current value in the faulted portion upon the fault location along the winding height is another area to explore with the improved internal fault model for a particular transformer.

- A grounding bank applied to the delta-connected side of a power transformer can be added in simulations to increase the zone of protection for ground faults and then performance of the SEL-487E relay for these cases can be studied.

- With some powerful test set equipment, experiments for all the internal faults can be performed with both the negative-sequence differential and REF elements enabled at the same time. 


\section{References}

[1] D. G. Alciatore. (2010 Aug. 10). Video Demonstrations of Mechatronic Devices and Principles [Online].

Available: http://video_demos.colostate.edu/mechatronics/index.html\#power

[2] A. Avendaño, "Transformer Modeling in ATP: Internal Faults \&High-Frequency Discretization," Ph.D. Dissertation, Michigan Technological University, Houghton, MI, 2011.

[3] J. L. Blackburn and T. J. Domin, Protective Relaying: Principles and Applications, $3^{\text {rd }}$ ed., CRC Press, Taylor \& Francis Group, LLC, 2007.

[4] IEEE Guide for Protective Relay Applications to Power Transformers, IEEE Std C37.91-2000. IEEE, 2000.

[5] Protecting Power Systems for Engineers PROT 401, SEL University, Pullman, WA, 2009.

[6] A. Guzman, N. Fisher, and C. Labuschagne, "Improvements in Transformer Protection and Control," in $62^{\text {nd }}$ Annual Conference for Protective Relay Engineers, Austin, TX, pp. 563-579, Mar./Apr. 2009.

[7] SEL-487E Relay, Current Differential and Voltage Protection, Instruction Manual, Pullman, WA, Schweitzer Engineering Laboratories, Inc., Pullman, WA, 2010. Available: $\underline{\text { http://www.selinc.com/literature/ }}$

[8] A. Guzman, "Transformer Internal Fault Model for Protection Analysis," M.S. thesis, 2002.

[9] C. Labuschagne, I. Merwe. (2010, Aug. 10). A Comparison Between HighImpedance and Low-Impedance Restricted Earth-Fault Transformer Protection [Online]. Available: http://www.selinc.com/literature/

[10] IEEE Guide for the Application of Neutral Grounding in Electrical Utility Systems, Part V-Transmission Systems and Subtransmission Systems, IEEE Std C62.92.52009 (Revision of IEEE Std C62.92.5-1992), 2009.

[11] IEEE Guide for the Application of Current Transformers Used for Protective Relaying Purposes, IEEE Std C37.110-2007, 2008.

[12] IEEE Standard Requirements for Instrument Transformers, IEEE Std C57.13-2008, 2008. 
[13] J. Ramamurthy, H. Bahirat, and A. Avendaño, "Transformer Protection Scheme using SEL Differential Relays," EE5223 Power System Protection Term Project, Michigan Technological University, Houghton, MI, 2009.

[14] Alternative Transients Program (ATP) Rule Book, Leuven EMTP Center, Jul. 1987.

[15] Schweitzer Engineering Laboratories, Inc. (2010, Aug 10). SEL-487E Transformer Protection Relay [Online]. Available: http://www.selinc.com/SEL-487E/

[16] L. Prikler, H. K. Hoidalen, ATPDraw version 5.6 for Windows 9x/NT/2000/XP/Vista Users' Manual, Bonneville Power Administration, Portland, OR, 2009.

[17] IEEE Standard General Requirements for Liquid-Immersed Distribution, Power, and Regulating Transformers, ANSI/IEEE Std C57.12.00-1987, 1988.

[18] M. Kezunovic, Lj. Kojovic, et al, "Experimental Evaluation of EMTP-Based Current Transformer Models for Protective Relay Transient Study," IEEE Transactions on Power Delivery., vol. 9, no. 1, pp. 405-413, Jan. 1994.

[19] IEEE Guide for Loading Mineral-Oil-Immersed Transformers Corrigendum1, IEEE Std C57.91-1995/Cor 1-2002, 2003.

[20] IEEE Recommended Practice for Grounding of Industrial and Commercial Power Systems, IEEE Std 142-2007 (Revision of IEEE Std 142-1991), 2007.

[21] Protection course lab procedures, MTU EE-4224/5223 - Protective Relaying Lab, Michigan Technological University, Houghton, MI, 2009.

[22] N. T. Stringer, "The Effect of DC Offset on Current-Operated Relays," IEEE Transactions on Industry Applications, vol. 34, no. 1, pp. 30-34, Jan./Feb. 1998. 


\section{Appendix A \\ Transformer data}

\begin{tabular}{|c|c|c|c|c|c|}
\hline POWER TRANSFO & RMERS & & TEST REPORT & & PAGE 1 \\
\hline $\begin{array}{r}\text { Purchaser: } \\
\text { Rating: }\end{array}$ & $11.20 / 14.00$ & MVA & $72.00 / 25.00 \mathrm{Y} \mathrm{kV}$ & $\begin{array}{c}\text { Serial No: } \\
\text { Date: }\end{array}$ & $03 / 02 / 2006$ \\
\hline
\end{tabular}

\section{GENERAL CHARACTERISTICS}

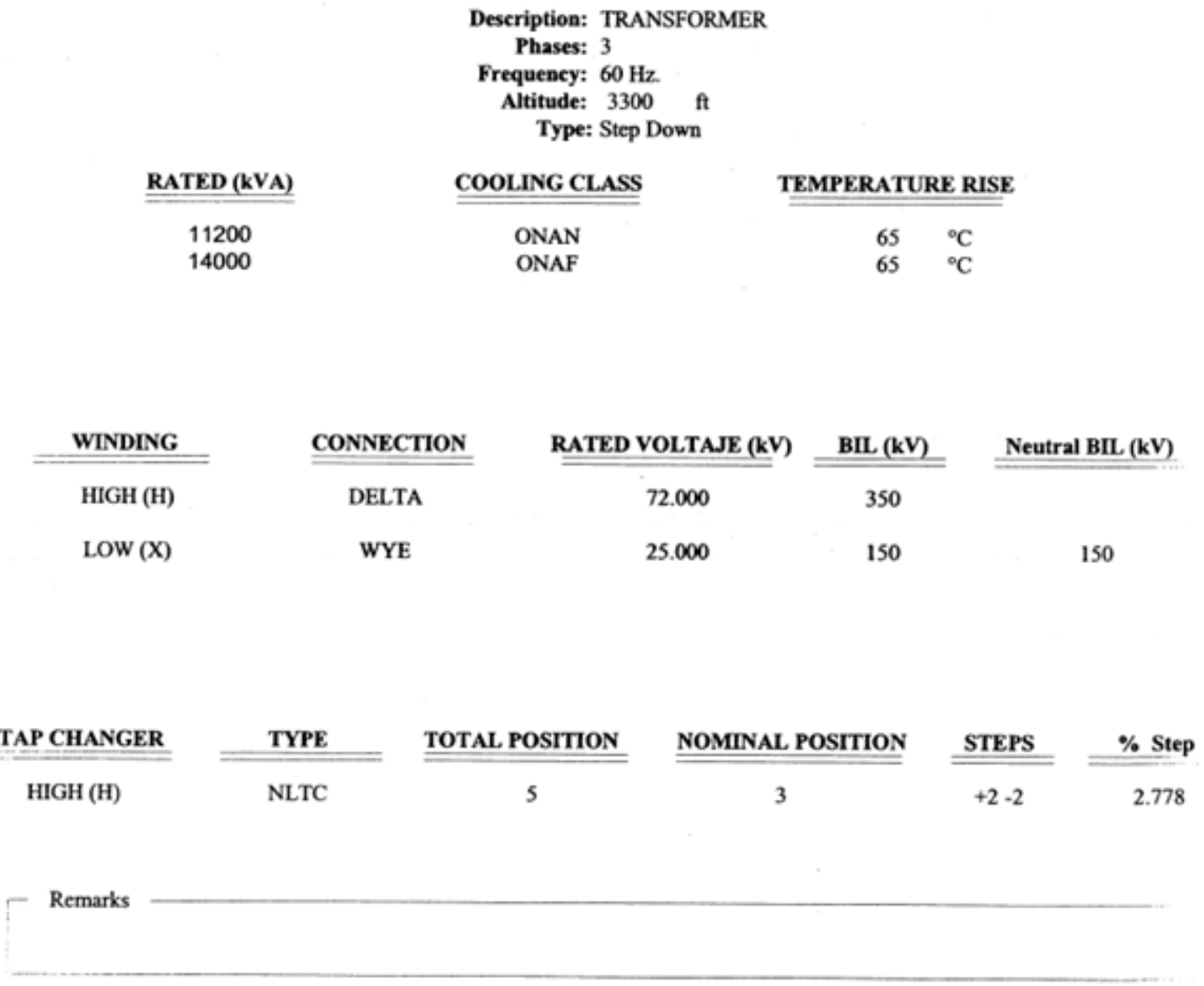

All measurements were made and reported in accordance to the following standards:

ANSI - IEEE Std. C57.12.00-2000 - General Requirements for Liquid Immersed Distribution, Power and regulation Transformers ANSI - IEEE Std. C57.12.90-1999 - Standard Test Code for Liquid Immersed Distribution, Power and regulation Transformers ANSI - IEEE Std. C57.98-1999 Guide for Transformers Impulse Test ANSI - IEEE Std. 4-19\%5 - Standard Techniques for High-Voltage Testing

Figure A.1: The 11.2-MVA transformer data. 
Table A.1: Load losses, impedance and total losses for the 11.2-MVA transformer.

\begin{tabular}{ccc} 
POWER TRANSFORMERS & TEST REPORT & PAGE 8 \\
\hline \hline $\begin{array}{c}\text { Purchasing : } \\
\text { Rating : } 11.20 / 14.00 \text { MVA }\end{array}$ & $72.00 / 25.00 \mathrm{Y} \mathrm{kV}$ & $\begin{array}{c}\text { Serial No. : } \\
\text { Date : 02/28/2006 }\end{array}$ \\
\hline \hline
\end{tabular}

\section{LOAD LOSSES, IMPEDANCE AND TOTAL LOSSES}

HIGH VOLTAGE / LOW VOLTAGE (TAP POSITION:N)

\begin{tabular}{|c|c|c|c|c|c|c|c|c|}
\hline HV TAP & Current rms A & Voltage rms kV & Power kW & $\% R$ & $\% \mathrm{X}$ & $\% \mathbf{z}$ & $\begin{array}{l}\text { Load Losses at } \\
85.00^{\circ} \mathrm{C}(\mathrm{kW})\end{array}$ & $\begin{array}{l}\text { Total Losses at } \\
85.00^{\circ} \mathrm{C}(\mathrm{kW})\end{array}$ \\
\hline$T$ & 85.047 & 6.700 & 43.580 & 0.430 & 8.809 & 8.819 & 48.111 & 57.410 \\
\hline 3 & 89.927 & 6.255 & 42.600 & 0.425 & 8.666 & 8.676 & 47.588 & 56.887 \\
\hline 5 & 95.013 & 5.951 & 42.300 & 0.428 & 8.748 & 8.759 & 47.918 & 57.217 \\
\hline
\end{tabular}


Table A.2: CT ratios, polarity and DC resistance tests for CTs of the 11.2-MVA transformer.

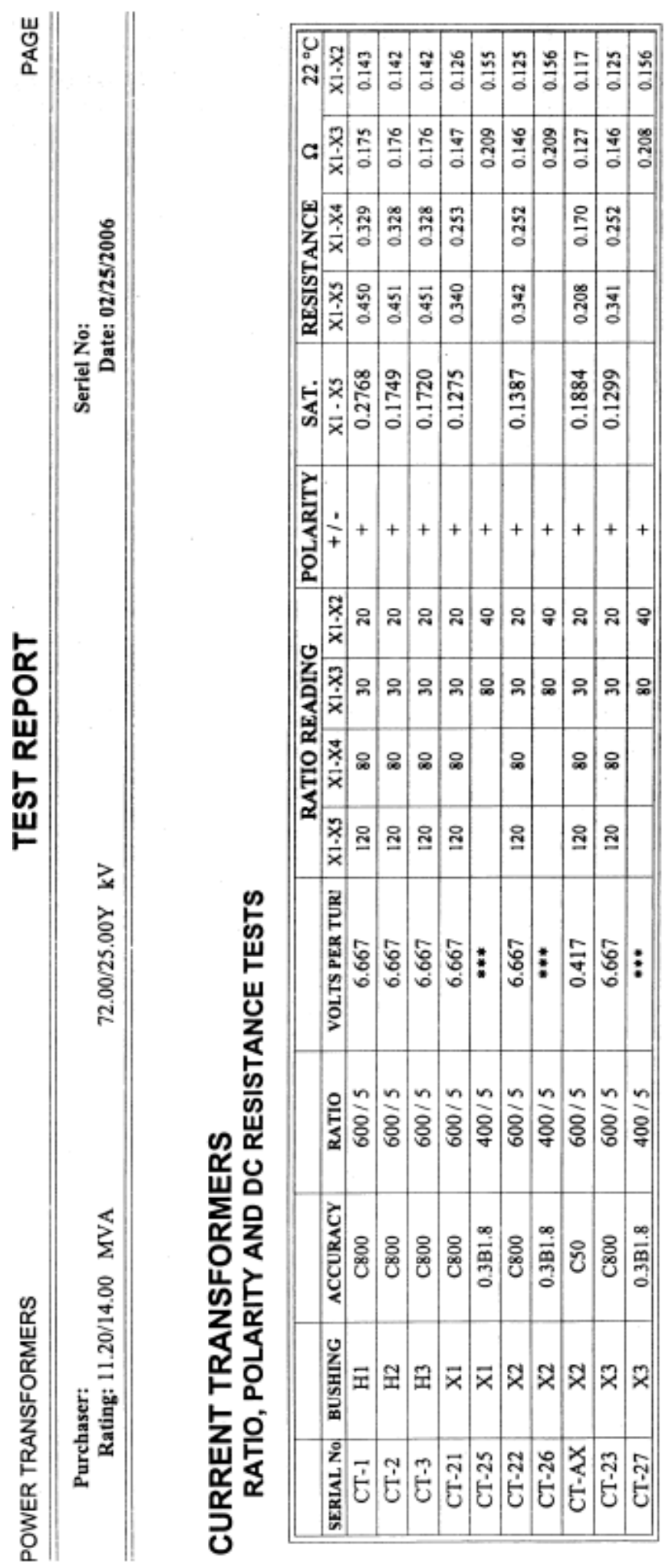




\section{Exc-X1-X3:}

Tipo: Excitación TC

Fecha/hora: 02/14/2006 14:53:40

Sobrecarga: no

Evaluación: n/a

$\mathrm{V}$ máx: $\quad 500.0 \mathrm{~V}$

I máx: $\quad 3.00000 \mathrm{~A}$

Frecuencia: $60.00 \mathrm{~Hz}$

Automático: sí

V I

$227.29 \mathrm{~V} \quad 3.4854 \mathrm{~A}$

$223.57 \mathrm{~V} 2.6636 \mathrm{~A}$

$221.94 \mathrm{~V} \quad 2.3918 \mathrm{~A}$

$218.94 \mathrm{~V} 2.0218 \mathrm{~A}$

$216.05 \mathrm{~V} \quad 1.7659 \mathrm{~A}$

$212.33 \mathrm{~V} \quad 1.5255 \mathrm{~A}$

$208.01 \mathrm{~V} \quad 1.3270 \mathrm{~A}$

$202.59 \mathrm{~V} \quad 1.1548 \mathrm{~A}$

$195.83 \mathrm{~V} \quad 1.0085 \mathrm{~A}$

$187.15 \mathrm{~V} \quad 882.6 \mathrm{~mA}$

$175.75 \mathrm{~V} \quad 772.6 \mathrm{~mA}$

$160.95 \mathrm{~V} \quad 674.5 \mathrm{~mA}$

$142.95 \mathrm{~V} \quad 586.2 \mathrm{~mA}$

$125.38 \mathrm{~V} \quad 516.4 \mathrm{~mA}$

$86.850 \mathrm{~V} 381.1 \mathrm{~mA}$

$59.980 \mathrm{~V} \quad 289.3 \mathrm{~mA}$

$41.400 \mathrm{~V} \quad 219.7 \mathrm{~mA}$

$28.540 \mathrm{~V} \quad 165.2 \mathrm{~mA}$

$19.720 \mathrm{~V} \quad 123.1 \mathrm{~mA}$

$13.590 \mathrm{~V} \quad 90.81 \mathrm{~mA}$

$9.3800 \mathrm{~V} \quad 67.17 \mathrm{~mA}$

$6.4600 \mathrm{~V} \quad 49.47 \mathrm{~mA}$

$3.4600 \mathrm{~V} 29.95 \mathrm{~mA}$

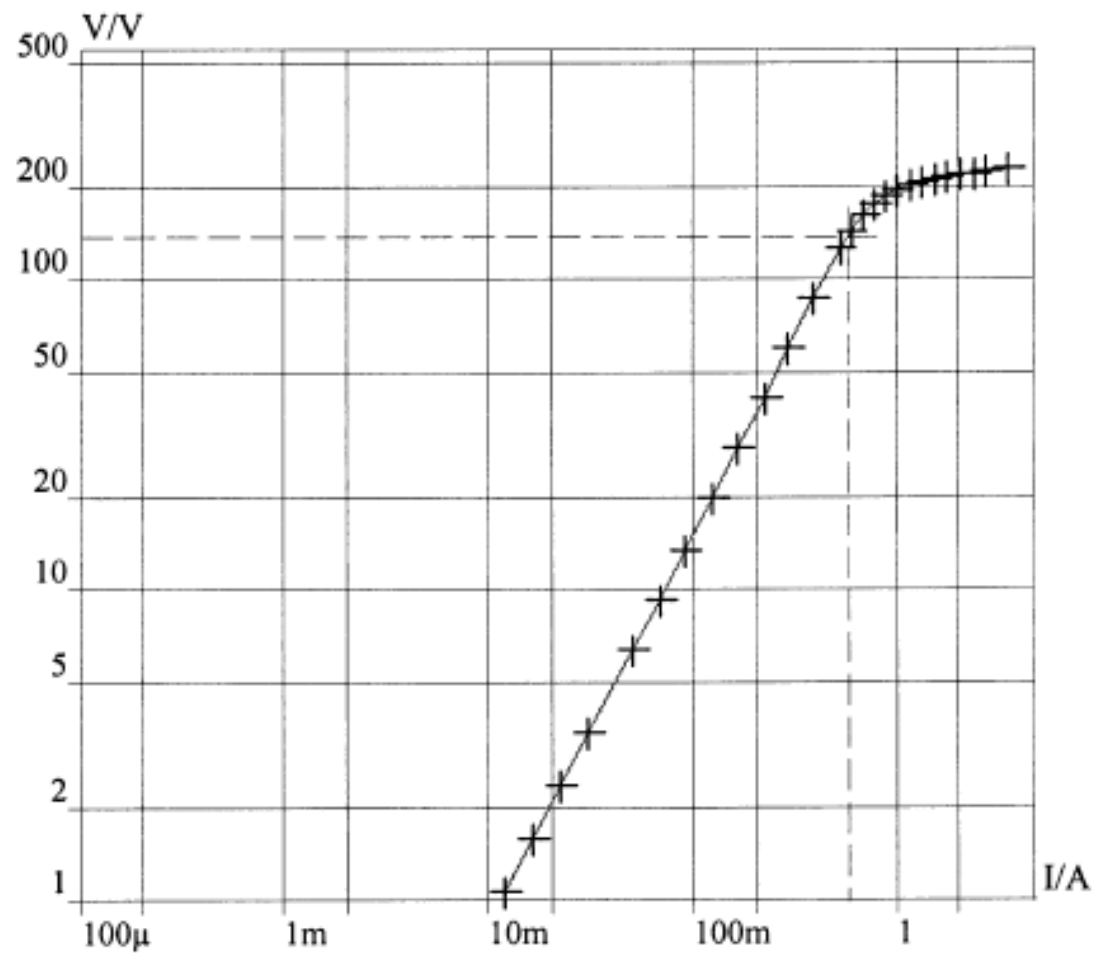

$2.3500 \mathrm{~V} 21.99 \mathrm{~mA}$

$1.5800 \mathrm{~V} \quad 16.11 \mathrm{~mA}$

$1.0800 \mathrm{~V} \quad 11.94 \mathrm{~mA}$

$760.0 \mathrm{mV} 8.830 \mathrm{~mA}$

Cálculo pto. saturación: ANSI $45^{\circ}$

$\mathrm{V}$ infl.: $\quad 136.83 \mathrm{~V}$

I infl.: $\quad 561.9 \mathrm{~mA}$

Figure A.2: Magnetizing curve of 600:5 CT tapped at 150:5 ratio. 
Tipo: Excitación TC

Fecha/hora: 02/14/2006 16:24:06

Sobrecarga: no

Evaluación: n/a

V máx: $\quad 800.0 \mathrm{~V}$

I máx: $\quad 2.50000 \mathrm{~A}$

Frecuencia: $60.00 \mathrm{~Hz}$

Automático: sí

v

$636.23 \mathrm{~V} 2.3341 \mathrm{~A}$

$629.58 \mathrm{~V} 1.6495 \mathrm{~A}$

$625.71 \mathrm{~V} 1.3345 \mathrm{~A}$

$621.41 \mathrm{~V} 1.0582 \mathrm{~A}$

$616.79 \mathrm{~V} 843.9 \mathrm{~mA}$

$611.98 \mathrm{~V} 673.0 \mathrm{~mA}$

$607.11 \mathrm{~V} 538.7 \mathrm{~mA}$

$601.37 . \mathrm{V} 431.5 \mathrm{~mA}$

$593.79 \mathrm{~V} 348.2 \mathrm{~mA}$

$584.18 \mathrm{~V} 283.6 \mathrm{~mA}$

$570.43 \mathrm{~V} 234.3 \mathrm{~mA}$

$547.15 \mathrm{~V} 195.2 \mathrm{~mA}$

$501.84 \mathrm{~V} 161.5 \mathrm{~mA}$

$427.05 \mathrm{~V} 132.8 \mathrm{~mA}$

$283.54 \mathrm{~V} 96.34 \mathrm{~mA}$

$188.02 \mathrm{~V} 73.59 \mathrm{~mA}$

$124.54 \mathrm{~V} 55.65 \mathrm{~mA}$

$82.430 \mathrm{~V} 40.85 \mathrm{~mA}$

$54.590 \mathrm{~V} 29.37 \mathrm{~mA}$

$36.130 \mathrm{~V} 20.98 \mathrm{~mA}$

$23.950 \mathrm{~V} 15.04 \mathrm{~mA}$

$15.880 \mathrm{~V} 10.81 \mathrm{~mA}$

$10.510 \mathrm{~V} 7.810 \mathrm{~mA}$

$6.2800 \mathrm{~V} 5.250 \mathrm{~mA}$

$4.0900 \mathrm{~V} 3.810 \mathrm{~mA}$

$2.6600 \mathrm{~V} 2.780 \mathrm{~mA}$

$1.7500 \mathrm{~V} 2.060 \mathrm{~mA}$

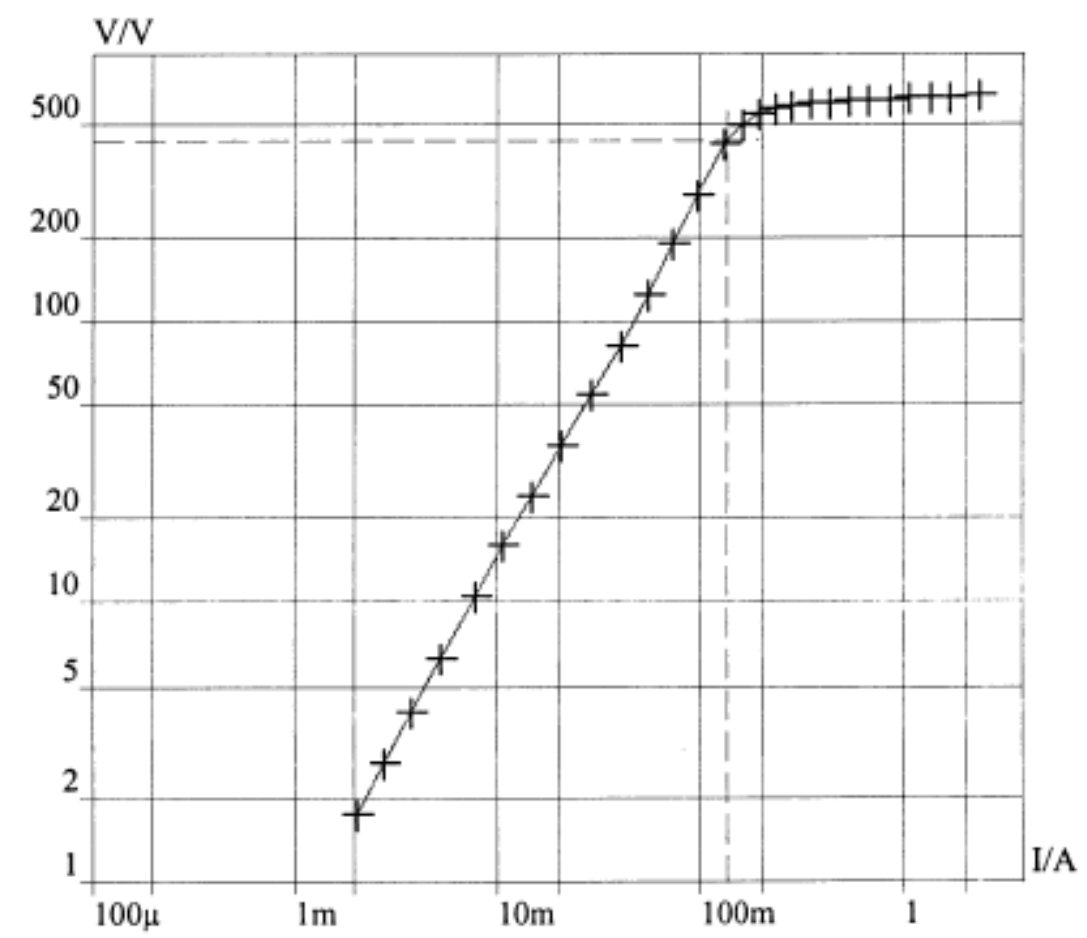

Cáleulo pto. saturación: ANSI $45^{\circ}$

$V$ infl.:

$435.69 \mathrm{~V}$

I infl.:

$136.0 \mathrm{~mA}$

Figure A.3: Magnetizing curve of 600:5 CT tapped at 400:5 ratio. 


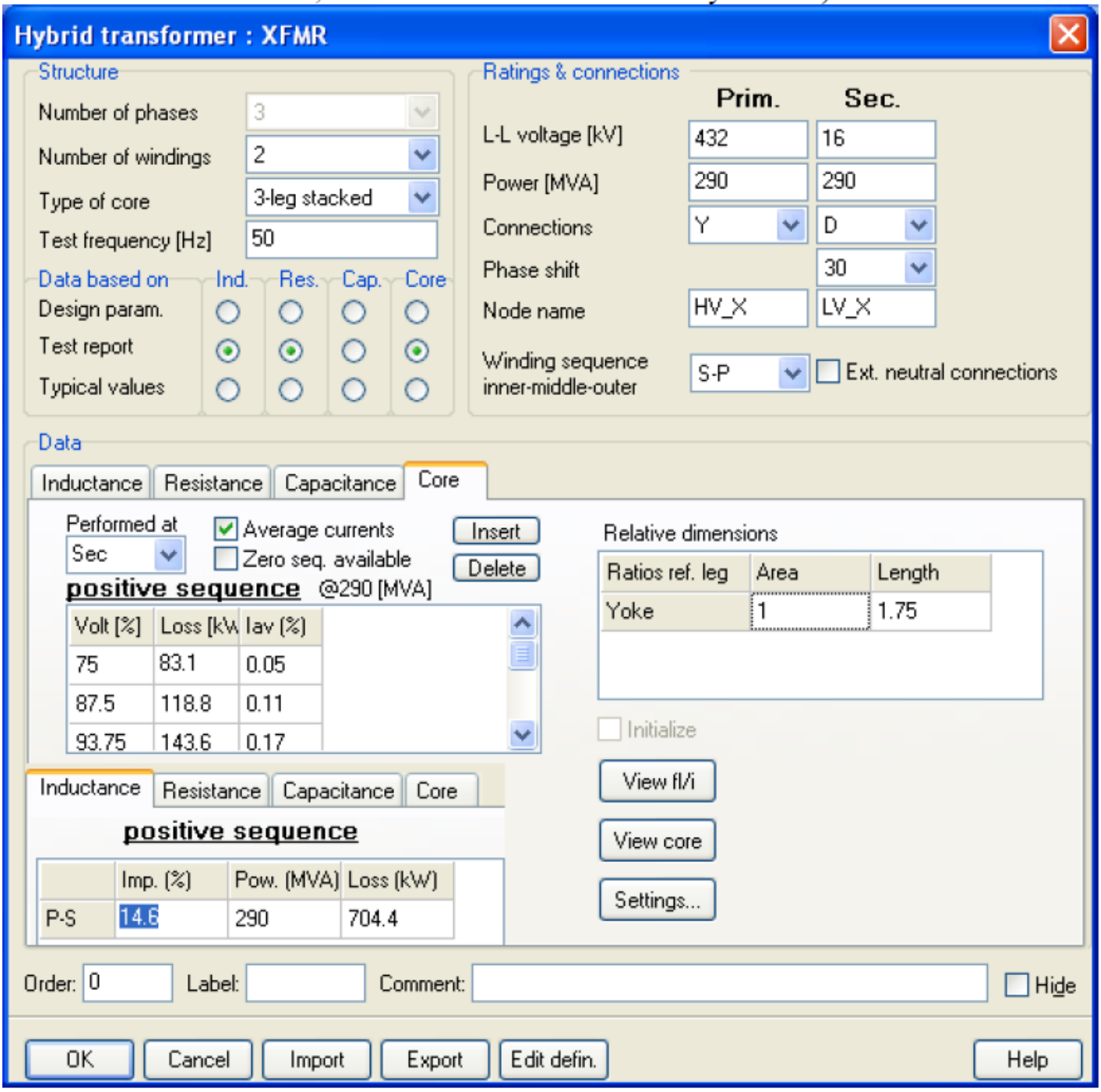

Figure A.4: The 290-MVA transformer data [16]. 


\begin{tabular}{|c|c|c|}
\hline $\begin{array}{c}\text { MANKED } \\
\text { RATI0 }\end{array}$ & $\begin{array}{c}\text { SEC. } \\
\text { TURN3 }\end{array}$ & $\begin{array}{c}\text { SEC. } \\
\text { TAPS }\end{array}$ \\
\hline $100 / 5$ & 20 & $\mathrm{X}_{2}-\mathrm{X}_{3}$ \\
\hline $200 / 5$ & 40 & $\mathrm{X}_{1}-\mathrm{X}_{2}$ \\
\hline $300 / 5$ & 60 & $\mathrm{X}_{1}-\mathrm{X}_{3}$ \\
\hline $400 / 5$ & 80 & $\mathrm{X}_{4}-\mathrm{X}_{5}$ \\
\hline $500 / 5$ & 100 & $\mathrm{X}_{3}-\mathrm{X}_{4}$ \\
\hline $600 / 5$ & 120 & $\mathrm{X}_{2}-\mathrm{X}_{4}$ \\
\hline $800 / 5$ & 160 & $\mathrm{X}_{1}-\mathrm{X}_{4}$ \\
\hline $900 / 5$ & 180 & $\mathrm{X}_{3}-\mathrm{X}_{5}$ \\
\hline $1000 / 5$ & 200 & $\mathrm{X}_{2}-\mathrm{X}_{5}$ \\
\hline $1200 / 5$ & 240 & $\mathrm{X}_{1}-\mathrm{X}_{5}$ \\
\hline
\end{tabular}

M G RAW-EDISON

POWER SYSTEMS GROUP BTCT EXCITING CURRENT CURVES

TYPE OE - 1200

DWG. NO. A-422534

OCB TYPE -

FRE OUENCY 60 CYCLES

MAXIMUM RATIO 1200/5

TOTAL SEC. TURNS 240

SEC. RES. .0027 OHMS/ TURN AT $75^{\circ} \mathrm{C}$

ASA ACCURACY $10 C 800$

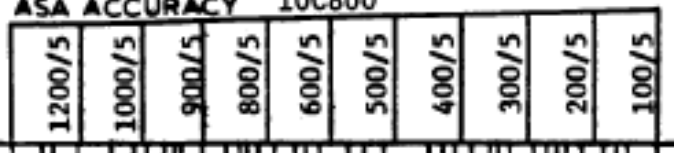

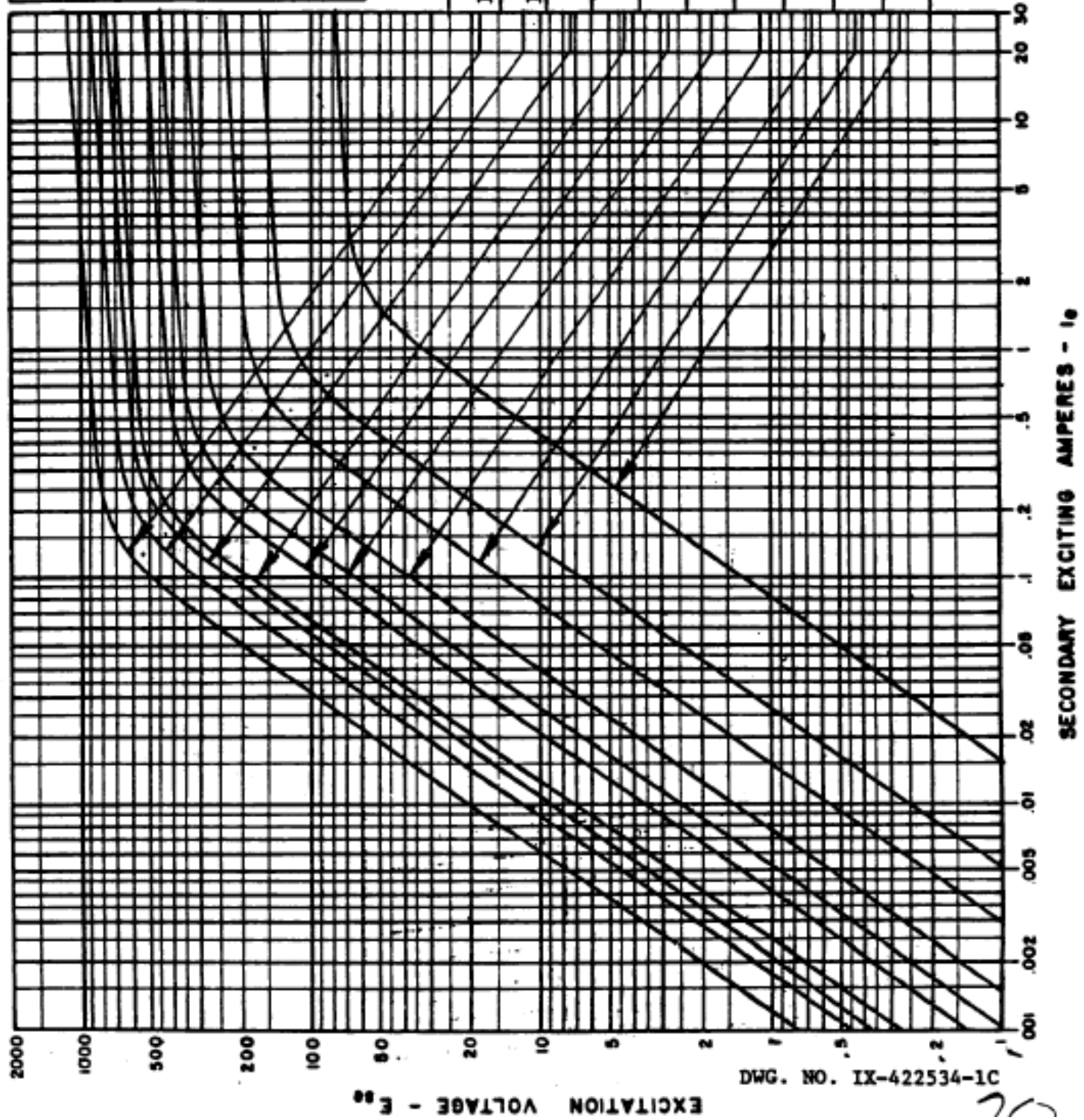

Figure A.5. 1200:5 CT magnetizing curves. 



\section{Appendix B \\ Transformer ATP configurations}

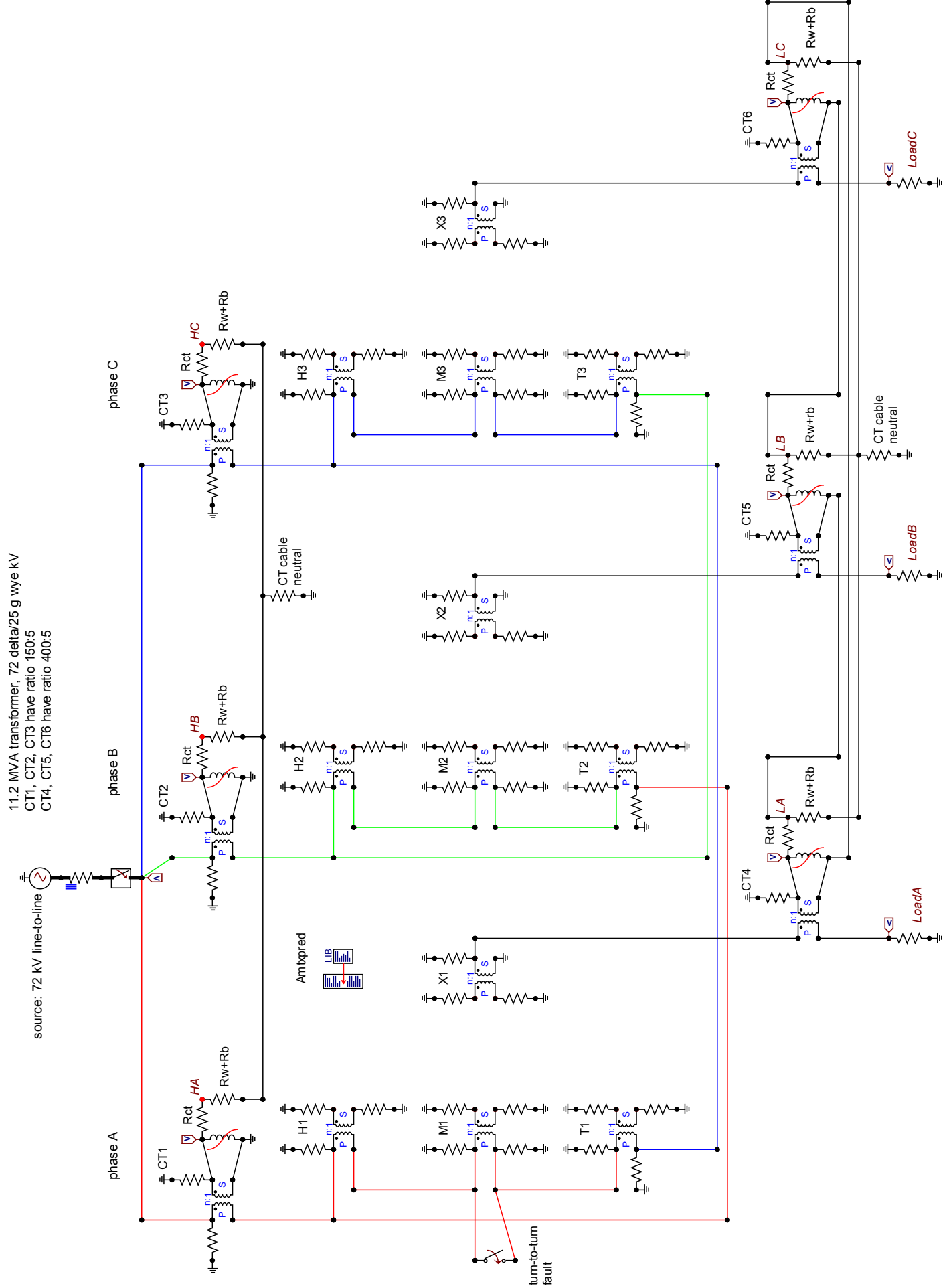

Figure B.1: ATP configuration of the 11.2-MVA transformer for turn-to-turn faults, light load. 


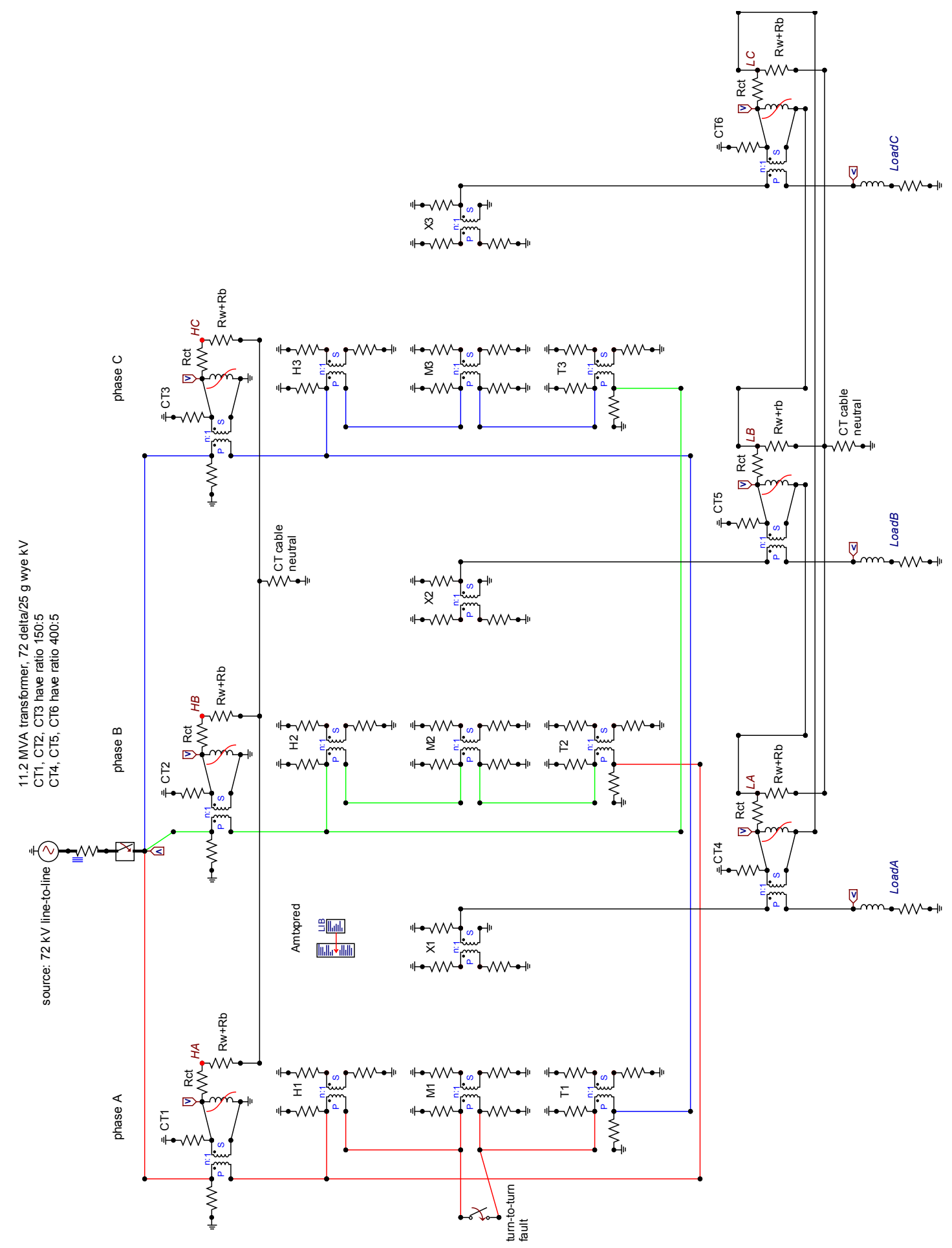

Figure B.2: ATP configuration of the 11.2-MVA transformer for turn-to-turn faults, heavy load. 


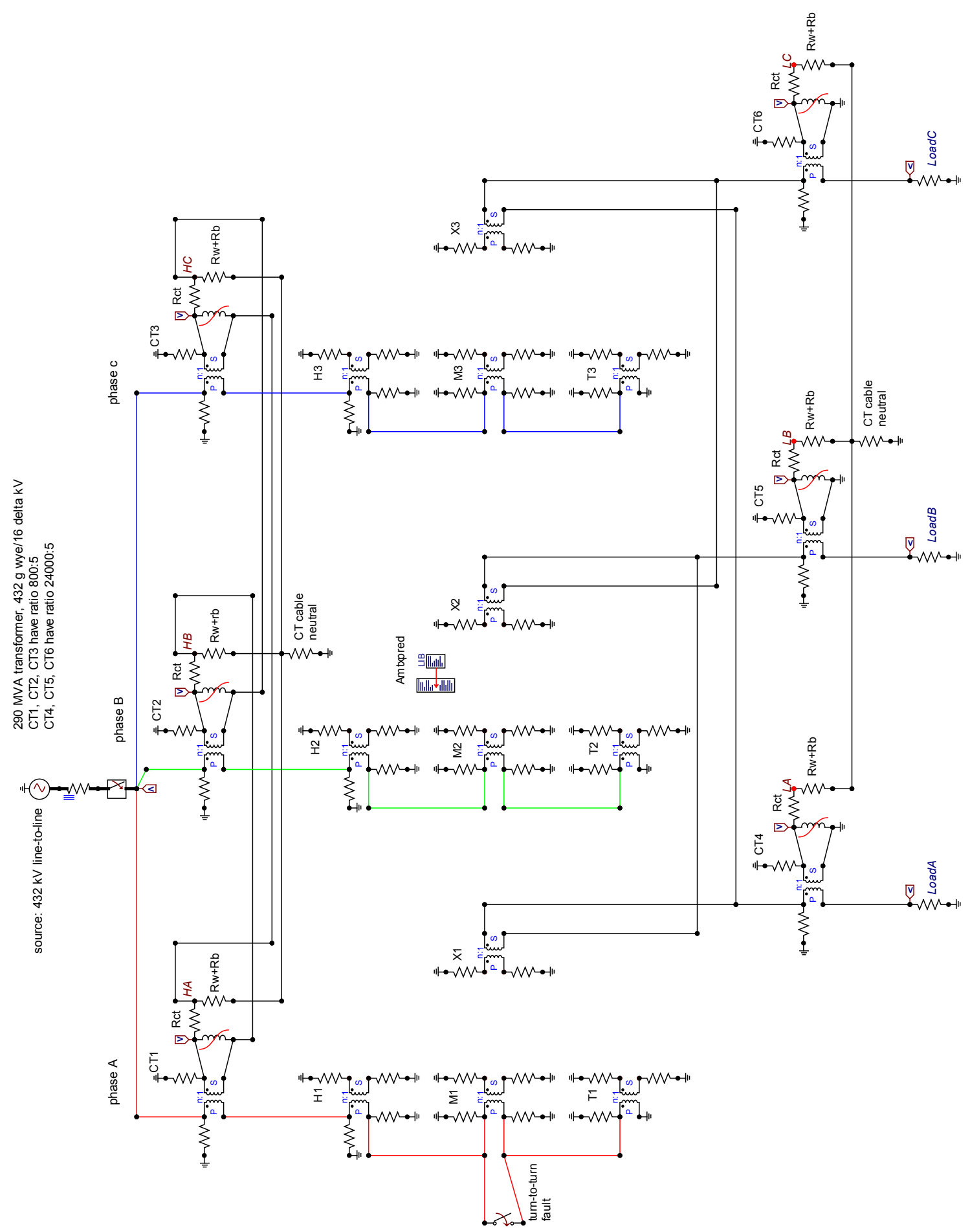

Figure B.3: ATP configuration of the 290-MVA transformer for turn-to-turn faults, light load. 


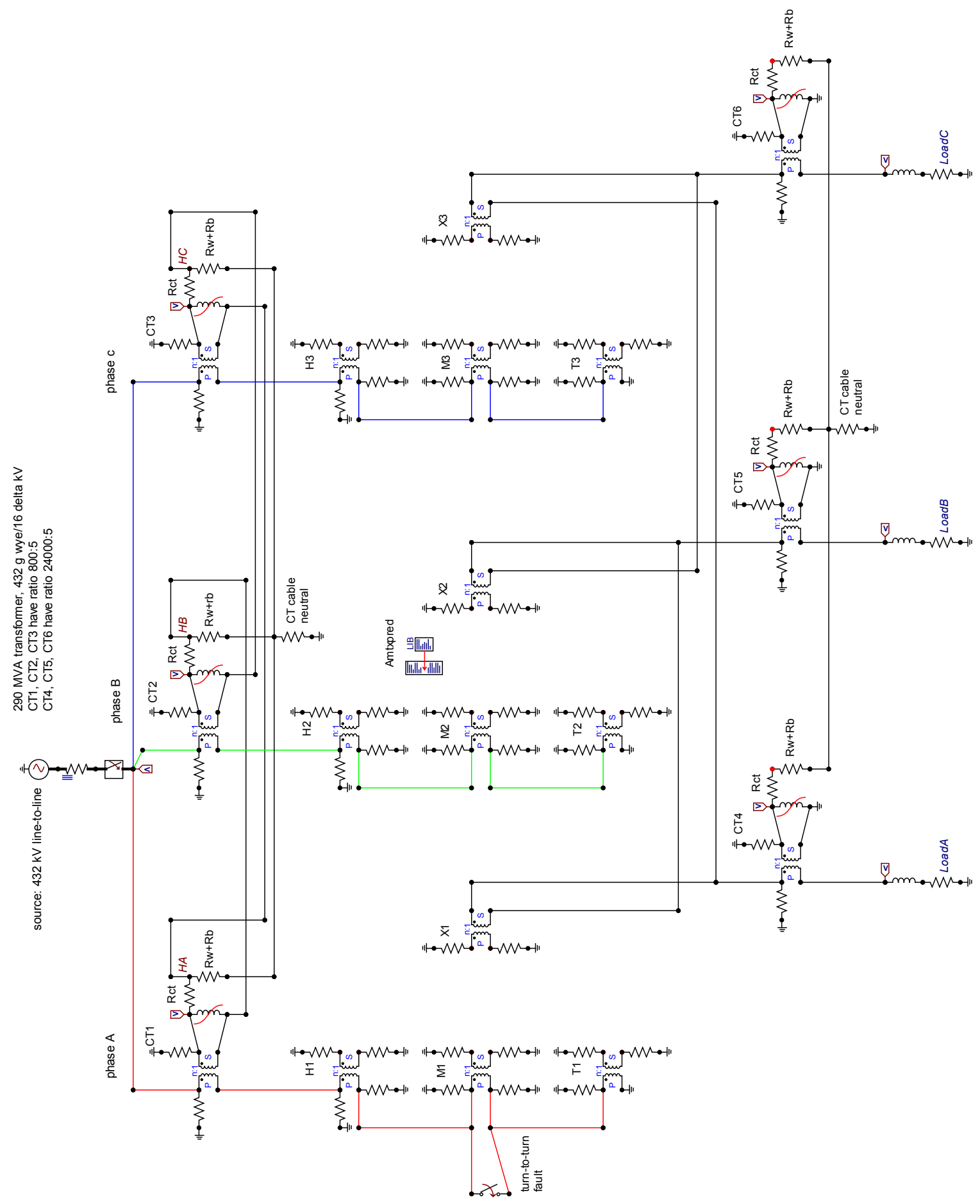

Figure B.4: ATP configuration of the 290-MVA transformer for turn-to-turn faults, heavy load. 


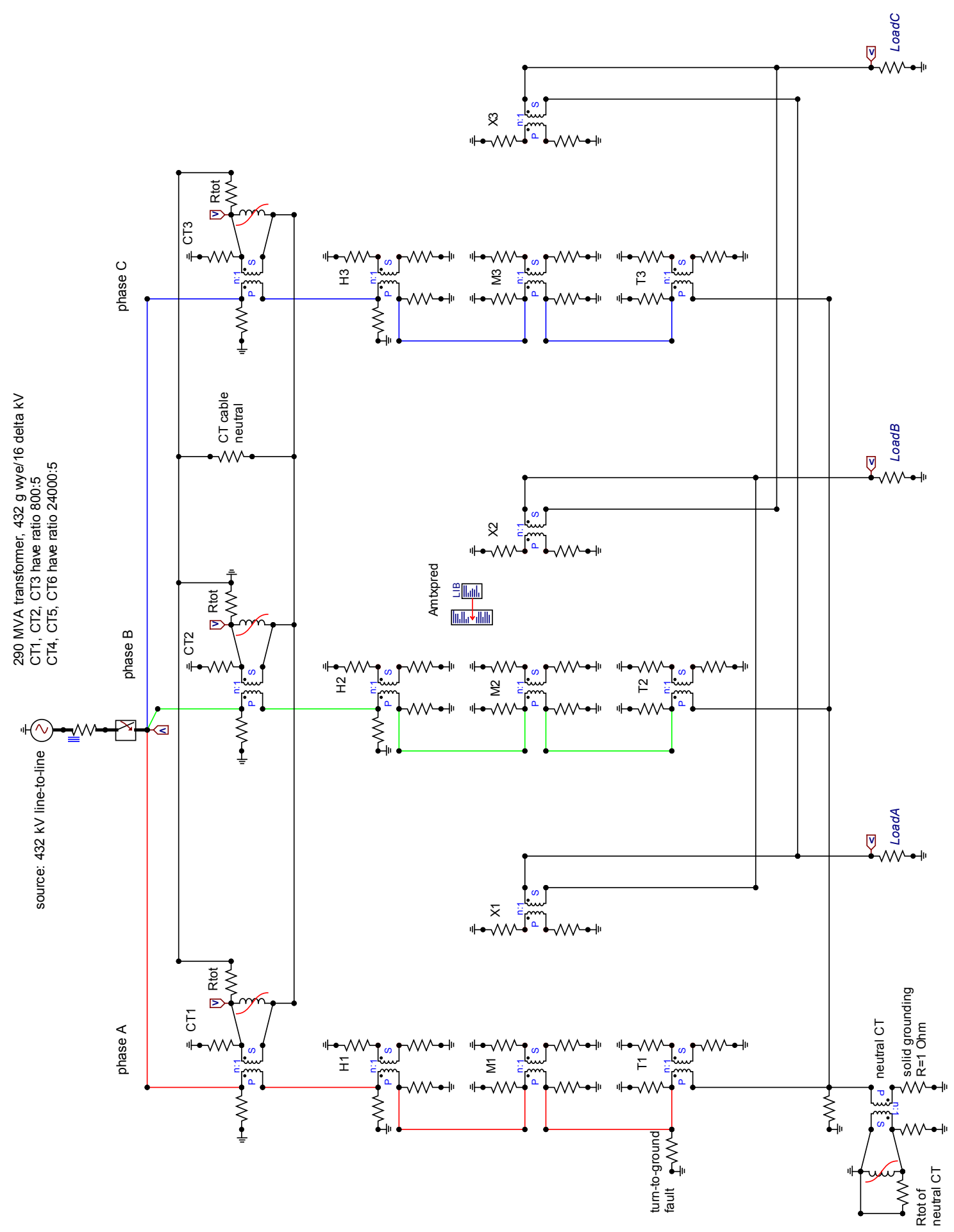

Figure B.5: ATP configuration of the 290-MVA transformer for turn-to-ground faults, solid grounding, light load. 


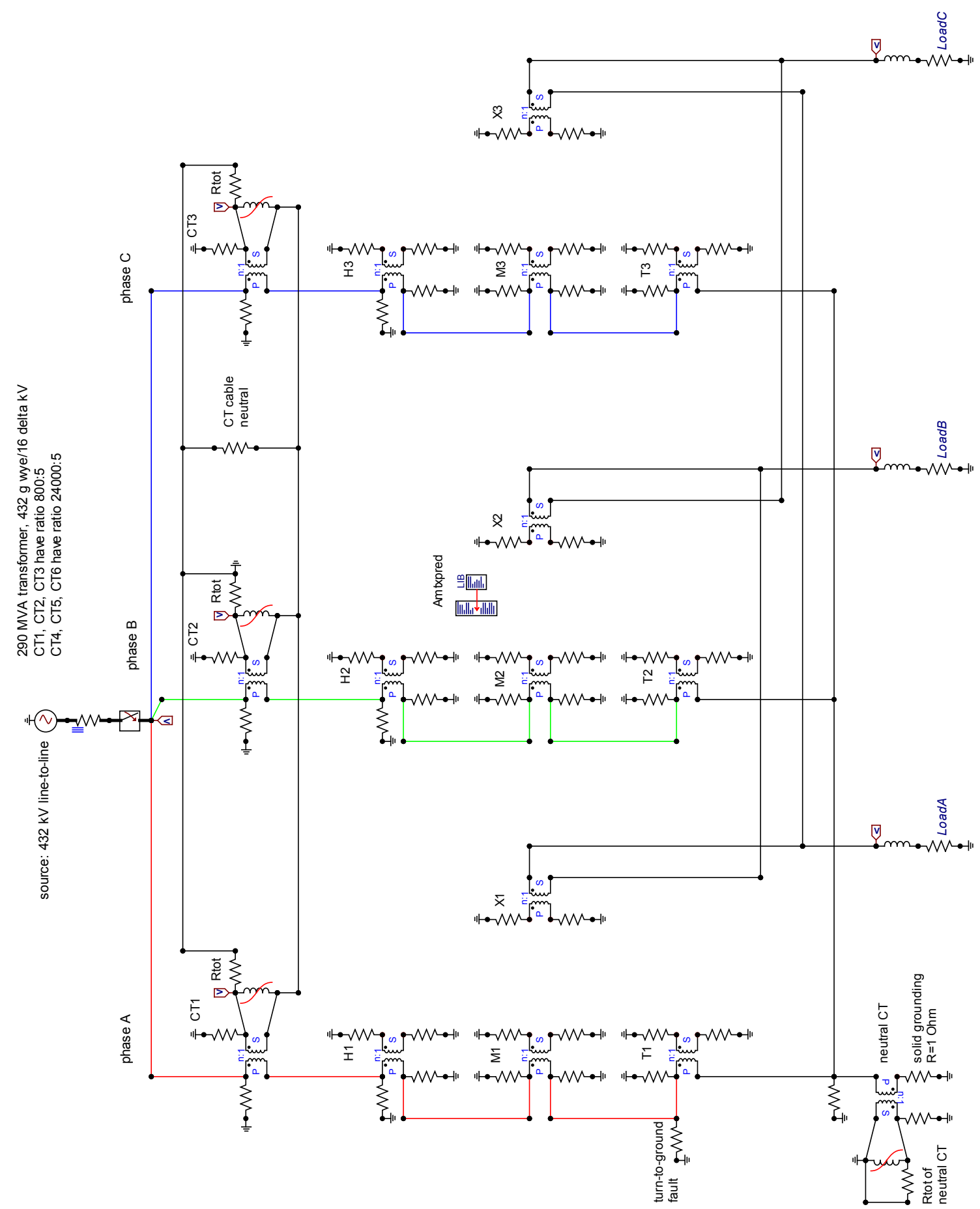

Figure B.6: ATP configuration of the 290-MVA transformer for turn-to-ground faults, solid grounding, heavy load. 


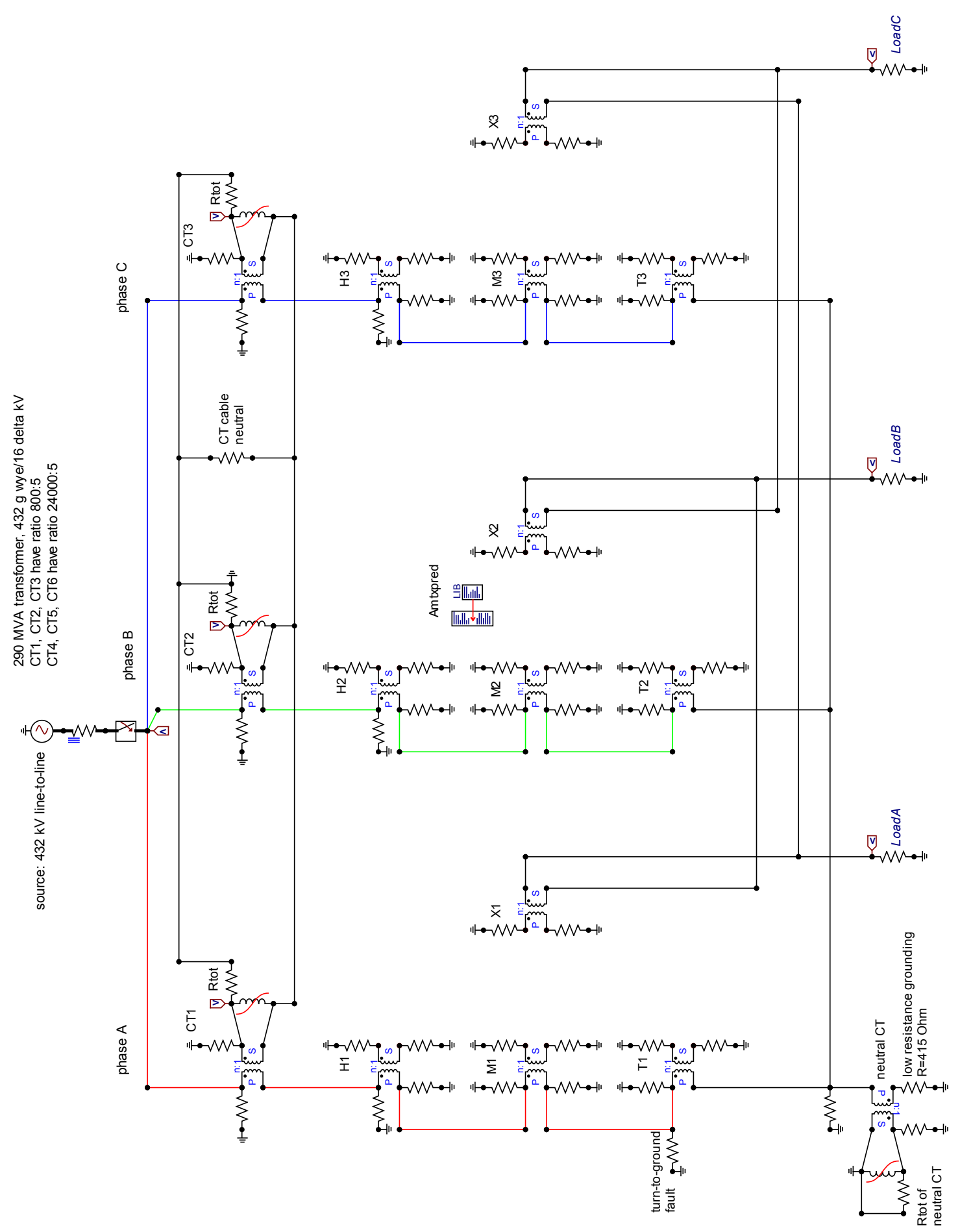

Figure B.7: ATP configuration of the 290-MVA transformer for turn-to-ground faults, low-resistance grounding, light load. 


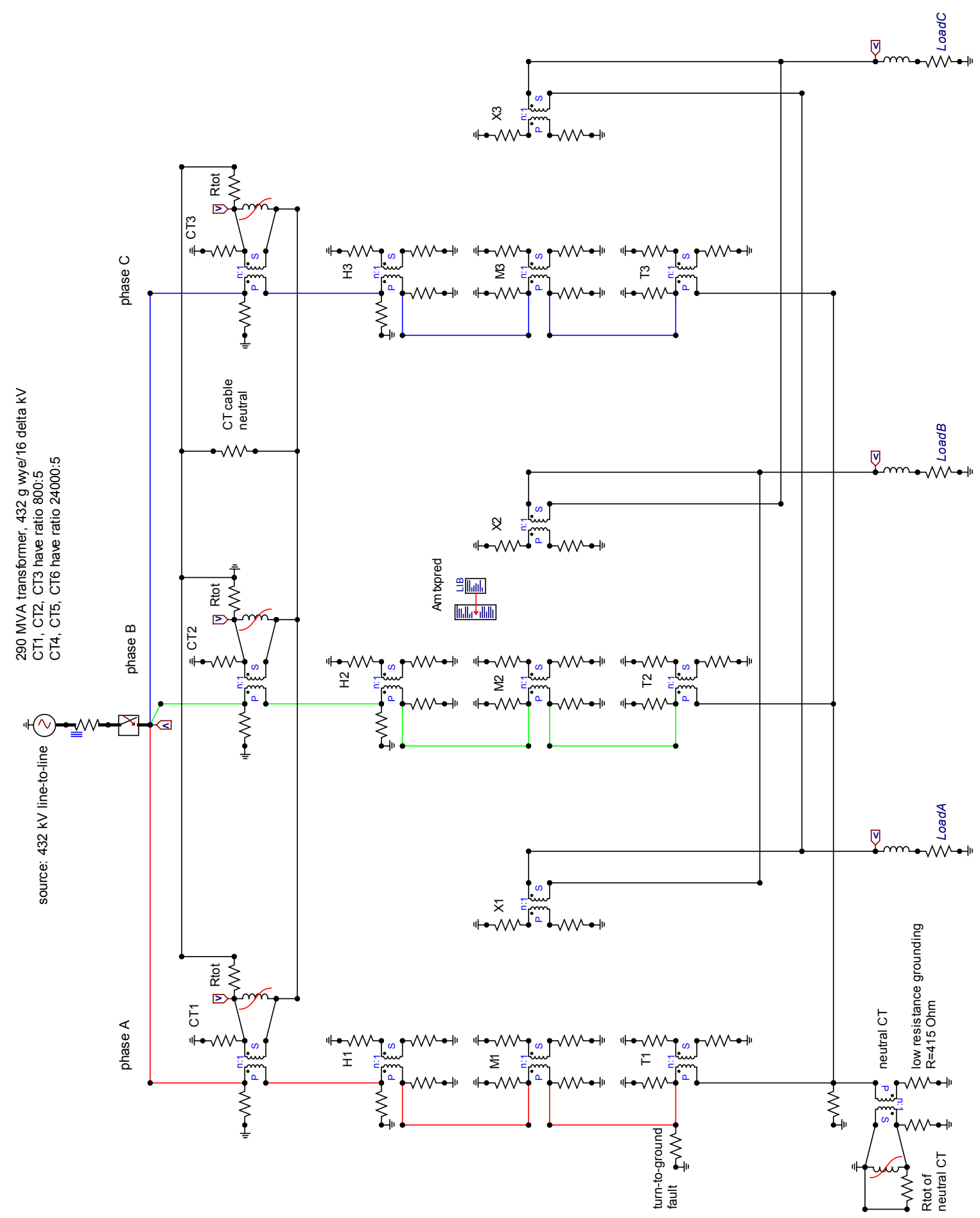

Figure B.8: ATP configuration of the 290-MVA transformer for turn-to-ground faults, low-resistance grounding, heavy load. 


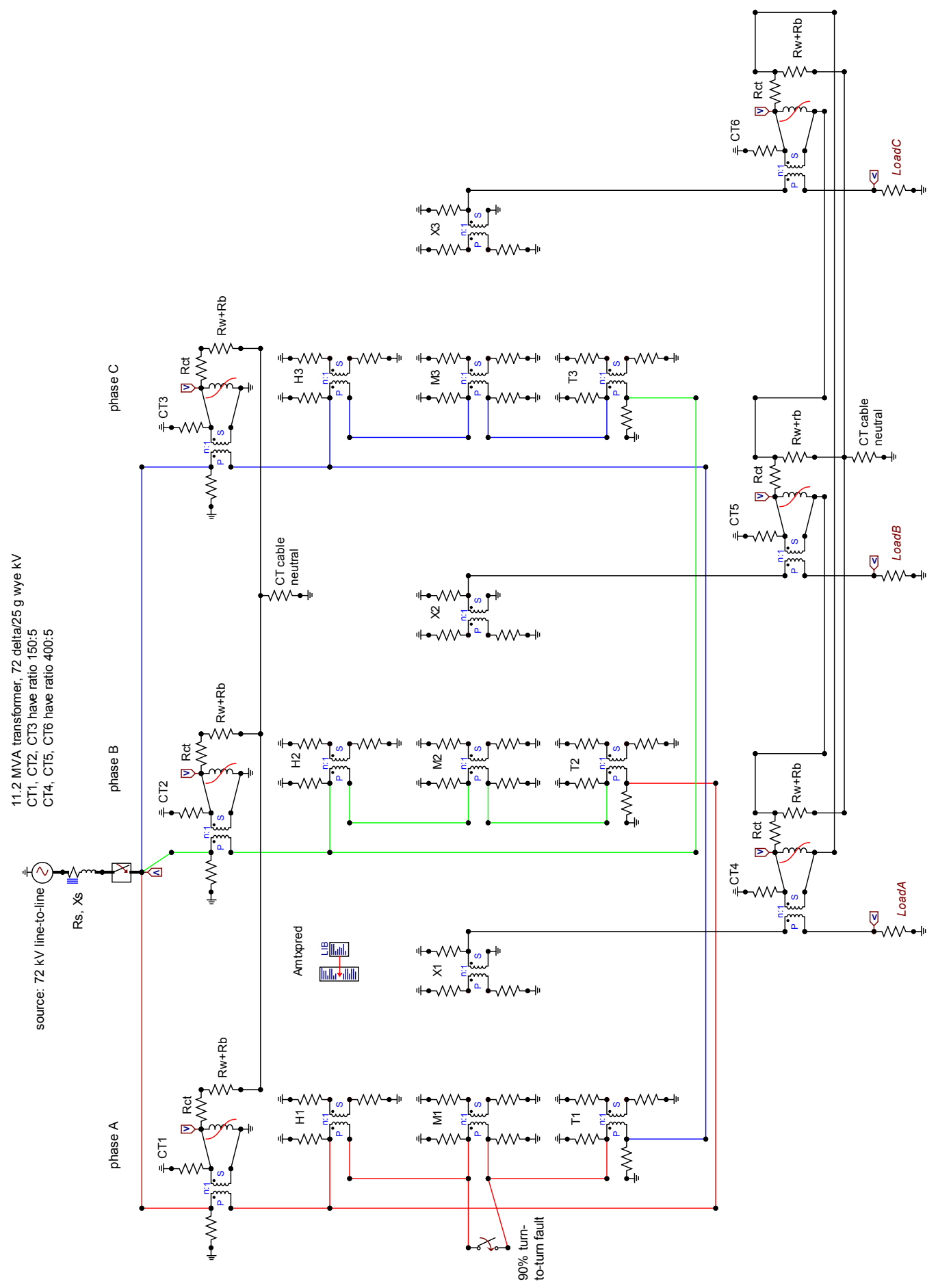

Figure B.9: ATP configuration of the 11.2-MVA transformer for CT saturation experiments, light load. 


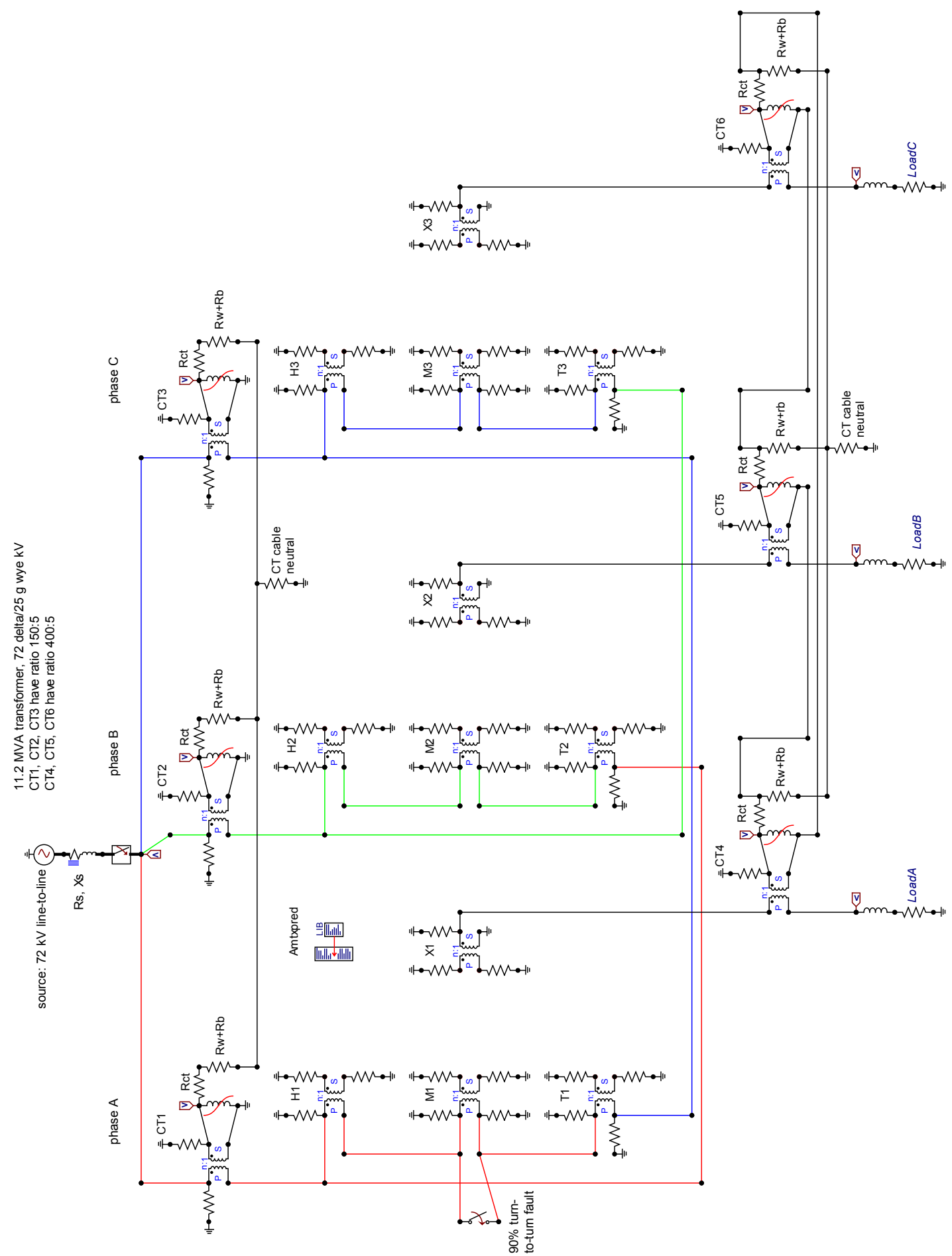

Figure B.10: ATP configuration of the 11.2-MVA transformer for CT saturation experiments, heavy load. 


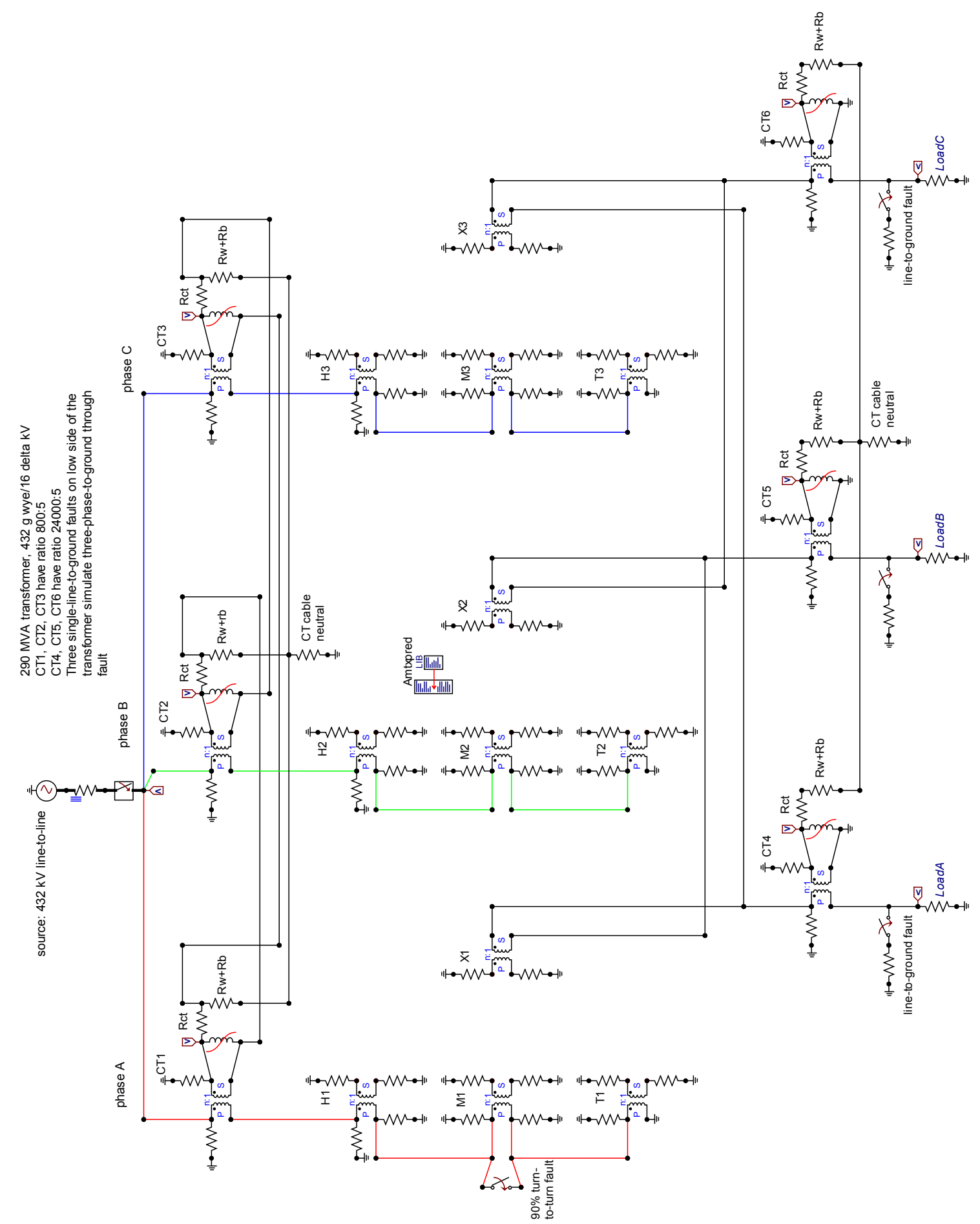

Figure B.11: ATP configuration of the 290-MVA transformer for CT saturation experiments, light load. 


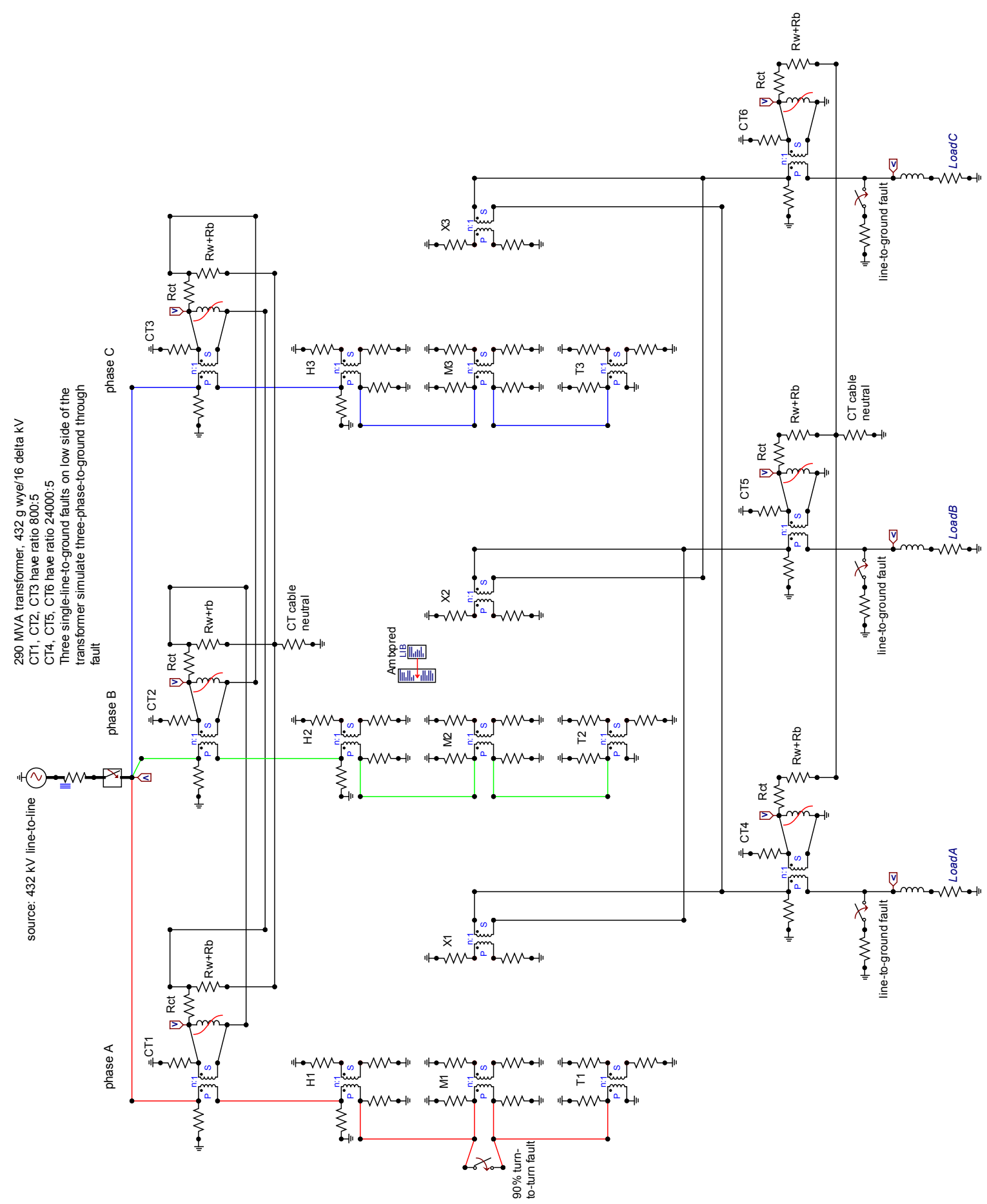

Figure B.12: ATP configuration of the 290-MVA transformer for CT saturation experiments, heavy load. 


\section{Appendix C \\ Calculations}

\section{C.1 Base impedances}

Calculations are given from the low side

1) 11.2 MVA transformer: $Z_{B}=\frac{25^{2}}{11.2}=55.8 \Omega$

2) 290 MVA transformer: $Z_{B}=\frac{16^{2}}{290}=0.8827 \Omega$

\section{C.2 Impedances of power transformers}

1) 11.2 MVA transformer

Taking per cent values from Table 3.1, transformer impedance from low side:

$$
\begin{aligned}
& R_{T}=0.00425 \times 55.8=0.237 \Omega \\
& X_{T}=0.08666 \times 55.8=4.836 \Omega
\end{aligned}
$$

2) 290 MVA transformer

Taking per cent values from Table 3.1, transformer impedance from low side:

$$
\begin{gathered}
R_{T}=0.0024 \times 0.8827=0.00212 \Omega \\
X_{T}=0.14598 \times 0.8827=0.129 \Omega
\end{gathered}
$$

\section{C.3 Load of power transformers}

1) 11.2 MVA transformer

a) Rated load, resistive, p.f. 1

$$
R_{\text {load }}=55.8-R_{T}=55.8-0.237=55.563 \Omega
$$

b) Dobled load, inductive, p.f. 0.9

$$
Z_{\text {load }}=\frac{25000 @ 0^{\circ} \mathrm{V}}{\sqrt{3} \times 515.406 @-26^{\circ} A_{\text {rms }}}=28.0046 @ 26^{\circ} \Omega
$$

From here $\mathrm{R}=25.17 \Omega, \mathrm{X}=12.276 \Omega$. However, the total load includes transformer impedance. To get the actual load, from the above calculated values, the transformer impedance should be subtracted.

Thus,

$$
\begin{aligned}
& R_{\text {load }}=25.17-0.237=24.933 \Omega, \\
& X_{\text {load }}=12.276-4.836=7.44 \Omega .
\end{aligned}
$$


2) 290 MVA transformer

a) Rated load, resistive, p.f. 1

$$
R_{\text {load }}=0.8827-R_{T}=0.8827-0.00212=0.88058 \Omega
$$

b) Doubled load, inductive, p.f. 0.9

$$
Z_{\text {load }}=\frac{16000 @ 0^{\circ} \mathrm{V}}{\sqrt{3} \times 20709.874 @-26^{\circ} A_{\text {rms }}}=0.446 @ 26^{\circ} \Omega
$$

From here $\mathrm{R}=0.401 \Omega, \mathrm{X}=0.1955 \Omega$. Again, subtracting transformer impedance, the actual load is

$$
\begin{gathered}
R_{\text {load }}=0.401-0.00212=0.3989 \Omega \\
X_{\text {load }}=0.1955-0.129=0.0665 \Omega
\end{gathered}
$$

\section{C.4 Secondary rated currents, p.f. 1}

1) 11.2 MVA transformer

$$
\begin{gathered}
I_{s e c}=\frac{25000 @ 0^{\circ} \mathrm{V}}{\sqrt{3} \times(55.563+0.237+j 4.836) \Omega}=257.703 @-5^{\circ} A_{r m s} \\
=364.448 @-5^{\circ} A_{\text {peak }}
\end{gathered}
$$

2) 290 MVA transformer

$$
\begin{gathered}
I_{\text {sec }}=\frac{16000 \mathrm{~V}}{\sqrt{3} \times(0.88058+0.00212+j 0.129) \Omega}=10354.937 @-8.3^{\circ} A_{\text {rms }} \\
=14644.092 @-8.3^{\circ} A_{\text {peak }}
\end{gathered}
$$

\section{C.5 Secondary currents at doubled load, p.f. 0.9}

1) 11.2 MVA transformer

$$
\begin{gathered}
I_{s e c}=257.703 A_{r m s} \times 2 @-26^{\circ}=515.406 @-26^{\circ} A_{r m s} \\
=728.89 @-26^{\circ} A_{\text {peak }}
\end{gathered}
$$

2) 290 MVA transformer

$$
\begin{gathered}
I_{s e c}=10354.937 A_{r m s} \times 2 @-26^{\circ}=20709.874 @-26^{\circ} A_{r m s} \\
=29288.185 @-26^{\circ} A_{\text {peak }}
\end{gathered}
$$




\section{C.6 Relay settings}

1) $11.2 \mathrm{MVA}$ transformer

$$
T A P_{S}=\frac{11.2 \times 1000}{\sqrt{3} \times 72 \times 30} \times 1=2.99 A
$$

However, the relay calculated this value as $2.94 \mathrm{~A}$. This number will be used for the O87P setting.

$$
087 P \geq \frac{0.1 \times 5}{2.94}=0.17 \text { pu tap }
$$

Thus, choose $\mathrm{O} 87 \mathrm{P}=0.18$ pu tap.

2) 290 MVA transformer

$$
T A P_{S}=\frac{290 \times 1000}{\sqrt{3} \times 432 \times 160} \times \sqrt{3}=4.2 A
$$

This number coincides with the relay calculation.

$$
\text { O87P } \geq \frac{0.1 \times 5}{4.2}=0.12 \text { pu tap }
$$

The relay did not accept $0.12 \mathrm{pu}$ tap setting and the first acceptable setting of 0.23 pu tap was utilized.

\section{C.7 Mismatch between CTs}

1) 11.2 MVA transformer

Secondary amperes $I_{H}=\frac{89.81}{30}=2.99$ at $72 \mathrm{kV}$.

Secondary amperes $I_{L}=\frac{258.65}{80}=3.23$ at $25 \mathrm{kV}$. However, at this side CTs are connected in delta which gives secondary amperes in restraint coil $3.23 \times \sqrt{3}=5.59$.

$$
M_{11.2}=100 \times \frac{\frac{2.99}{5.59}-\frac{2.94}{5.5}}{2.99 / 5.59}=0.06 \%
$$

2) 290 MVA transformer

Secondary amperes $I_{H}=\frac{387.57}{160}=2.42$ at $432 \mathrm{kV}$. However, at this side CTs are connected in delta which gives secondary amperes in restraint coil $2.42 \times \sqrt{3}=4.19$.

Secondary amperes $I_{L}=\frac{10464.47}{4800}=2.18$ at $16 \mathrm{kV}$. 


$$
M_{290}=100 \times \frac{\frac{4.19}{2.18}-\frac{4.2}{2.18}}{4.19 / 2.18}=0.24 \%
$$

\section{C.8 Source impedance $\mathrm{Zs}=5 \%$ on 100 MVA base}

1) 11.2 MVA transformer with $\mathrm{X} / \mathrm{R}=5$

$$
\begin{gathered}
Z_{\text {new }}=5 \% \times \frac{11.2}{100}=0.56 \% \\
Z_{\text {base }}=\frac{72^{2}}{11.2}=462.86 \Omega \\
Z_{\text {src }}=0.0056 \times 462.86=2.59 \Omega
\end{gathered}
$$

Which gives $\mathrm{R}_{\mathrm{src}}=0.508 \Omega$ and $\mathrm{X}_{\mathrm{src}}=2.542 \Omega$.

2) $290 \mathrm{MVA}$ transformer with $\mathrm{X} / \mathrm{R}=5$

$$
\begin{gathered}
Z_{\text {new }}=5 \% \times \frac{290}{100}=14.5 \% \\
Z_{\text {base }}=\frac{432^{2}}{290}=643.53 \Omega \\
Z_{\text {src }}=0.145 \times 643.53=93.31 \Omega
\end{gathered}
$$

Which gives $\mathrm{R}_{\text {src }}=18.299 \Omega$ and $\mathrm{X}_{\mathrm{src}}=91.495 \Omega$.

\section{C.9 Source impedance $\mathrm{Zs}_{\mathbf{s}}=1 \%$ on 100 MVA base}

11.2 MVA transformer with $\mathrm{X} / \mathrm{R}=1$

$$
\begin{gathered}
Z_{\text {new }}=1 \% \times \frac{11.2}{100}=0.112 \% \\
Z_{\text {src }}=0.00112 \times 462.86=0.5184 \Omega
\end{gathered}
$$

Which gives $\mathrm{R}_{\mathrm{src}}=0.3666 \Omega$ and $\mathrm{X}_{\mathrm{src}}=0.3666 \Omega$.

\section{C.10 Source impedance $Z_{s}=10 \%$ on 100 MVA base}

290 MVA transformer with $\mathrm{X} / \mathrm{R}=10$

$$
\begin{gathered}
Z_{\text {new }}=10 \% \times \frac{290}{100}=29 \% \\
Z_{\text {src }}=0.29 \times 643.53=186.62 \Omega
\end{gathered}
$$

Which gives $R_{\text {src }}=18.569 \Omega$ and $X_{\text {src }}=185.69 \Omega$. 


\section{Appendix D \\ $\lambda$-i characteristics of CTs used}

\section{D.1 The 11. 2-MVA transformer, $60 \mathrm{~Hz}$}

Table D.1: 600:5 CT tapped at 150:5 turns ratio.

\begin{tabular}{|c|c|c|c|}
\hline $\mathrm{V}, \mathrm{V}_{\mathrm{RMS}}$ & $\mathrm{I}, \mathrm{A}_{\mathrm{RMS}}$ & $\mathrm{I}, \mathrm{A}_{\text {peak }}$ & $\lambda, \mathrm{Wb}-\mathrm{T}_{\text {peak }}$ \\
\hline 0 & 0 & 0 & 0 \\
\hline 0.76 & 0.0088 & 0.0125 & 0.0029 \\
\hline 3.46 & 0.0299 & 0.0411 & 0.013 \\
\hline 28.54 & 0.1652 & 0.2336 & 0.1071 \\
\hline 86.85 & 0.3811 & 0.5137 & 0.3258 \\
\hline 125.38 & 0.5164 & 0.7068 & 0.4703 \\
\hline 142.95 & 0.5862 & 0.8219 & 0.5363 \\
\hline 160.95 & 0.6745 & 0.9809 & 0.6038 \\
\hline 175.75 & 0.7726 & 1.1812 & 0.6593 \\
\hline 187.15 & 0.8826 & 1.4361 & 0.7021 \\
\hline 195.83 & 1.0085 & 1.7569 & 0.7346 \\
\hline 202.59 & 1.1548 & 2.1518 & 0.76 \\
\hline 208.01 & 1.3270 & 2.6373 & 0.7803 \\
\hline 212.33 & 1.5255 & 3.2206 & 0.7965 \\
\hline 216.05 & 1.7659 & 3.9359 & 0.8105 \\
\hline 227.29 & 3.4854 & 8.7532 & 0.8529 \\
\hline
\end{tabular}

Table D.2: 600:5 CT tapped at 400:5 turns ratio.

\begin{tabular}{|c|c|c|c|}
\hline $\mathrm{V}, \mathrm{V}_{\mathrm{RMS}}$ & $\mathrm{I}, \mathrm{A}_{\mathrm{RMS}}$ & $\mathrm{I}, \mathrm{A}_{\text {peak }}$ & $\lambda, \mathrm{Wb}-\mathrm{T}_{\text {peak }}$ \\
\hline 0 & 0 & 0 & 0 \\
\hline 1.75 & 0.0021 & 0.0029 & 0.0066 \\
\hline 15.88 & 0.0108 & 0.0149 & 0.0596 \\
\hline 54.59 & 0.0294 & 0.0403 & 0.2048 \\
\hline 124.54 & 0.0557 & 0.0754 & 0.4672 \\
\hline 283.54 & 0.0964 & 0.1271 & 1.0636 \\
\hline 427.05 & 0.1328 & 0.1805 & 1.602 \\
\hline 501.84 & 0.1615 & 0.2373 & 1.8826 \\
\hline 547.15 & 0.1952 & 0.322 & 2.0525 \\
\hline 570.43 & 0.2343 & 0.4476 & 2.1399 \\
\hline 584.18 & 0.2836 & 0.6223 & 2.1914 \\
\hline 593.79 & 0.3482 & 0.8539 & 2.2275 \\
\hline 601.37 & 0.4315 & 1.1423 & 2.2559 \\
\hline 607.11 & 0.5387 & 1.5527 & 2.2775 \\
\hline 611.98 & 0.6730 & 2.0275 & 2.2957 \\
\hline 616.79 & 0.8439 & 2.5767 & 2.3138 \\
\hline 629.58 & 1.6495 & 5.1251 & 2.3618 \\
\hline 636.23 & 2.3341 & 7.4205 & 2.3867 \\
\hline
\end{tabular}




\section{D.2 The 290-MVA transformer, $50 \mathrm{~Hz}$}

Table D.3: 1200:5 CT tapped at 800:5 turns ratio.

\begin{tabular}{|c|c|c|c|c|}
\hline Voltage, $\mathrm{V}_{\mathrm{RMS}}$ & $\mathrm{I}_{\mathrm{E} 60}, \mathrm{~A}_{\mathrm{RMS}}$ & $\mathrm{I}_{\mathrm{E} 50}, \mathrm{~A}_{\mathrm{RMS}}$ & $\mathrm{I}, \mathrm{A}_{\text {peak }}$ & $\lambda, \mathrm{Wb}-\mathrm{T}_{\text {peak }}$ \\
\hline 0 & 0 & 0 & 0 & 0 \\
\hline 0.25 & 0.0010 & 0.0012 & 0.0017 & 0.0001 \\
\hline 100 & 0.0650 & 0.0761 & 0.1072 & 0.4502 \\
\hline 250 & 0.1300 & 0.1521 & 0.2044 & 1.1254 \\
\hline 300 & 0.1450 & 0.1697 & 0.2191 & 1.3505 \\
\hline 350 & 0.1750 & 0.2048 & 0.3027 & 1.5756 \\
\hline 500 & 0.3000 & 0.3510 & 0.5367 & 2.2508 \\
\hline 525 & 0.3500 & 0.4095 & 0.7299 & 2.3633 \\
\hline 550 & 0.4500 & 0.5265 & 1.0619 & 2.4759 \\
\hline 575 & 0.6000 & 0.7020 & 1.4819 & 2.5884 \\
\hline 600 & 1.0000 & 1.1700 & 2.8952 & 2.7009 \\
\hline 625 & 2.5000 & 2.9250 & 8.2264 & 2.8135 \\
\hline 650 & 5.0000 & 5.8500 & 15.5208 & 2.9260 \\
\hline 700 & 20.0000 & 23.4000 & 60.1377 & 3.1511 \\
\hline
\end{tabular}

Table D.4: 24000:5 CT.

\begin{tabular}{|c|c|c|c|c|}
\hline Voltage, $\mathrm{V}_{\mathrm{RMS}}$ & $\mathrm{I}_{\mathrm{E} 60}, \mathrm{~A}_{\mathrm{RMS}}$ & $\mathrm{I}_{\mathrm{E} 50}, \mathrm{~A}_{\mathrm{RMS}}$ & $\mathrm{I}, \mathrm{A}_{\text {peak }}$ & $\lambda, \mathrm{Wb}-\mathrm{T}_{\text {peak }}$ \\
\hline 0 & 0 & 0 & 0 & 0 \\
\hline 400 & 3.3000 & 3.8610 & 5.4603 & 1.8006 \\
\hline 800 & 5.8000 & 6.7860 & 9.2121 & 3.6013 \\
\hline 1200 & 13.9000 & 16.2630 & 26.913 & 5.4019 \\
\hline 1400 & 38.2000 & 44.6940 & 93.6638 & 6.3022 \\
\hline
\end{tabular}

Table D.5: 600:5 CT tapped at 150:5 turns ratio.

\begin{tabular}{|c|c|c|c|c|}
\hline Voltage, $\mathrm{V}_{\mathrm{RMS}}$ & $\mathrm{I}_{\mathrm{E} 60}, \mathrm{~A}_{\mathrm{RMS}}$ & $\mathrm{I}_{\mathrm{E} 50}, \mathrm{~A}_{\mathrm{RMS}}$ & $\mathrm{I}, \mathrm{A}_{\text {peak }}$ & $\lambda, \mathrm{Wb}-\mathrm{T}_{\text {peak }}$ \\
\hline 0 & 0 & 0 & 0 & 0 \\
\hline 86.85 & 0.3810 & 0.4459 & 0.6303 & 0.3910 \\
\hline 125.38 & 0.5164 & 0.6042 & 0.8212 & 0.5644 \\
\hline 160.95 & 0.6745 & 0.7892 & 1.1378 & 0.7245 \\
\hline 175.75 & 0.7726 & 0.9039 & 1.384 & 0.7912 \\
\hline 187.15 & 0.8826 & 1.0326 & 1.6793 & 0.8425 \\
\hline 195.83 & 1.0085 & 1.1799 & 2.0557 & 0.8815 \\
\hline 202.59 & 1.1548 & 1.3511 & 2.5177 & 0.9120 \\
\hline 208.01 & 1.3270 & 1.5526 & 3.0858 & 0.9364 \\
\hline 212.33 & 1.5255 & 1.7848 & 3.7679 & 0.9558 \\
\hline 216.05 & 1.7659 & 2.0661 & 4.6052 & 0.9726 \\
\hline 2218.94 & 2.0218 & 2.3655 & 5.5243 & 0.9856 \\
\hline 227.29 & 3.4854 & 4.0779 & 10.4921 & 1.0232 \\
\hline
\end{tabular}




\section{Appendix E \\ Complete tables with results}

\section{E.1 Negative-sequence differential element sensititvity}

Table E.1: Negative-sequence differential element sensitivity for the 11.2-MVA transformer, light load.

\begin{tabular}{|c|c|c|c|c|c|}
\hline Transformer & $87 \mathrm{QP}$, pu tap & 87QP slope, \% & $\begin{array}{l}\text { Shorted winding } \\
\text { percentage, } \%\end{array}$ & $\begin{array}{l}\text { Element } \\
\text { asserted }\end{array}$ & $\begin{array}{l}3 \mathrm{I}_{2}, \mathrm{~A}_{\mathrm{RMS} \text { pri }} \text { S-winding } \\
\text { (calculated from Event } \\
\text { Summary data) }\end{array}$ \\
\hline \multirow{49}{*}{ 11.2 MVA } & \multirow{9}{*}{0.05} & 5 & 0.3 & $87 \mathrm{Q}$ & \multirow{5}{*}{ 5.409@-75.95 } \\
\hline & & 25 & 0.3 & $87 \mathrm{Q}$ & \\
\hline & & 50 & 0.3 & $87 \mathrm{Q}$ & \\
\hline & & 75 & 0.3 & $87 \mathrm{Q}$ & \\
\hline & & 80 & 0.3 & $87 \mathrm{Q}$ & \\
\hline & & 85 & 0.4 & $87 \mathrm{Q}$ & \multirow{2}{*}{ 9.258@-73.22 } \\
\hline & & 90 & 0.4 & $87 \mathrm{Q}$ & \\
\hline & & 95 & 0.6 & $87 \mathrm{Q}$ & $19.004 @-83.41^{\circ}$ \\
\hline & & 100 & 2.3 & $87 \mathrm{RA}$ & $130.972 @-81.56^{\circ}$ \\
\hline & \multirow{3}{*}{0.06} & 5 & 0.3 & $87 \mathrm{Q}$ & $5.409 @-75.95^{\circ}$ \\
\hline & & 95 & 0.6 & $87 \mathrm{Q}$ & $19.004 @-83.41^{\circ}$ \\
\hline & & 100 & 2.3 & $87 \mathrm{RA}$ & $130.972 @-81.56^{\circ}$ \\
\hline & \multirow{3}{*}{0.07} & 5 & 0.4 & $87 \mathrm{Q}$ & $9.258 @-73.22^{\circ}$ \\
\hline & & 95 & 0.6 & $87 \mathrm{Q}$ & $19.004 @-83.41^{\circ}$ \\
\hline & & 100 & 2.3 & $87 \mathrm{RA}$ & $130.972 @-81.56^{\circ}$ \\
\hline & \multirow{3}{*}{0.08} & 5 & 0.4 & $87 \mathrm{Q}$ & $9.258 @-73.22^{\circ}$ \\
\hline & & 95 & 0.6 & $87 \mathrm{Q}$ & $19.004 @-83.41^{\circ}$ \\
\hline & & 100 & 2.3 & 87RA & $130.972 @-81.56^{\circ}$ \\
\hline & \multirow{3}{*}{0.09} & 5 & 0.4 & $87 \mathrm{Q}$ & $9.258 @-73.22^{\circ}$ \\
\hline & & 95 & 0.6 & $87 \mathrm{Q}$ & $19.004 @-83.41^{\circ}$ \\
\hline & & 100 & 2.3 & $87 \mathrm{RA}$ & $130.972 @-81.56^{\circ}$ \\
\hline & \multirow{10}{*}{0.1} & 5 & 0.4 & $87 \mathrm{Q}$ & \multirow{8}{*}{$9.258 @-73.22^{\circ}$} \\
\hline & & 15 & 0.4 & $87 \mathrm{Q}$ & \\
\hline & & 25 & 0.4 & $87 Q$ & \\
\hline & & 50 & 0.4 & $87 Q$ & \\
\hline & & 75 & 0.4 & $87 \mathrm{Q}$ & \\
\hline & & 80 & 0.4 & $87 \mathrm{Q}$ & \\
\hline & & 85 & 0.4 & $87 \mathrm{Q}$ & \\
\hline & & 90 & 0.4 & $87 \mathrm{Q}$ & \\
\hline & & 95 & 0.6 & $87 \mathrm{Q}$ & $19.004 @-83.41^{\circ}$ \\
\hline & & 100 & 2.3 & 87RA & $130.972 @-81.56^{\circ}$ \\
\hline & \multirow{3}{*}{0.11} & 5 & 0.5 & $87 \mathrm{Q}$ & $13.805 @-79.8^{\circ}$ \\
\hline & & 95 & 0.6 & $87 \mathrm{Q}$ & $19.004 @-83.41^{\circ}$ \\
\hline & & 100 & 2.3 & 87RA & $130.972 @-81.56^{\circ}$ \\
\hline & \multirow{3}{*}{0.12} & 5 & 0.5 & $87 \mathrm{Q}$ & $13.805 @-79.8^{\circ}$ \\
\hline & & 95 & 0.6 & $87 \mathrm{Q}$ & $19.004 @-83.41^{\circ}$ \\
\hline & & 100 & 2.3 & 87RA & $130.972 @-81.56^{\circ}$ \\
\hline & \multirow{3}{*}{0.13} & 5 & 0.5 & $87 \mathrm{Q}$ & $13.805 @-79.8^{\circ}$ \\
\hline & & 95 & 0.6 & $87 \mathrm{Q}$ & $19.004 @-83.41^{\circ}$ \\
\hline & & 100 & 2.3 & 87RA & $130.972 @-81.56^{\circ}$ \\
\hline & \multirow{3}{*}{0.14} & 5 & 0.5 & $87 \mathrm{Q}$ & $13.805 @-79.8^{\circ}$ \\
\hline & & 95 & 0.6 & $87 \mathrm{Q}$ & $19.004 @-83.41^{\circ}$ \\
\hline & & 100 & 2.3 & $87 \mathrm{RA}$ & $130.972 @-81.56^{\circ}$ \\
\hline & \multirow{3}{*}{0.15} & 5 & 0.5 & $87 \mathrm{Q}$ & $13.805 @-79.8^{\circ}$ \\
\hline & & 95 & 0.6 & $87 \mathrm{Q}$ & 19.004@-83.41 \\
\hline & & 100 & 2.3 & 87RA & $130.972 @-81.56^{\circ}$ \\
\hline & \multirow{3}{*}{0.2} & 5 & 0.6 & $87 \mathrm{Q}$ & \multirow{2}{*}{$19.004 @-83.41^{\circ}$} \\
\hline & & 95 & 0.6 & $87 \mathrm{Q}$ & \\
\hline & & 100 & 2.3 & $87 \mathrm{RA}$ & $130.972 @-81.56^{\circ}$ \\
\hline
\end{tabular}




\begin{tabular}{|c|c|c|c|c|}
\hline \multirow{3}{*}{0.25} & 5 & 0.7 & $87 \mathrm{Q}$ & \multirow{2}{*}{ 24.334@-85.69 } \\
\hline & 95 & 0.7 & $87 \mathrm{Q}$ & \\
\hline & 100 & 2.3 & 87RA & $130.972 @-81.56^{\circ}$ \\
\hline \multirow{3}{*}{0.3} & 5 & 0.8 & $87 \mathrm{Q}$ & \multirow{2}{*}{ 31.007@-85.86 } \\
\hline & 95 & 0.8 & $87 \mathrm{Q}$ & \\
\hline & 100 & 2.3 & 87RA & $130.972 @-81.56^{\circ}$ \\
\hline \multirow{3}{*}{0.4} & 5 & 0.9 & $87 \mathrm{Q}$ & \multirow{2}{*}{ 36.836@-86.94 } \\
\hline & 95 & 0.9 & $87 Q$ & \\
\hline & 100 & 2.3 & 87RA & 130.972@-81.56 \\
\hline \multirow{3}{*}{0.5} & 5 & 1.1 & $87 Q$ & \multirow{2}{*}{ 49.840@-88.05 } \\
\hline & 95 & 1.1 & $87 \mathrm{Q}$ & \\
\hline & 100 & 2.3 & 87RA & $130.972 @-81.56^{\circ}$ \\
\hline \multirow{3}{*}{0.6} & 5 & 1.2 & $87 Q$ & \multirow{2}{*}{$56.947 @-88.44^{\circ}$} \\
\hline & 95 & 1.2 & $87 \mathrm{Q}$ & \\
\hline & 100 & 2.3 & 87RA & $130.972 @-81.56^{\circ}$ \\
\hline \multirow{3}{*}{0.7} & 5 & 1.3 & $87 Q$ & \multirow{2}{*}{ 63.074@-88.14 } \\
\hline & 95 & 1.3 & $87 Q$ & \\
\hline & 100 & 2.3 & 87RA & $130.972 @-81.56^{\circ}$ \\
\hline \multirow{3}{*}{0.8} & 5 & 1.5 & $87 Q$ & \multirow{2}{*}{ 76.705@-88.27인 } \\
\hline & 95 & 1.5 & $87 \mathrm{Q}$ & \\
\hline & 100 & 2.3 & 87RA & $130.972 @-81.56^{\circ}$ \\
\hline \multirow{3}{*}{0.9} & 5 & 1.6 & $87 \mathrm{Q}$ & \multirow{2}{*}{ 84.122@-87.79 } \\
\hline & 95 & 1.6 & $87 \mathrm{Q}$ & \\
\hline & 100 & 2.3 & 87RA & $130.972 @-81.56^{\circ}$ \\
\hline \multirow{14}{*}{1.0} & 5 & 1.7 & $87 \mathrm{Q}$ & \multirow{12}{*}{ 90.446@-87.15 } \\
\hline & 15 & 1.7 & $87 \mathrm{Q}$ & \\
\hline & 25 & 1.7 & $87 \mathrm{Q}$ & \\
\hline & 50 & 1.7 & $87 \mathrm{Q}$ & \\
\hline & 75 & 1.7 & $87 \mathrm{Q}$ & \\
\hline & 80 & 1.7 & $87 \mathrm{Q}$ & \\
\hline & 85 & 1.7 & $87 \mathrm{Q}$ & \\
\hline & 90 & 1.7 & $87 \mathrm{Q}$ & \\
\hline & 95 & 1.7 & $87 \mathrm{Q}$ & \\
\hline & 96 & 1.7 & $87 \mathrm{Q}$ & \\
\hline & 97 & 1.7 & $87 \mathrm{Q}$ & \\
\hline & 98 & 1.7 & $87 \mathrm{Q}$ & \\
\hline & 99 & 1.8 & $87 Q$ & 96.953@-85.74 \\
\hline & 100 & 2.3 & 87RA & $130.972 @-81.56^{\circ}$ \\
\hline lisabled & N/A & 2.3 & 87RA & $130.972 @-81.56^{\circ}$ \\
\hline
\end{tabular}


Table E.2: Negative-sequence differential element sensitivity for the 290-MVA transformer, light load.

\begin{tabular}{|c|c|c|c|c|c|}
\hline Transformer & 87QP, pu tap & 87QP slope, \% & $\begin{array}{l}\text { Shorted winding } \\
\text { percentage, } \%\end{array}$ & $\begin{array}{l}\text { Element } \\
\text { asserted }\end{array}$ & $\begin{array}{c}3 \mathrm{I}_{2}, \mathrm{~A}_{\mathrm{RMS} \text { pri }} \mathrm{S} \text {-winding } \\
\text { (calculated from Event } \\
\text { Summary data) } \\
\end{array}$ \\
\hline \multirow{58}{*}{290 MVA } & \multirow{9}{*}{0.05} & 5 & 0.4 & $87 Q$ & \multirow{5}{*}{ 21.717@-22.43 } \\
\hline & & 25 & 0.4 & $87 Q$ & \\
\hline & & 50 & 0.4 & $87 \mathrm{Q}$ & \\
\hline & & 75 & 0.4 & $87 \mathrm{Q}$ & \\
\hline & & 80 & 0.4 & $87 \mathrm{Q}$ & \\
\hline & & 85 & 0.6 & $87 Q$ & $32.704 @-19.15^{\circ}$ \\
\hline & & 90 & 0.8 & $87 Q$ & 42.872@-18.62ํ․ \\
\hline & & 95 & 1.6 & $87 Q$ & $85.847 @-16.06^{\circ}$ \\
\hline & & 100 & 7.6 & $87 \mathrm{RB}$ & 437.302@-1.21 \\
\hline & \multirow{3}{*}{0.06} & 5 & 0.5 & $87 Q$ & 26.783@-21.73 \\
\hline & & 95 & 1.6 & $87 Q$ & 85.847@-16.06 \\
\hline & & 100 & 7.6 & $87 \mathrm{RB}$ & 437.302@-1.21․ \\
\hline & \multirow{3}{*}{0.07} & 5 & 0.6 & $87 Q$ & $32.704 @-19.15^{\circ}$ \\
\hline & & 95 & 1.6 & $87 Q$ & $85.847 @-16.06^{\circ}$ \\
\hline & & 100 & 7.6 & $87 \mathrm{RB}$ & 437.302@-1.21임 \\
\hline & \multirow{3}{*}{0.08} & 5 & 0.6 & $87 Q$ & $32.704 @-19.15^{\circ}$ \\
\hline & & 95 & 1.6 & $87 \mathrm{Q}$ & $85.847 @-16.06^{\circ}$ \\
\hline & & 100 & 7.6 & $87 \mathrm{RB}$ & $437.302 @-1.21^{\circ}$ \\
\hline & \multirow{3}{*}{0.09} & 5 & 0.7 & $87 Q$ & $37.788 @-18.85^{\circ}$ \\
\hline & & 95 & 1.6 & $87 \mathrm{Q}$ & $85.847 @-16.06^{\circ}$ \\
\hline & & 100 & 7.6 & $87 \mathrm{RB}$ & 437.302@-1.21․ \\
\hline & \multirow{10}{*}{0.1} & 5 & 0.8 & $87 Q$ & \multirow{8}{*}{ 42.872@-18.62 } \\
\hline & & 15 & 0.8 & $87 \mathrm{Q}$ & \\
\hline & & 25 & 0.8 & $87 Q$ & \\
\hline & & 50 & 0.8 & $87 \mathrm{Q}$ & \\
\hline & & 75 & 0.8 & $87 \mathrm{Q}$ & \\
\hline & & 80 & 0.8 & $87 Q$ & \\
\hline & & 85 & 0.8 & $87 \mathrm{Q}$ & \\
\hline & & 90 & 0.8 & $87 \mathrm{Q}$ & \\
\hline & & 95 & 1.6 & $87 Q$ & 85.847@-16.06 \\
\hline & & 100 & 7.6 & $87 \mathrm{RB}$ & 437.302@-1.21․ \\
\hline & \multirow{3}{*}{0.11} & 5 & 0.8 & $87 \mathrm{Q}$ & 42.872@-18.62 \\
\hline & & 95 & 1.6 & $87 \mathrm{Q}$ & $85.847 @-16.06^{\circ}$ \\
\hline & & 100 & 7.6 & $87 \mathrm{RB}$ & 437.302@-1.21 \\
\hline & \multirow{3}{*}{0.12} & 5 & 0.9 & $87 Q$ & 47.956@-18.43 \\
\hline & & 95 & 1.6 & $87 \mathrm{Q}$ & 85.847@-16.06 \\
\hline & & 100 & 7.6 & $87 \mathrm{RB}$ & 437.302@-1.21잉 \\
\hline & \multirow{3}{*}{0.13} & 5 & 1.0 & $87 Q$ & $56.79 @-17.93^{\circ}$ \\
\hline & & 95 & 1.6 & $87 \mathrm{Q}$ & 85.847@-16.06 \\
\hline & & 100 & 7.6 & $87 \mathrm{RB}$ & 437.302@-1.21ํ. \\
\hline & \multirow{3}{*}{0.14} & 5 & 1.1 & $87 Q$ & 59.244@-17.75 \\
\hline & & 95 & 1.6 & $87 Q$ & $85.847 @-16.06^{\circ}$ \\
\hline & & 100 & 7.6 & $87 \mathrm{RB}$ & 437.302@-1.21ํ. \\
\hline & \multirow{3}{*}{0.15} & 5 & 1.1 & $87 Q$ & 59.244@-17.75 \\
\hline & & 95 & 1.6 & $87 Q$ & $85.847 @-16.06^{\circ}$ \\
\hline & & 100 & 7.6 & $87 \mathrm{RB}$ & 437.302@-1.21ํ․ \\
\hline & \multirow{3}{*}{0.2} & 5 & 1.5 & $87 \mathrm{Q}$ & 81.226@-15.73 \\
\hline & & 95 & 1.7 & $87 Q$ & 92.069@-15.85 \\
\hline & & 100 & 7.6 & $87 \mathrm{RB}$ & 437.302@-1.21임 \\
\hline & \multirow{3}{*}{0.25} & 5 & 1.8 & $87 Q$ & \multirow{2}{*}{ 97.624@-15.59 } \\
\hline & & 95 & 1.8 & $87 Q$ & \\
\hline & & 100 & 7.6 & $87 \mathrm{RB}$ & 437.302@-1.21ํ. \\
\hline & & 5 & 1.9 & $87 Q$ & $102963 \Omega 1421^{\circ}$ \\
\hline & 0.26 & 95 & 1.9 & $87 Q$ & $102.905 \omega-14.21$ \\
\hline & & 100 & 7.6 & $87 \mathrm{RB}$ & 437.302@-1.21ํ․ \\
\hline & & 5 & 2.0 & $87 \mathrm{Q}$ & \\
\hline & 0.27 & 95 & 2.0 & $87 Q$ & 108.505@-14.59 \\
\hline & & 100 & 7.6 & $87 \mathrm{RB}$ & 437.302@-1.21ํ․ \\
\hline
\end{tabular}




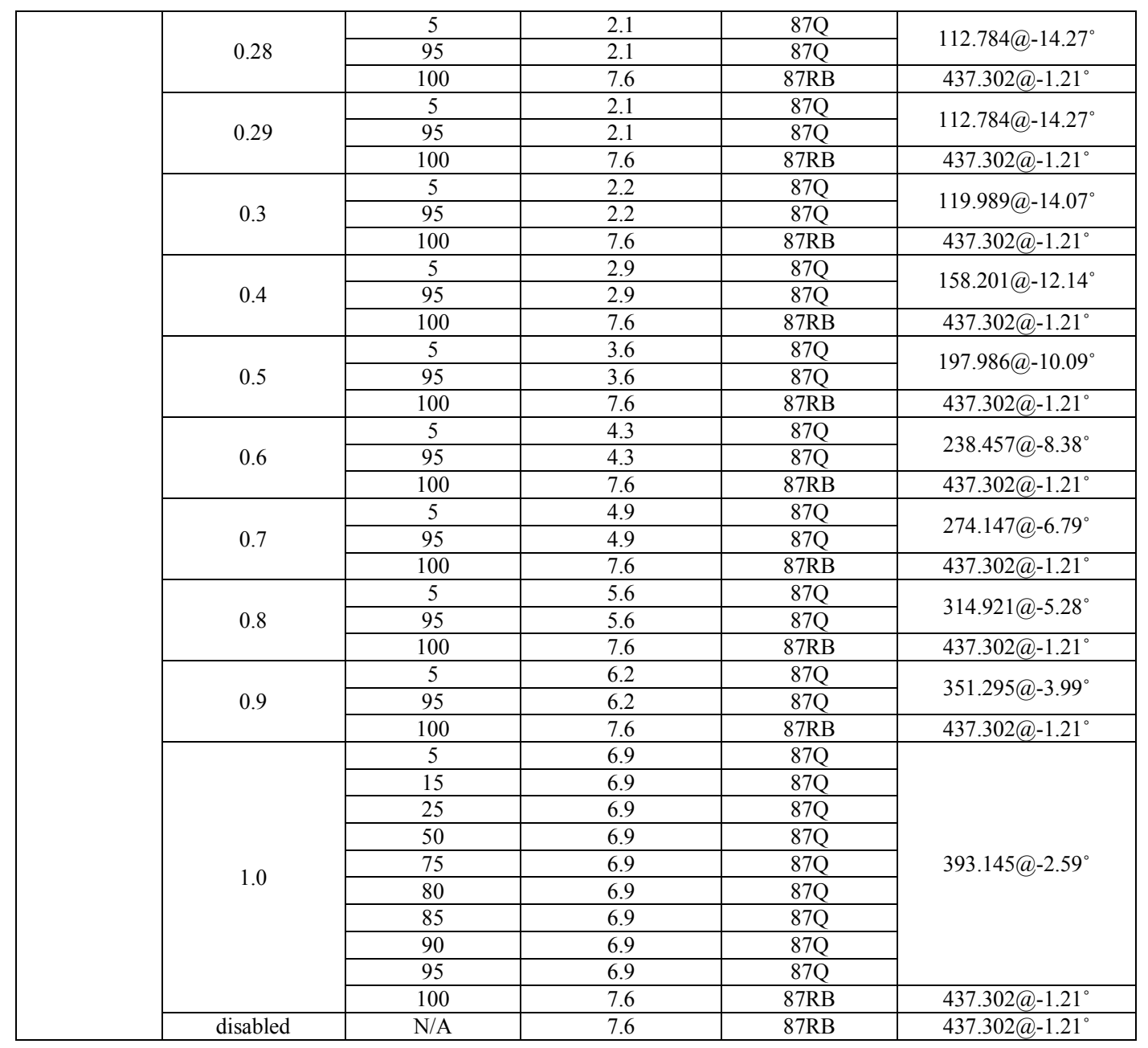


Table E.3: Negative-sequence differential element sensitivity for the 11.2-MVA transformer, heavy load.

\begin{tabular}{|c|c|c|c|c|c|}
\hline Transformer & 87QP, pu tap & 87QP slope, \% & $\begin{array}{l}\text { Shorted winding } \\
\text { percentage, } \%\end{array}$ & $\begin{array}{l}\text { Element } \\
\text { asserted }\end{array}$ & $\begin{array}{c}3 \mathrm{I}_{2}, \mathrm{~A}_{\mathrm{RMS} \text { pri }} \mathrm{S} \text {-winding } \\
\text { (calculated from Event } \\
\text { Summary data) }\end{array}$ \\
\hline \multirow{58}{*}{ 11.2 MVA } & \multirow{9}{*}{0.05} & 5 & 0.3 & $87 Q$ & \multirow{5}{*}{ 5.904@-56.3 } \\
\hline & & 25 & 0.3 & $87 Q$ & \\
\hline & & 50 & 0.3 & $87 \mathrm{Q}$ & \\
\hline & & 75 & 0.3 & $87 Q$ & \\
\hline & & 80 & 0.3 & $87 Q$ & \\
\hline & & 85 & 0.4 & $87 Q$ & \multirow{2}{*}{ 9.679@-61.15 } \\
\hline & & 90 & 0.4 & $87 \mathrm{Q}$ & \\
\hline & & 95 & 0.6 & $87 Q$ & $19.839 @-68.13^{\circ}$ \\
\hline & & 100 & 4.5 & 87RA & $282.533 @-76.13^{\circ}$ \\
\hline & \multirow{3}{*}{0.06} & 5 & 0.3 & $87 \mathrm{Q}$ & $5.904 @-56.3^{\circ}$ \\
\hline & & 95 & 0.6 & $87 Q$ & 19.839@-68.13 \\
\hline & & 100 & 4.5 & $87 \mathrm{RA}$ & $282.533 @-76.13^{\circ}$ \\
\hline & \multirow{3}{*}{0.07} & 5 & 0.4 & $87 \mathrm{Q}$ & $9.679 @-61.15^{\circ}$ \\
\hline & & 95 & 0.6 & $87 \mathrm{Q}$ & $19.839 @-68.13^{\circ}$ \\
\hline & & 100 & 4.5 & $87 \mathrm{RA}$ & $282.533 @-76.13^{\circ}$ \\
\hline & \multirow{3}{*}{0.08} & 5 & 0.4 & $87 Q$ & $9.679 @-61.15^{\circ}$ \\
\hline & & 95 & 0.6 & $87 Q$ & $19.839 @-68.13^{\circ}$ \\
\hline & & 100 & 4.5 & 87RA & 282.533@-76.13 \\
\hline & \multirow{3}{*}{0.09} & 5 & 0.4 & $87 Q$ & 9.679@-61.15 \\
\hline & & 95 & 0.6 & $87 Q$ & $19.839 @-68.13^{\circ}$ \\
\hline & & 100 & 4.5 & 87RA & $282.533 @-76.13^{\circ}$ \\
\hline & \multirow{10}{*}{0.1} & 5 & 0.4 & $87 \mathrm{Q}$ & \multirow{8}{*}{ 9.679@-61.15 } \\
\hline & & 15 & 0.4 & $87 Q$ & \\
\hline & & 25 & 0.4 & $87 Q$ & \\
\hline & & 50 & 0.4 & $87 Q$ & \\
\hline & & 75 & 0.4 & $87 \mathrm{Q}$ & \\
\hline & & 80 & 0.4 & $87 Q$ & \\
\hline & & 85 & 0.4 & $87 \mathrm{Q}$ & \\
\hline & & 90 & 0.4 & $87 \mathrm{Q}$ & \\
\hline & & 95 & 0.6 & $87 \mathrm{Q}$ & 19.839@-68.13 \\
\hline & & 100 & 4.5 & 87RA & $282.533 @-76.13^{\circ}$ \\
\hline & \multirow{3}{*}{0.11} & 5 & 0.5 & $87 \mathrm{Q}$ & 14.664@-64.73ํ․ \\
\hline & & 95 & 0.6 & $87 \mathrm{Q}$ & $19.839 @-68.13^{\circ}$ \\
\hline & & 100 & 4.5 & 87RA & $282.533 @-76.13^{\circ}$ \\
\hline & \multirow{3}{*}{0.12} & 5 & 0.5 & $87 Q$ & 14.664@-64.73 \\
\hline & & 95 & 0.6 & $87 \mathrm{Q}$ & 19.839@-68.13 \\
\hline & & 100 & 4.5 & 87RA & $282.533 @-76.13^{\circ}$ \\
\hline & \multirow{3}{*}{0.13} & 5 & 0.5 & $87 Q$ & 14.664@-64.73 \\
\hline & & 95 & 0.6 & $87 \mathrm{Q}$ & $19.839 @-68.13^{\circ}$ \\
\hline & & 100 & 4.5 & 87RA & $282.533 @-76.13^{\circ}$ \\
\hline & \multirow{3}{*}{0.14} & 5 & 0.5 & $87 Q$ & 14.664@-64.73 \\
\hline & & 95 & 0.6 & $87 Q$ & $19.839 @-68.13^{\circ}$ \\
\hline & & 100 & 4.5 & 87RA & $282.533 @-76.13^{\circ}$ \\
\hline & \multirow{3}{*}{0.15} & 5 & 0.5 & $87 \mathrm{Q}$ & 14.664@-64.73 \\
\hline & & 95 & 0.6 & $87 Q$ & $19.839 @-68.13^{\circ}$ \\
\hline & & 100 & 4.5 & 87RA & $282.533 @-76.13^{\circ}$ \\
\hline & \multirow{3}{*}{0.2} & 5 & 0.6 & $87 \mathrm{Q}$ & \multirow{2}{*}{ 19.839@-68.13 } \\
\hline & & 95 & 0.6 & $87 \mathrm{Q}$ & \\
\hline & & 100 & 4.5 & $87 \mathrm{RA}$ & $282.533 @-76.13^{\circ}$ \\
\hline & & 5 & 0.7 & $87 \mathrm{Q}$ & $2510197064^{\circ}$ \\
\hline & 0.25 & 95 & 0.7 & $87 \mathrm{Q}$ & 25.191@-70.64 \\
\hline & & 100 & 4.5 & 87RA & $282.533 @-76.13^{\circ}$ \\
\hline & & 5 & 0.8 & $87 Q$ & $31378 \Omega 7334^{\circ}$ \\
\hline & 0.3 & 95 & 0.8 & $87 \mathrm{Q}$ & $31.3 / 8 @-13.34$ \\
\hline & & 100 & 4.5 & $87 \mathrm{RA}$ & $282.533 @-76.13^{\circ}$ \\
\hline & & 5 & 0.9 & $87 \mathrm{Q}$ & $36888 \cap 7643^{\circ}$ \\
\hline & 0.4 & 95 & 0.9 & $87 \mathrm{Q}$ & 36.888@--16.43 \\
\hline & & 100 & 4.5 & 87RA & $282.533 @-76.13^{\circ}$ \\
\hline
\end{tabular}




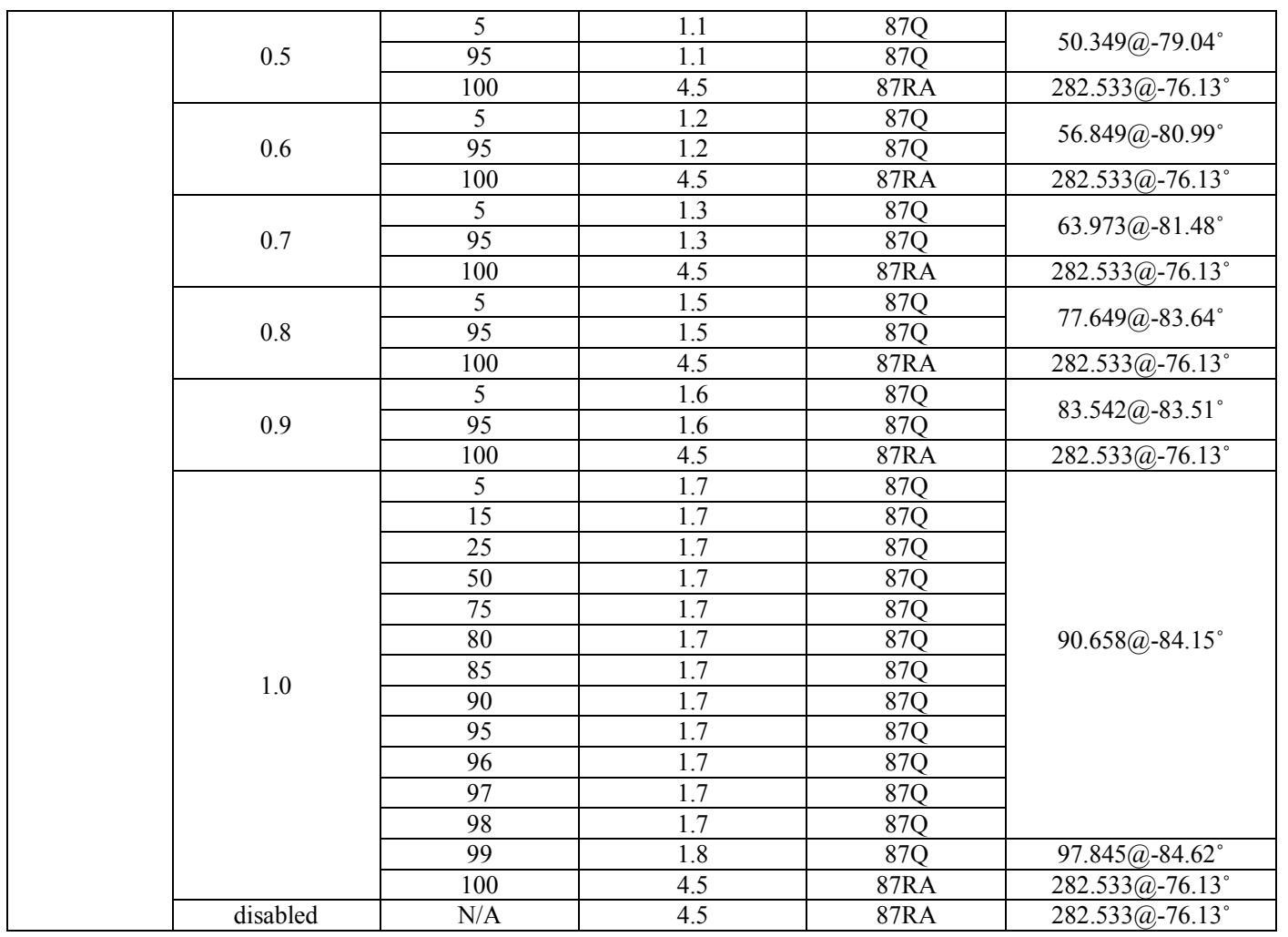


Table E.4: Negative-sequence differential element sensitivity for the 290-MVA transformer, heavy load.

\begin{tabular}{|c|c|c|c|c|c|}
\hline Transformer & 87QP, pu tap & 87QP slope, \% & $\begin{array}{l}\text { Shorted winding } \\
\text { percentage, } \%\end{array}$ & $\begin{array}{l}\text { Element } \\
\text { asserted }\end{array}$ & $\begin{array}{c}3 \mathrm{I}_{2}, \mathrm{~A}_{\mathrm{RMS} \text { pri }} \mathrm{S} \text {-winding } \\
\text { (calculated from Event } \\
\text { Summary data) }\end{array}$ \\
\hline \multirow{58}{*}{290 MVA } & \multirow{9}{*}{0.05} & 5 & 0.4 & $87 Q$ & \multirow{5}{*}{ 22.271@-5.65 } \\
\hline & & 25 & 0.4 & $87 Q$ & \\
\hline & & 50 & 0.4 & $87 \mathrm{Q}$ & \\
\hline & & 75 & 0.4 & $87 Q$ & \\
\hline & & 80 & 0.4 & $87 Q$ & \\
\hline & & 85 & 0.6 & $87 Q$ & 31.918@-3.93 \\
\hline & & 90 & 0.8 & $87 \mathrm{Q}$ & $42.588 @-2.93^{\circ}$ \\
\hline & & 95 & 1.6 & $87 Q$ & 87.640@-1.98 \\
\hline & & 100 & 15.1 & $87 \mathrm{RB}$ & 943.554@10.44 \\
\hline & \multirow{3}{*}{0.06} & 5 & 0.5 & $87 Q$ & $27.023 @-2.79^{\circ}$ \\
\hline & & 95 & 1.6 & $87 Q$ & $87.640 @-1.98^{\circ}$ \\
\hline & & 100 & 15.1 & $87 \mathrm{RB}$ & 943.554@10.44 \\
\hline & \multirow{3}{*}{0.07} & 5 & 0.6 & $87 Q$ & $31.918 @-3.93^{\circ}$ \\
\hline & & 95 & 1.6 & $87 Q$ & 87.640@-1.98 \\
\hline & & 100 & 15.1 & $87 \mathrm{RB}$ & 943.554@10.44 \\
\hline & \multirow{3}{*}{0.08} & 5 & 0.6 & $87 Q$ & $31.918 @-3.93^{\circ}$ \\
\hline & & 95 & 1.6 & $87 Q$ & $87.640 @-1.98^{\circ}$ \\
\hline & & 100 & 15.1 & $87 \mathrm{RB}$ & 943.554@10.44 \\
\hline & \multirow{3}{*}{0.09} & 5 & 0.7 & $87 Q$ & $37.251 @-3.36^{\circ}$ \\
\hline & & 95 & 1.6 & $87 \mathrm{Q}$ & 87.640@-1.98 \\
\hline & & 100 & 15.1 & $87 \mathrm{RB}$ & 943.554@10.44 \\
\hline & \multirow{10}{*}{0.1} & 5 & 0.8 & $87 Q$ & \multirow{8}{*}{ 42.588@-2.93 } \\
\hline & & 15 & 0.8 & $87 Q$ & \\
\hline & & 25 & 0.8 & $87 \mathrm{Q}$ & \\
\hline & & 50 & 0.8 & $87 Q$ & \\
\hline & & 75 & 0.8 & $87 \mathrm{Q}$ & \\
\hline & & 80 & 0.8 & $87 Q$ & \\
\hline & & 85 & 0.8 & $87 \mathrm{Q}$ & \\
\hline & & 90 & 0.8 & $87 Q$ & \\
\hline & & 95 & 1.6 & $87 Q$ & $87.640 @-1.98^{\circ}$ \\
\hline & & 100 & 15.1 & $87 \mathrm{RB}$ & 943.554@10.44 \\
\hline & \multirow{3}{*}{0.11} & 5 & 0.8 & $87 Q$ & $42.588 @-2.93^{\circ}$ \\
\hline & & 95 & 1.6 & $87 Q$ & $87.640 @-1.98^{\circ}$ \\
\hline & & 100 & 15.1 & $87 \mathrm{RB}$ & 943.554@10.44 \\
\hline & \multirow{3}{*}{0.12} & 5 & 0.9 & $87 \mathrm{Q}$ & 49.279@-2.53 \\
\hline & & 95 & 1.6 & $87 Q$ & 87.640@-1.98 \\
\hline & & 100 & 15.1 & $87 \mathrm{RB}$ & 943.554@10.44 \\
\hline & \multirow{3}{*}{0.13} & 5 & 1.0 & $87 Q$ & $54.627 @-2.28^{\circ}$ \\
\hline & & 95 & 1.6 & $87 Q$ & $87.640 @-1.98^{\circ}$ \\
\hline & & 100 & 15.1 & $87 \mathrm{RB}$ & 943.554@10.44 \\
\hline & \multirow{3}{*}{0.14} & 5 & 1.1 & $87 Q$ & $59.938 @-2.07^{\circ}$ \\
\hline & & 95 & 1.6 & $87 Q$ & $87.640 @-1.98^{\circ}$ \\
\hline & & 100 & 15.1 & $87 \mathrm{RB}$ & 943.554@10.44 \\
\hline & \multirow{3}{*}{0.15} & 5 & 1.1 & $87 \mathrm{Q}$ & $59.938 @-2.07^{\circ}$ \\
\hline & & 95 & 1.6 & $87 Q$ & $87.640 @-1.98^{\circ}$ \\
\hline & & 100 & 15.1 & $87 \mathrm{RB}$ & 943.554@10.44 \\
\hline & \multirow{3}{*}{0.2} & 5 & 1.5 & $87 Q$ & $81.561 @-1.96^{\circ}$ \\
\hline & & 95 & 1.7 & $87 Q$ & 92.449@-1.33 \\
\hline & & 100 & 15.1 & $87 \mathrm{RB}$ & 943.554@10.44 \\
\hline & \multirow{3}{*}{0.25} & 5 & 1.8 & $87 Q$ & \multirow{2}{*}{ 96.882@-1.27ำ } \\
\hline & & 95 & 1.8 & $87 Q$ & \\
\hline & & 100 & 15.1 & $87 \mathrm{RB}$ & 943.554@10.44 \\
\hline & & 5 & 1.9 & $87 Q$ & $107256 \Omega 12^{\circ}$ \\
\hline & 0.26 & 95 & 1.9 & $87 Q$ & 102.256@-1.2 \\
\hline & & 100 & 15.1 & $87 \mathrm{RB}$ & 943.554@10.44 \\
\hline & & 5 & 2.0 & $87 Q$ & $1080270145^{\circ}$ \\
\hline & 0.27 & 95 & 2.0 & $87 Q$ & 108.83/@-1.45 \\
\hline & & 100 & 15.1 & $87 \mathrm{RB}$ & 943.554@10.44 \\
\hline
\end{tabular}




\begin{tabular}{|c|c|c|c|c|}
\hline \multirow{3}{*}{0.28} & 5 & 2.1 & $87 Q$ & \multirow{2}{*}{ 114.391@-1.07 } \\
\hline & 95 & 2.1 & $87 \mathrm{Q}$ & \\
\hline & 100 & 15.1 & $87 \mathrm{RB}$ & 943.554@10.44 \\
\hline \multirow{3}{*}{0.29} & 5 & 2.1 & $87 \mathrm{Q}$ & \multirow{2}{*}{ 114.391@-1.07 } \\
\hline & 95 & 2.1 & $87 Q$ & \\
\hline & 100 & 15.1 & $87 \mathrm{RB}$ & 943.554@10.44 \\
\hline \multirow{3}{*}{0.3} & 5 & 2.2 & $87 \mathrm{Q}$ & \multirow{2}{*}{ 119.773@-1.01 } \\
\hline & 95 & 2.2 & $87 \mathrm{Q}$ & \\
\hline & 100 & 15.1 & $87 \mathrm{RB}$ & 943.554@10.44 \\
\hline \multirow{3}{*}{0.4} & 5 & 2.9 & $87 Q$ & \multirow{2}{*}{ 159.654@-0.22 } \\
\hline & 95 & 2.9 & $87 \mathrm{Q}$ & \\
\hline & 100 & 15.1 & $87 \mathrm{RB}$ & 943.554@10.44 \\
\hline \multirow{3}{*}{0.5} & 5 & 3.6 & $87 Q$ & \multirow{2}{*}{$198.102 @ 0.69^{\circ}$} \\
\hline & 95 & 3.6 & $87 Q$ & \\
\hline & 100 & 15.1 & $87 \mathrm{RB}$ & 943.554@10.44 \\
\hline \multirow{3}{*}{0.6} & 5 & 4.3 & $87 \mathrm{Q}$ & \multirow{2}{*}{ 239.214@1.28 } \\
\hline & 95 & 4.3 & $87 Q$ & \\
\hline & 100 & 15.1 & $87 \mathrm{RB}$ & 943.554@10.44 \\
\hline \multirow{3}{*}{0.7} & 5 & 4.9 & $87 Q$ & \multirow{2}{*}{ 274.526@2.02 } \\
\hline & 95 & 4.9 & $87 \mathrm{Q}$ & \\
\hline & 100 & 15.1 & $87 \mathrm{RB}$ & 943.554@10.44 \\
\hline \multirow{3}{*}{0.8} & 5 & 5.6 & $87 \mathrm{Q}$ & \multirow{2}{*}{$314.001 @ 2.82^{\circ}$} \\
\hline & 95 & 5.6 & $87 \mathrm{Q}$ & \\
\hline & 100 & 15.1 & $87 \mathrm{RB}$ & 943.554@10.44 \\
\hline \multirow{3}{*}{0.9} & 5 & 6.2 & $87 Q$ & \multirow{2}{*}{ 350.778@3.45 } \\
\hline & 95 & 6.2 & $87 \mathrm{Q}$ & \\
\hline & 100 & 15.1 & $87 \mathrm{RB}$ & 943.554@10.44 \\
\hline \multirow{10}{*}{1.0} & 5 & 6.9 & $87 \mathrm{Q}$ & \multirow{9}{*}{ 393.735@3.95ํํ․ } \\
\hline & 15 & 6.9 & $87 \mathrm{Q}$ & \\
\hline & 25 & 6.9 & $87 \mathrm{Q}$ & \\
\hline & 50 & 6.9 & $87 \mathrm{Q}$ & \\
\hline & 75 & 6.9 & $87 \mathrm{Q}$ & \\
\hline & 80 & 6.9 & $87 \mathrm{Q}$ & \\
\hline & 85 & 6.9 & $87 \mathrm{Q}$ & \\
\hline & 90 & 6.9 & $87 \mathrm{Q}$ & \\
\hline & 95 & 6.9 & $87 \mathrm{Q}$ & \\
\hline & 100 & 15.1 & $87 \mathrm{RB}$ & 943.554@10.44 \\
\hline disabled & N/A & 15.1 & $87 \mathrm{RB}$ & 943.554@10.44 \\
\hline
\end{tabular}




\section{E.2 ATP results for turn-to-ground faults}

Table E.5: Turn-to-ground fault results for solidly grounded neutral $(\mathrm{R}=1 \Omega)$, light load.

\begin{tabular}{|c|c|c|c|c|c|c|c|c|}
\hline $\begin{array}{c}\text { Shorted } \\
\text { winding } \\
\text { percentage, \% }\end{array}$ & $\mathrm{I}_{\mathrm{A}}, \mathrm{A}_{\text {peak pri }}$ & $\mathrm{I}_{\mathrm{B}}, \mathrm{A}_{\text {peak pri }}$ & $\mathrm{I}_{\mathrm{C}}, \mathrm{A}_{\text {peak pri }}$ & $\mathrm{I}_{\mathrm{a}}, \mathrm{A}_{\text {peak pri }}$ & $\mathrm{I}_{\mathrm{b}}, \mathrm{A}_{\text {peak pri }}$ & $\mathrm{I}_{\mathrm{c}}, \mathrm{A}_{\text {peak pri }}$ & $\mathrm{I}_{\mathrm{N}}, \mathrm{A}_{\text {peak pri }}$ & $\mathrm{I}_{\text {fault }}, \mathrm{A}_{\text {peak pri }}$ \\
\hline Rated load & 546.27 & 546.27 & 546.27 & 14645 & 14645 & 14645 & 0 & N/A \\
\hline 1 & 569.01 & 578.88 & 523.29 & 14645 & 14645 & 14645 & 3159.6 & 3195 \\
\hline 2 & 609.66 & 600.14 & 524.21 & 14645 & 14645 & 14645 & 5072.6 & 5181.5 \\
\hline 3 & 654.55 & 608.77 & 532.59 & 14645 & 14645 & 14645 & 6045.7 & 6239.3 \\
\hline 4 & 702.93 & 611.65 & 540.47 & 14645 & 14645 & 14645 & 6553.8 & 6834.1 \\
\hline 5 & 755.86 & 612.3 & 546.6 & 14645 & 14645 & 14645 & 6840.5 & 7208.2 \\
\hline 6 & 813.82 & 612.11 & 551.24 & 14645 & 14645 & 14645 & 7015 & 7470.8 \\
\hline 7 & 872.67 & 611.63 & 554.78 & 14645 & 14645 & 14645 & 7127.7 & 7673.1 \\
\hline 8 & 944.4 & 611.05 & 557.54 & 14645 & 14645 & 14645 & 7205.9 & 7840.8 \\
\hline 9 & 1016.5 & 610.48 & 559.75 & 14645 & 14645 & 14645 & 7261.1 & 7987.8 \\
\hline 10 & 1092.7 & 609.93 & 561.54 & 14645 & 14645 & 14645 & 7301.9 & 8121.9 \\
\hline 15 & 1528.9 & 607.88 & 567.04 & 14645 & 14645 & 14645 & 7404.2 & 8720.1 \\
\hline 20 & 2049.2 & 606.66 & 569.88 & 14645 & 14645 & 14645 & 7443.2 & 9313.8 \\
\hline 25 & 2654.2 & 605.91 & 571.63 & 14645 & 14645 & 14645 & 7462.4 & 9960.4 \\
\hline 30 & 3354.9 & 605.45 & 572.87 & 14645 & 14645 & 14645 & 7473.4 & 10687 \\
\hline 35 & 4169.4 & 605.18 & 573.82 & 14645 & 14645 & 14645 & 7480.5 & 11520 \\
\hline 40 & 5124 & 605.03 & 574.61 & 14645 & 14645 & 14645 & 7485.2 & 12488 \\
\hline 45 & 6254.9 & 604.99 & 575.3 & 14645 & 14645 & 14645 & 7488.6 & 13630 \\
\hline 50 & 7615.2 & 604.68 & 575.57 & 14645 & 14645 & 14645 & 7491.2 & 14998 \\
\hline 55 & 9279.5 & 604.75 & 576.13 & 14645 & 14645 & 14645 & 7493.1 & 16669 \\
\hline 60 & 11362 & 604.82 & 576.6 & 14645 & 14645 & 14645 & 7494.7 & 18756 \\
\hline 65 & 14040 & 605.06 & 577.18 & 14645 & 14645 & 14645 & 7495.9 & 21439 \\
\hline 70 & 17613 & 605.15 & 577.57 & 14645 & 14645 & 14645 & 7497 & 25016 \\
\hline 75 & 22616 & 605.41 & 578.07 & 14645 & 14645 & 14645 & 7497.8 & 30022 \\
\hline 80 & 30123 & 605.63 & 578.52 & 14645 & 14645 & 14645 & 7498.6 & 37532 \\
\hline 85 & 42635 & 605.88 & 578.97 & 14645 & 14645 & 14645 & 7499.2 & 50046 \\
\hline 90 & 67661 & 606.23 & 579.49 & 14645 & 14645 & 14645 & 7499.6 & 75075 \\
\hline 95 & 142740 & 606.58 & 580.02 & 14645 & 14645 & 14645 & 7500.2 & 150160 \\
\hline
\end{tabular}


Table E.6: Turn-to-ground fault results for low-resistance grounded neutral $(\mathrm{R}=415 \Omega)$, light load.

\begin{tabular}{|c|c|c|c|c|c|c|c|c|}
\hline $\begin{array}{c}\text { Shorted } \\
\text { winding } \\
\text { percentage, \% }\end{array}$ & $\mathrm{I}_{\mathrm{A}}, \mathrm{A}_{\text {peak pri }}$ & $\mathrm{I}_{\mathrm{B}}, \mathrm{A}_{\text {peak pri }}$ & $\mathrm{I}_{\mathrm{C}}, \mathrm{A}_{\text {peak pri }}$ & $\mathrm{I}_{\mathrm{a}}, \mathrm{A}_{\text {peak pri }}$ & $\mathrm{I}_{\mathrm{b}}, \mathrm{A}_{\text {peak pri }}$ & $\mathrm{I}_{\mathrm{c}}, \mathrm{A}_{\text {peak pri }}$ & $\mathrm{I}_{\mathrm{N}}, \mathrm{A}_{\text {peak rpi }}$ & $\mathrm{I}_{\text {fault }}, \mathrm{A}_{\text {peak pri }}$ \\
\hline Rated load & 546.23 & 546.23 & 546.23 & 14645 & 14645 & 14645 & 0 & N/A \\
\hline 1 & 553.71 & 575.69 & 511.5 & 14645 & 14645 & 14645 & 8.4569 & 113.67 \\
\hline 2 & 564.39 & 605.76 & 477.55 & 14645 & 14645 & 14645 & 16.83 & 228.51 \\
\hline 3 & 578.49 & 636.32 & 444.44 & 14645 & 14645 & 14645 & 25.12 & 344.59 \\
\hline 4 & 596.17 & 667.21 & 412.28 & 14645 & 14645 & 14645 & 33.328 & 461.95 \\
\hline 5 & 617.62 & 698.35 & 381.23 & 14645 & 14645 & 14645 & 41.456 & 580.66 \\
\hline 6 & 642.92 & 729.65 & 351.41 & 14645 & 14645 & 14645 & 49.505 & 700.72 \\
\hline 7 & 672.11 & 761.06 & 323.08 & 14645 & 14645 & 14645 & 57.475 & 822.34 \\
\hline 8 & 705.2 & 792.5 & 296.53 & 14645 & 14645 & 14645 & 65.368 & 945.44 \\
\hline 9 & 742.19 & 823.96 & 272.14 & 14645 & 14645 & 14645 & 73.185 & 1070.1 \\
\hline 10 & 783.05 & 855.37 & 250.41 & 14645 & 14645 & 14645 & 80.928 & 1196.5 \\
\hline 15 & 1043.9 & 1011 & 202.99 & 14645 & 14645 & 14645 & 118.55 & 1855.8 \\
\hline 20 & 1396.6 & 1162.7 & 269.79 & 14645 & 14645 & 14645 & 154.45 & 2568.9 \\
\hline 25 & 1843.9 & 1309.5 & 387.86 & 14645 & 14645 & 14645 & 188.74 & 3348.4 \\
\hline 30 & 2395.5 & 1451.1 & 517.71 & 14645 & 14645 & 14645 & 221.52 & 4210.7 \\
\hline 35 & 3068.7 & 1587.4 & 648.25 & 14645 & 14645 & 14645 & 252.89 & 5176.7 \\
\hline 40 & 3388.6 & 1718.6 & 776.12 & 14645 & 14645 & 14645 & 282.93 & 6274.3 \\
\hline 45 & 4891.3 & 1844.8 & 900.19 & 14645 & 14645 & 14645 & 311.74 & 7541.5 \\
\hline 50 & 6128.3 & 1965.9 & 1020.4 & 14645 & 14645 & 14645 & 339.37 & 9031 \\
\hline 55 & 7674.8 & 2082.7 & 1136 & 14645 & 14645 & 14645 & 365.91 & 10819 \\
\hline 60 & 9643.9 & 2195.2 & 1247.6 & 14645 & 14645 & 14645 & 391.41 & 13019 \\
\hline 65 & 12214 & 2303.5 & 1355 & 14645 & 14645 & 14645 & 415.93 & 15811 \\
\hline 70 & 15682 & 2407.8 & 1458.7 & 14645 & 14645 & 14645 & 439.53 & 13493 \\
\hline 75 & 20585 & 2508.4 & 1558.5 & 14645 & 14645 & 14645 & 462.25 & 24601 \\
\hline 80 & 27995 & 2605.4 & 1654.9 & 14645 & 14645 & 14645 & 484.15 & 32209 \\
\hline 85 & 40414 & 2699.1 & 1747.9 & 14645 & 14645 & 14645 & 505.27 & 44818 \\
\hline 90 & 65350 & 2789.6 & 1837.6 & 14645 & 14645 & 14645 & 525.64 & 69938 \\
\hline 95 & 140340 & 2877 & 1924.2 & 14645 & 14645 & 14645 & 545.32 & 145110 \\
\hline
\end{tabular}


Table E.7: Turn-to-ground fault results for solidly grounded neutral $(\mathrm{R}=1 \Omega)$, heavy load.

\begin{tabular}{|c|c|c|c|c|c|c|c|c|}
\hline $\begin{array}{c}\text { Shorted } \\
\text { winding } \\
\text { percentage, \% }\end{array}$ & $\mathrm{I}_{\mathrm{A}}, \mathrm{A}_{\text {peak pri }}$ & $\mathrm{I}_{\mathrm{B}}, \mathrm{A}_{\text {peak pri }}$ & $\mathrm{I}_{\mathrm{C}}, \mathrm{A}_{\text {peak pri }}$ & $\mathrm{I}_{\mathrm{a}}, \mathrm{A}_{\text {peak pri }}$ & $\mathrm{I}_{\mathrm{b}}, \mathrm{A}_{\text {peak pri }}$ & $\mathrm{I}_{\mathrm{c}}, \mathrm{A}_{\text {peak pri }}$ & $\mathrm{I}_{\mathrm{N}}, \mathrm{A}_{\text {peak pri }}$ & $\mathrm{I}_{\text {fault }}, \mathrm{A}_{\text {peak pri }}$ \\
\hline Rated load & 1088.2 & 1088.2 & 1088.2 & 29286 & 29286 & 29286 & 0 & N/A \\
\hline 1 & 1121.7 & 1116.8 & 1058.6 & 29286 & 29286 & 29286 & 3156.9 & 3192.3 \\
\hline 2 & 1174.9 & 1140.6 & 1051.1 & 29286 & 29286 & 29286 & 5069.7 & 5178.7 \\
\hline 3 & 1231.1 & 1152.5 & 1054.3 & 29286 & 29286 & 29286 & 6043.5 & 6237.1 \\
\hline 4 & 1287.5 & 1157.8 & 1059.4 & 29286 & 29286 & 29286 & 6552.2 & 6832.5 \\
\hline 5 & 1345.1 & 1160.2 & 1064 & 29286 & 29286 & 29286 & 6839.3 & 7206.9 \\
\hline 6 & 1405 & 1161.3 & 1067.8 & 29286 & 29286 & 29286 & 7014.2 & 7469.8 \\
\hline 7 & 1467.6 & 1161.8 & 1070.9 & 29286 & 29286 & 29286 & 7127.7 & 7672.3 \\
\hline 8 & 1533.4 & 1161.9 & 1073.3 & 29286 & 29286 & 29286 & 7205.3 & 7840.2 \\
\hline 9 & 1602.3 & 1161.9 & 1075.3 & 29286 & 29286 & 29286 & 7260.7 & 7987.3 \\
\hline 10 & 1674.6 & 1161.8 & 1077 & 29286 & 29286 & 29286 & 7301.5 & 8121.4 \\
\hline 15 & 2085.8 & 1161 & 1082.3 & 29286 & 29286 & 29286 & 7404 & 8719.9 \\
\hline 20 & 2580.8 & 1160.4 & 1085.2 & 29286 & 29286 & 29286 & 7443.1 & 9313.7 \\
\hline 25 & 3164.4 & 1160.1 & 1087 & 29286 & 29286 & 29286 & 7462.3 & 9960.3 \\
\hline 30 & 3847.3 & 1159.8 & 1088.2 & 29286 & 29286 & 29286 & 7473.4 & 10688 \\
\hline 35 & 4647.4 & 1159.7 & 1089.2 & 29286 & 29286 & 29286 & 7480.4 & 11520 \\
\hline 40 & 5590 & 1159.7 & 1090 & 29286 & 29286 & 29286 & 7485.2 & 12488 \\
\hline 45 & 6711.2 & 1159.7 & 1090.7 & 29286 & 29286 & 29286 & 7488.6 & 13630 \\
\hline 50 & 8062.7 & 1159.5 & 1091 & 29286 & 29286 & 29286 & 7491.1 & 14998 \\
\hline 55 & 9719.7 & 1159.6 & 1091.6 & 29286 & 29286 & 29286 & 7493.1 & 16669 \\
\hline 60 & 11796 & 1159.7 & 1092 & 29286 & 29286 & 29286 & 7494.7 & 18756 \\
\hline 65 & 14469 & 1160 & 1092.6 & 29286 & 29286 & 29286 & 7495.9 & 21439 \\
\hline 70 & 18037 & 1160 & 1093 & 29286 & 29286 & 29286 & 7496.9 & 25016 \\
\hline 75 & 23036 & 1160.3 & 1093.5 & 29286 & 29286 & 29286 & 7497.8 & 30022 \\
\hline 80 & 30538 & 1160.6 & 1094 & 29286 & 29286 & 29286 & 7498.5 & 37532 \\
\hline 85 & 43047 & 1160.8 & 1094.4 & 29286 & 29286 & 29286 & 7499.1 & 50046 \\
\hline 90 & 68071 & 1161.1 & 1094.9 & 29286 & 29286 & 29286 & 7499.7 & 75075 \\
\hline 95 & 143150 & 1161.4 & 1095.4 & 29286 & 29286 & 29286 & 7500.2 & 150160 \\
\hline
\end{tabular}


Table E.8: Turn-to-ground fault results for low-resistance grounded neutral $(\mathrm{R}=415 \Omega)$, heavy load.

\begin{tabular}{|c|c|c|c|c|c|c|c|c|}
\hline $\begin{array}{c}\text { Shorted } \\
\text { winding } \\
\text { percentage, \% }\end{array}$ & $\mathrm{I}_{\mathrm{A}}, \mathrm{A}_{\text {peak pri }}$ & $\mathrm{I}_{\mathrm{B}}, \mathrm{A}_{\text {peak pri }}$ & $\mathrm{I}_{\mathrm{C}}, \mathrm{A}_{\text {peak pri }}$ & $\mathrm{I}_{\mathrm{a}}, \mathrm{A}_{\text {peak pri }}$ & $\mathrm{I}_{\mathrm{b}}, \mathrm{A}_{\text {peak pri }}$ & $\mathrm{I}_{\mathrm{c}}, \mathrm{A}_{\text {peak pri }}$ & $\mathrm{I}_{\mathrm{N}}, \mathrm{A}_{\text {peak pri }}$ & $\mathrm{I}_{\text {fault }}, \mathrm{A}_{\text {peak pri }}$ \\
\hline Rated load & 1088.2 & 1088.2 & 1088.2 & 29286 & 29286 & 29286 & 0 & N/A \\
\hline 1 & 1106.1 & 1109.1 & 1050.9 & 29286 & 29286 & 29286 & 8.457 & 113.67 \\
\hline 2 & 1126.1 & 1130.7 & 1013.9 & 29286 & 29286 & 29286 & 16.83 & 228.51 \\
\hline 3 & 1148.3 & 1152.9 & 977.42 & 29286 & 29286 & 29286 & 25.12 & 344.59 \\
\hline 4 & 1172.8 & 1175.7 & 941.28 & 29286 & 29286 & 29286 & 33.328 & 461.95 \\
\hline 5 & 1199.7 & 1199 & 905.48 & 29286 & 29286 & 29286 & 41.456 & 580.66 \\
\hline 6 & 1229.2 & 1222.7 & 870.06 & 29286 & 29286 & 29286 & 49.505 & 700.77 \\
\hline 7 & 1261.2 & 1246.8 & 834.98 & 29286 & 29286 & 29286 & 57.475 & 822.34 \\
\hline 8 & 1295.9 & 1271.2 & 800.3 & 29286 & 29286 & 29286 & 65.368 & 945.44 \\
\hline 9 & 1333.5 & 1296 & 765.95 & 29286 & 29286 & 29286 & 73.185 & 1070.1 \\
\hline 10 & 1373.8 & 1320.9 & 731.94 & 29286 & 29286 & 29286 & 80.927 & 1196.5 \\
\hline 15 & 1621.7 & 1448.3 & 567.26 & 29286 & 29286 & 29286 & 118.55 & 1855.8 \\
\hline 20 & 1952.9 & 1577.5 & 411.52 & 29286 & 29286 & 29286 & 154.45 & 2568.9 \\
\hline 25 & 2377.5 & 1706.4 & 266.35 & 29286 & 29286 & 29286 & 188.74 & 3348.4 \\
\hline 30 & 2908.4 & 1833.5 & 141.26 & 29286 & 29286 & 29286 & 221.52 & 4210.7 \\
\hline 35 & 3563.6 & 1958 & 102.99 & 29286 & 29286 & 29286 & 252.89 & 5176.7 \\
\hline 40 & 4368.3 & 2079.4 & 194.47 & 29286 & 29286 & 29286 & 282.93 & 6274.3 \\
\hline 45 & 5358.3 & 2197.5 & 311.63 & 29286 & 29286 & 29286 & 311.74 & 7541.5 \\
\hline 50 & 6584.5 & 2311.8 & 429.85 & 29286 & 29286 & 29286 & 339.37 & 9031 \\
\hline 55 & 8121.9 & 2422.9 & 544.94 & 29286 & 29286 & 29286 & 365.91 & 10819 \\
\hline 60 & 10083 & 2530.4 & 656.34 & 29286 & 29286 & 29286 & 391.41 & 13020 \\
\hline 65 & 12647 & 2634.5 & 763.78 & 29286 & 29286 & 29286 & 415.93 & 15811 \\
\hline 70 & 16109 & 2735.2 & 867.54 & 29286 & 29286 & 29286 & 439.53 & 13493 \\
\hline 75 & 21007 & 2832.7 & 967.49 & 29286 & 29286 & 29286 & 462.25 & 24601 \\
\hline 80 & 28412 & 2927 & 1063.9 & 29286 & 29286 & 29286 & 484.15 & 32209 \\
\hline 85 & 40827 & 3018.3 & 1157 & 29286 & 29286 & 29286 & 505.27 & 44818 \\
\hline 90 & 65760 & 3106.7 & 1246.8 & 29286 & 29286 & 29286 & 525.64 & 69938 \\
\hline 95 & 140750 & 3192.4 & 1333.5 & 29286 & 29286 & 29286 & 545.32 & 145110 \\
\hline
\end{tabular}




\section{Appendix F \\ Event reports}

\section{F.1 The 11.2-MVA transformer Event Report for turn-to-turn fault}

REPORT HEADER:

=>EVE 18527

Relay 1

Station A

FID=SEL-487E-R103-V0-Z001001-D20081008

ANALOG SECTION:

\begin{tabular}{|c|c|c|c|c|c|c|c|c|}
\hline & & & rents & Pri. & & & & \\
\hline IAS & IBS & ICS & IAT & IBT & ICT & IAU & IBU & ICU \\
\hline [69] & & & & & & & & \\
\hline 7 & 75 & -82 & -22 & -213 & 235 & 0 & 0 & 0 \\
\hline-91 & 52 & 39 & 258 & -148 & -110 & 0 & 0 & 0 \\
\hline-7 & -75 & 82 & 22 & 213 & -235 & 0 & 0 & 0 \\
\hline 91 & -52 & -39 & -258 & 148 & 110 & 0 & 0 & 0 \\
\hline [ 70 ] & & & & & & & & \\
\hline 7 & 75 & -82 & -22 & -213 & 235 & 0 & 0 & 0 \\
\hline-91 & 52 & 39 & 258 & -148 & -110 & 0 & 0 & 0 \\
\hline-7 & -75 & 82 & 22 & 213 & -235 & 0 & 0 & 0 \\
\hline 91 & -52 & -39 & -258 & 148 & 110 & 0 & 0 & 0 \\
\hline [71] & & & & & & & & \\
\hline 7 & 75 & -82 & -22 & -213 & 235 & 0 & 0 & 0 \\
\hline-91 & 52 & 39 & 258 & -148 & -110 & 0 & 0 & 0 \\
\hline-7 & -75 & 82 & 22 & 213 & -235 & 0 & 0 & 0 \\
\hline 91 & -52 & -39 & -258 & 148 & 110 & 0 & 0 & 0 \\
\hline [ 72] & & & & & & & & \\
\hline 7 & 75 & -82 & -22 & -213 & 235 & 0 & 0 & 0 \\
\hline-91 & 52 & 39 & 258 & -148 & -110 & 0 & 0 & 0 \\
\hline-7 & -75 & 82 & 22 & 213 & -235 & 0 & 0 & 0 \\
\hline 91 & -52 & -39 & -258 & 148 & 110 & 0 & 0 & 0 \\
\hline [73] & & & & & & & & \\
\hline 9 & 75 & -84 & -22 & -213 & 235 & 0 & 0 & 0 \\
\hline-92 & 52 & 40 & 258 & -148 & -110 & 0 & 0 & 0 \\
\hline-11 & -75 & 86 & 22 & 213 & -235 & 0 & 0 & 0 \\
\hline 93 & -52 & -42 & -258 & 148 & 110 & 0 & 0 & 0 \\
\hline [ 74$]$ & & & & & & & & \\
\hline 12 & 75 & -87 & -22 & -213 & 235 & 0 & 0 & 0 \\
\hline-94 & 52 & 42 & 258 & -148 & -110 & 0 & 0 & 0 \\
\hline-12 & -75 & 87 & 22 & 213 & -235 & 0 & 0 & 0 \\
\hline 94 & -52 & -42 & -258 & 148 & 110 & 0 & 0 & 0 \\
\hline [75] & & & & & & & & \\
\hline 12 & 75 & -87 & -22 & -213 & 235 & 0 & 0 & 0 \\
\hline-94 & 52 & 42 & 258 & -148 & -110 & 0 & 0 & 0 \\
\hline-12 & -75 & 87 & 22 & 213 & -235 & 0 & 0 & 0 \\
\hline 94 & -52 & -42 & -258 & 148 & 110 & 0 & 0 & 0 \\
\hline [ 76] & & & & & & & & \\
\hline 12 & 75 & -87 & -22 & -213 & 235 & 0 & 0 & 0 \\
\hline-94 & 52 & 42 & 258 & -148 & -110 & 0 & 0 & 0 \\
\hline-12 & -75 & 87 & 22 & 213 & -235 & 0 & 0 & 0 \\
\hline 94 & -52 & -42 & -258 & 148 & 110 & 0 & 0 & 0 \\
\hline [77] & & & & & & & & \\
\hline 12 & 75 & -87 & -22 & -213 & 235 & 0 & 0 & 0 \\
\hline-94 & 52 & 42 & 258 & -148 & -110 & 0 & 0 & 0 \\
\hline-12 & -75 & 87 & 22 & 213 & -235 & 0 & 0 & 0 \\
\hline 94 & -52 & -42 & -258 & 148 & 110 & 0 & 0 & 0 \\
\hline
\end{tabular}




\begin{tabular}{|c|c|c|c|c|c|c|c|c|}
\hline 12 & 75 & -87 & -22 & -213 & 235 & 0 & 0 & 0 \\
\hline-94 & 52 & 42 & 258 & -148 & -110 & 0 & 0 & 0 \\
\hline-12 & -75 & 87 & 22 & 213 & -235 & 0 & 0 & 0 \\
\hline 94 & -52 & -42 & -258 & 148 & 110 & 0 & 0 & 0 \\
\hline \multicolumn{9}{|l|}{$[79]$} \\
\hline 12 & 75 & -87 & -22 & -213 & 235 & 0 & 0 & 0> trigger row \\
\hline-94 & 52 & 42 & 258 & -148 & -110 & 0 & 0 & 0 \\
\hline-12 & -75 & 87 & 22 & 213 & -235 & 0 & 0 & 0 \\
\hline 94 & -52 & -42 & -258 & 148 & 110 & 0 & 0 & 0 \\
\hline \multicolumn{9}{|l|}{$[80]$} \\
\hline 12 & 75 & -87 & -22 & -213 & 235 & 0 & 0 & 0 \\
\hline-94 & 52 & 42 & 258 & -148 & -110 & 0 & 0 & $0 * 1.25$ cycles after trigger \\
\hline-12 & -75 & 87 & 22 & 213 & -235 & 0 & 0 & 0 \\
\hline 94 & -52 & -42 & -258 & 148 & 110 & 0 & 0 & 0 \\
\hline \multicolumn{9}{|l|}{$[81]$} \\
\hline 12 & 75 & -87 & -22 & -213 & 235 & 0 & 0 & 0 \\
\hline-94 & 52 & 42 & 258 & -148 & -110 & 0 & 0 & 0 \\
\hline-12 & -75 & 87 & 22 & 213 & -235 & 0 & 0 & 0 \\
\hline 94 & -52 & -42 & -258 & 148 & 110 & 0 & 0 & 0 \\
\hline \multicolumn{9}{|l|}{$[82]$} \\
\hline 12 & 75 & -87 & -22 & -213 & 235 & 0 & 0 & 0 \\
\hline-94 & 52 & 42 & 258 & -148 & -110 & 0 & 0 & 0 \\
\hline-12 & -75 & 87 & 22 & 213 & -235 & 0 & 0 & 0 \\
\hline 94 & -52 & -42 & -258 & 148 & 110 & 0 & 0 & 0 \\
\hline \multicolumn{9}{|l|}{ [83] } \\
\hline 12 & 75 & -87 & -22 & -213 & 235 & 0 & 0 & 0 \\
\hline-94 & 52 & 42 & 258 & -148 & -110 & 0 & 0 & 0 \\
\hline-11 & -75 & 87 & 22 & 213 & -235 & 0 & 0 & 0 \\
\hline 94 & -52 & -42 & -258 & 148 & 110 & 0 & 0 & 0 \\
\hline
\end{tabular}

DIGITAL SECTION :

T

$\mathrm{R}$

PTTTTT RRRRRR VV SSSSSS TTTTTT UUUUUU WWWWWW XXXXXX IIIIIII UUUUUU XRRRRR 888 EEEEEE PPLL FRFRFR FRFRFR FRFRFR FRFRFR FRFRFR FFFFF NNNNNNN TTTTTT FIIIII 7778 FFFFFF OOOO $333333 \quad 333333 \quad 333333 \quad 333333 \quad 333333$ BBBBB 111111111111 MPPPPP RRR7 FFFRRR LLPP 222222222222222222222222222222 FFFFF 0000000000000 RSTUWX ABCQ 123123 VZVZ PPQQGG PPQQGG PPQQGG PPQQGG PPQQGG STUWX 1234567123456

[69]

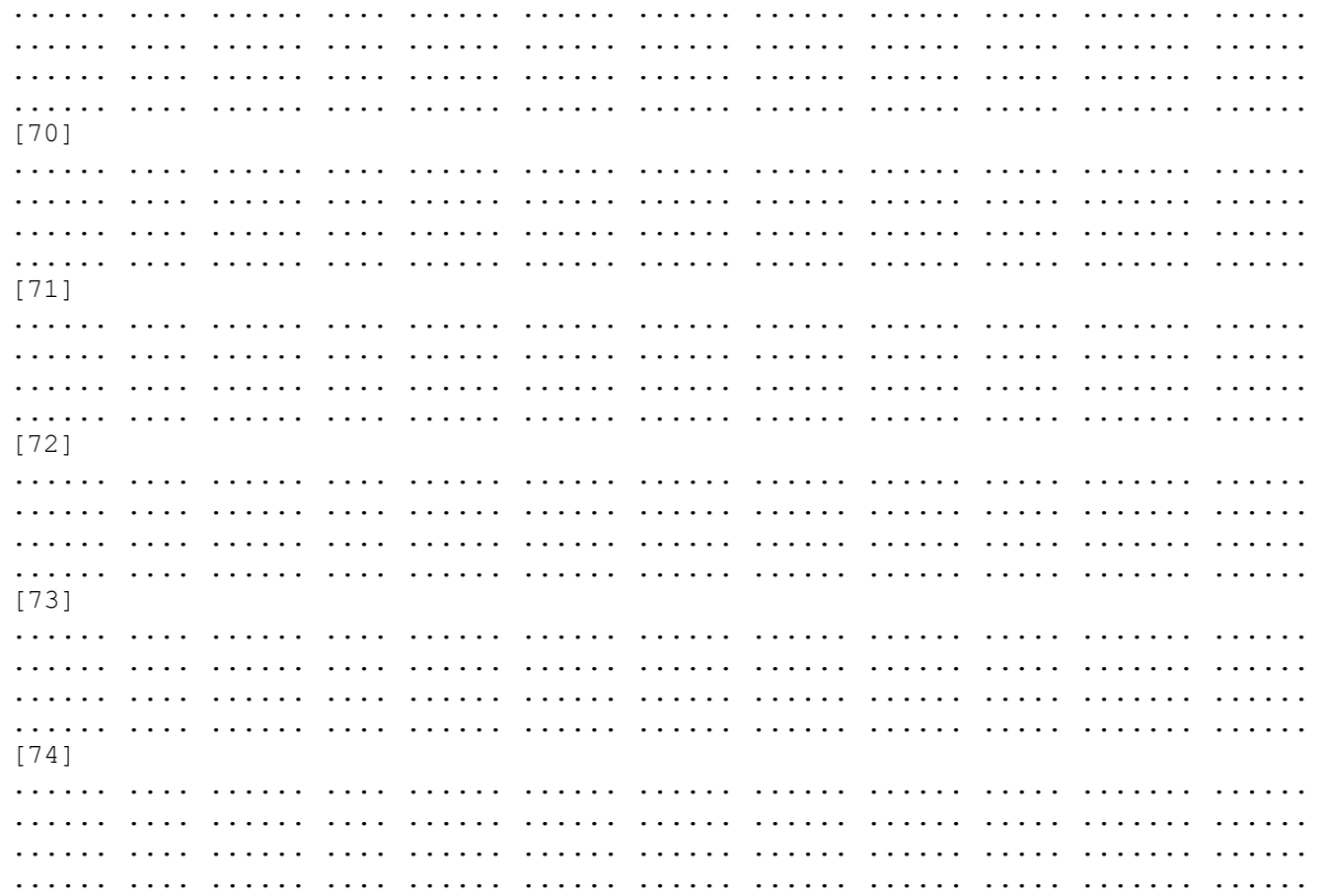

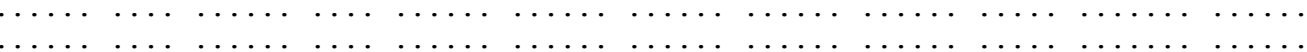


$[75]$

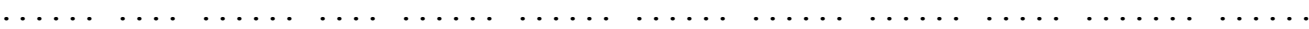

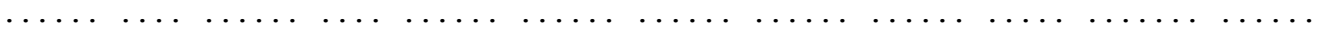

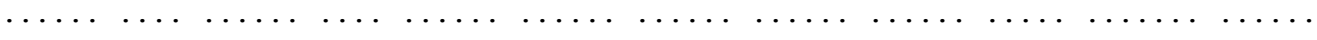

$[76]$

$\ldots \ldots \ldots \ldots \ldots \ldots \ldots \ldots \ldots \ldots$

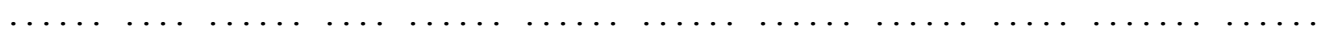

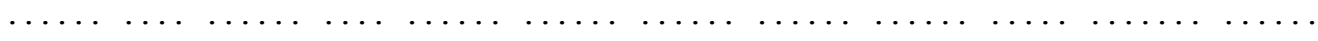

$[77]$

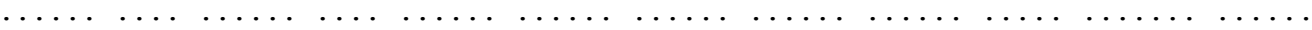

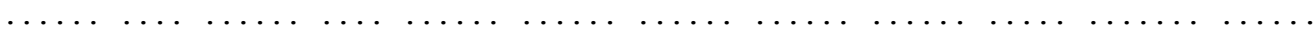

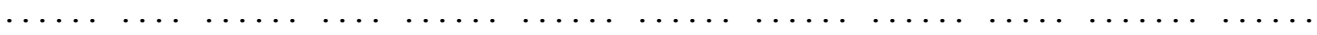

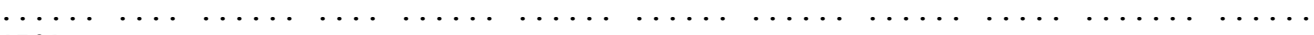

$[78]$

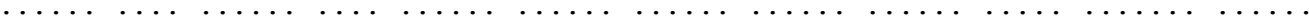

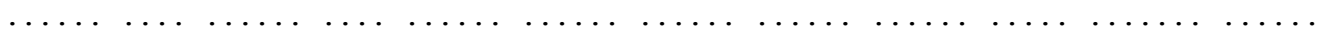

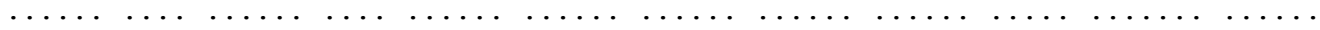

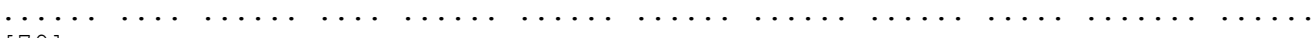

$[79]$

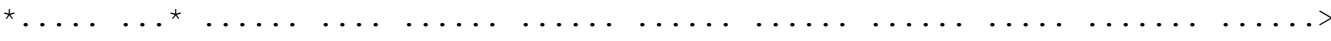

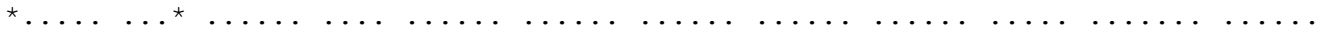

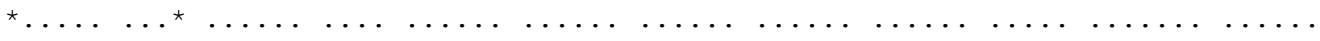

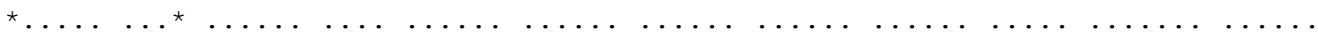

$[80]$

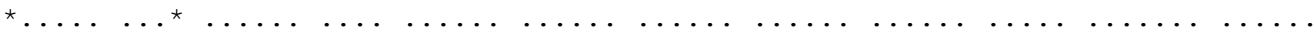

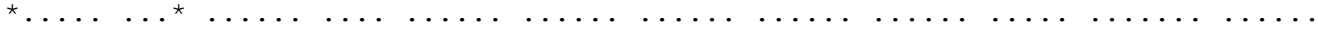

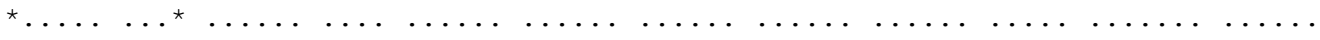

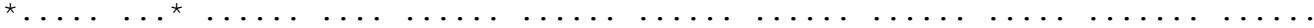

$[81]$

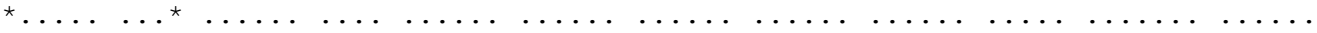

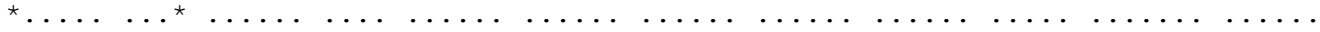

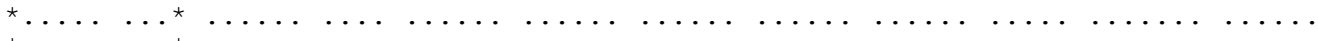

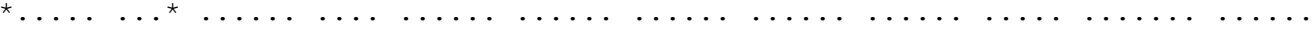

[82]

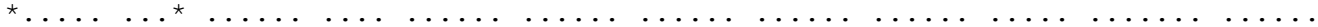

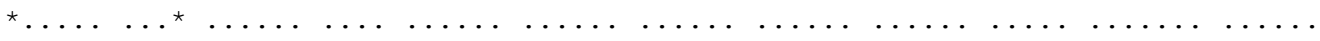

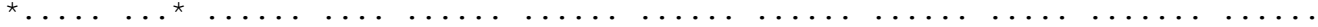

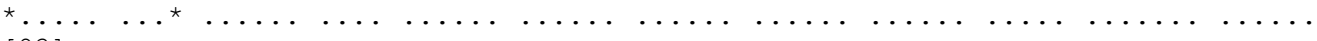

[83]

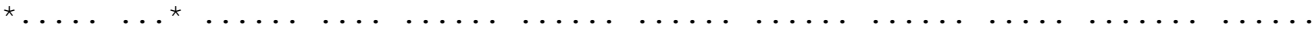

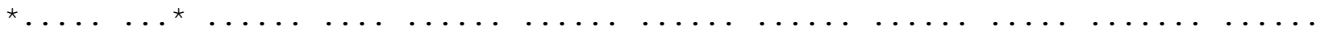

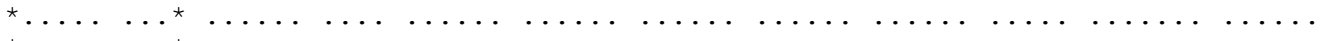

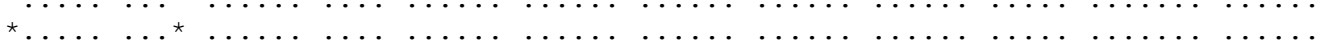

$00 \quad$ PPPPPPPP

UU RRRRRRRR TTTTTTTT RCLA PPPPPPPP PPPPPPPP CCCCCCCC

TT MMMMMMMM MMMMMMMM RBBBND SSSSSSSS LLLLLLLL TTTTTTTT

OOOC7LLLLLLLI

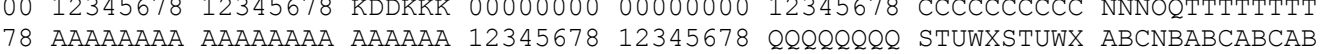

[69]

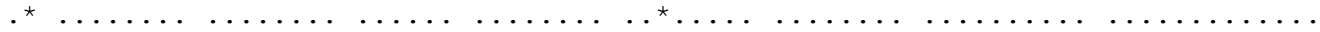

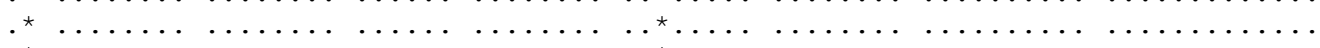

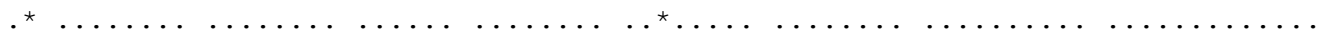

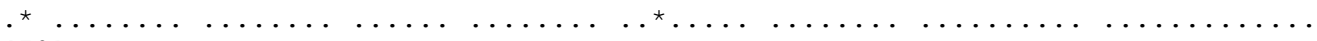

$[70]$

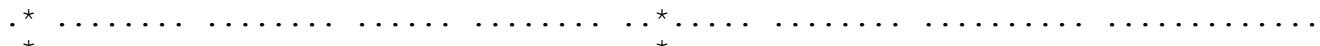

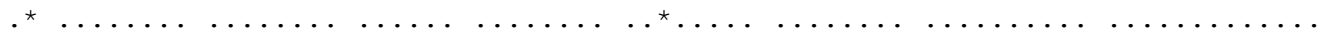

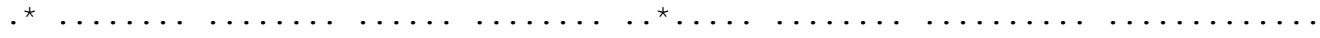

$[71]$

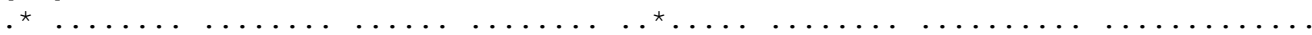

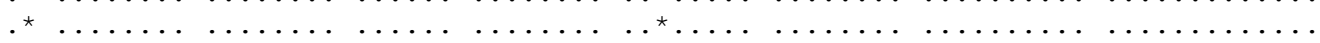

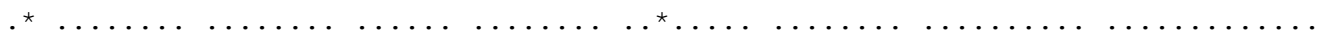

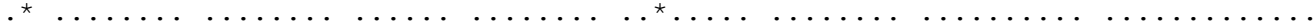

$[72]$

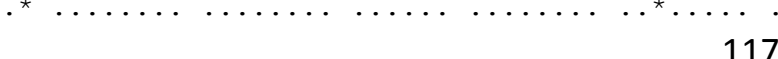




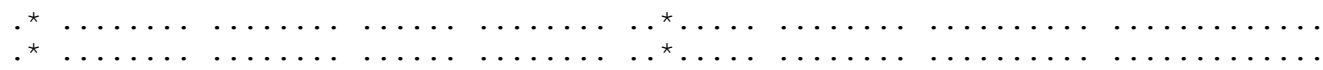

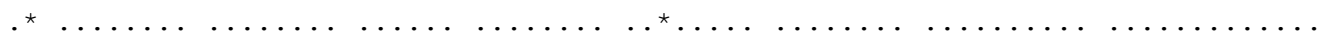

$[73]$

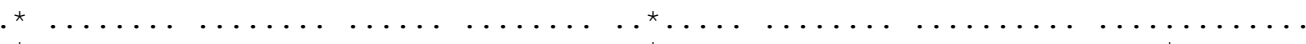

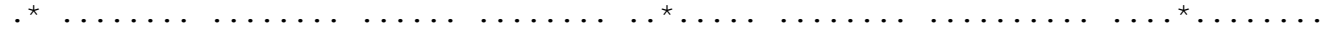

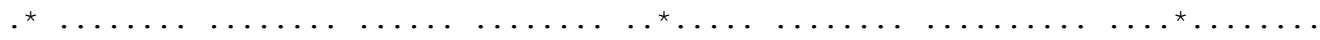

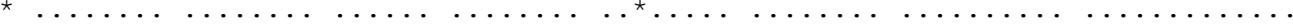

$[74]$

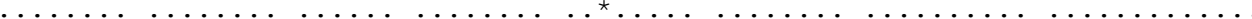

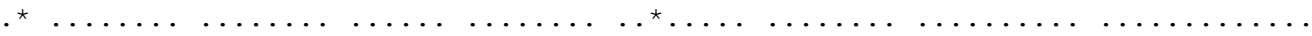

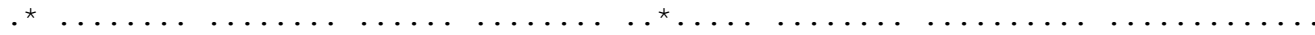

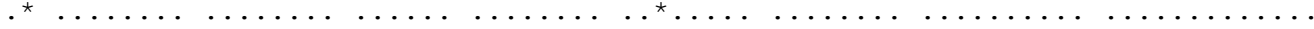

$[75]$

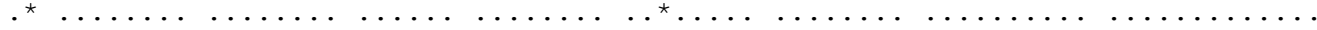

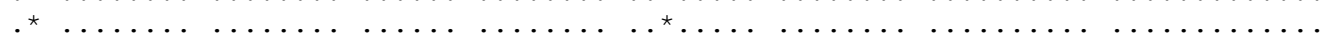

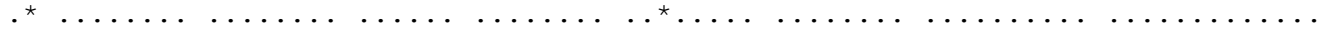

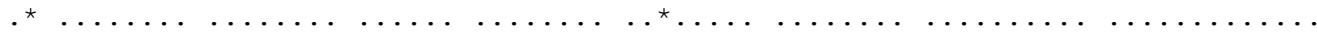

$[76]$

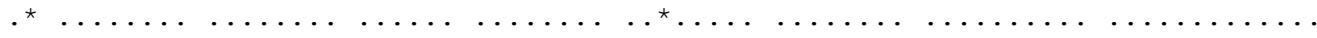

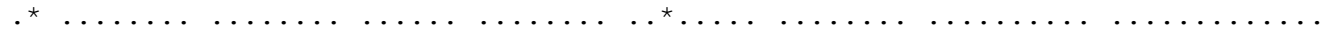

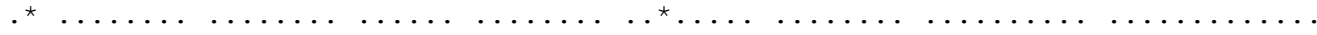

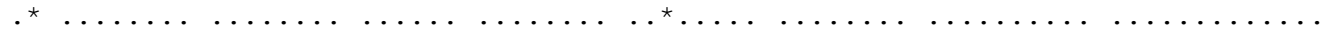

$[77]$

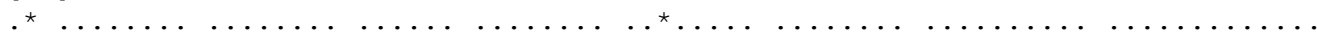

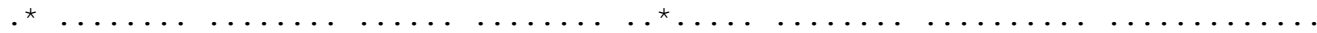

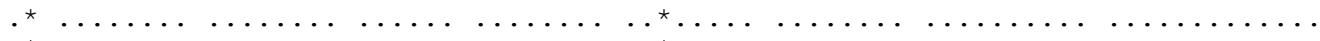

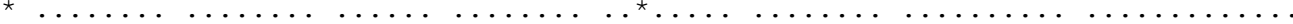

$[78]$

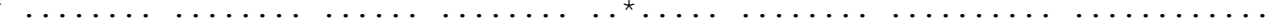

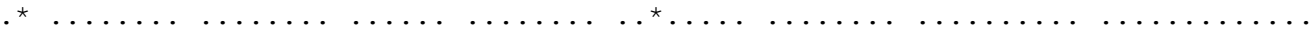

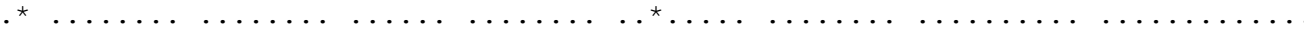

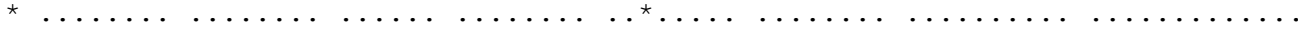

$[79]$

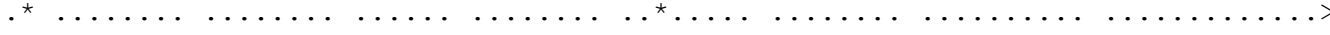

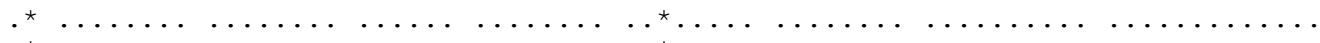

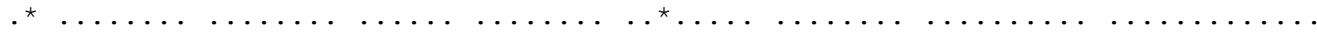

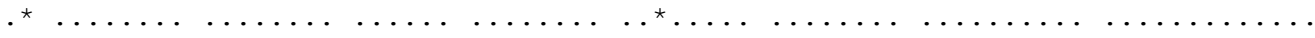

$[80]$

${ }^{\star} \ldots \ldots \ldots \ldots \ldots \ldots \ldots \ldots \ldots \ldots$

${ }^{\star} \quad \ldots \ldots \ldots \ldots \ldots \ldots$

${ }_{\star}^{\star} \cdots \cdots \cdots \cdots$

[81]

${ }^{\star} \ldots \ldots \ldots \ldots \ldots \ldots \ldots$

${ }^{\star} \ldots \ldots \ldots \ldots \ldots$

${ }^{\star} \ldots \ldots \ldots \ldots \ldots \ldots \ldots$

[82]

${ }^{\star} \ldots \ldots \ldots \ldots \ldots \ldots \ldots$

${ }^{\star} \ldots \ldots \ldots \ldots \ldots \ldots \ldots$

${ }_{[83]}^{\star} \ldots \ldots \ldots \ldots \ldots \ldots$

${ }^{\star} \ldots \ldots \ldots \ldots \ldots \ldots \ldots$

${ }^{\star} \ldots \ldots \ldots \ldots \ldots \ldots \ldots$

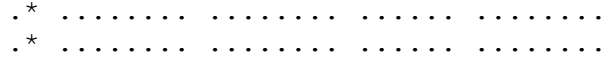

${ }^{\star} \ldots \ldots \ldots \ldots \ldots \ldots \ldots \ldots \ldots$

${ }^{\star} \ldots \ldots \ldots \ldots \ldots \ldots \ldots \ldots \ldots \ldots \ldots \ldots \ldots \ldots$

${ }^{\star} \ldots \ldots \ldots \ldots \ldots \ldots \ldots \ldots \ldots$

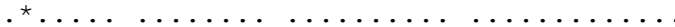

8888888

I888888 $7777777 \mathrm{TT} \quad \mathrm{EEEEE} 55$

F777777888 PPP ABCXABCHНCCC88888 00

LABCABC 77788888 BBBBBBB55TTT77777 SS

THHHHHHUUU77777KKKKKKKAAUUUTTTTT PQ

CBBBRRRABCUABCR2222555PDABCSTUWX 11

[69]

$\ldots \ldots \ldots \ldots \ldots \ldots \ldots \ldots \ldots \ldots \ldots \ldots \ldots \ldots \ldots$

$\ldots \ldots \ldots \ldots \ldots \ldots{ }^{\star \star} \ldots{ }^{\star}{ }^{\star}$ $\ldots \ldots \ldots \ldots \ldots \ldots{ }^{\star} \ldots \ldots{ }^{\star}$. 


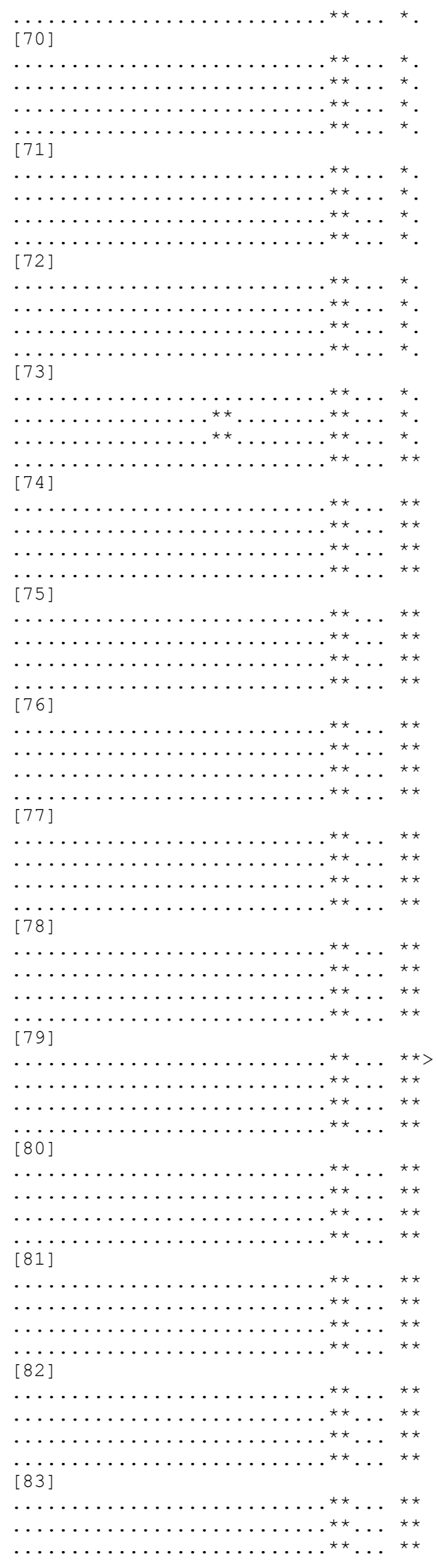




\section{$\ldots \ldots \ldots \ldots \ldots \ldots \ldots \ldots \ldots \ldots$}

EVENT SUMMARY SECTION:

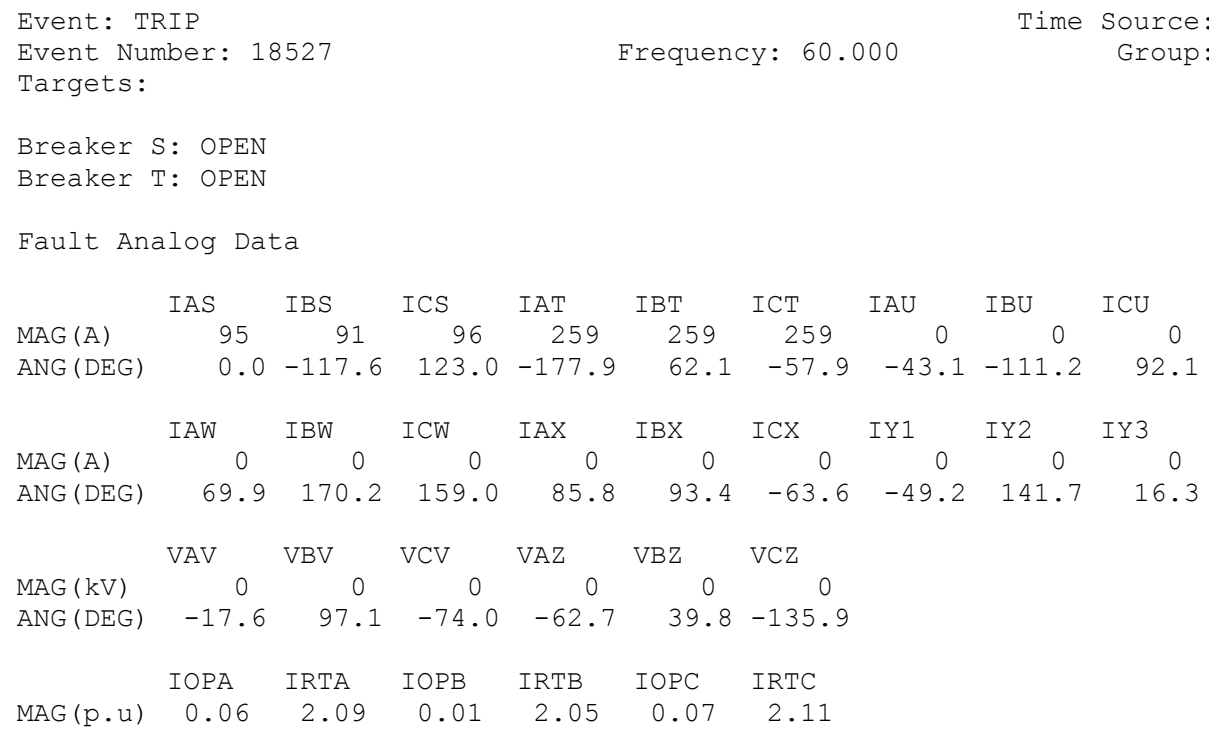




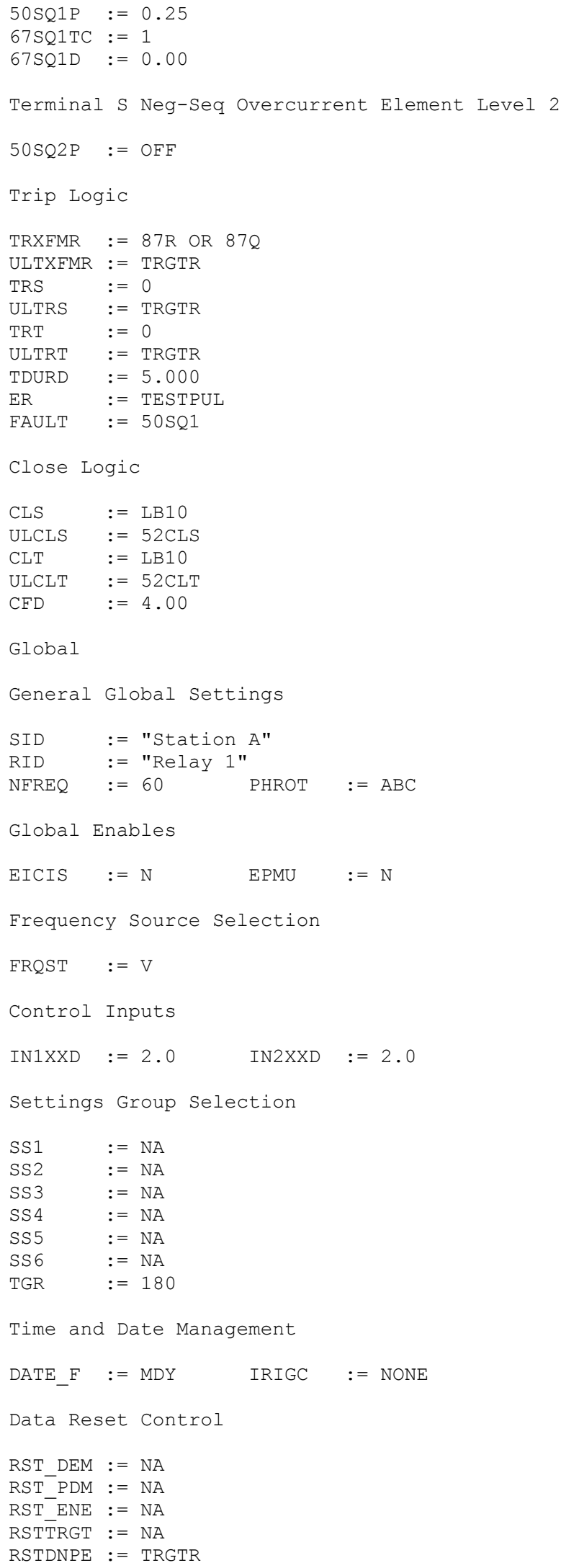




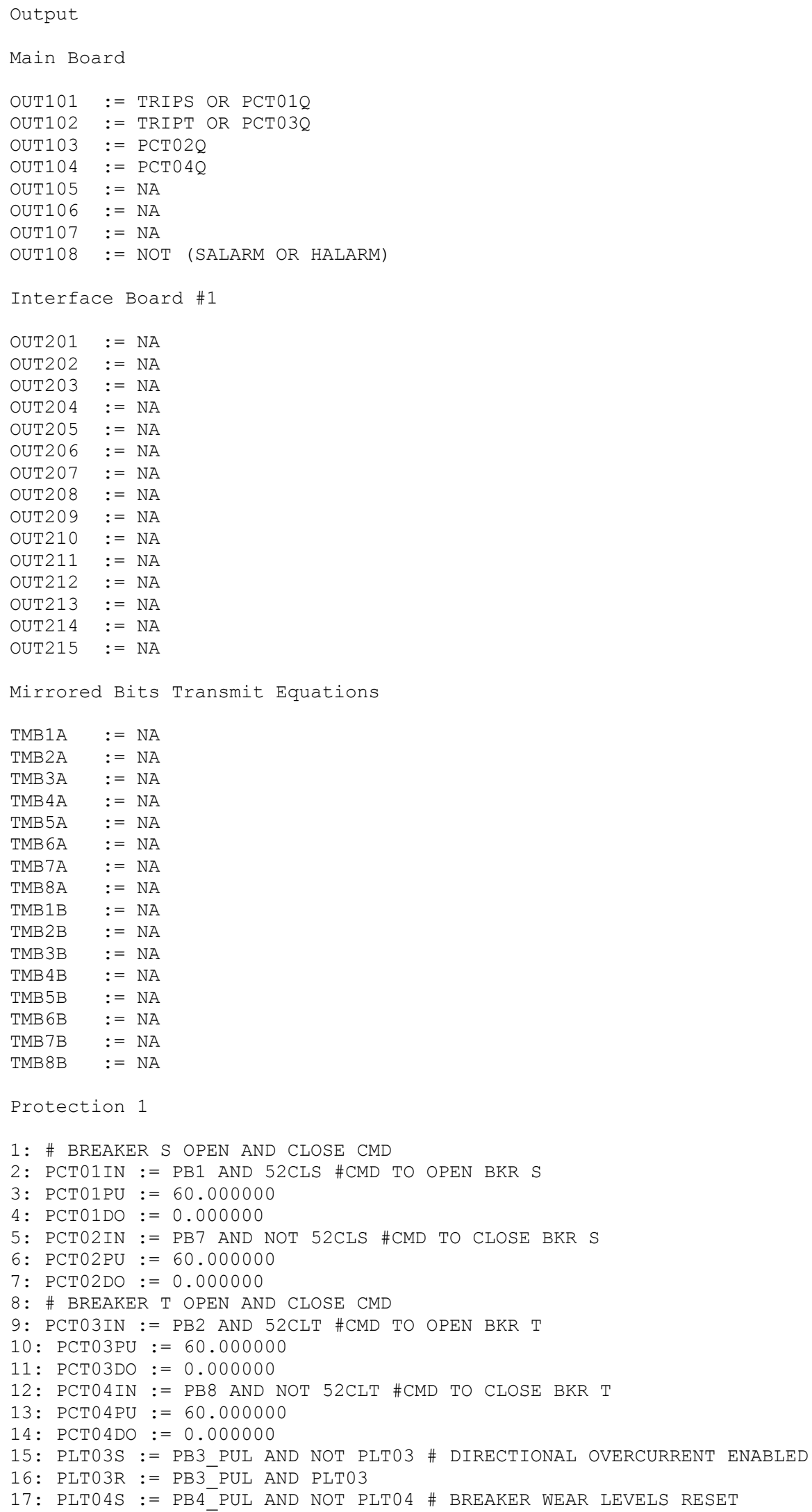


18: PLTO4R $:=($ PB4 PUL AND PLTO4) OR RST BKS OR RST BKT

19: PLTO9S := PB9 PUL AND NOT PLT09 \# ADĀPTIVE OVERC $\bar{C}$ ARRENT ENABLED

20: PLTO9R := PB9 PUL AND PLTO9

Alias

Relay Aliases

(RW Bit or Analog Qty. 7 Character Alias [0-9 A-Z ])

1: EN, "EN_RLY"

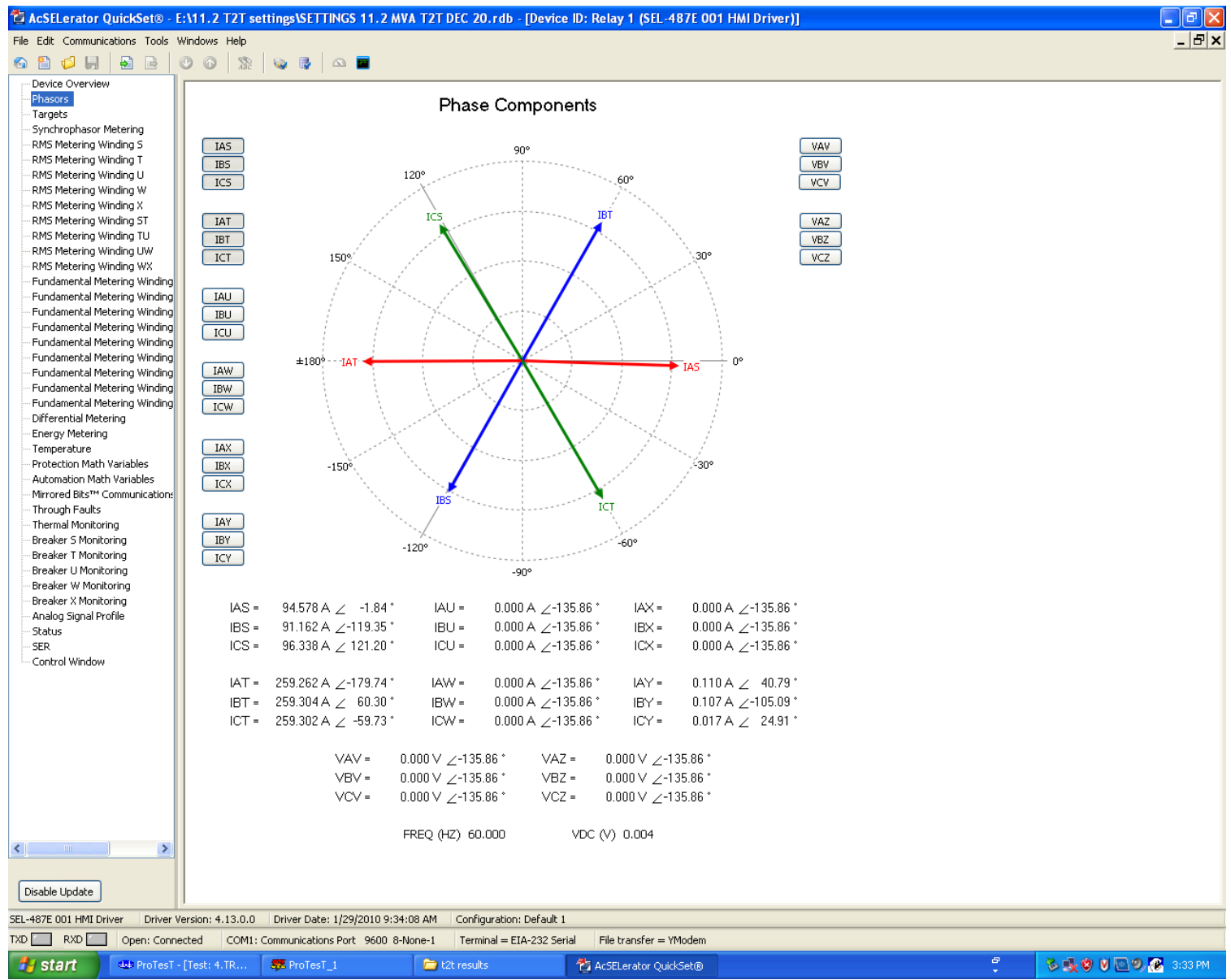

Figure F.1: Phasors screenshot for the 11.2-MVA transformer for turn-to-turn fault. 


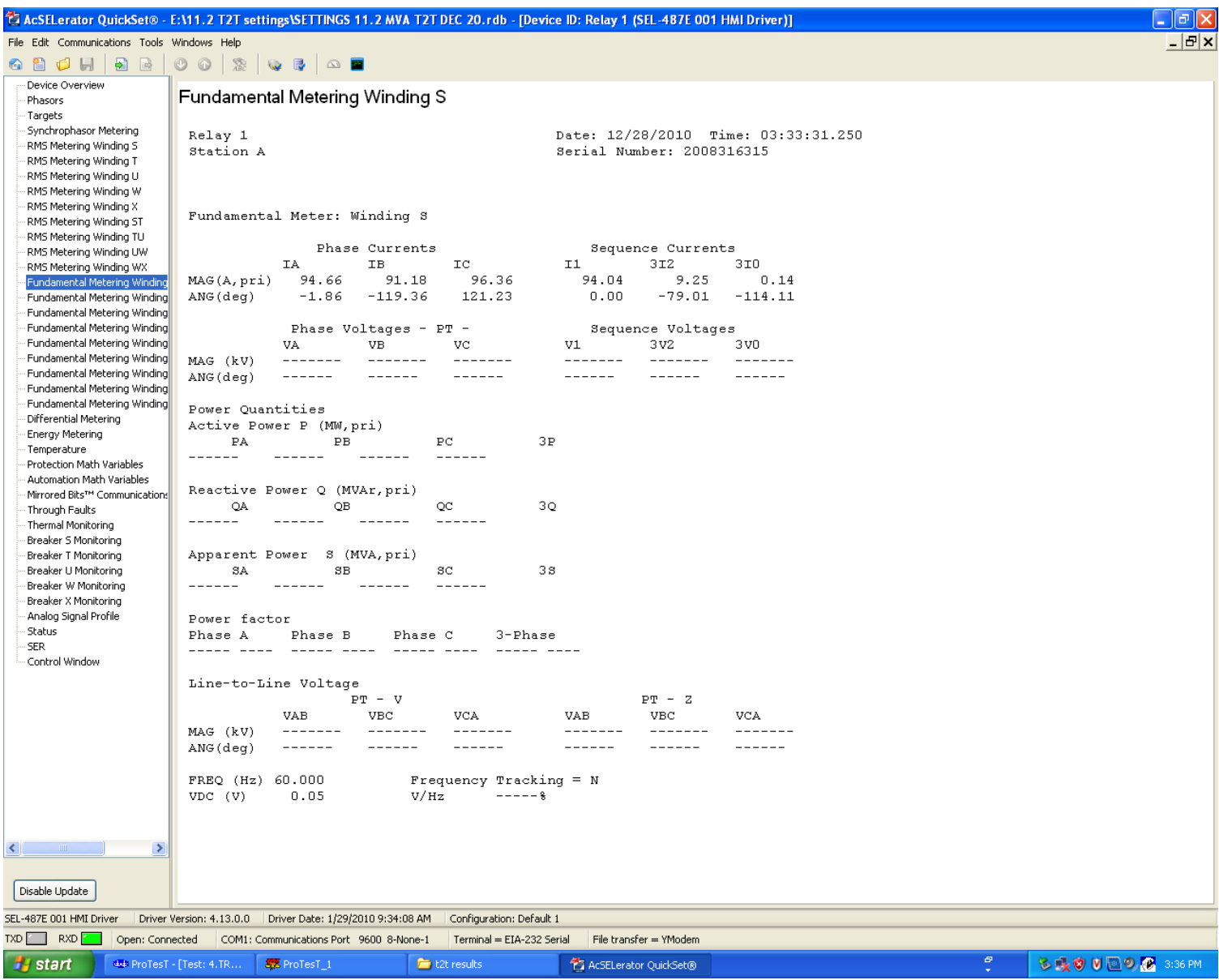

Figure F.2: Winding S Fundamental Metering for the 11.2-MVA transformer for turn-to-turn fault. 


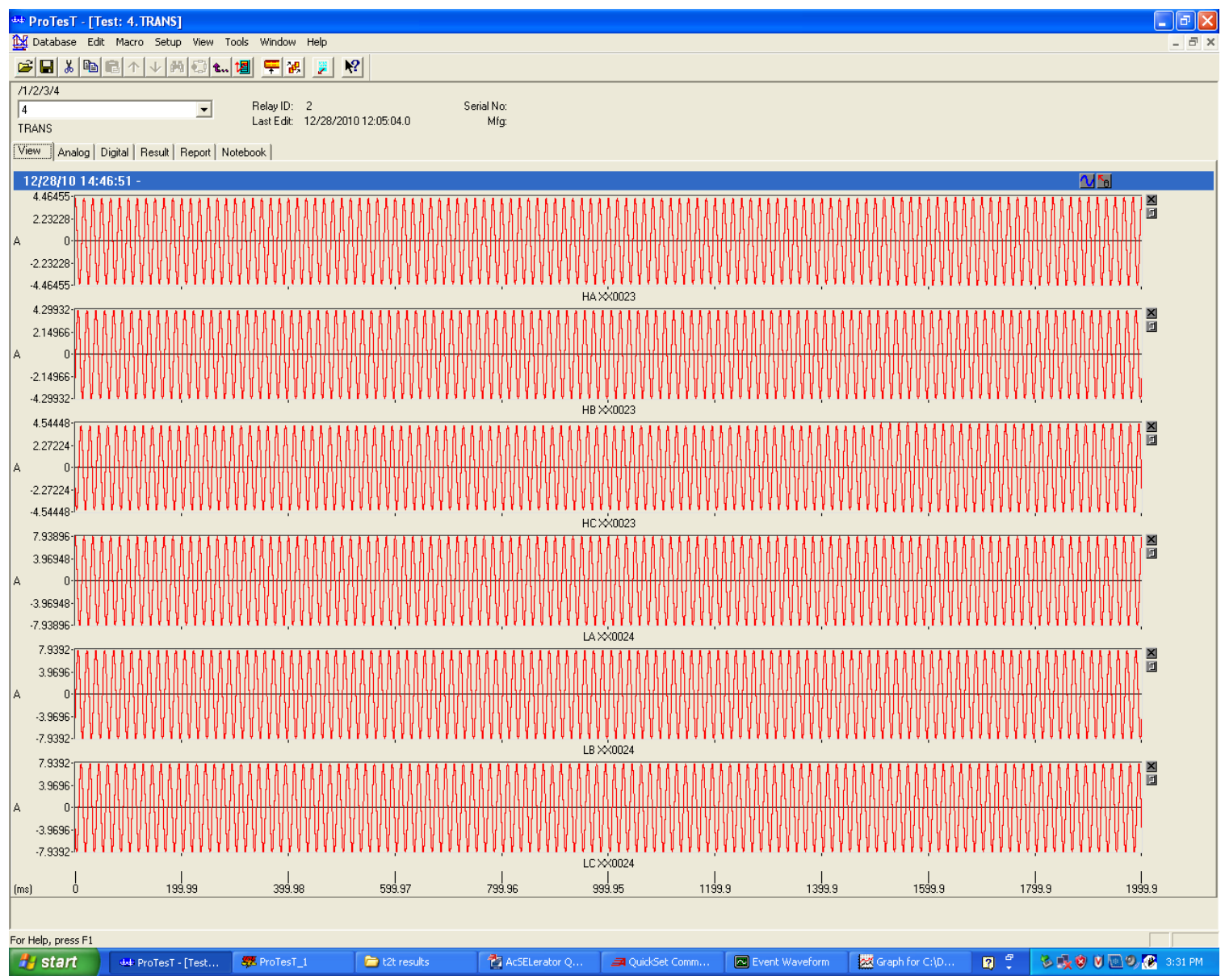

Figure F.3: Currents from CTs in TRANS macro for the 11.2-MVA transformer for turn-to-turn fault. 


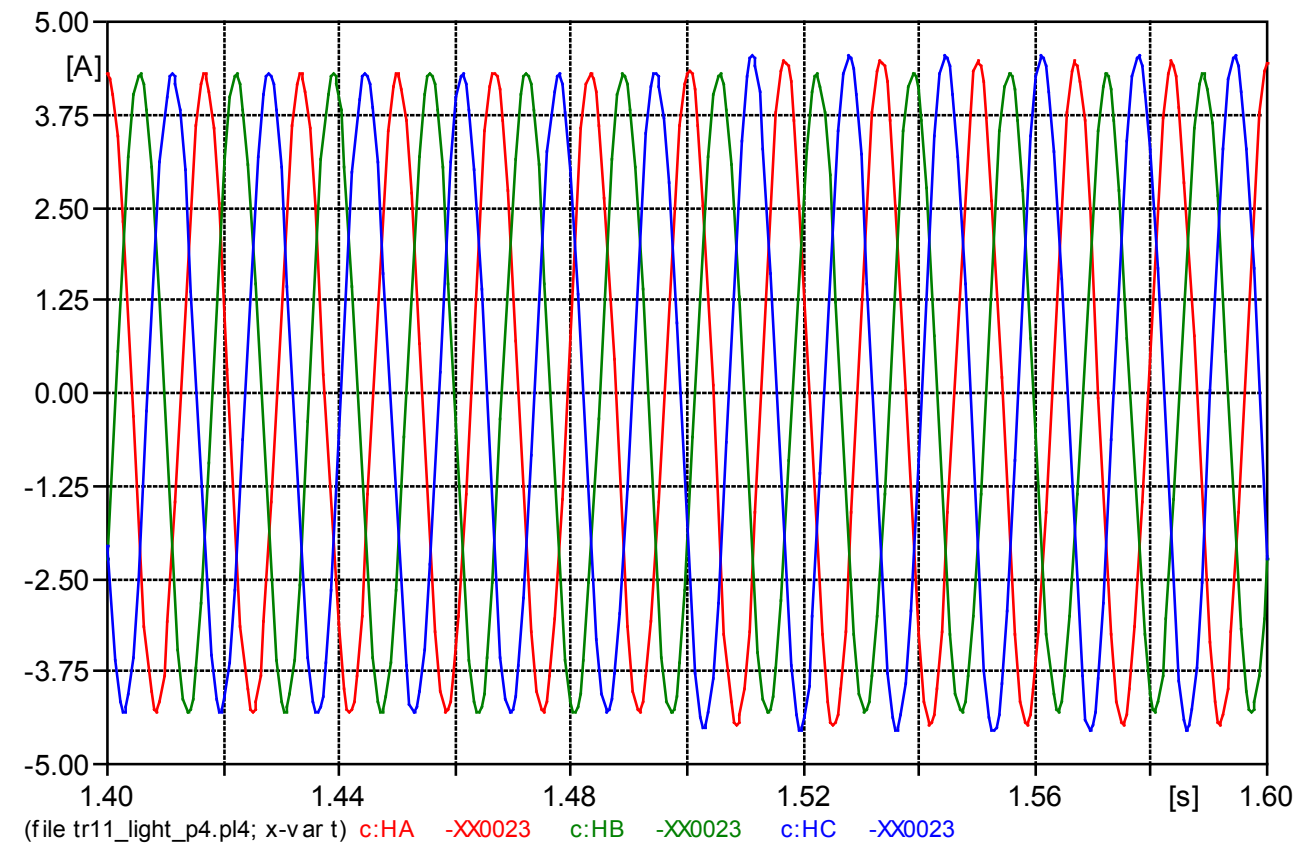

Figure F.4: ATP currents supplied to the SEL-487E relay from high-side CTs of the 11.2-MVA transformer for turn-to-turn fault.

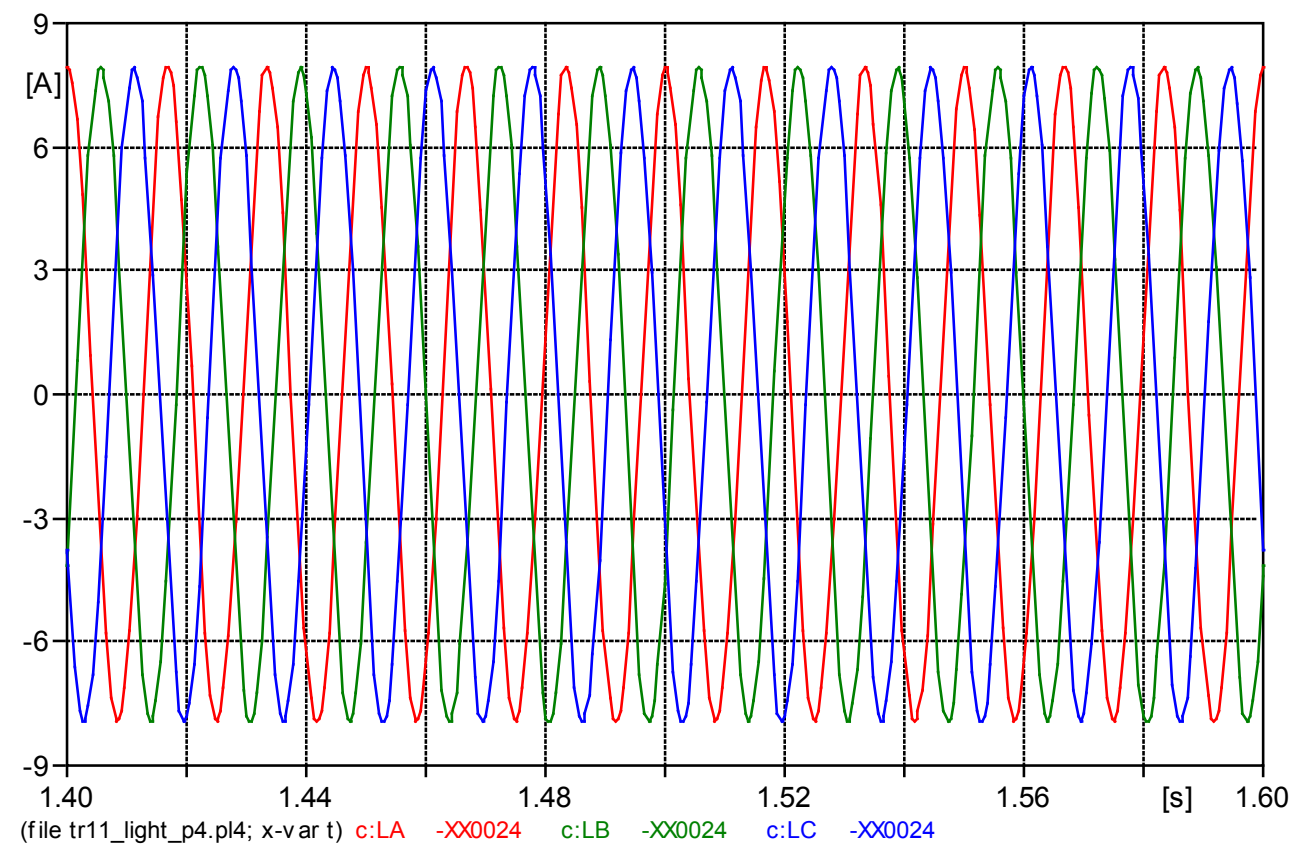

Figure F.5: ATP currents supplied to the SEL-487E relay from low-side CTs of the 11.2-MVA transformer for turn-to-turn fault. 


\section{F.2 The 290-MVA transformer Event Report for turn-to-turn fault} REPORT HEADER:

$=>\mathrm{EVE} 18532$

Relay 1

Station A

FID $=S E L-487 E-R 103-V 0-Z 001001-D 20081008$

ANALOG SECTION:

\begin{tabular}{|c|c|c|c|c|c|}
\hline & & & crents & (Pri & Amps ) \\
\hline IAS & IBS & ICS & IAT & IBT & ICT \\
\hline [57] & & & & & \\
\hline 268 & -375 & 106 & -7641 & 9807 & -2161 \\
\hline 278 & 93 & -372 & -6916 & -3165 & 10078 \\
\hline-268 & 375 & -106 & 7643 & -9811 & 2161 \\
\hline-278 & -94 & 372 & 6913 & 3165 & -10078 \\
\hline [58] & & & & & \\
\hline 269 & -375 & 107 & -7643 & 9809 & -2165 \\
\hline 278 & 94 & -372 & -6910 & -3167 & 10093 \\
\hline-268 & 375 & -106 & 7638 & -9804 & 2158 \\
\hline-278 & -93 & 372 & 6916 & 3164 & -10087 \\
\hline [59] & & & & & \\
\hline 269 & -375 & 106 & -7636 & 9808 & -2154 \\
\hline 278 & 93 & -372 & -6916 & -3160 & 10073 \\
\hline-269 & 375 & -106 & 7644 & -9815 & 2161 \\
\hline-278 & -94 & 372 & 6912 & 3161 & -10081 \\
\hline [60 ] & & & & & \\
\hline 268 & -375 & 106 & -7643 & 9816 & -2160 \\
\hline 284 & 88 & -372 & -6918 & -3162 & 10081 \\
\hline-267 & 374 & -106 & 7643 & -9816 & 2161 \\
\hline-296 & -76 & 372 & 6920 & 3169 & -10077 \\
\hline [61] & & & & & \\
\hline 266 & -372 & 106 & -7650 & 9807 & -2161 \\
\hline 303 & 69 & -372 & -6908 & -3172 & 10076 \\
\hline-265 & 372 & -106 & 7645 & -9804 & 2153 \\
\hline-303 & -69 & 372 & 6910 & 3166 & -10072 \\
\hline [62] & & & & & \\
\hline 266 & -372 & 106 & -7644 & 9812 & -2157 \\
\hline 303 & 69 & -372 & -6915 & -3164 & 10071 \\
\hline-266 & 372 & -106 & 7646 & -9818 & 2165 \\
\hline-303 & -69 & 372 & 6914 & 3162 & -10081 \\
\hline [63] & & & & & \\
\hline 265 & -372 & 106 & -7644 & 9816 & -2157 \\
\hline 303 & 69 & -372 & -6917 & -3161 & 10083 \\
\hline-265 & 372 & -106 & 7643 & -9809 & 2147 \\
\hline-303 & -69 & 372 & 6917 & 3167 & -10081 \\
\hline [64 ] & & & & & \\
\hline 266 & -372 & 106 & -7648 & 9811 & -2152 \\
\hline 303 & 69 & -372 & -6912 & -3167 & 10086 \\
\hline-266 & 372 & -107 & 7647 & -9816 & 2156 \\
\hline-303 & -69 & 372 & 6911 & 3169 & -10083 \\
\hline [65] & & & & & \\
\hline 266 & -372 & 106 & -7646 & 9812 & -2154 \\
\hline 303 & 69 & -372 & -6912 & -3177 & 10080 \\
\hline-266 & 372 & -106 & 7649 & -9806 & 2153 \\
\hline-303 & -69 & 372 & 6908 & 3173 & -10083 \\
\hline [66] & & & & & \\
\hline 266 & -372 & 106 & -7642 & 9805 & -2154 \\
\hline 303 & 69 & -372 & -6914 & -3169 & 10077 \\
\hline-266 & 372 & -106 & 7638 & -9812 & 2158 \\
\hline-303 & -69 & 372 & 6916 & 3170 & -10068 \\
\hline [67] & & & & & \\
\hline 266 & -372 & 106 & -7644 & 9813 & -2166 \\
\hline 303 & 69 & -372 & -6911 & -3171 & 10073 \\
\hline
\end{tabular}

\section{7}

Date: 12/28/2010 Time: 05:00:47.956

Serial Number: 2008316315

Event Number $=18532 \quad \mathrm{CID}=0 \times 97 \mathrm{~B} 3$

IAU IBU ICU

$\begin{array}{lll}0 & 0 & 0 \\ 0 & 0 & 0 \\ 0 & 0 & 0 \\ 0 & 0 & 0 \\ 0 & 0 & 0 \\ 0 & 0 & 0 \\ 0 & 0 & 0 \\ 0 & 0 & 0 \\ 0 & 0 & 0 \\ 0 & 0 & 0 \\ 0 & 0 & 0 \\ 0 & 0 & 0 \\ 0 & 0 & 0 \\ 0 & 0 & 0 \\ 0 & 0 & 0 \\ 0 & 0 & 0 \\ 0 & 0 & \end{array}$

$\begin{array}{lll}0 & 0 & 0 \\ 0 & 0 & 0 \\ 0 & 0 & 0 \\ 0 & 0 & 0\end{array}$

$$
0
$$$$
\begin{array}{lll}
0 & 0 & 0 \\
0 & 0 & 0 \\
0 & 0 & 0 \\
0 & 0 & 0
\end{array}
$$

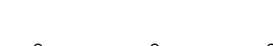$$
\begin{array}{lll}
0 & 0 & 0 \\
0 & 0 & 0 \\
0 & 0 & 0 \\
0 & 0 & 0
\end{array}
$$$$
\begin{array}{lll}
0 & 0 & 0
\end{array}
$$$$
\begin{array}{lll}
0 & 0 & 0 \\
0 & 0 & 0 \\
0 & 0 & 0 \\
0 & 0 & 0
\end{array}
$$$$
\begin{array}{lll}
0 & 0 & 0 \\
0 & 0 & 0 \\
0 & 0 & 0 \\
0 & 0 & 0
\end{array}
$$$$
\begin{array}{lll}
0 & 0 & 0>\text { trigger row } \\
0 & 0 & 0 \\
0 & 0 & 0 \\
0 & 0 & 0
\end{array}
$$$$
\begin{array}{lll}
0 & 0 & 0 \\
0 & 0 & 0 * 1.25 \text { cycles after trigger }
\end{array}
$$ 


$\begin{array}{crrrrrlll}-266 & 372 & -106 & 7647 & -9809 & 2162 & 0 & 0 & 0 \\ -303 & -69 & 372 & 6909 & 3174 & -10081 & 0 & 0 & 0 \\ {[68]} & & & & & & & & \\ 266 & -372 & 106 & -7642 & 9810 & -2156 & 0 & 0 & 0 \\ 303 & 69 & -372 & -6913 & -3174 & 10082 & 0 & 0 & 0 \\ -266 & 372 & -106 & 7646 & -9808 & 2160 & 0 & 0 & 0 \\ -303 & -69 & 372 & 6913 & 3175 & -10080 & 0 & 0 & 0 \\ {[69]} & & & & & & & & \\ 266 & -372 & 106 & -7649 & 9809 & -2153 & 0 & 0 & 0 \\ 303 & 69 & -372 & -6915 & -3175 & 10072 & 0 & 0 & 0 \\ -266 & 372 & -106 & 7646 & -9808 & 2152 & 0 & 0 & 0 \\ -303 & -69 & 372 & 6914 & 3172 & -10070 & 0 & 0 & 0 \\ {[70]} & & & & & & & & \\ 266 & -372 & 106 & -7648 & 9813 & -2159 & 0 & 0 & 0 \\ 303 & 69 & -372 & -6912 & -3176 & 10076 & 0 & 0 & 0 \\ -266 & 372 & -106 & 7645 & -9812 & 2151 & 0 & 0 & 0 \\ -303 & -69 & 372 & 6910 & 3170 & -10077 & 0 & 0 & 0 \\ {[71]} & & & & & & & & \\ 265 & -372 & 106 & -7645 & 9806 & -2152 & 0 & 0 & 0 \\ 303 & 69 & -372 & -6913 & -3164 & 10080 & 0 & 0 & 0 \\ -266 & 372 & -106 & 7652 & -9807 & 2161 & 0 & 0 & 0 \\ -303 & -69 & 372 & 6915 & 3170 & -10089 & 0 & 0 & 0\end{array}$

DIGITAL SECTION:

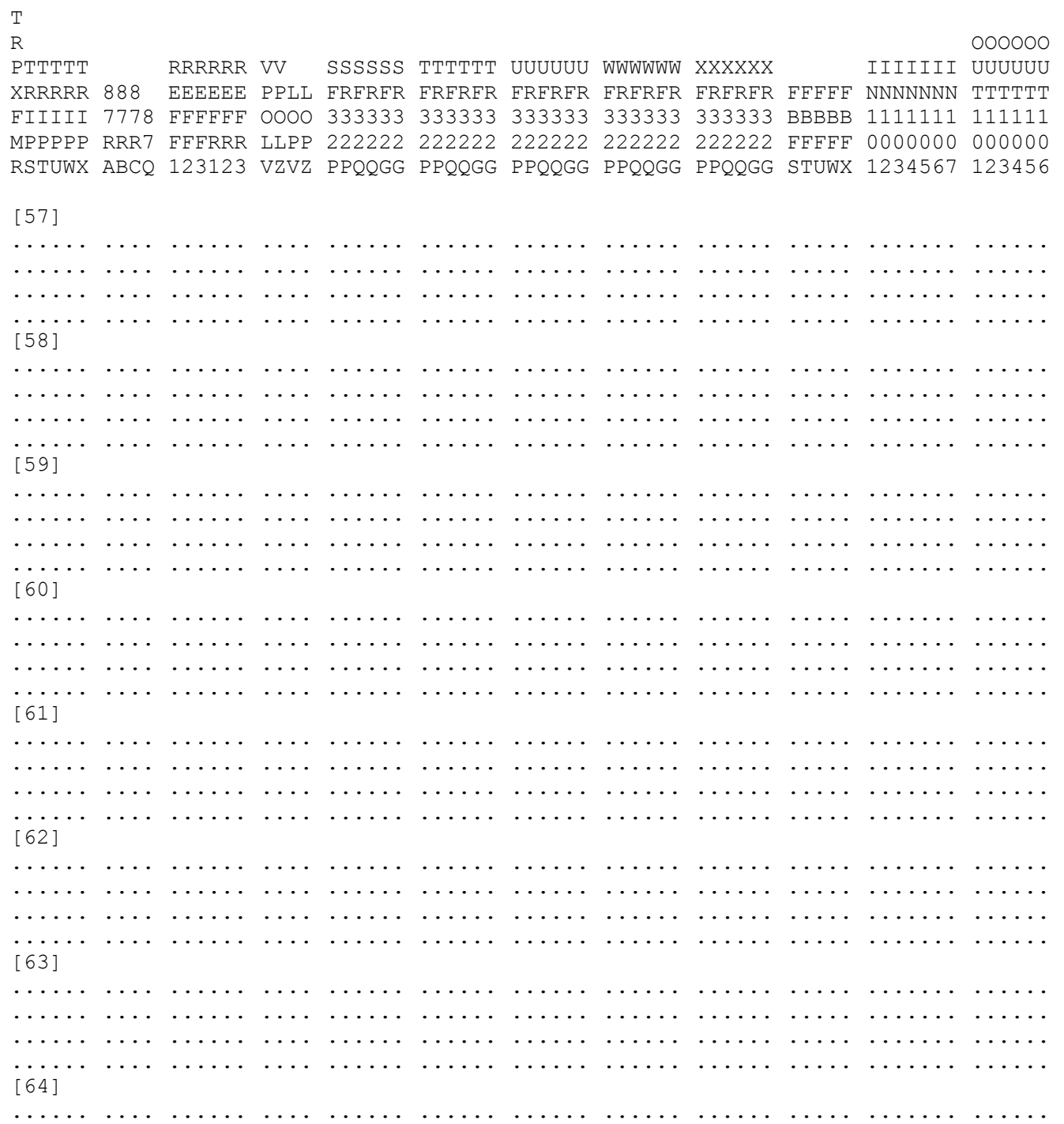




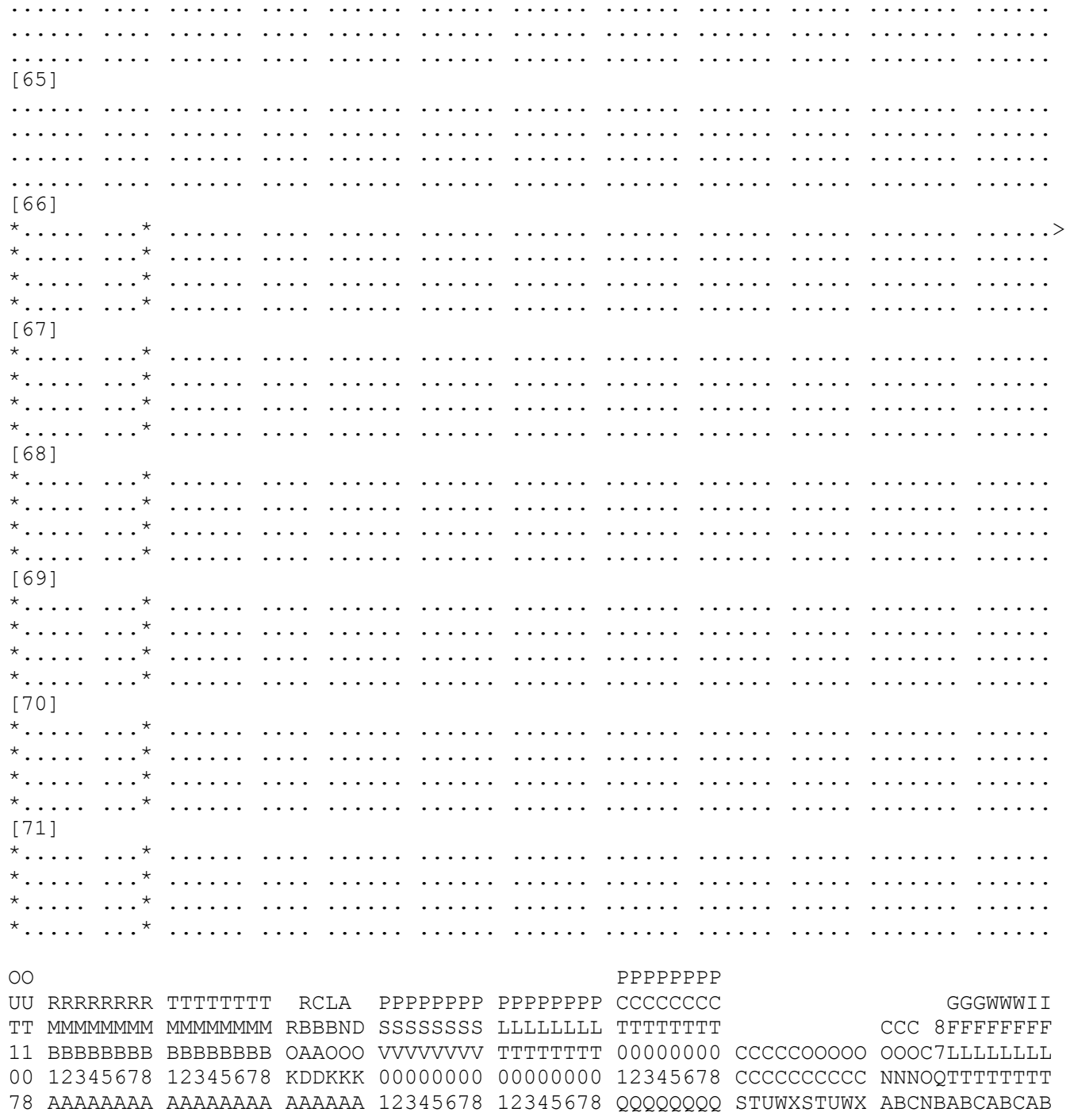




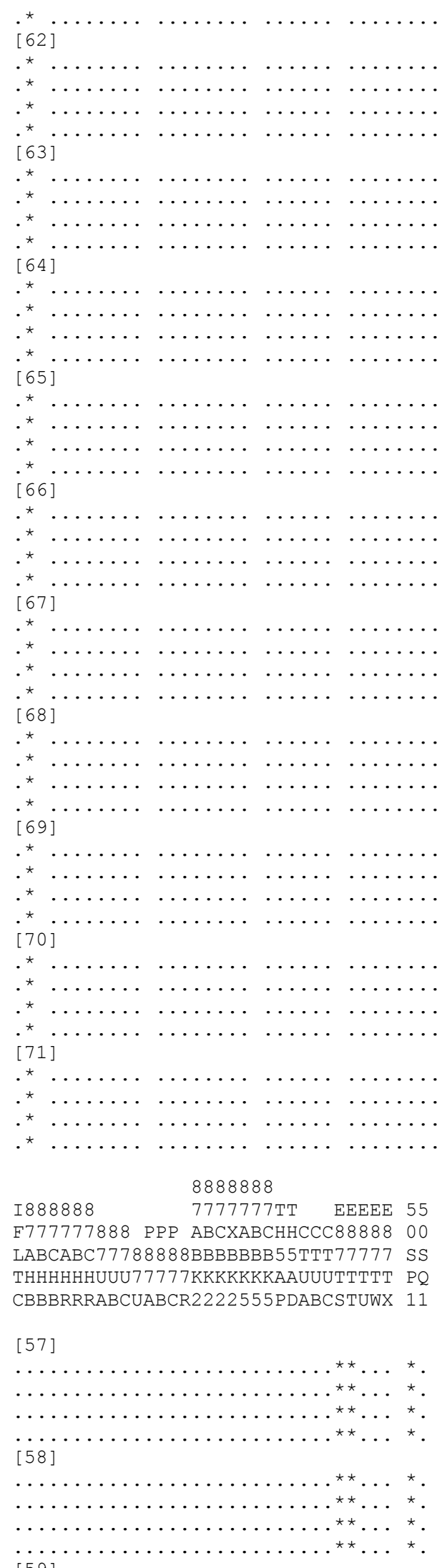

${ }^{\star} \ldots \ldots \ldots \ldots \ldots \ldots \ldots \ldots$

$\ldots{ }^{\star} \ldots \ldots \ldots \ldots \ldots \ldots \ldots \ldots \ldots$

${ }^{\star} \ldots \ldots \ldots \ldots \ldots \ldots \ldots \ldots$

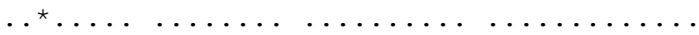

${ }^{\star} \ldots \ldots \ldots \ldots \ldots \ldots \ldots \ldots$

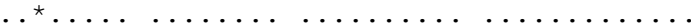

${ }^{\star} \ldots \ldots \ldots \ldots \ldots \ldots \ldots \ldots$

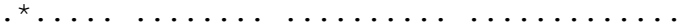

${ }^{\star} \ldots \ldots \ldots \ldots \ldots \ldots \ldots \ldots \ldots \ldots$

${ }^{\star} \ldots \ldots \ldots \ldots \ldots \ldots \ldots \ldots$

$\ldots{ }^{\star} \ldots \ldots . \ldots \ldots \ldots \ldots$

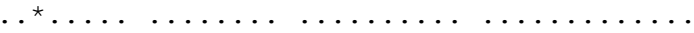

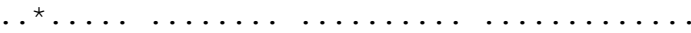

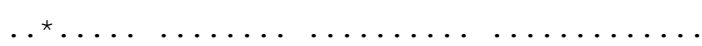

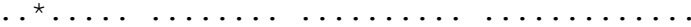

${ }^{\star} \ldots \ldots+\ldots \ldots \ldots \ldots \ldots$

${ }^{\star} \ldots \ldots, \ldots \ldots \ldots, \ldots \ldots \ldots \ldots \ldots$

${ }^{\star} \ldots \ldots \ldots \ldots \ldots \ldots \ldots \ldots$

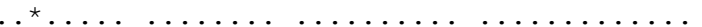

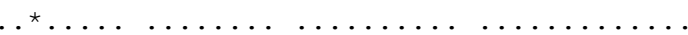

${ }^{\star} \ldots \ldots \ldots \ldots \ldots \ldots \ldots$

${ }^{\star} \ldots \ldots \ldots \ldots \ldots \ldots \ldots \ldots \ldots \ldots \ldots$

${ }^{\star} \ldots \ldots \ldots \ldots \ldots \ldots \ldots$

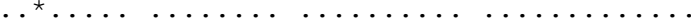

${ }^{\star} \ldots \ldots, \ldots \ldots \ldots \ldots \ldots \ldots \ldots$

${ }^{\star}{ }^{\star} \ldots \ldots \ldots \ldots \ldots \ldots \ldots \ldots$

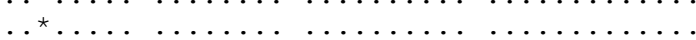

${ }^{\star} \ldots \ldots \ldots \ldots \ldots \ldots \ldots \ldots \ldots$

${ }^{\star} \ldots \ldots \ldots \ldots \ldots \ldots \ldots \ldots$

${ }^{\star} \ldots \ldots \ldots \ldots \ldots \ldots \ldots \ldots \ldots$

${ }^{\star} \ldots \ldots \ldots \ldots \ldots \ldots \ldots \ldots$

${ }^{\star} \ldots \ldots \ldots \ldots \ldots \ldots \ldots$

${ }^{\star} \ldots \ldots \ldots \ldots \ldots \ldots \ldots \ldots$

${ }^{\star} \ldots \ldots \ldots \ldots \ldots \ldots \ldots \ldots$

${ }^{\star} \ldots \ldots \ldots \ldots \ldots \ldots \ldots \ldots \ldots \ldots \ldots \ldots$

${ }^{\star}{ }^{\star} \ldots \ldots \ldots \ldots \ldots \ldots \ldots \ldots \ldots$

${ }^{\star}{ }^{\star} \ldots \ldots \ldots \ldots \ldots \ldots \ldots$

${ }^{\star} \ldots \ldots \ldots \ldots \ldots \ldots \ldots$

${ }^{\star} \ldots \ldots \ldots \ldots \ldots \ldots \ldots \ldots$

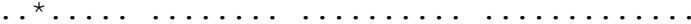

${ }^{\star}{ }^{\star} \ldots \ldots, \ldots \ldots \ldots \ldots \ldots \ldots$

I888888 $7777777 \mathrm{TT} \quad$ EEEEE 55 F777777888 PPP ABCXABCHHCCC88888 00

$[57]$

$\ldots \ldots \ldots \ldots \ldots \ldots \ldots \ldots \ldots \ldots \ldots \ldots \ldots$

$\ldots \ldots \cdots \cdots \cdots \cdots \cdots \cdots^{\star \star} \cdots \cdots^{\star}$

[58] $\ldots \ldots \ldots \ldots \ldots \ldots \ldots \ldots \ldots{ }^{\star \star} \ldots{ }^{\star}$

$\ldots \ldots \ldots \ldots \ldots \ldots \ldots \ldots \ldots \ldots \ldots \ldots$

[59] 


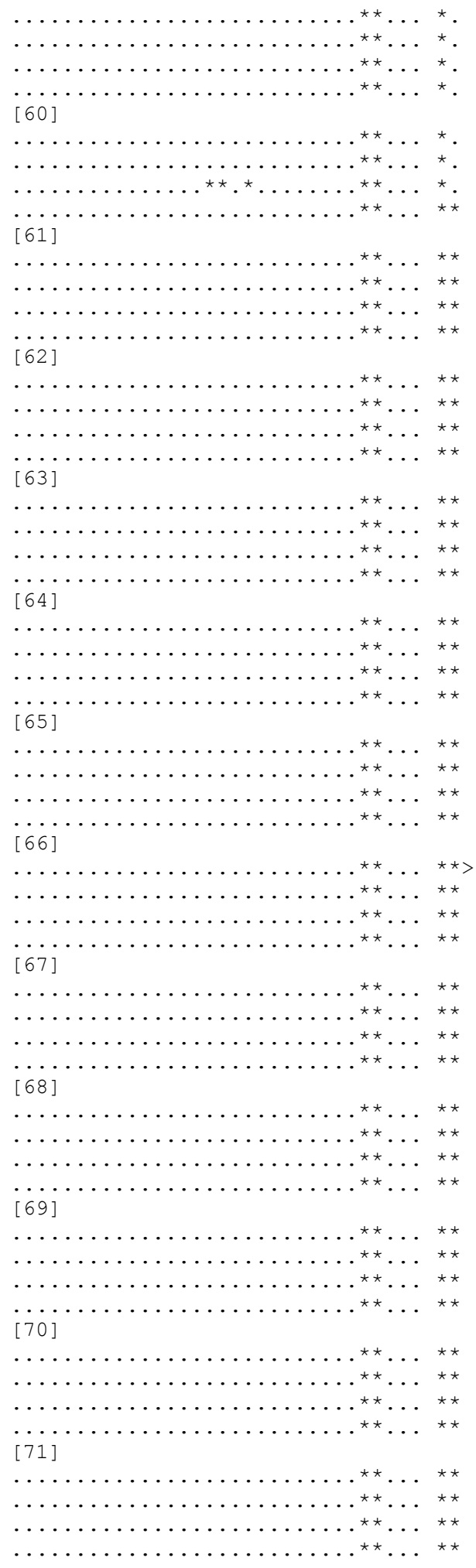

EVENT SUMMARY SECTION:

Event: TRIP

Event Number: 18532

Targets:
Frequency: 50.000

Time Source: OTHER Group: 1 


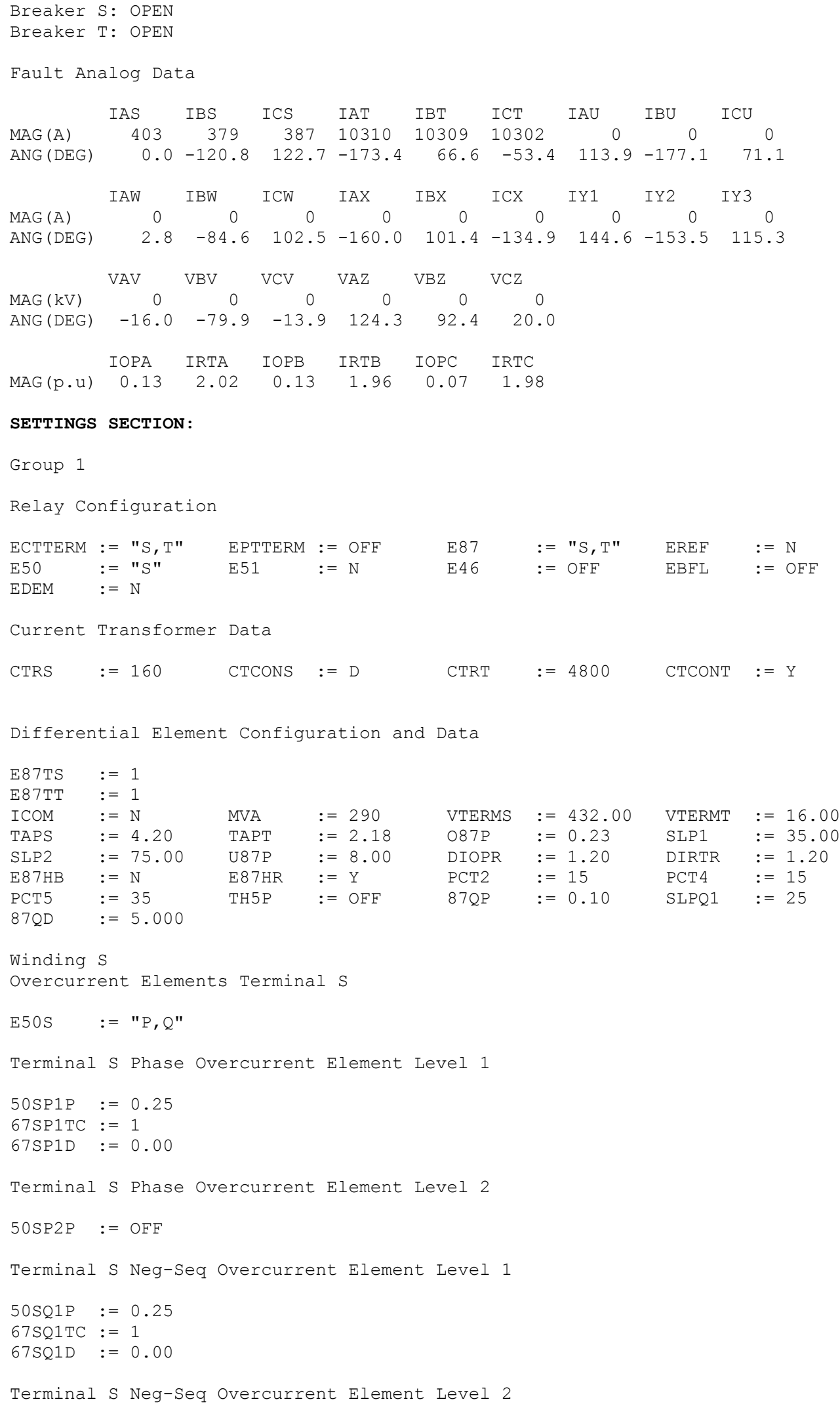

\section{SETTINGS SECTION:}




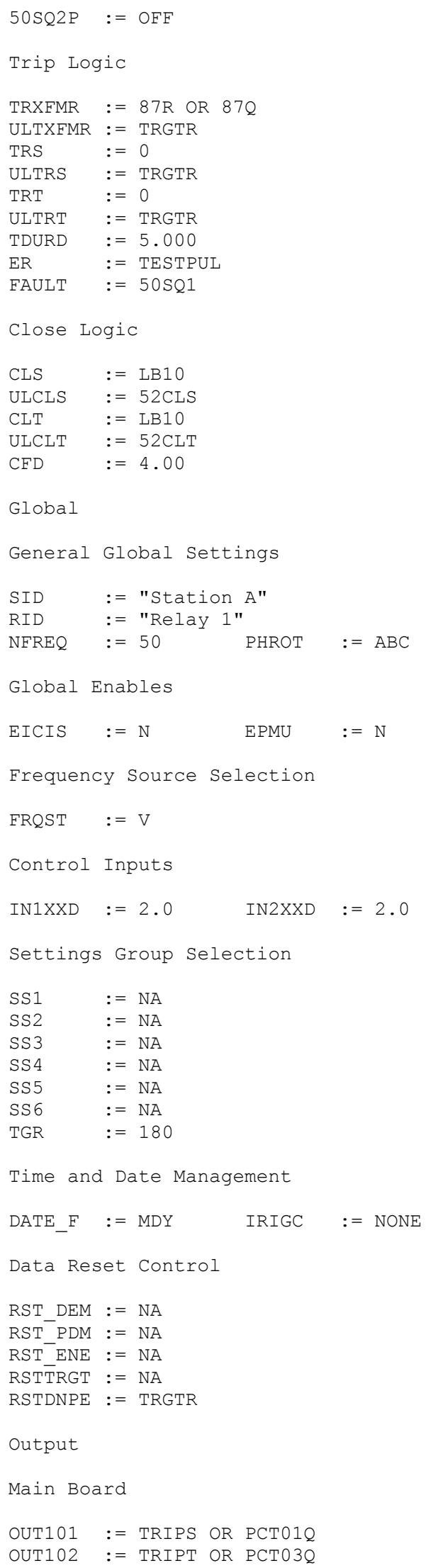




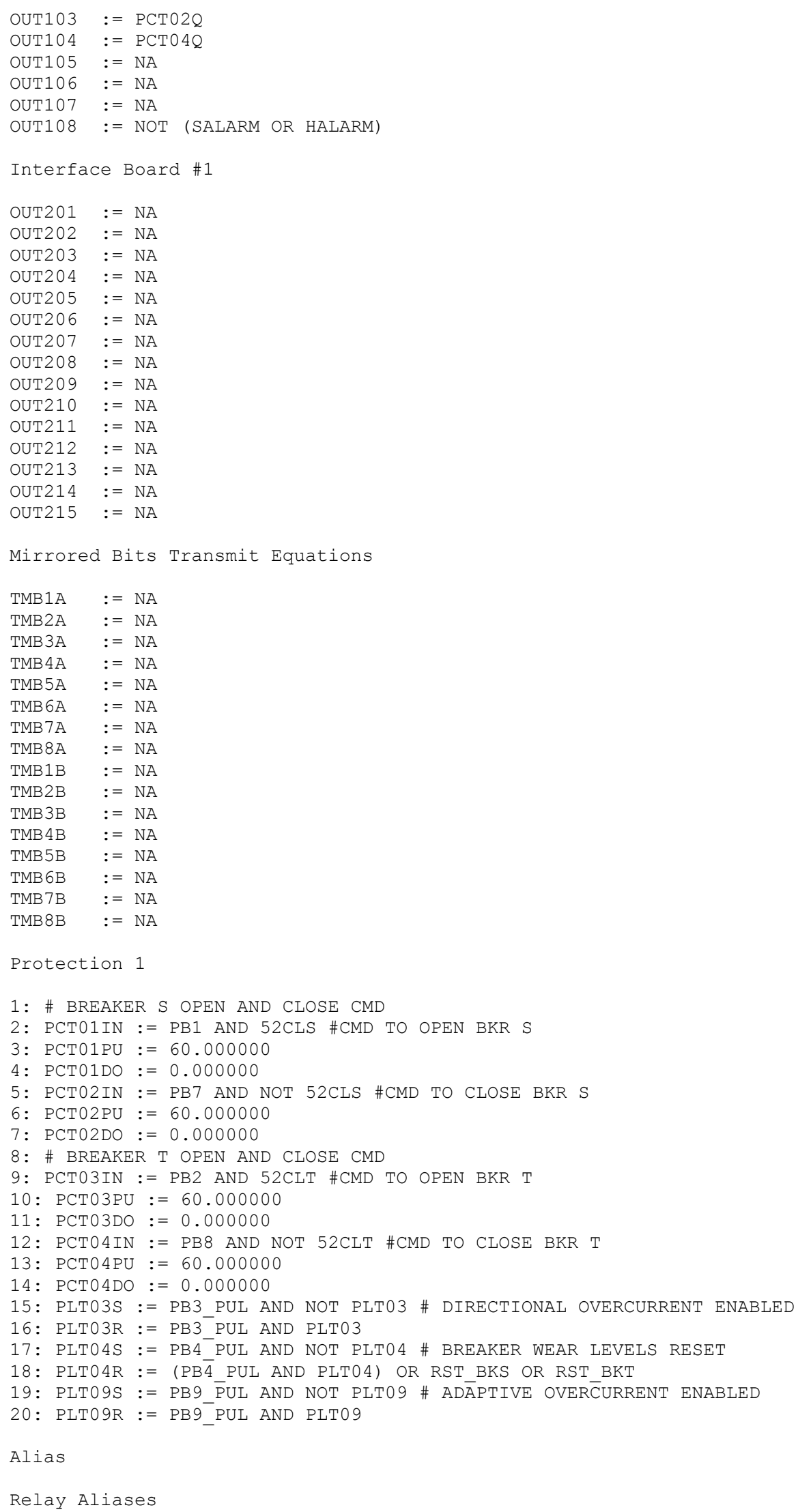


(RW Bit or Analog Qty. 7 Character Alias [0-9 A-Z_])

1: EN, "EN_RLY"

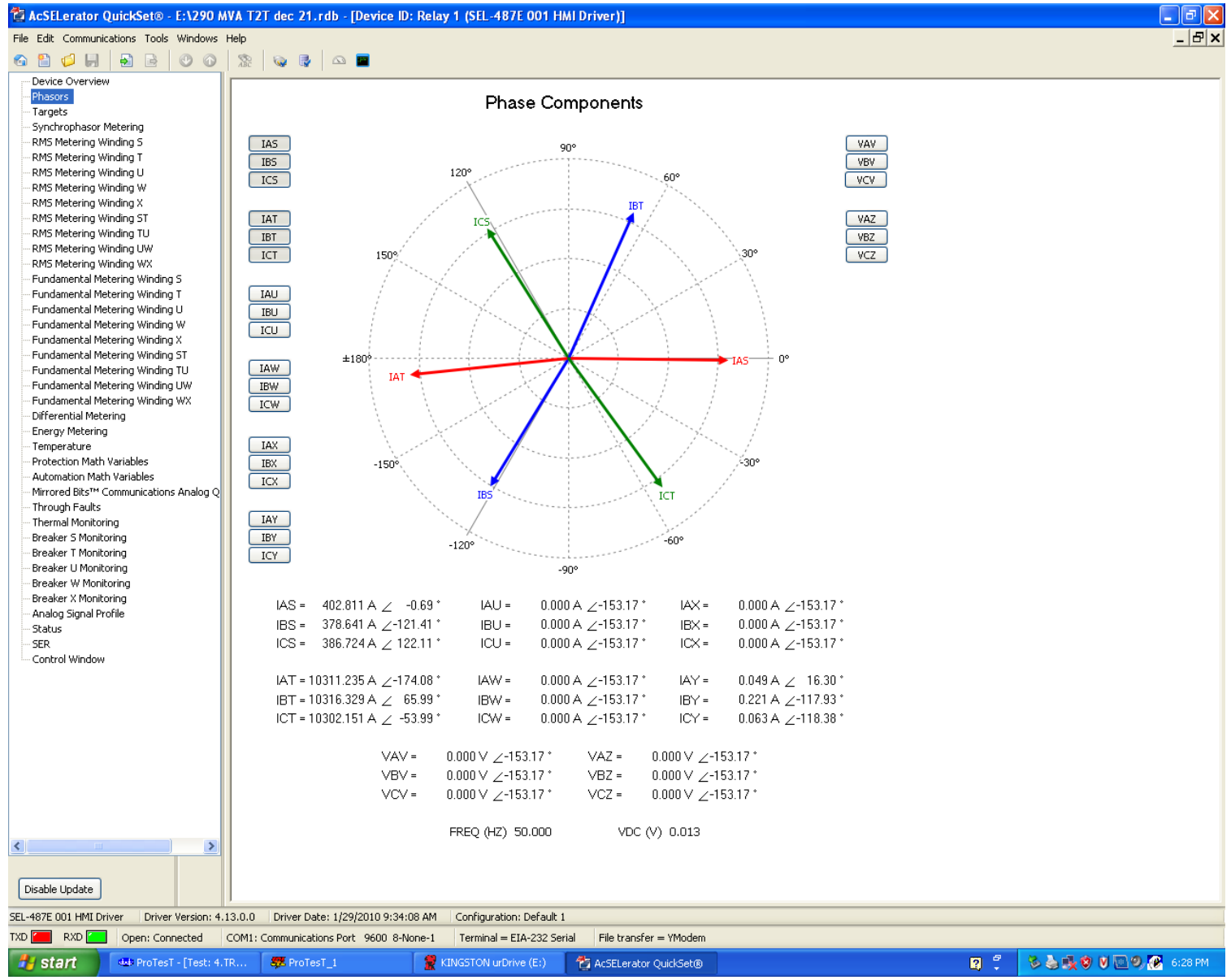

Figure F.6: Phasors screenshot for the 290-MVA transformer for turn-to-turn fault. 


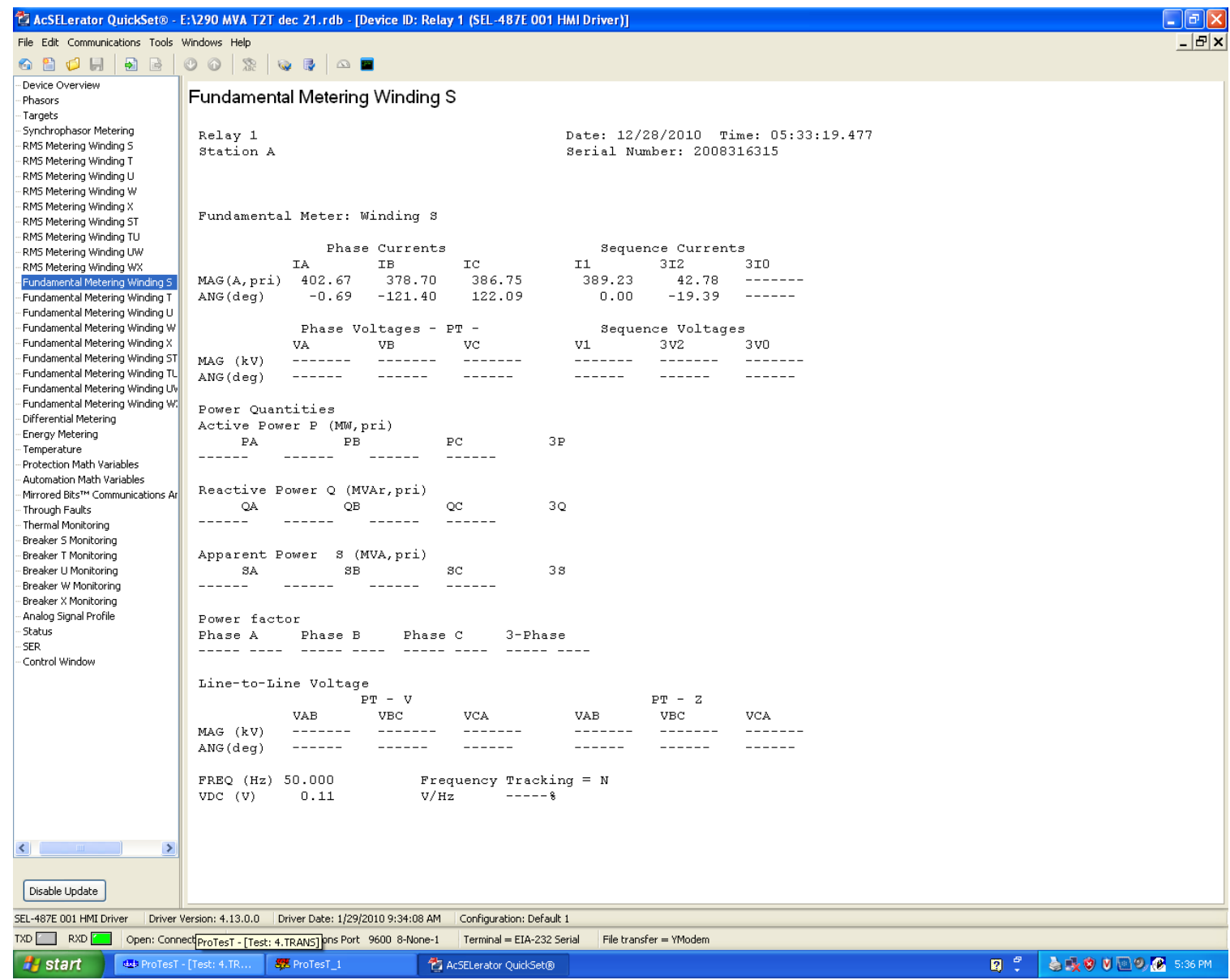

Figure F.7: Winding S Fundamental Metering for the 290-MVA transformer for turn-to-turn fault. 


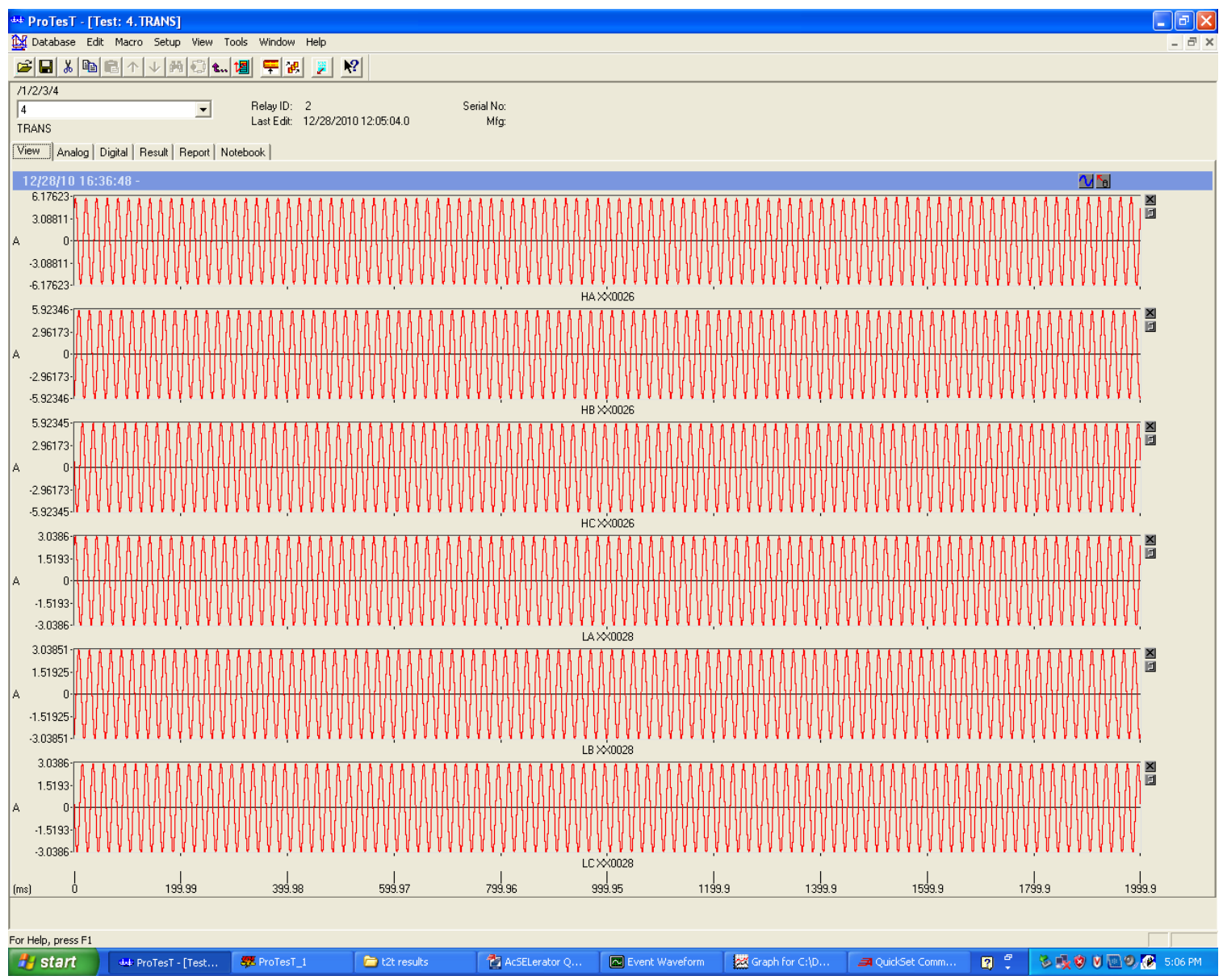

Figure F.8: Currents from CTs in TRANS macro for the 290-MVA transformer for turn-to-turn fault. 


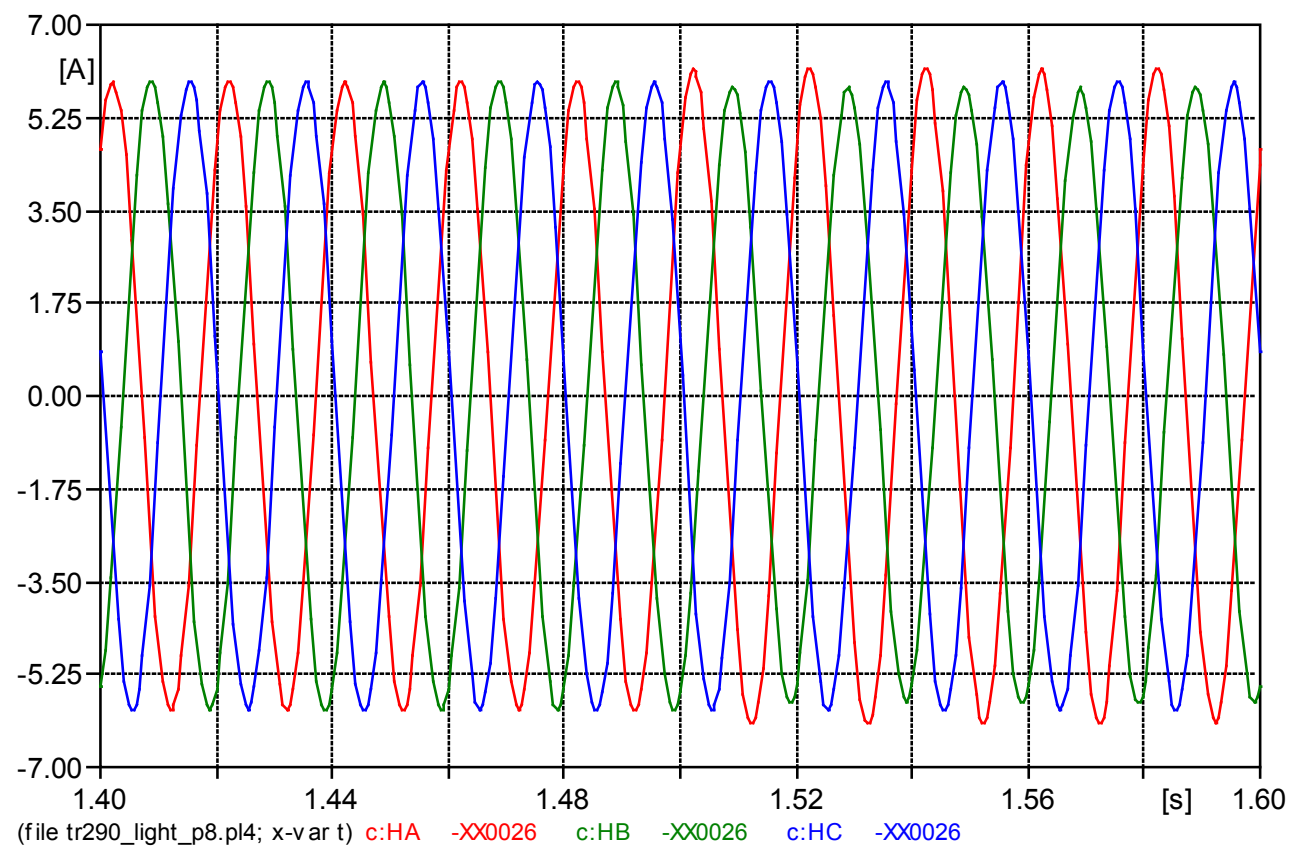

Figure F.9: ATP currents supplied to the SEL-487E relay from high-side CTs of the 290-MVA transformer for turn-to-turn fault.

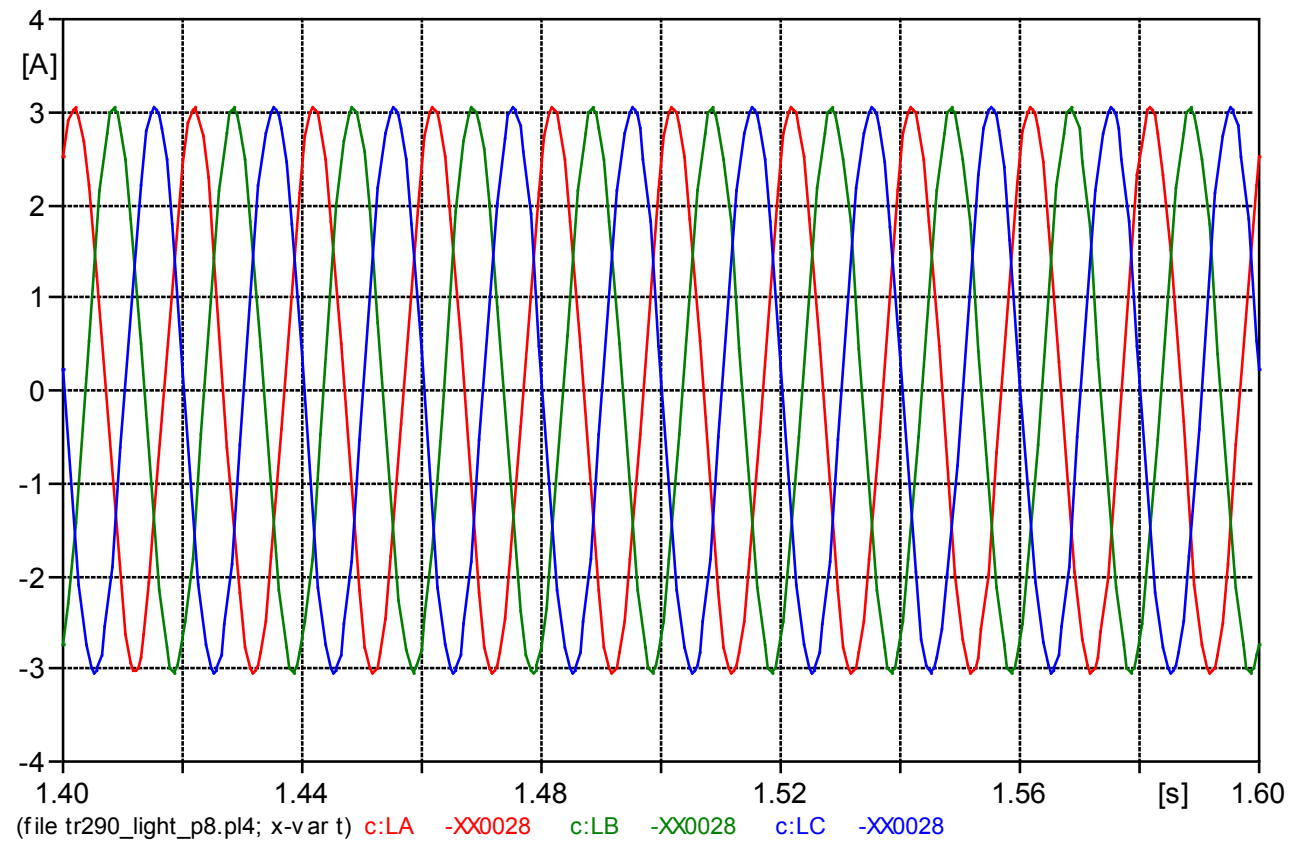

Figure F.10: ATP currents supplied to the SEL-487E relay from low-side CTs of the 290-MVA transformer for turn-to-turn fault. 


\section{F.3 The 290-MVA transformer Event Report for turn-to-ground fault}

REPORT HEADER: 


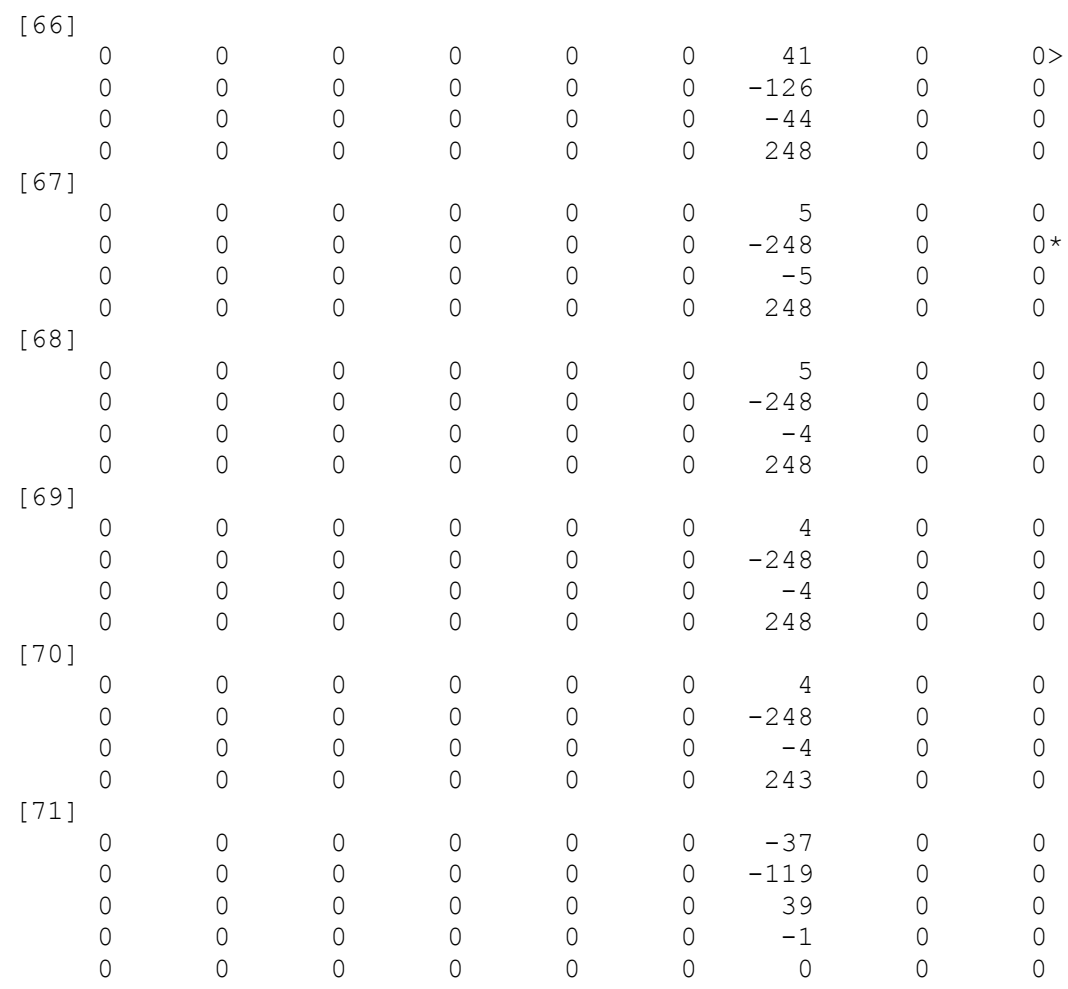

DIGITAL SECTION:

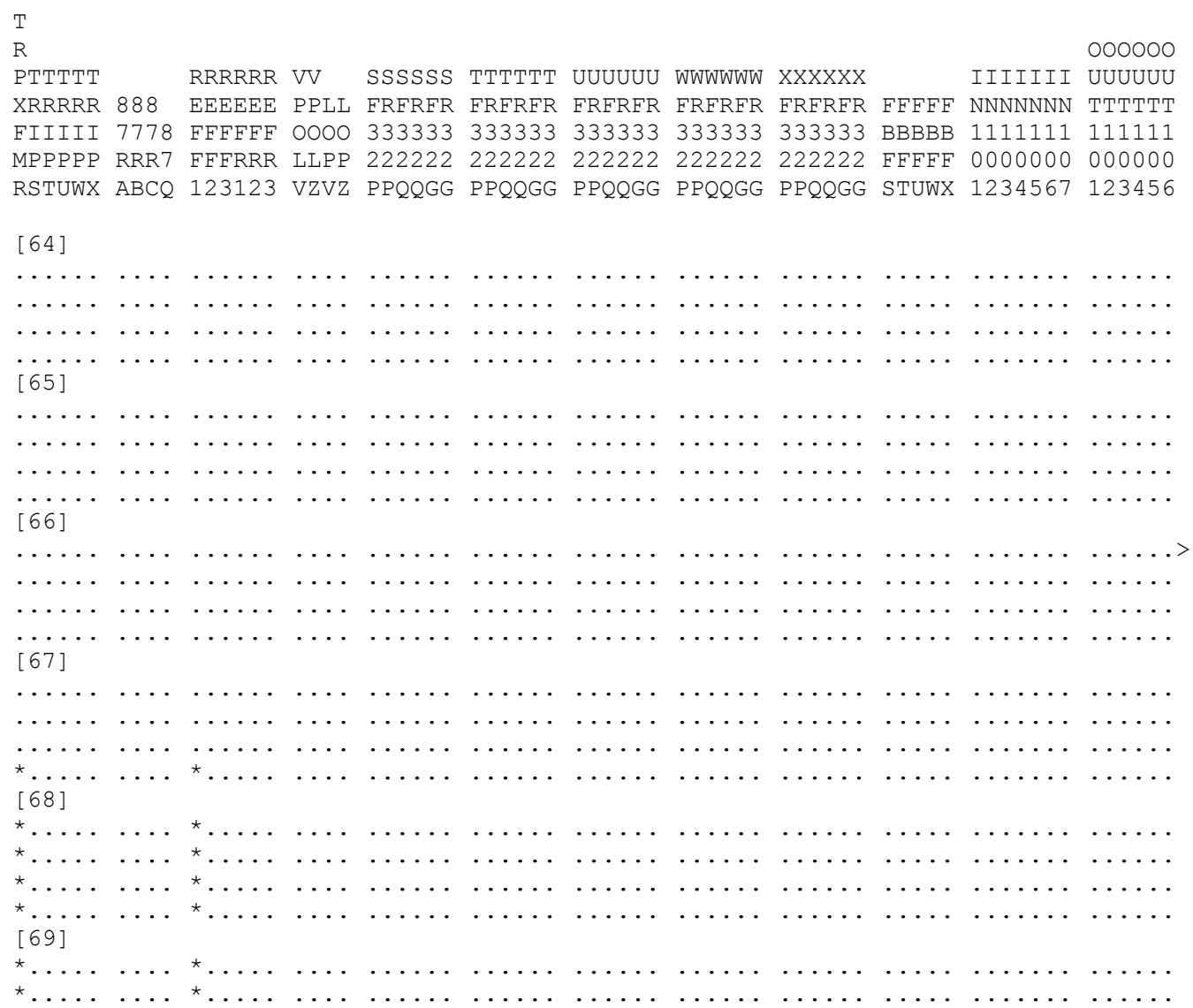




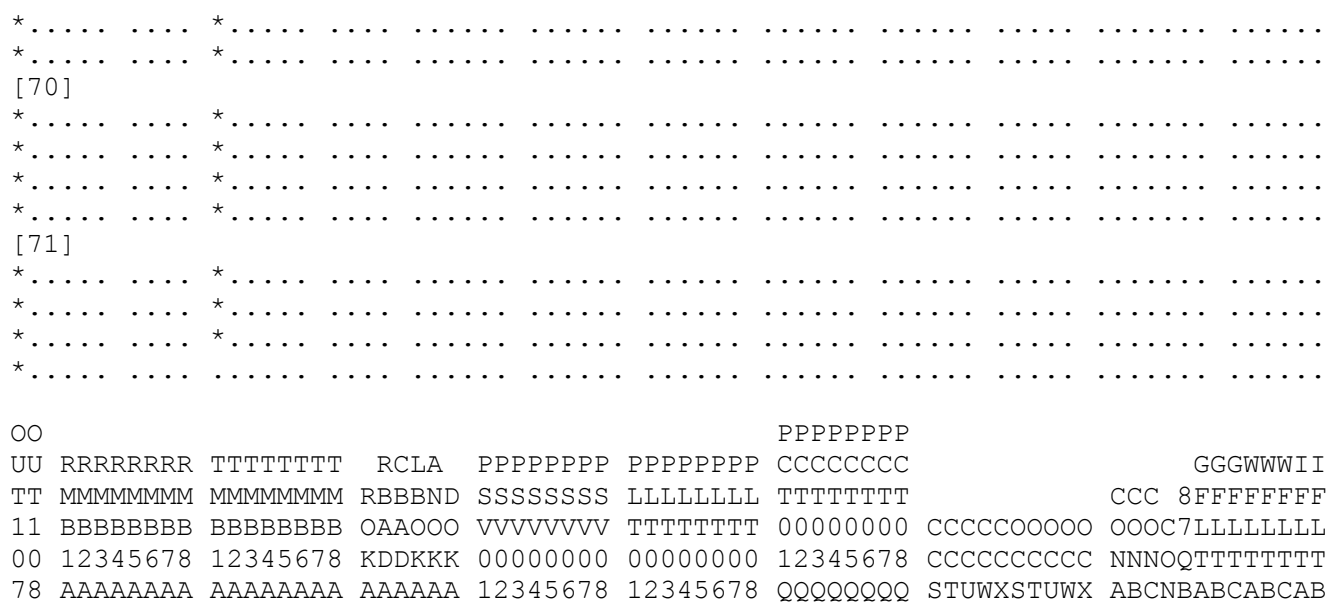

[64]

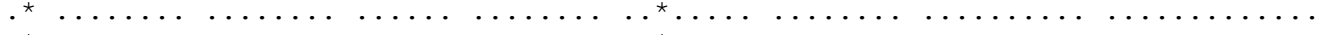

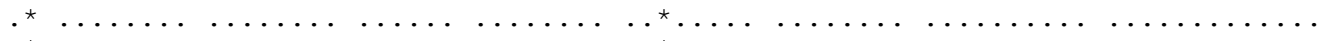

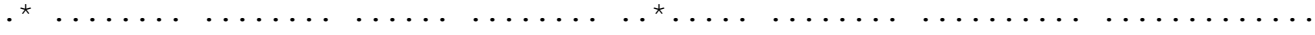

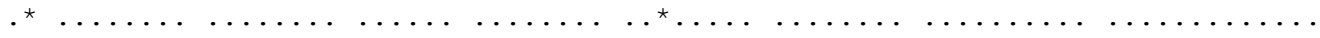

$[65]$

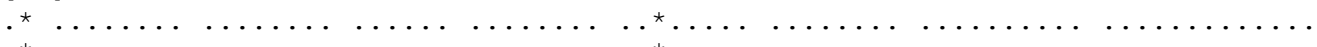

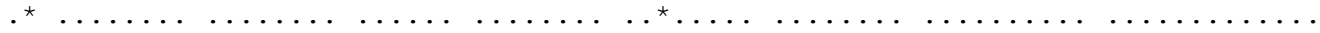

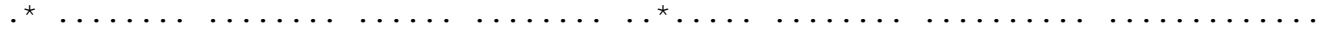

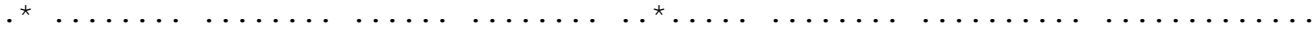

$[66]$

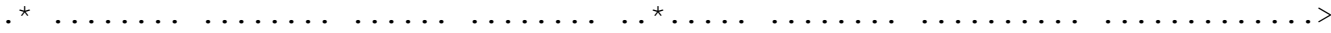

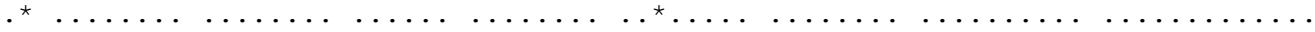

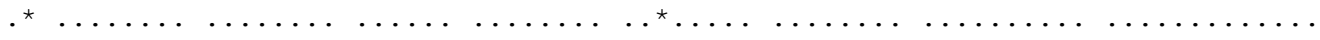

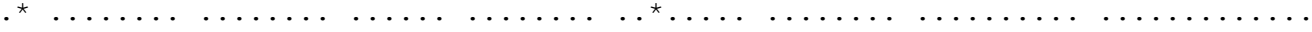

[67]

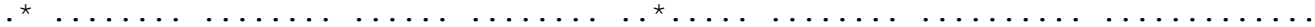

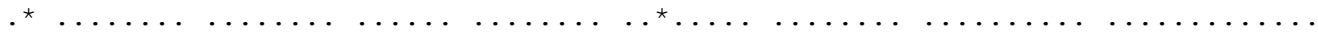

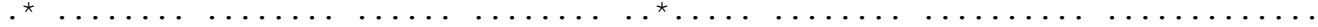

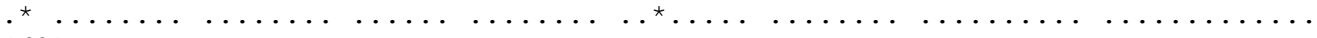

[68]

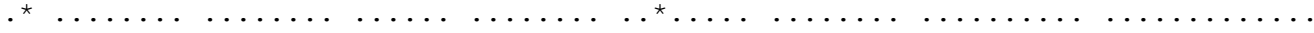

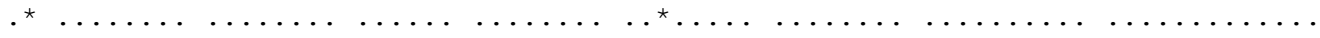

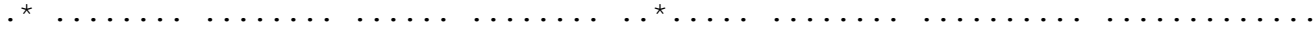

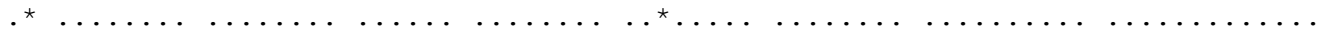

[69]

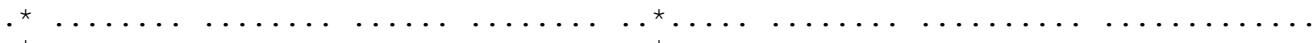

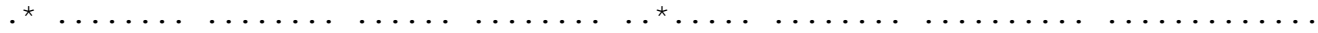

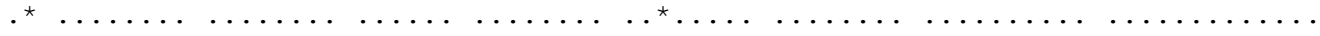

$[70]$

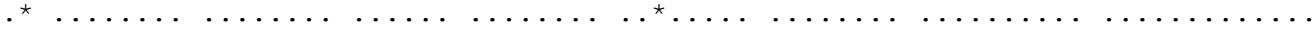

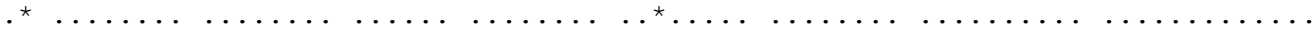

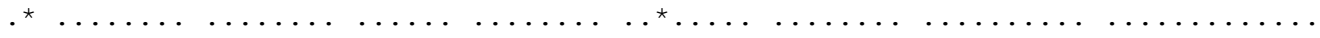

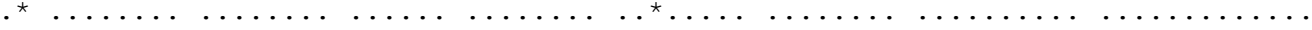

[71]

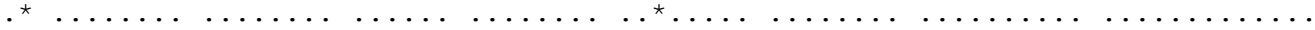

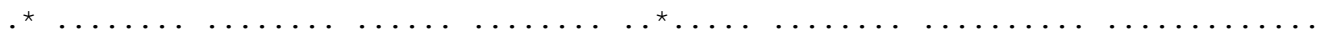

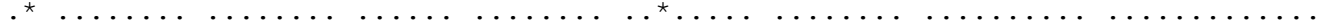

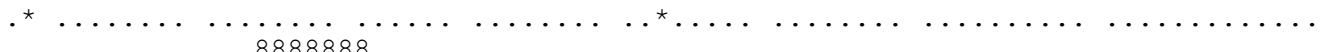

I888888 7777777TT EEEEE 55

F777777888 PPP ABCXABCHHCCC88888 00

LABCABC77788888BBBBBBB55TTT77777 SS

THHHHHHUUU77777KKKKKKKAAUUUTTTTT PQ

CBBBRRRABCUABCR2222555PDABCSTUWX 11

[64]

......................

$\ldots \ldots \ldots \ldots \ldots \ldots \ldots \ldots \ldots \ldots \ldots$ 


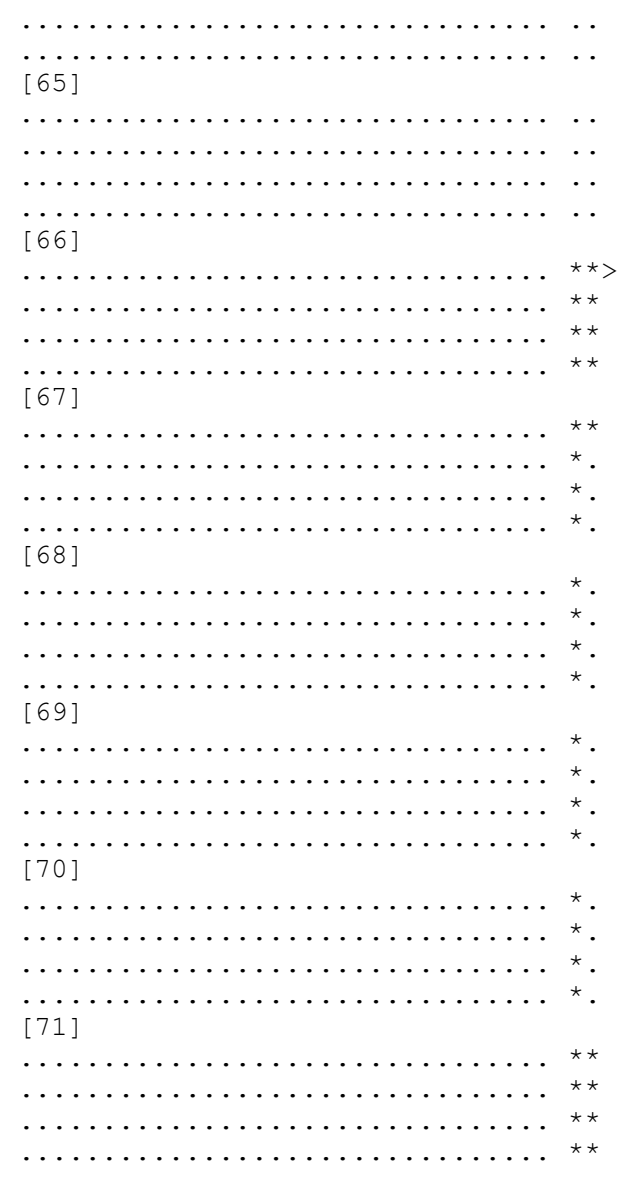

EVENT SUMMARY SECTION:

\begin{tabular}{|c|c|c|c|c|c|c|c|c|c|}
\hline \multicolumn{3}{|c|}{$\begin{array}{l}\text { Event: TRIP } \\
\text { Event Number: } 18518 \\
\text { Targets: TLED_6 }\end{array}$} & & \multicolumn{4}{|c|}{ Frequency: 50.000} & Time & $\begin{array}{l}\text { Source: } \\
\text { Group: }\end{array}$ \\
\hline \multicolumn{10}{|c|}{$\begin{array}{l}\text { Breaker } \mathrm{S}: \text { OPEN } \\
\text { Breaker } \mathrm{T}: \text { CLOSED }\end{array}$} \\
\hline \multicolumn{10}{|c|}{ Fault Analog Data } \\
\hline MAC $(A)$ & IAS & IBS & ICS & IAT & IBT & ICT & IAU & IBU & ICU \\
\hline ANG (DEG) & 0.0 & -119.4 & $\begin{array}{l}385 \\
120.6\end{array}$ & -78.8 & -60.6 & -34.6 & 168.5 & -78.5 & 40.9 \\
\hline & IAW & IBW & ICW & IAX & IBX & ICX & IY1 & IY2 & IY3 \\
\hline $\begin{array}{l}\text { MAG (A) } \\
\text { ANG (DEG) }\end{array}$ & $\begin{array}{c}0 \\
97.0\end{array}$ & $\begin{array}{c}0 \\
129.3\end{array}$ & $\begin{array}{c}0 \\
80.0\end{array}$ & $\begin{array}{c}0 \\
168.9\end{array}$ & $\begin{array}{c}0 \\
21.0\end{array}$ & $\begin{array}{c}0 \\
137.9\end{array}$ & $\begin{array}{c}248 \\
6.1\end{array}$ & $\begin{array}{c}0 \\
67.7\end{array}$ & $\begin{array}{c}0 \\
-15.3\end{array}$ \\
\hline $\begin{array}{l}\text { MAG }(k V) \\
\text { ANG }(D E G)\end{array}$ & $\begin{array}{l}\text { VAV } \\
0 \\
-138.7\end{array}$ & $\begin{array}{l}\text { VBV } \\
0 \\
159.7\end{array}$ & $\begin{array}{l}\text { VCV } \\
0 \\
-102.9\end{array}$ & $\begin{array}{l}\text { VAZ } \\
0 \\
-145.0\end{array}$ & $\begin{array}{l}\text { VBZ } \\
0 \\
109.9\end{array}$ & $\begin{array}{l}\text { VCZ } \\
0 \\
-65.9\end{array}$ & & & \\
\hline MAG (p.u) & $\begin{array}{l}\text { IOPA } \\
0.00\end{array}$ & $\begin{array}{l}\text { IRTA } \\
0.00\end{array}$ & $\begin{array}{l}\text { IOPB } \\
0.00\end{array}$ & $\begin{array}{l}\text { IRTB } \\
0.00\end{array}$ & $\begin{array}{l}\text { IOPC } \\
0.00\end{array}$ & $\begin{array}{l}\text { IRTC } \\
0.00\end{array}$ & & & \\
\hline
\end{tabular}

\section{SETTINGS SECTION:}

Group 1

Relay Configuration 


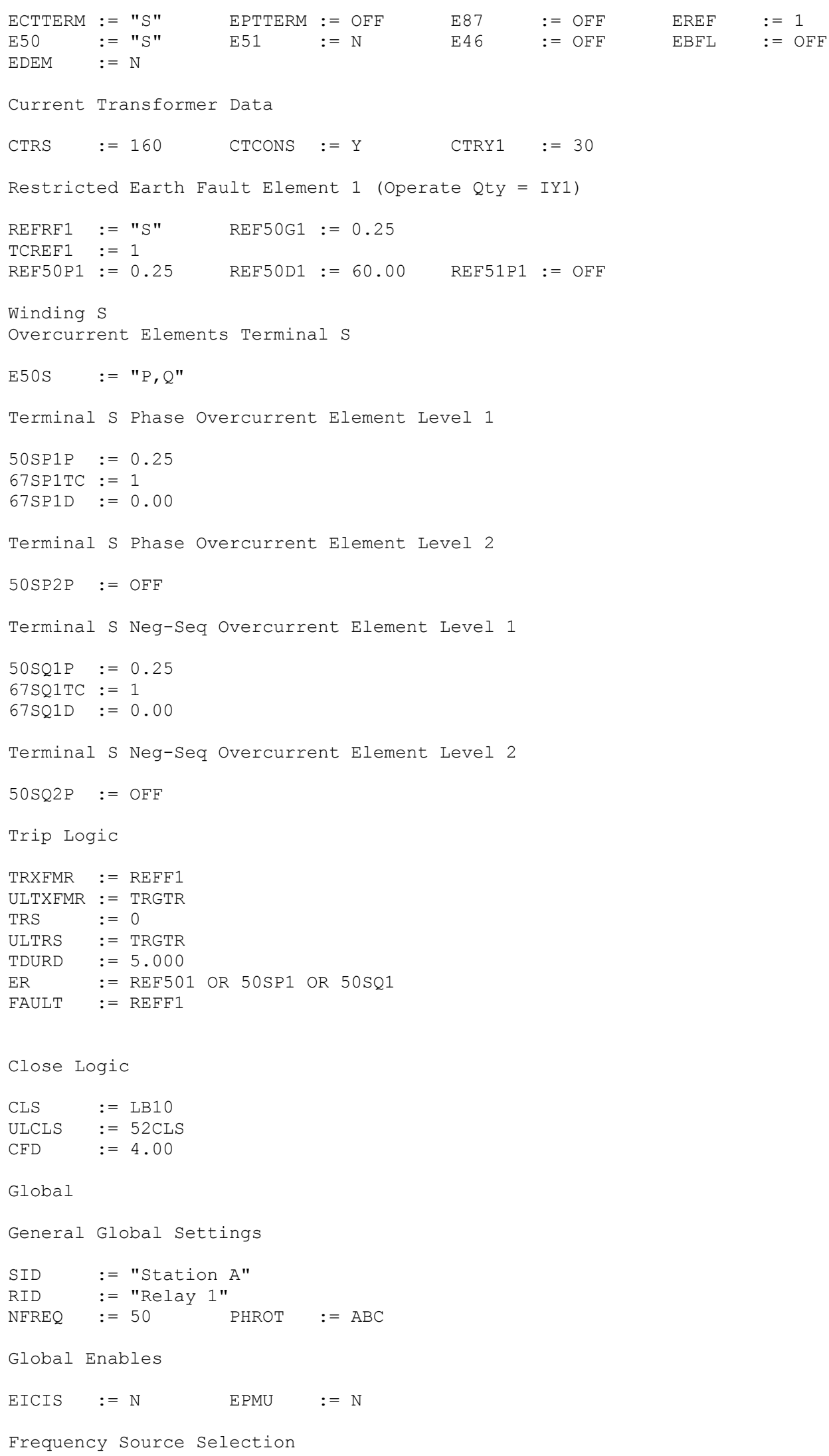




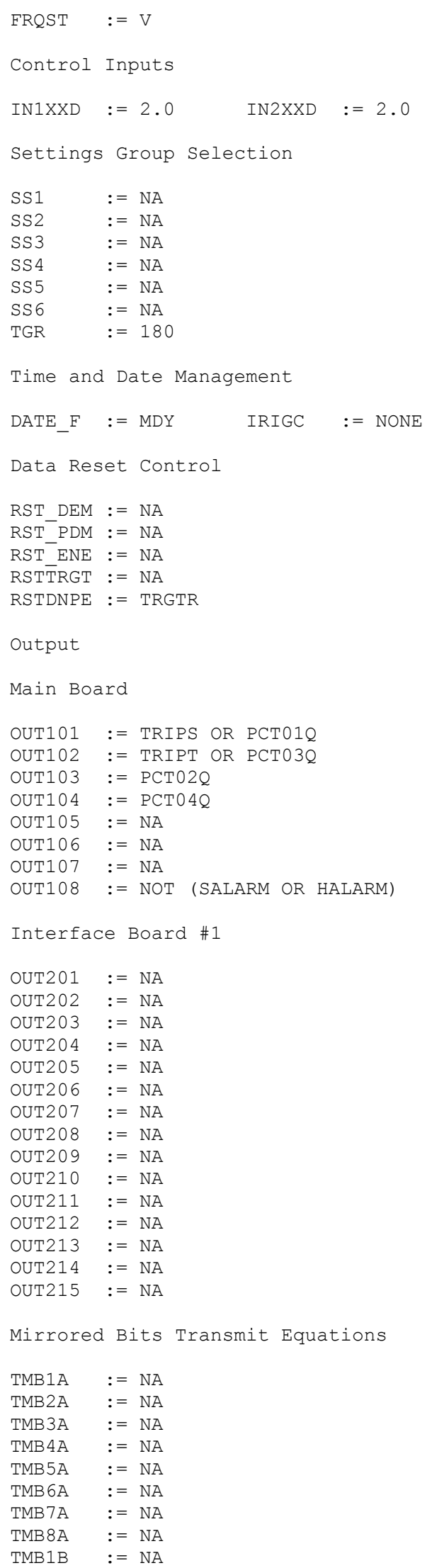




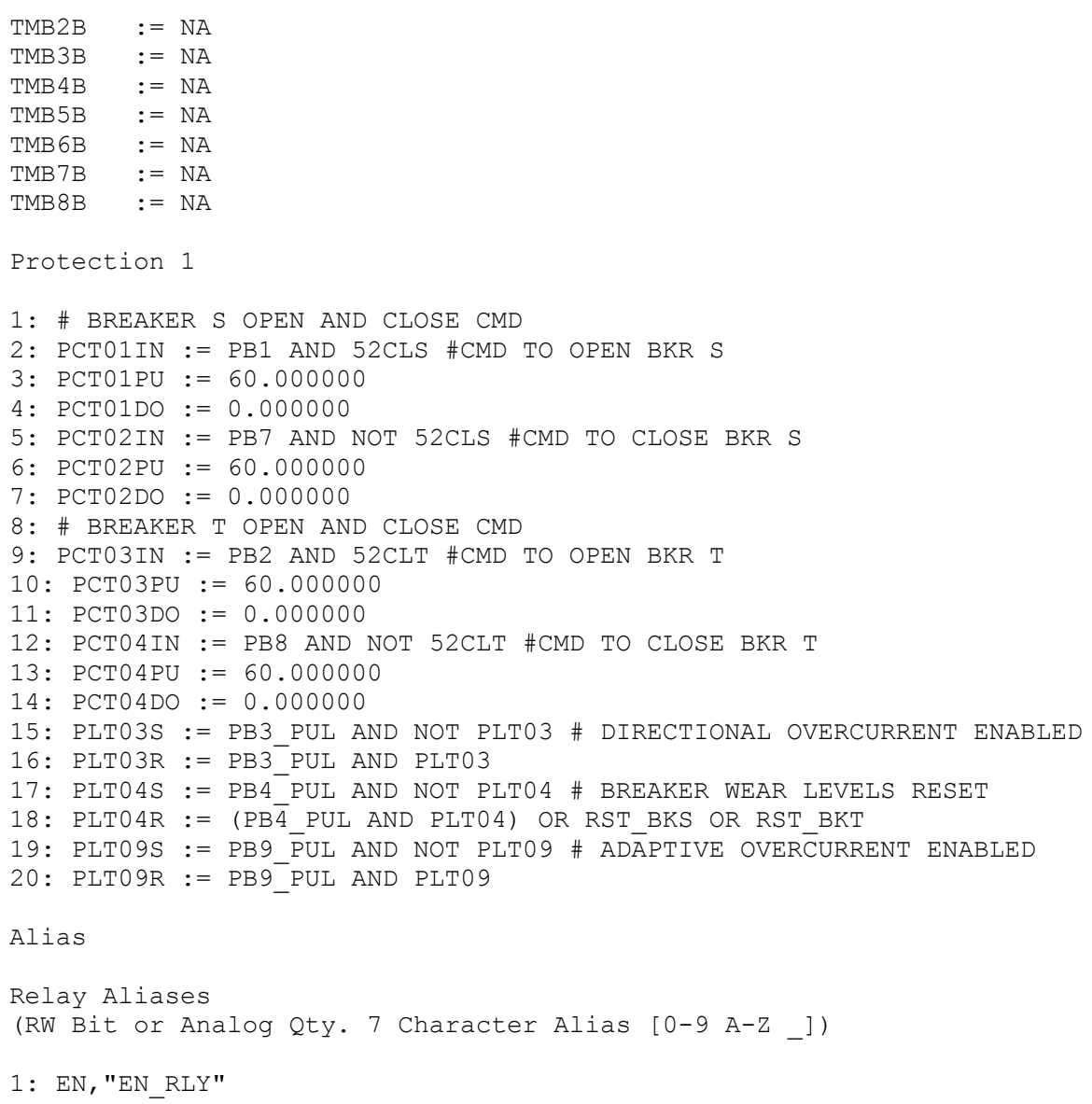




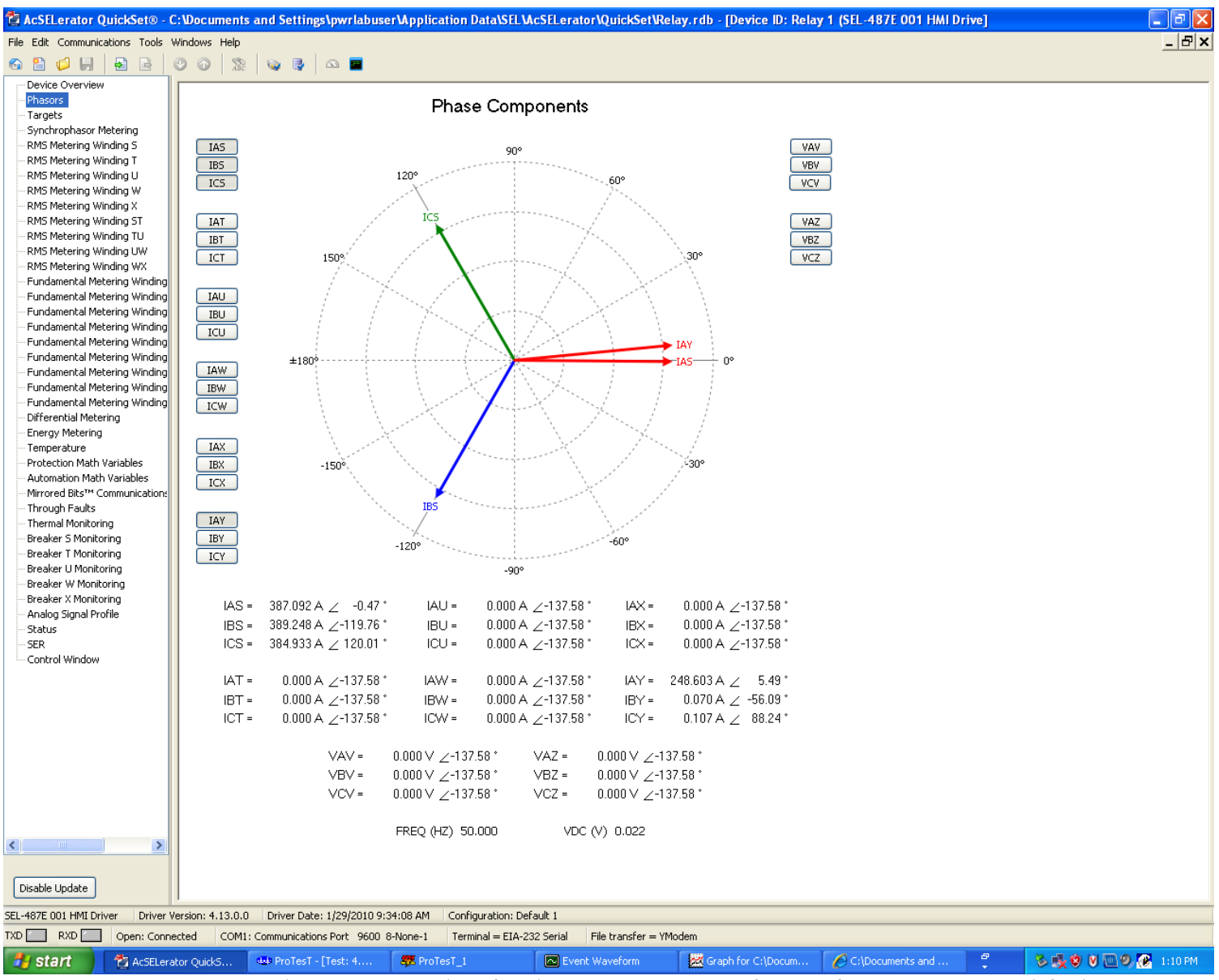

Figure F.11: Phasors screenshot for the 290-MVA transformer for turn-to-ground fault. 


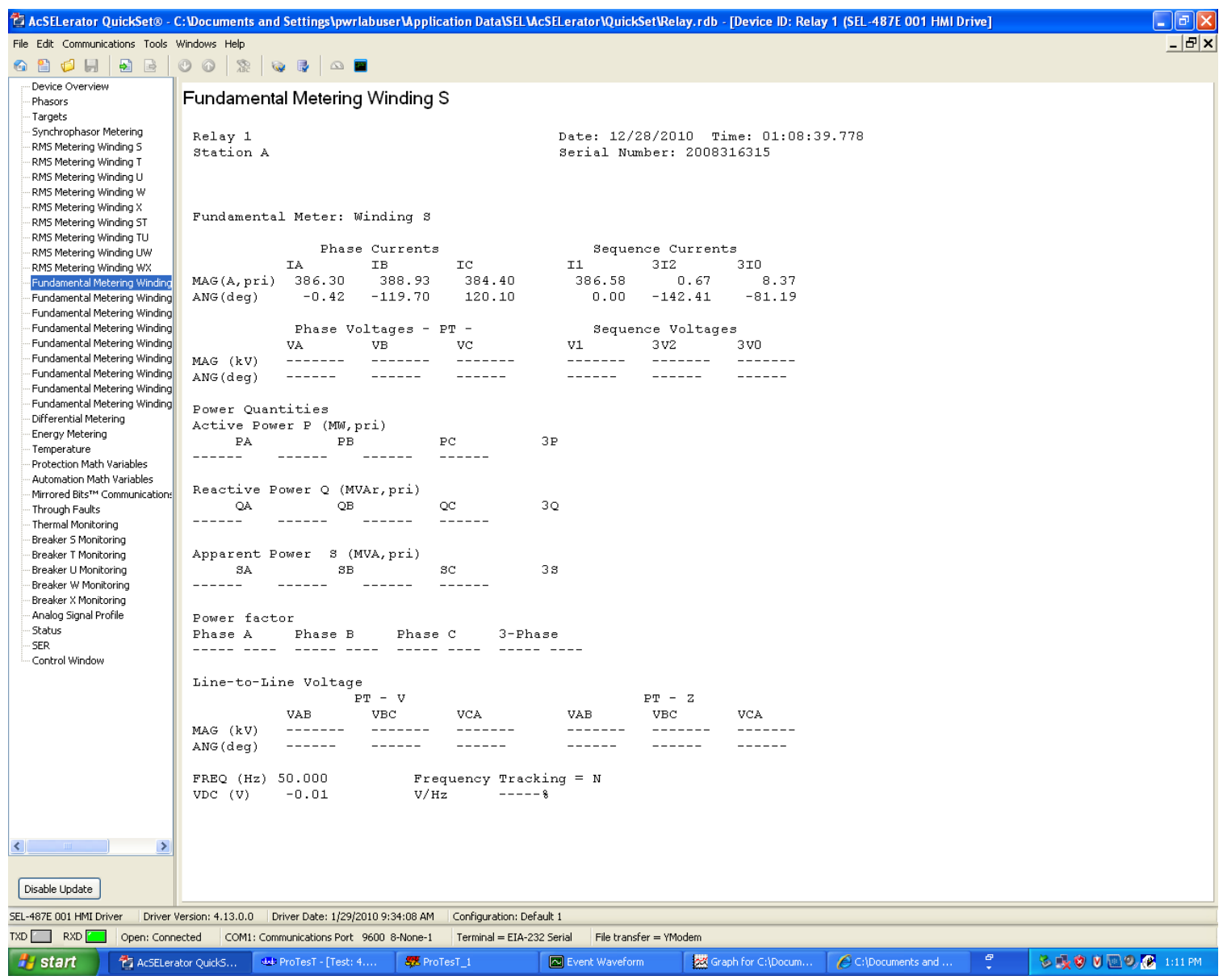

Figure F.12: Winding S Fundamental Metering for the 290-MVA transformer for turn-to-ground fault. 


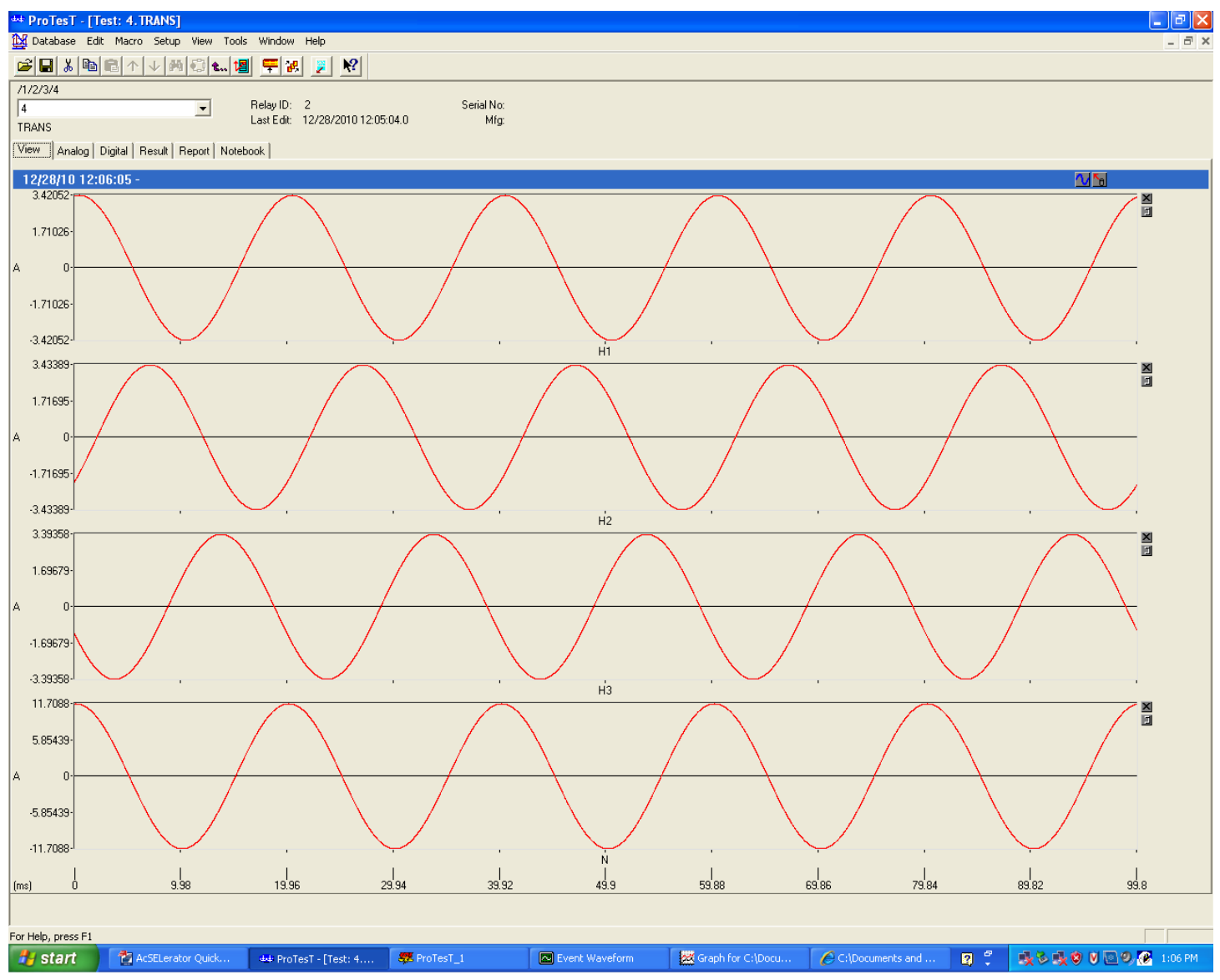

Figure F.13: Currents from CTs in TRANS macro for the 290-MVA transformer for turn-to-ground fault.

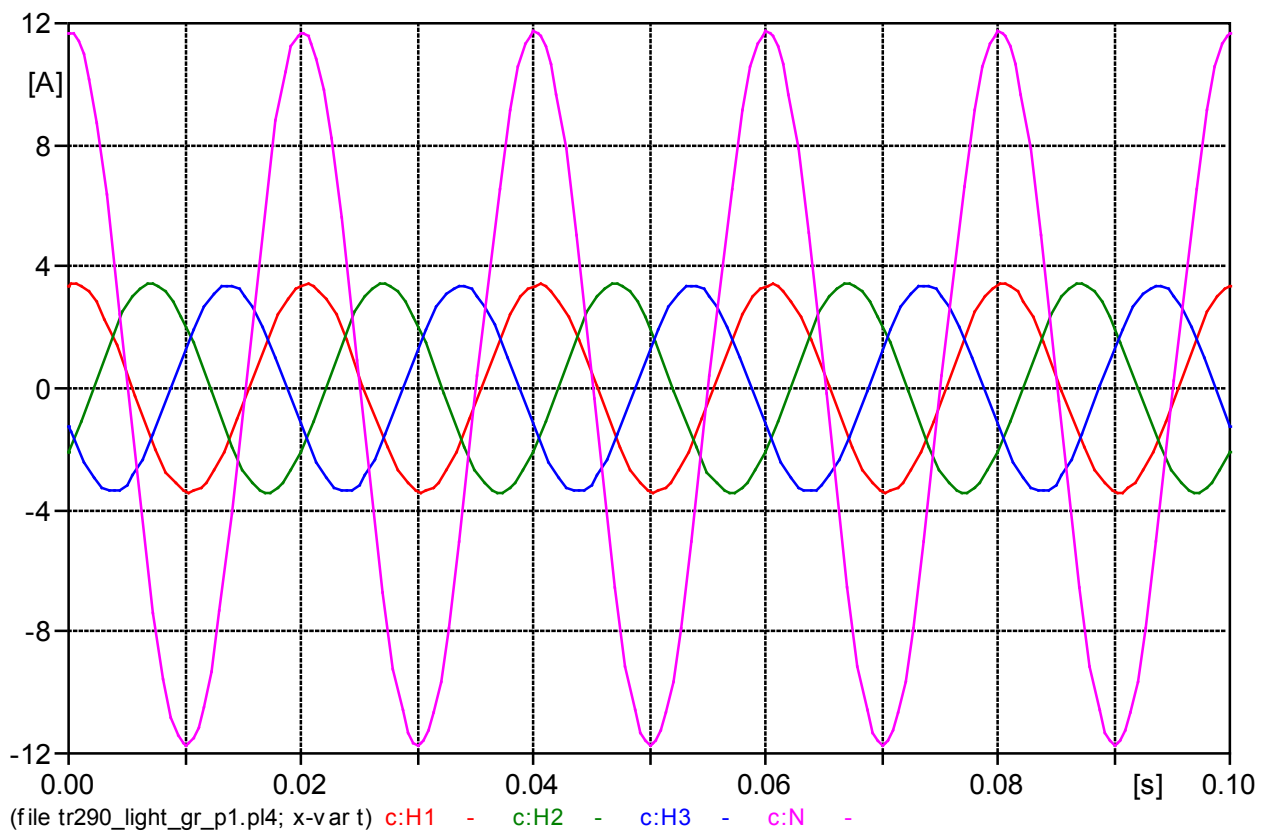

Figure F.14: ATP currents supplied to the SEL-487E relay from high-side and neutral CTs of the 290-MVA transformer for turn-to-ground fault. 


\section{Appendix G CT saturation results}

\section{G.1 The 11.2-MVA transformer, high-side 600:5 CTs tapped at 150:5}

Phase A has a turn-to-turn fault involving $90 \%$ of the winding $(\mathrm{Va}(0)=\mathrm{V}$ peak $)$

\section{G.1.1 Zsourse $=5 \%$ on $100 \mathrm{MVA}$ base, $\mathrm{X} / \mathrm{R}=\mathbf{5}$}

\section{G.1.1.1 Light load}

1. $\mathrm{R}_{\mathrm{TOT}}=0.256 \Omega$.

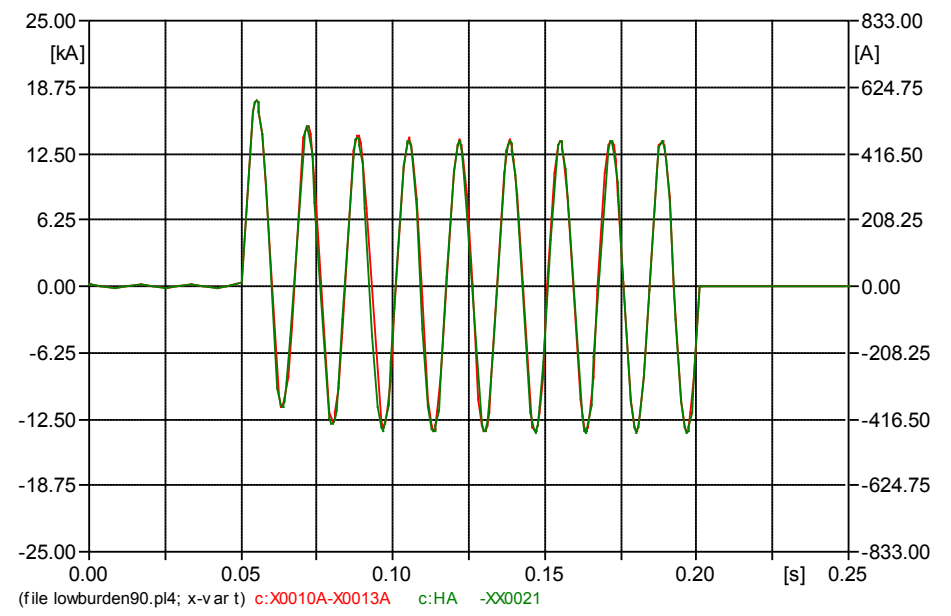

Figure G.1: $11.2 \mathrm{MVA}, \mathrm{Zs}=5 \%$, light load, $\mathrm{R}_{\mathrm{TOT}}=0.256 \Omega$ : Phase-A pri and sec $\mathrm{CT}$ currents.

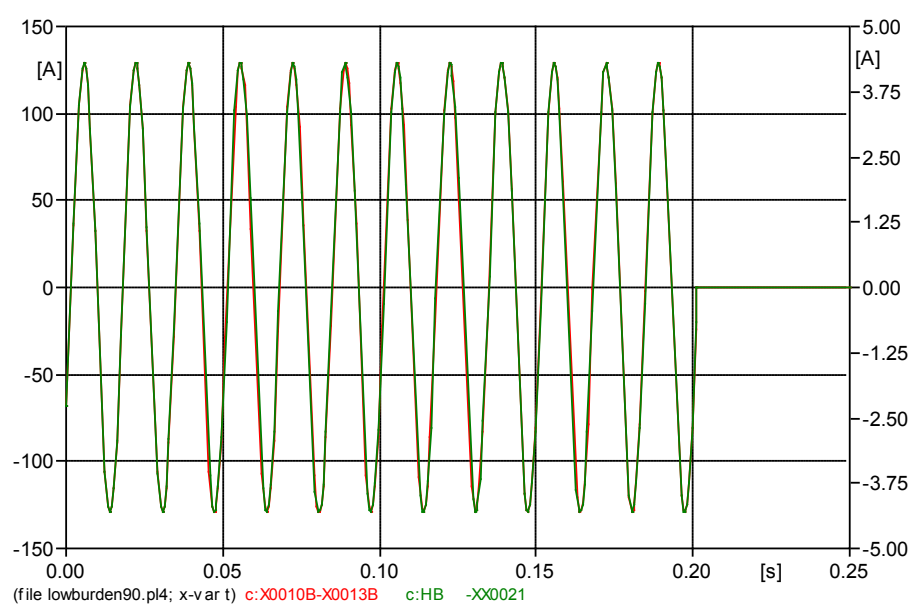

Figure G.2: $11.2 \mathrm{MVA}, \mathrm{Zs}=5 \%$, light load, $\mathrm{R}_{\mathrm{TOT}}=0.256 \Omega$ : Phase-B pri and sec $\mathrm{CT}$ currents. 


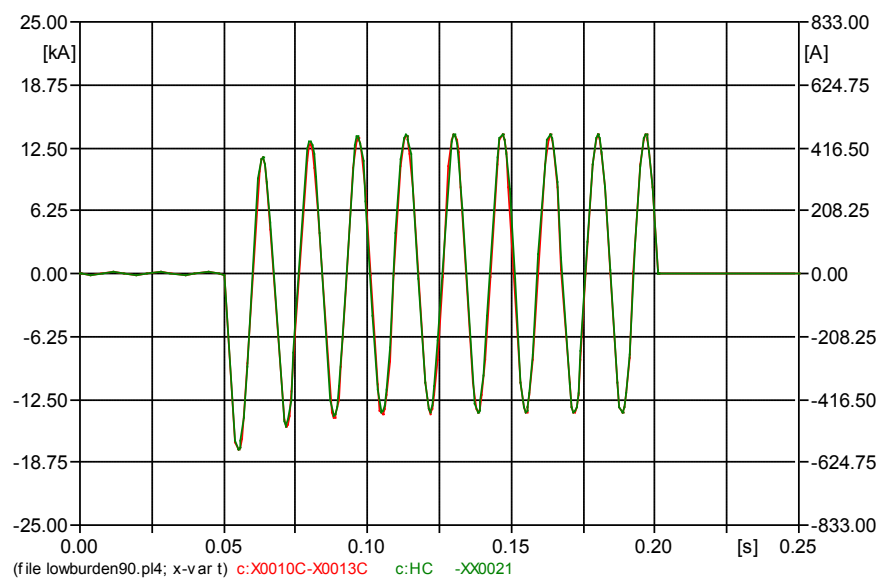

Figure G.3: 11.2 MVA, $Z s=5 \%$, light load, $\mathrm{R}_{\mathrm{TOT}}=0.256 \Omega$ : Phase-C pri and sec $\mathrm{CT}$ currents.

2. $\mathrm{R}_{\mathrm{TOT}}=0.676 \Omega$.

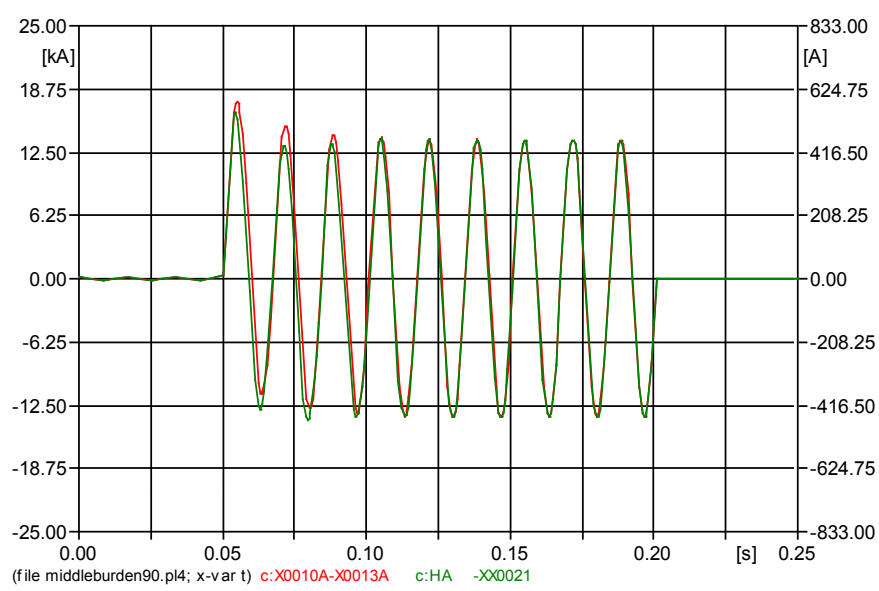

Figure G.4: 11.2 MVA, $Z s=5 \%$, light load, $\mathrm{R}_{\mathrm{TOT}}=0.676 \Omega$ : Phase-A pri and sec $\mathrm{CT}$ currents.

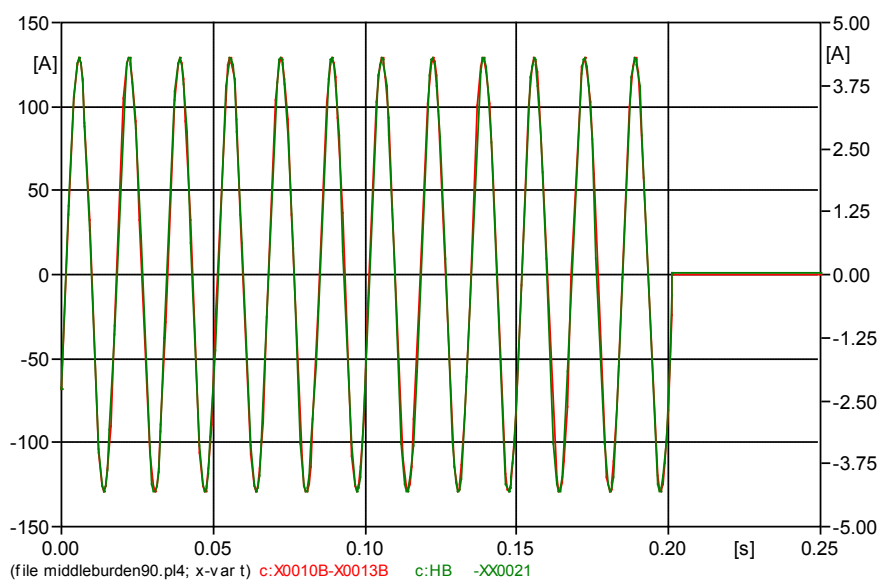

Figure G.5: 11.2 MVA, $Z s=5 \%$, light load, $\mathrm{R}_{\mathrm{TOT}}=0.676 \Omega$ : Phase-B pri and sec $\mathrm{CT}$ currents. 


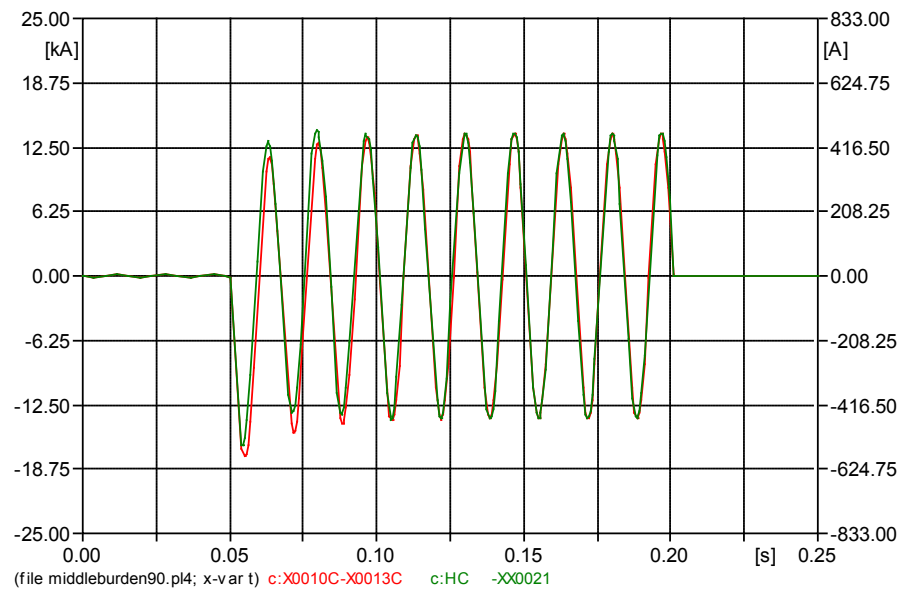

Figure G.6: 11.2 MVA, $Z s=5 \%$, light load, $\mathrm{R}_{\mathrm{TOT}}=0.676 \Omega$ : Phase- $\mathrm{C}$ pri and sec $\mathrm{CT}$ currents.

3. $\mathrm{R}_{\mathrm{TOT}}=1.396 \Omega$.

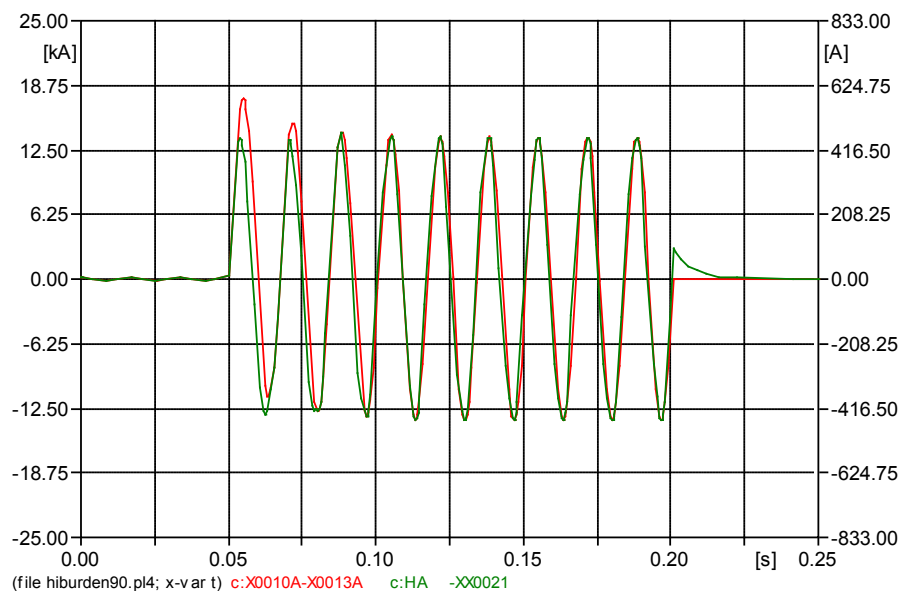

Figure G.7: $11.2 \mathrm{MVA}, \mathrm{Zs}=5 \%$, light load, $\mathrm{R}_{\mathrm{TOT}}=1.396 \Omega$ : Phase-A pri and sec $\mathrm{CT}$ currents.

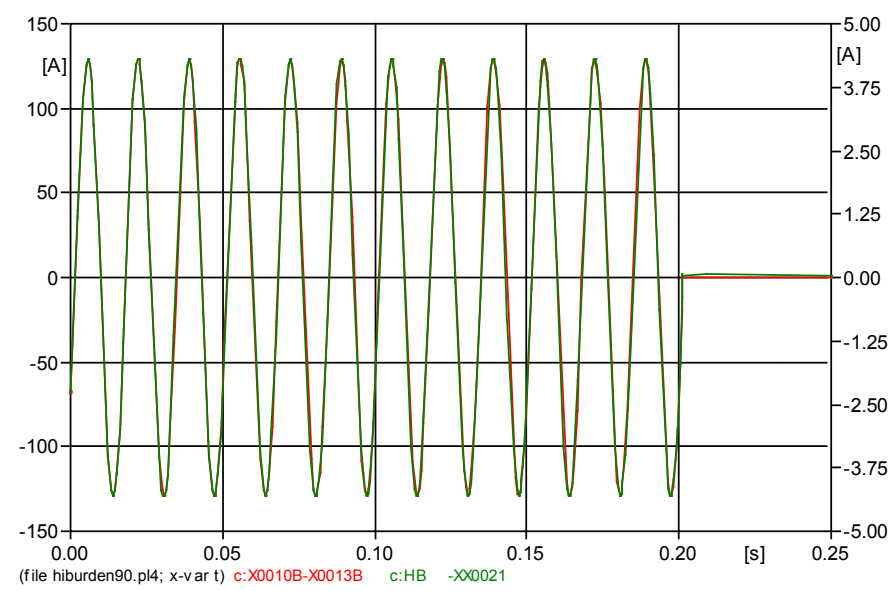

Figure G.8: 11.2 MVA, $Z s=5 \%$, light load, $\mathrm{R}_{\mathrm{TOT}}=1.396 \Omega$ : Phase-B pri and sec $\mathrm{CT}$ currents. 


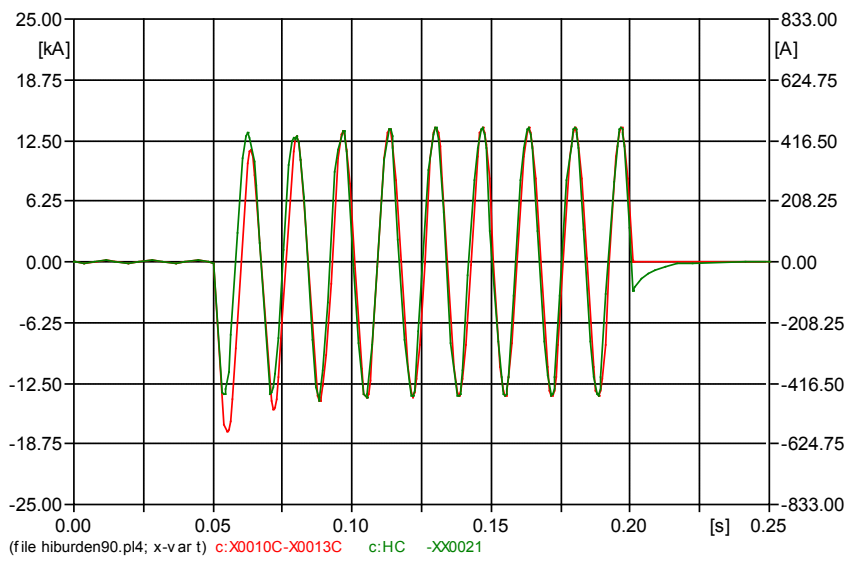

Figure G.9: 11.2 MVA, $Z s=5 \%$, light load, $\mathrm{R}_{\mathrm{TOT}}=1.396 \Omega$ : Phase-C pri and sec $\mathrm{CT}$ currents.

\section{G.1.1.2 Heavy load}

1. $\mathrm{R}_{\mathrm{TOT}}=0.256 \Omega$.

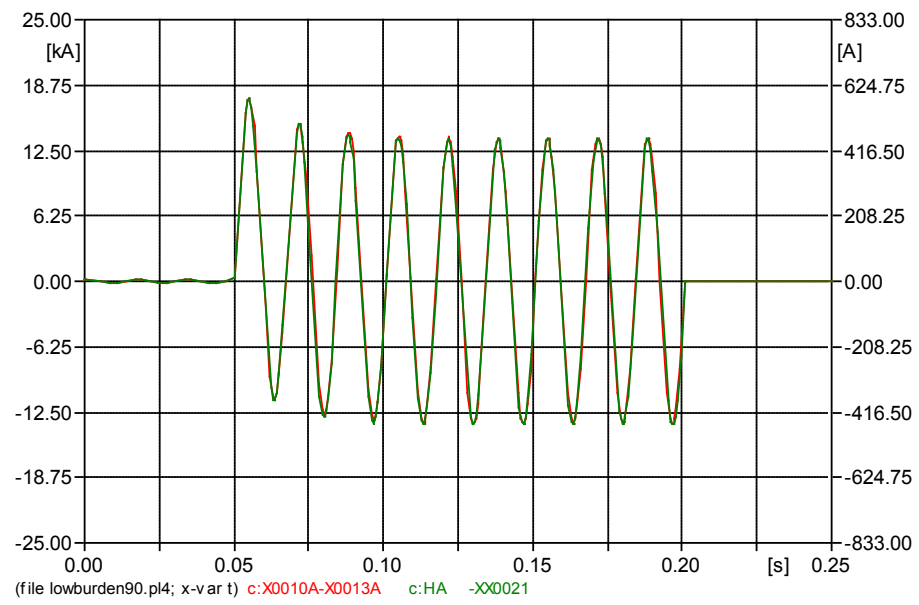

Figure G.10: $11.2 \mathrm{MVA}, \mathrm{Zs}=5 \%$, heavy load, $\mathrm{R}_{\mathrm{TOT}}=0.256 \Omega$ : Phase-A pri and sec $\mathrm{CT}$ currents.

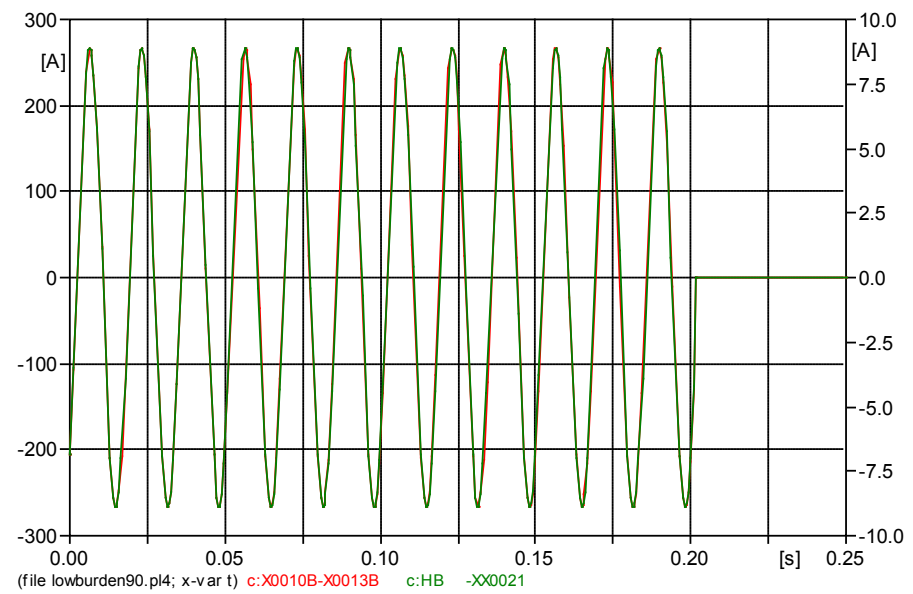

Figure G.11: 11.2 MVA, Zs $=5 \%$, heavy load, $\mathrm{R}_{\mathrm{TOT}}=0.256 \Omega$ : Phase-B pri and sec $\mathrm{CT}$ currents. 


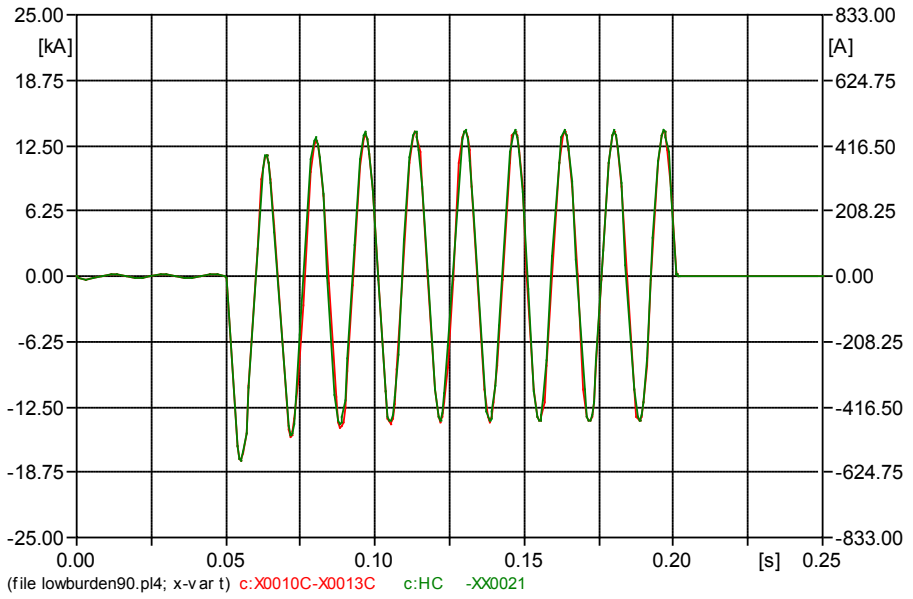

Figure G.12: $11.2 \mathrm{MVA}, \mathrm{Zs}_{\mathrm{s}}=5 \%$, heavy load, $\mathrm{R}_{\mathrm{TOT}}=0.256 \Omega$ : Phase-C pri and sec $\mathrm{CT}$ currents.

2. $\mathrm{R}_{\mathrm{TOT}}=0.676 \Omega$.

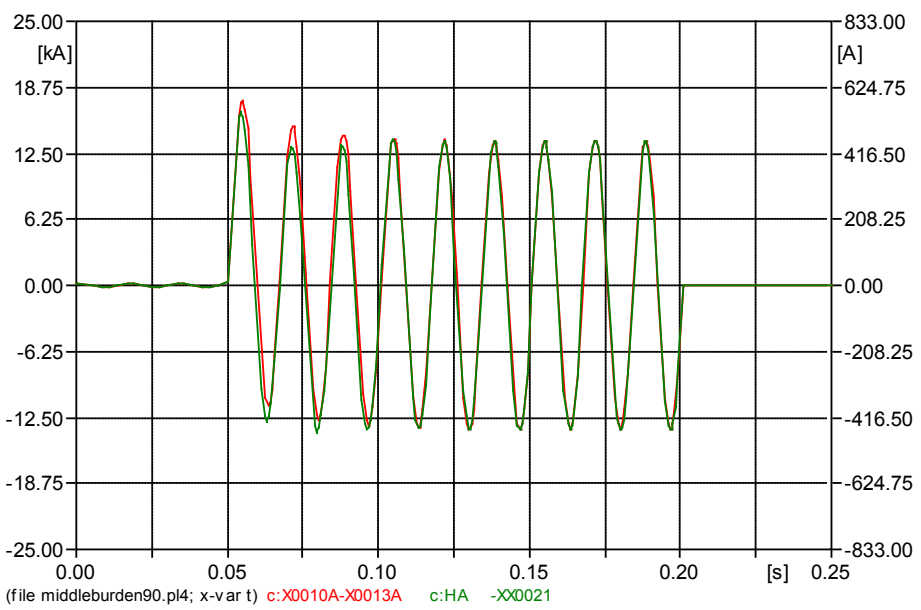

Figure G.13: 11.2 MVA, $Z s=5 \%$, heavy load, $\mathrm{R}_{\mathrm{TOT}}=0.676 \Omega$ : Phase-A pri and sec $\mathrm{CT}$ currents.

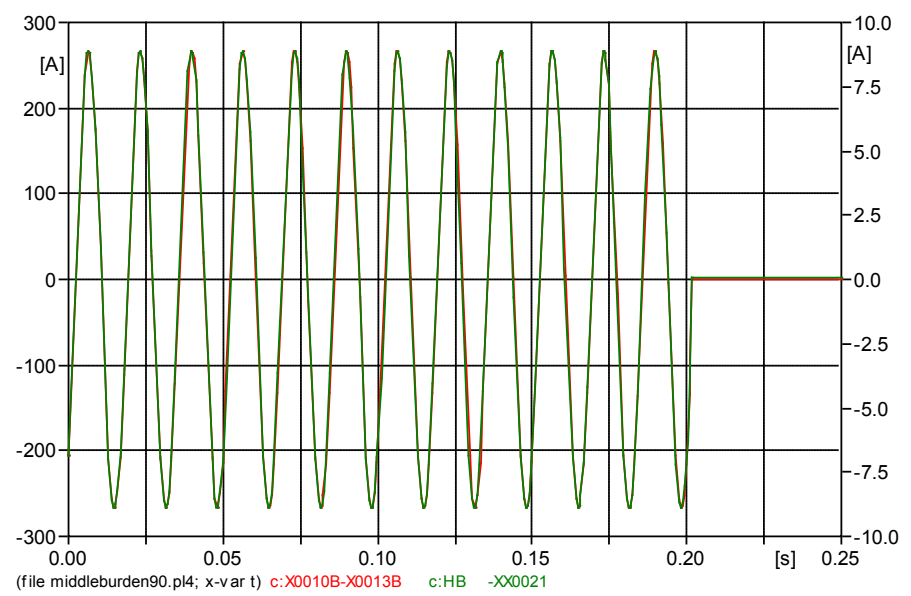

Figure G.14: 11.2 MVA, $Z s=5 \%$, heavy load, $\mathrm{R}_{\mathrm{TOT}}=0.676 \Omega$ : Phase-B pri and sec CT currents. 


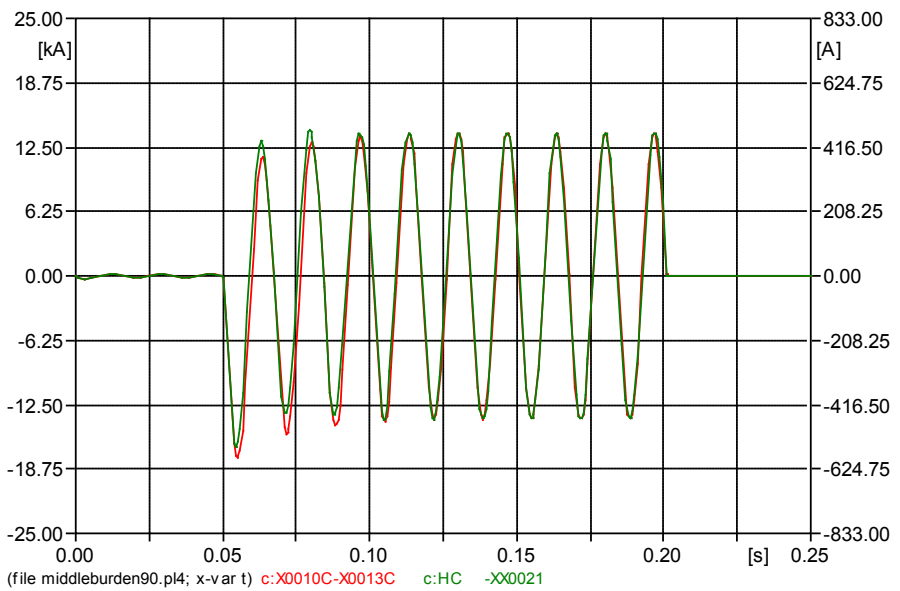

Figure G.15: 11.2 MVA, Zs=5\%, heavy load, $\mathrm{R}_{\mathrm{TOT}}=0.676 \Omega$ : Phase-C pri and sec CT currents.

3. $\mathrm{R}_{\mathrm{TOT}}=1.396 \Omega$.

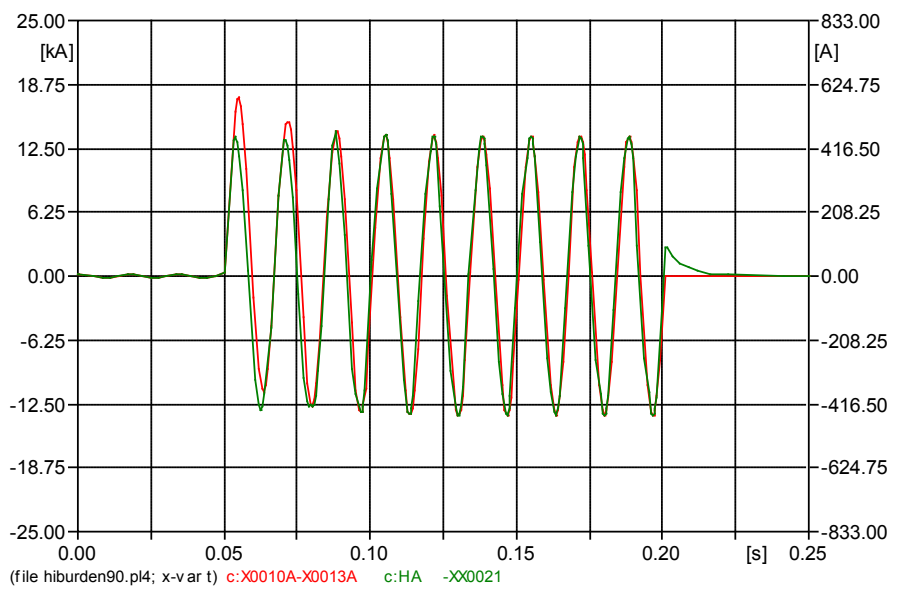

Figure G.16: 11.2 MVA, Zs=5\%, heavy load, $\mathrm{R}_{\mathrm{TOT}}=1.396 \Omega$ : Phase-A pri and sec CT currents.

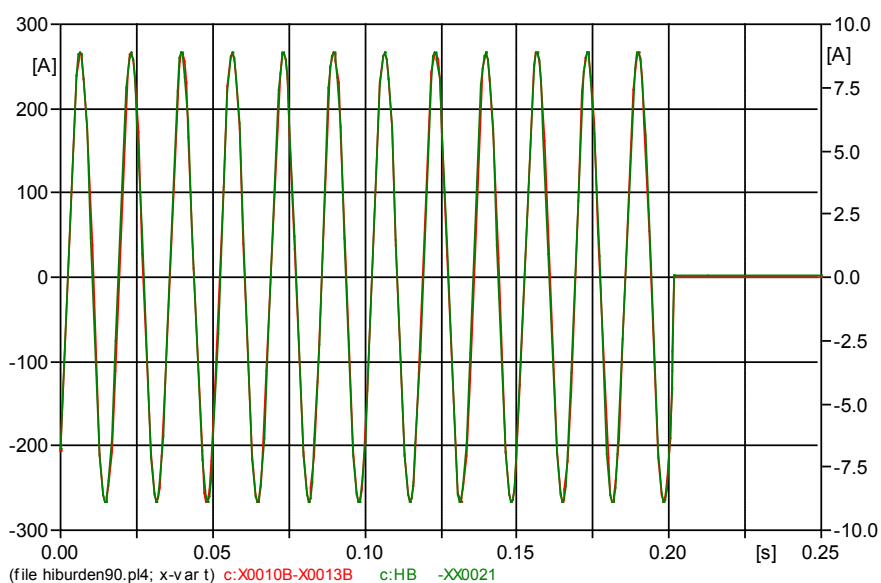

Figure G.17: 11.2 MVA, Zs=5\%, heavy load, $\mathrm{R}_{\mathrm{TOT}}=1.396 \Omega$ : Phase-B pri and sec $\mathrm{CT}$ currents. 


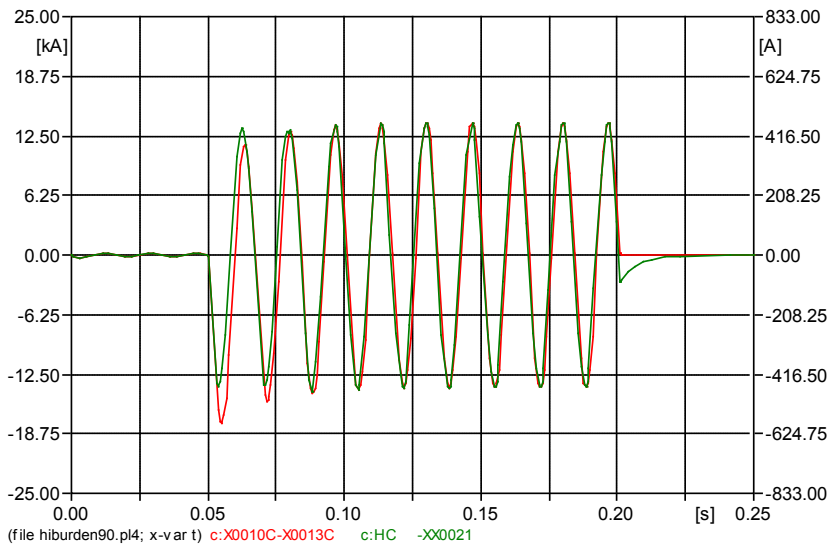

Figure G.18: 11.2 MVA, $Z s=5 \%$, heavy load, $\mathrm{R}_{\mathrm{TOT}}=1.396 \Omega$ : Phase-C pri and sec $\mathrm{CT}$ currents.

\section{G.1.2 Zsourse $=1 \%$ on 100 MVA base, $X / R=1$}

\section{G.1.2.1 Light load}

1. $\mathrm{R}_{\mathrm{TOT}}=0.256 \Omega$.

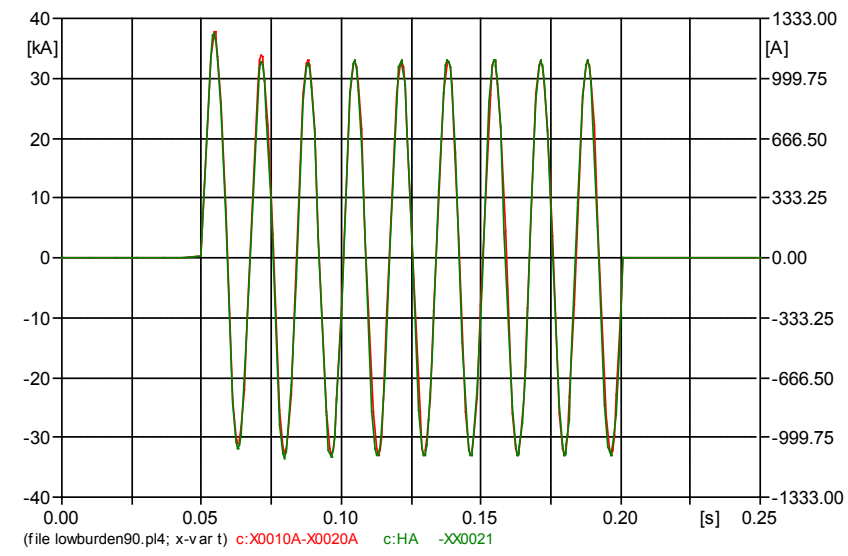

Figure G.19: $11.2 \mathrm{MVA}, \mathrm{Zs}_{\mathrm{s}}=1 \%$, light load, $\mathrm{R}_{\mathrm{TOT}}=0.256 \Omega$ : Phase-A pri and sec $\mathrm{CT}$ currents.

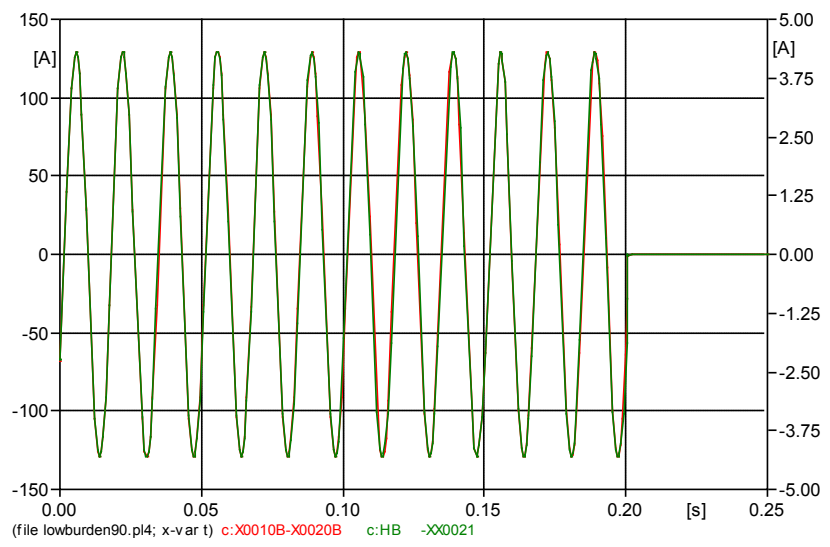

Figure G.20: 11.2 MVA, $Z s=1 \%$, light load, $\mathrm{R}_{\mathrm{TOT}}=0.256 \Omega$ : Phase-B pri and sec CT currents. 


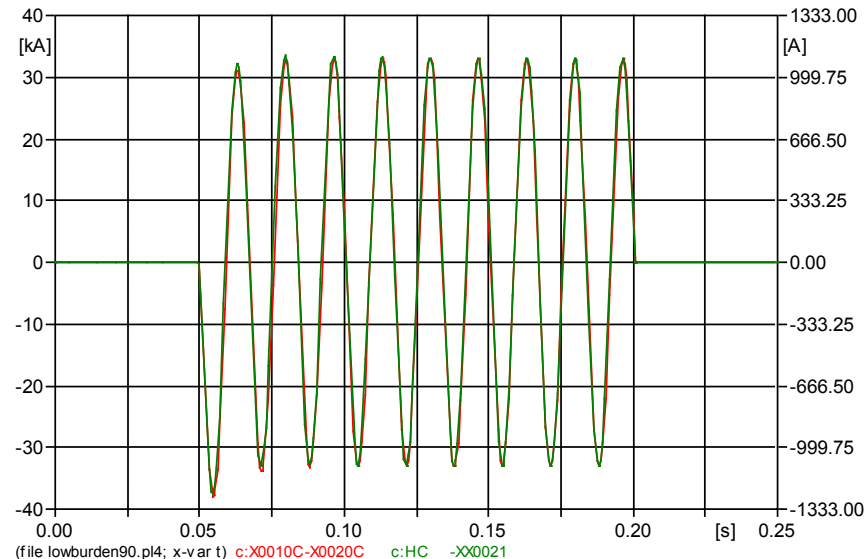

Figure G.21: 11.2 MVA, $Z_{\mathrm{s}}=1 \%$, light load, $\mathrm{R}_{\mathrm{TOT}}=0.256 \Omega$ : Phase-C pri and sec $\mathrm{CT}$ currents.

2. $\mathrm{R}_{\mathrm{TOT}}=0.676 \Omega$.

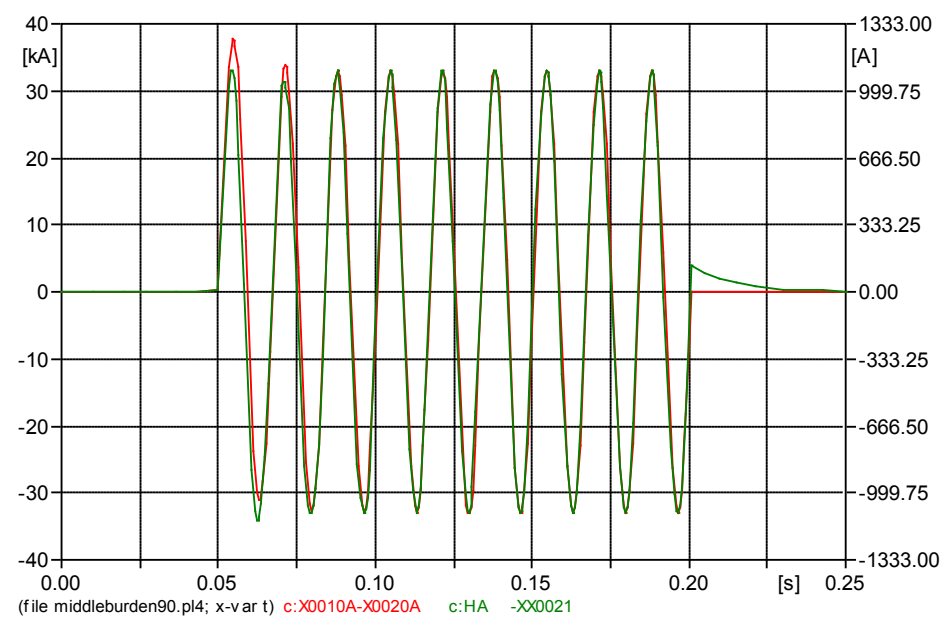

Figure G.22: 11.2 MVA, $Z s=1 \%$, light load, $\mathrm{R}_{\mathrm{TOT}}=0.676 \Omega$ : Phase-A pri and sec $\mathrm{CT}$ currents.

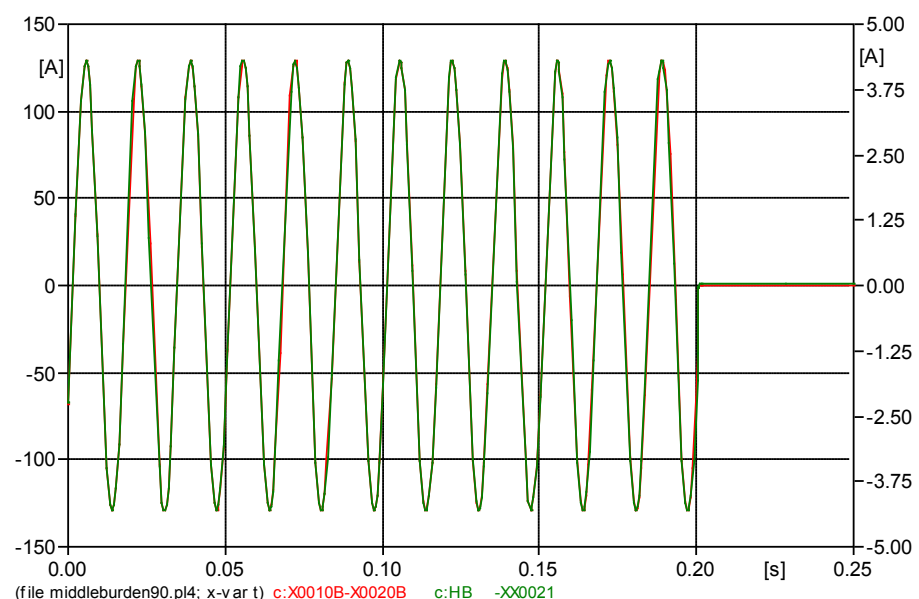

Figure G.23: 11.2 MVA, $Z s=1 \%$, light load, $\mathrm{R}_{\mathrm{TOT}}=0.676 \Omega$ : Phase-B pri and sec $\mathrm{CT}$ currents. 


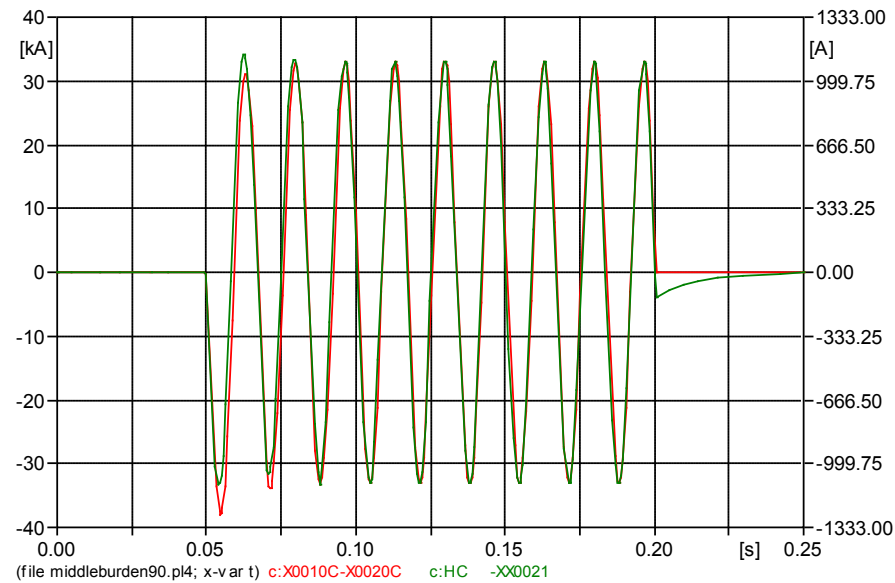

Figure G.24: $11.2 \mathrm{MVA}, \mathrm{Zs}_{\mathrm{s}}=1 \%$, light load, $\mathrm{R}_{\mathrm{TOT}}=0.676 \Omega$ : Phase-C pri and sec $\mathrm{CT}$ currents.

3. $\mathrm{R}_{\mathrm{TOT}}=1.396 \Omega$.

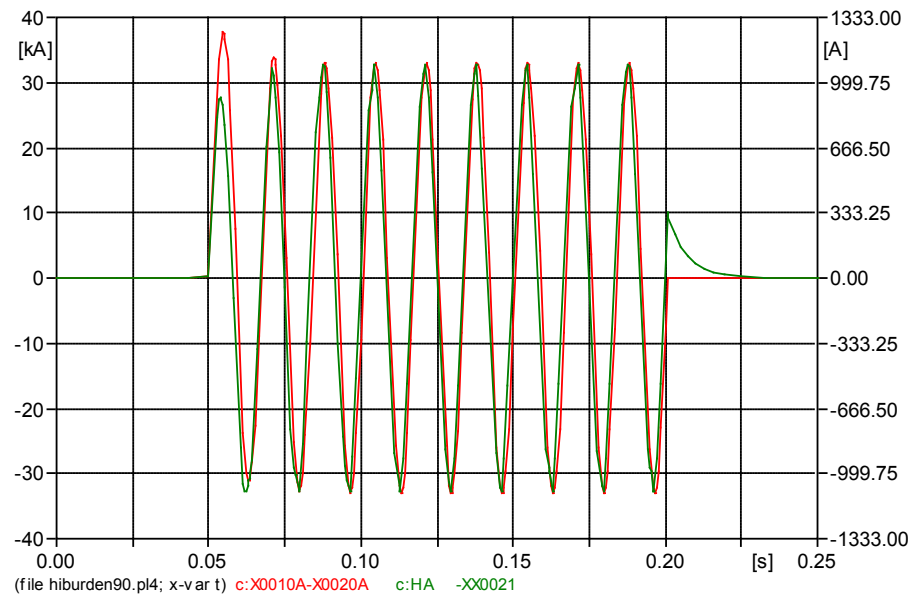

Figure G.25: 11.2 MVA, $Z_{s}=1 \%$, light load, $\mathrm{R}_{\mathrm{TOT}}=1.396 \Omega$ : Phase-A pri and sec CT currents.

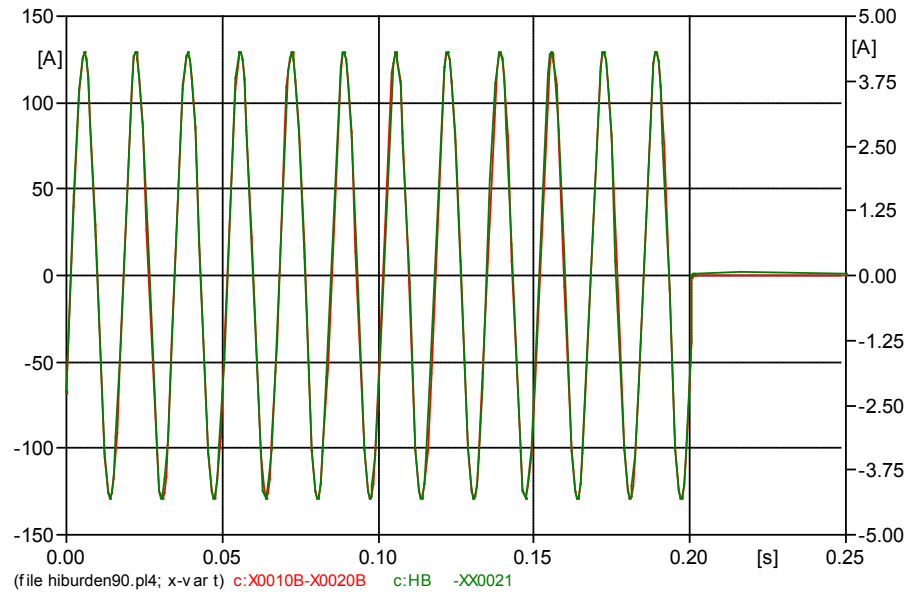

Figure G.26: $11.2 \mathrm{MVA}, \mathrm{Zs}_{\mathrm{s}}=1 \%$, light load, $\mathrm{R}_{\mathrm{TOT}}=1.396 \Omega$ : Phase-B pri and sec $\mathrm{CT}$ currents. 


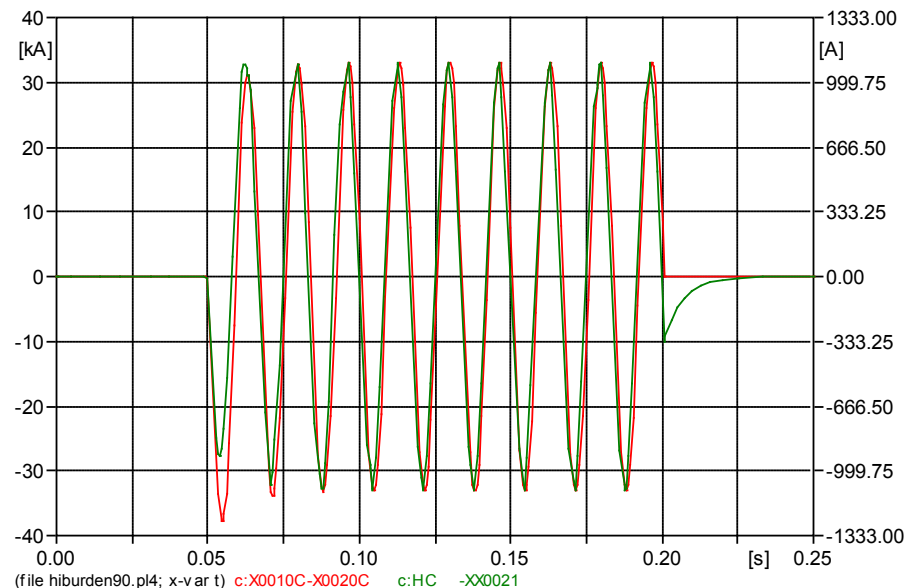

Figure G.27: 11.2 MVA, Zs=1\%, light load, $\mathrm{R}_{\mathrm{TOT}}=1.396 \Omega$ : Phase-C pri and sec $\mathrm{CT}$ currents.

\section{G.1.2.2 Heavy load}

1. $\mathrm{R}_{\mathrm{TOT}}=0.256 \Omega$.

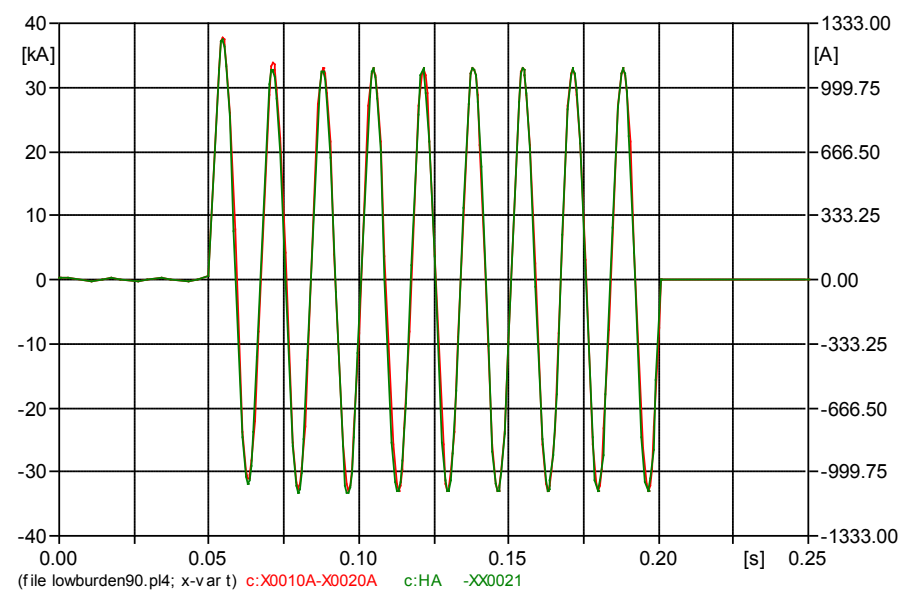

Figure G.28: 11.2 MVA, $Z s=1 \%$, heavy load, $\mathrm{R}_{\mathrm{TOT}}=0.256 \Omega$ : Phase-A pri and sec $\mathrm{CT}$ currents.

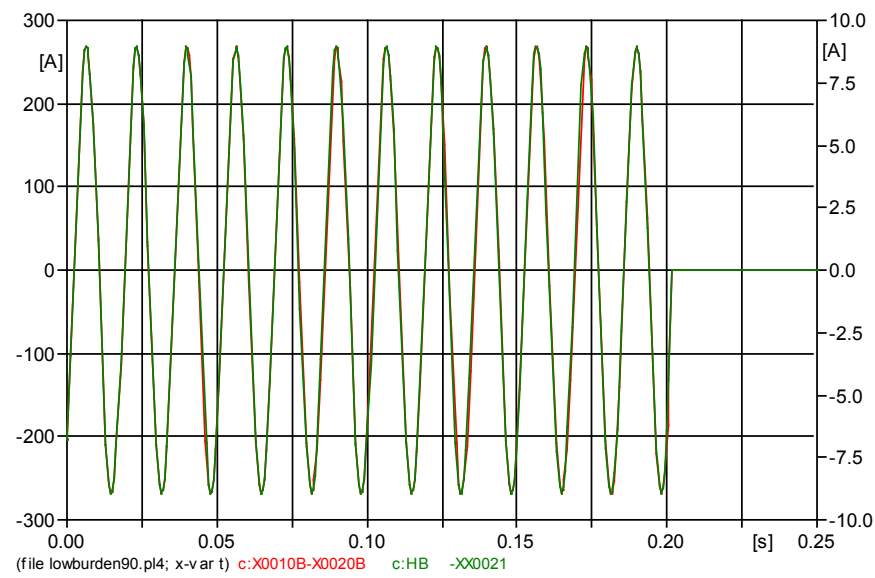

Figure G.29: 11.2 MVA, $Z s=1 \%$, heavy load, $\mathrm{R}_{\mathrm{TOT}}=0.256 \Omega$ : Phase-B pri and sec $\mathrm{CT}$ currents. 


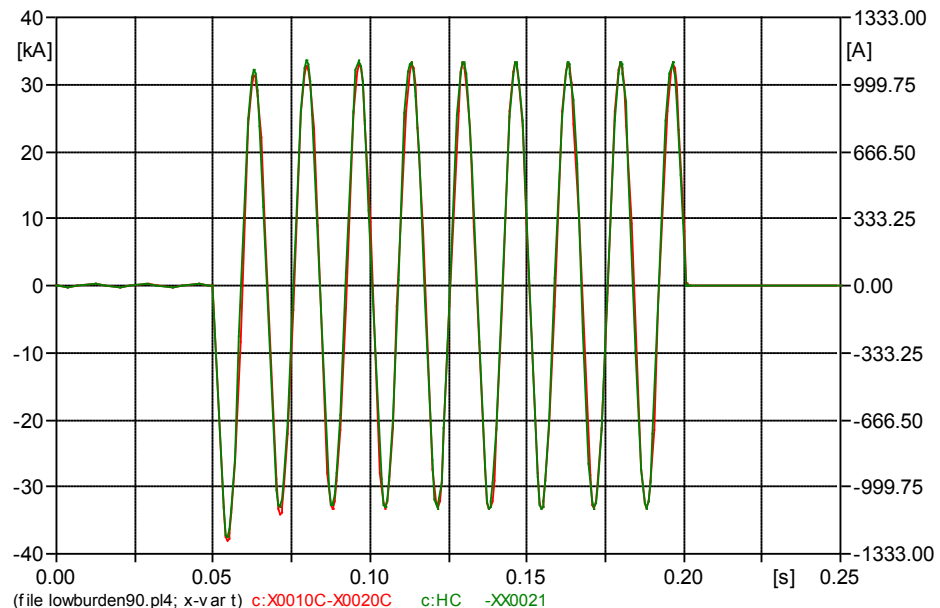

Figure G.30: $11.2 \mathrm{MVA}, \mathrm{Zs}=1 \%$, heavy load, $\mathrm{R}_{\mathrm{TOT}}=0.256 \Omega$ : Phase-C pri and sec $\mathrm{CT}$ currents.

2. $\mathrm{R}_{\mathrm{TOT}}=0.676 \Omega$

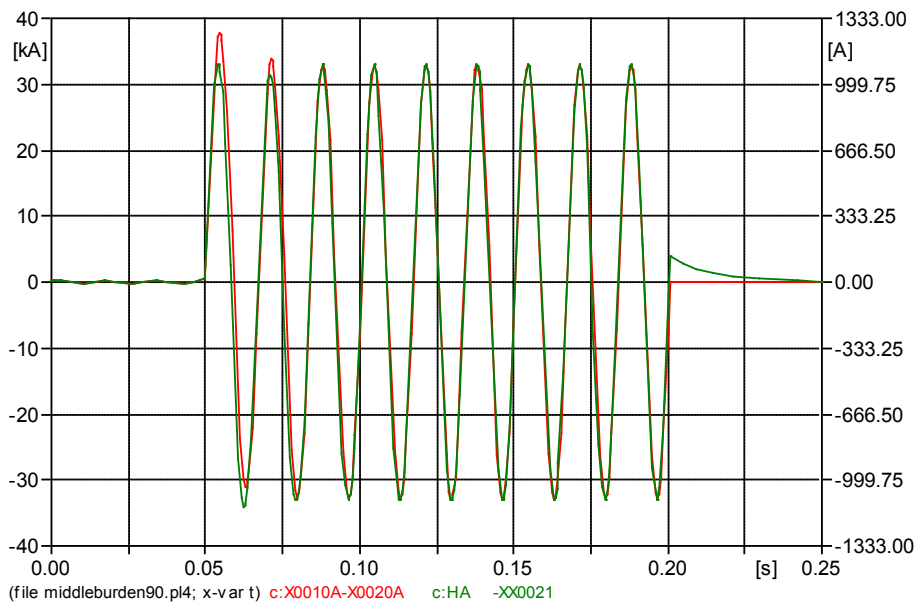

Figure G.31: 11.2 MVA, $Z s=1 \%$, heavy load, $\mathrm{R}_{\mathrm{TOT}}=0.676 \Omega$ : Phase-A pri and sec CT currents.

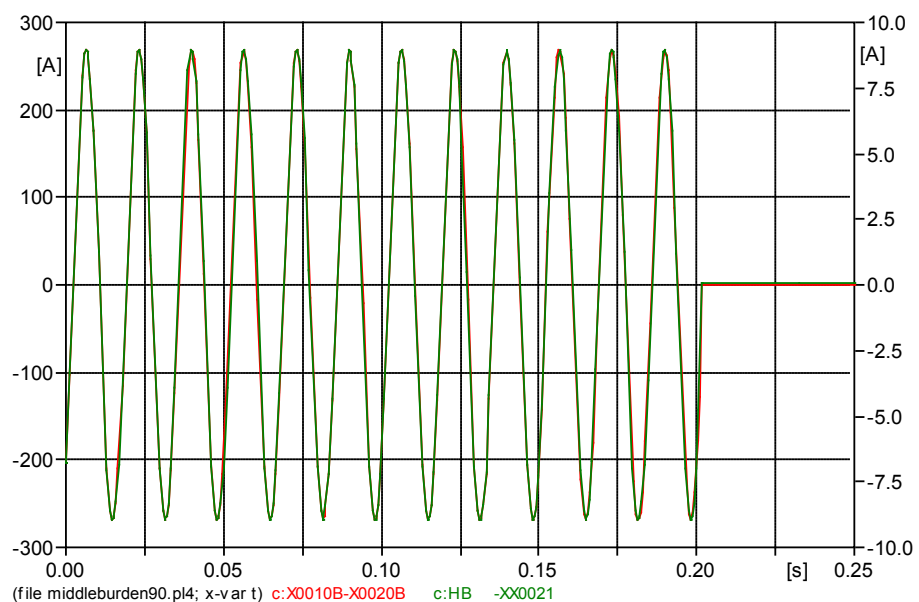

Figure G.32: $11.2 \mathrm{MVA}, \mathrm{Zs}=1 \%$, heavy load, $\mathrm{R}_{\mathrm{TOT}}=0.676 \Omega$ : Phase-B pri and sec $\mathrm{CT}$ currents. 


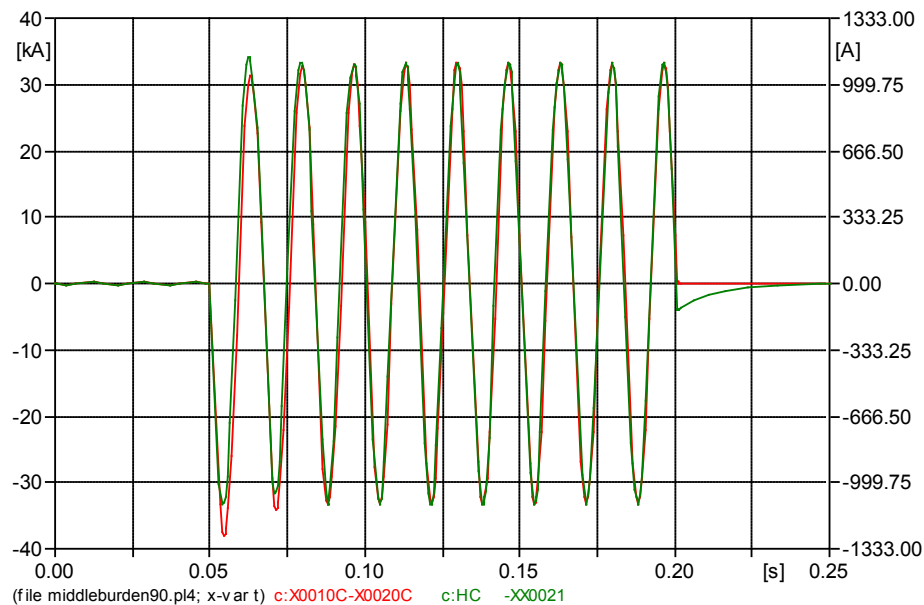

Figure G.33: 11.2 MVA, $Z s=1 \%$, heavy load, $\mathrm{R}_{\mathrm{TOT}}=0.676 \Omega$ : Phase-C pri and sec $\mathrm{CT}$ currents.

3. $\mathrm{R}_{\mathrm{TOT}}=1.396 \Omega$.

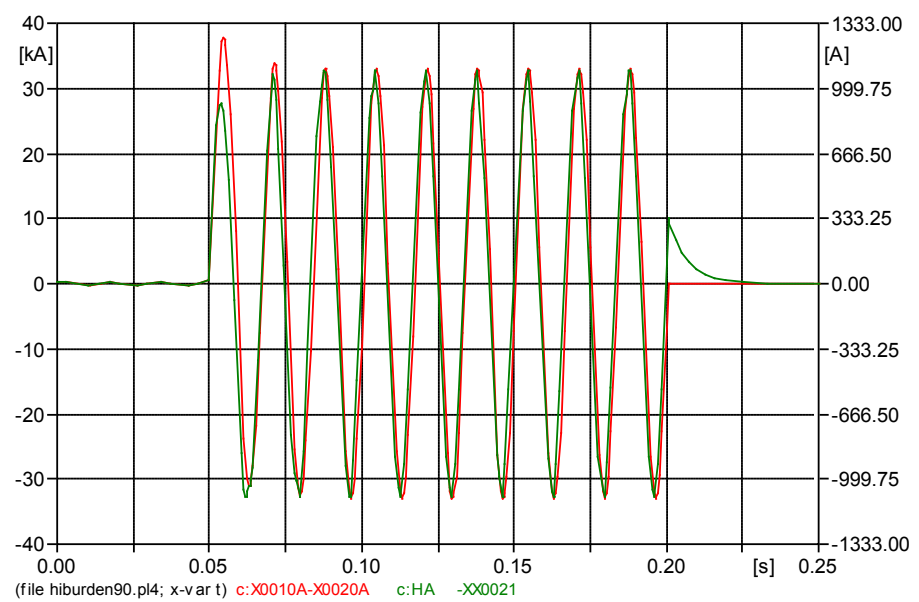

Figure G.34: 11.2 MVA, Zs=1\%, heavy load, $\mathrm{R}_{\mathrm{TOT}}=1.396 \Omega$ : Phase-A pri and sec CT currents.

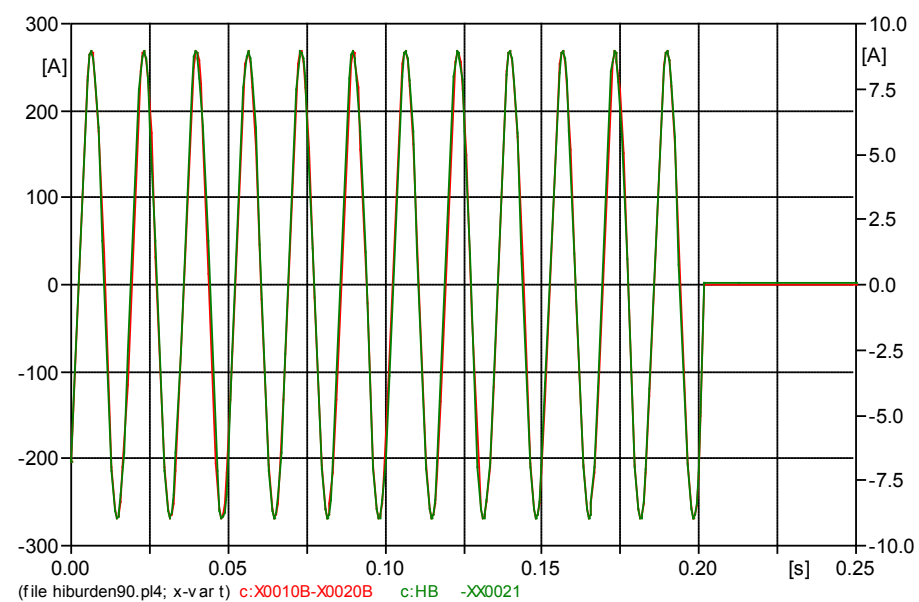

Figure G.35: 11.2 MVA, $Z_{\mathrm{s}}=1 \%$, heavy load, $\mathrm{R}_{\mathrm{TOT}}=1.396 \Omega$ : Phase-B pri and sec $\mathrm{CT}$ currents. 


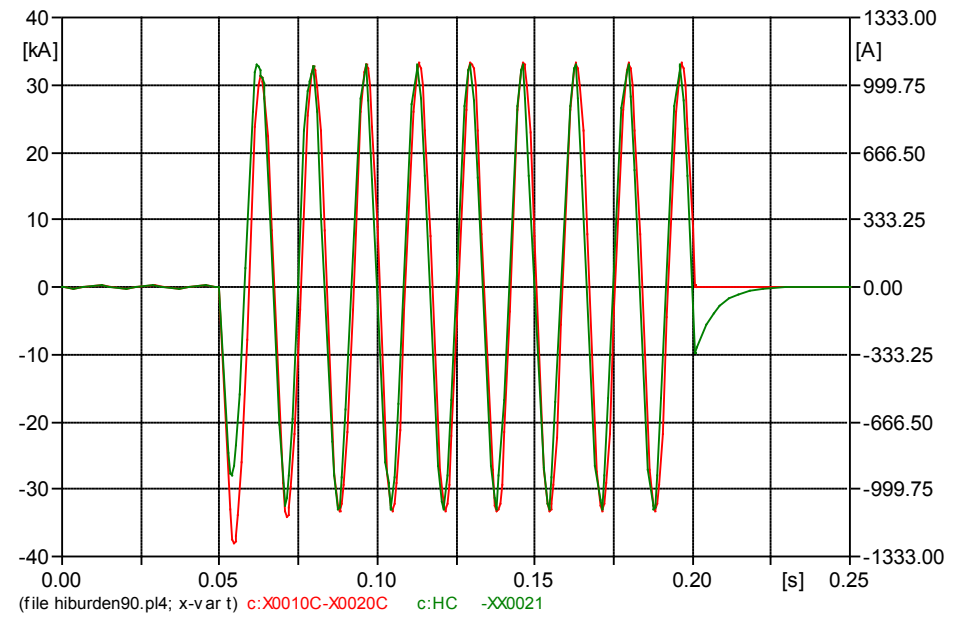

Figure G.36: 11.2 MVA, $Z_{s}=1 \%$, heavy load, $\mathrm{R}_{\mathrm{TOT}}=1.396 \Omega$ : Phase-C pri and sec $\mathrm{CT}$ currents.

For the case where $\mathrm{Zs}=5 \%$ on $100 \mathrm{MVA}$ base, load is heavy and $\mathrm{R}_{\mathrm{TOT}}=1.396 \Omega$, the currents in magnetizing branches of CTs are shown in Figures G.37 through G.39.

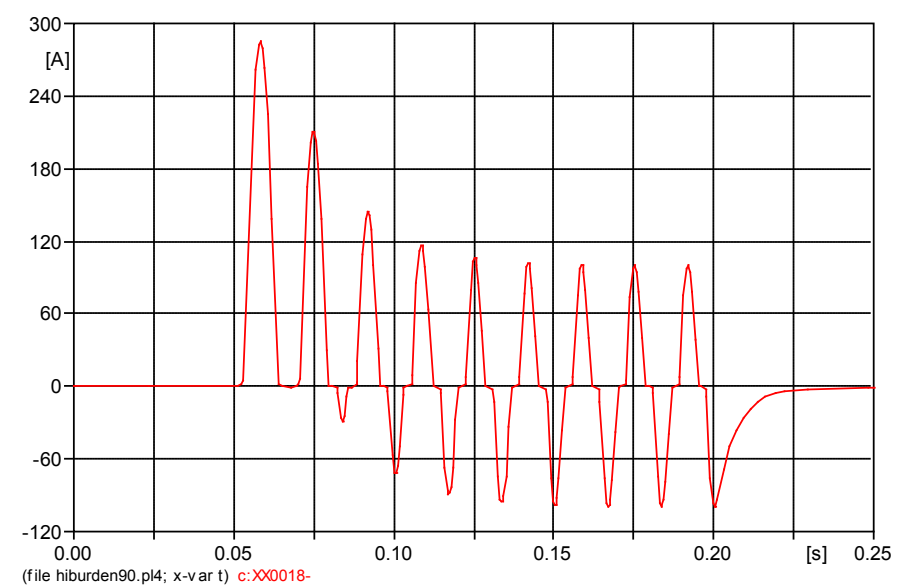

Figure G.37: 11.2 MVA, $Z s=5 \%$, heavy load, $\mathrm{R}_{\mathrm{TOT}}=1.396 \Omega$ : magnetizing current of phase-A CT.

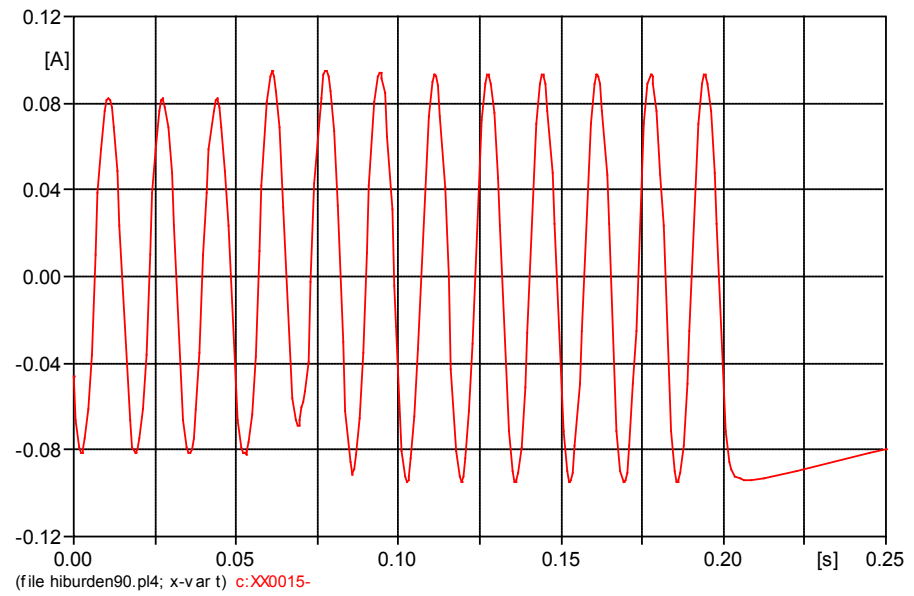

Figure G.38: 11.2 MVA, $Z s=5 \%$, heavy load, $\mathrm{R}_{\mathrm{TOT}}=1.396 \Omega$ : magnetizing current of phase-B CT. 


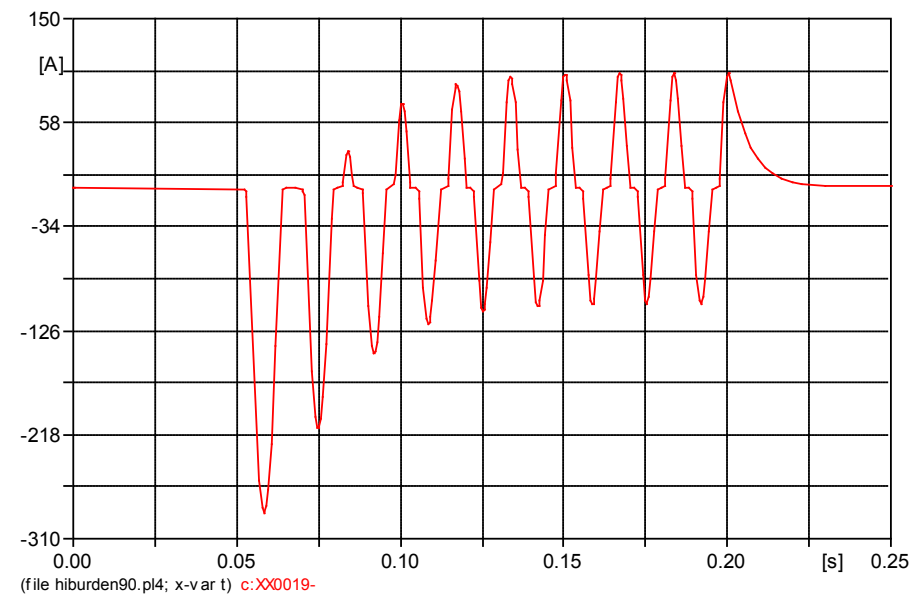

Figure G.39: 11.2 -MVA, $Z s=5 \%$, heavy load, $\mathrm{R}_{\mathrm{TOT}}=1.396 \Omega$ : magnetizing current of phase-C CT.

\section{G.2 The 290-MVA transformer, high-side 1200:5 CTs tapped at 800:5}

The three-phase through fault applied at time $\mathrm{t}=0.05 \mathrm{~s}$ is accompanied with the turn-toturn fault involving $90 \%$ of turns on phase-A winding, applied at time $\mathrm{t}=0.1 \mathrm{~s}$. Source voltage $\mathrm{Va}(0)=\mathrm{Vpeak}, \mathrm{Zs}_{\mathrm{s}}=10^{-8} \Omega$.

\section{G.2.1 Light load}

1. $\mathrm{R}_{\mathrm{TOT}}=0.512 \Omega$.

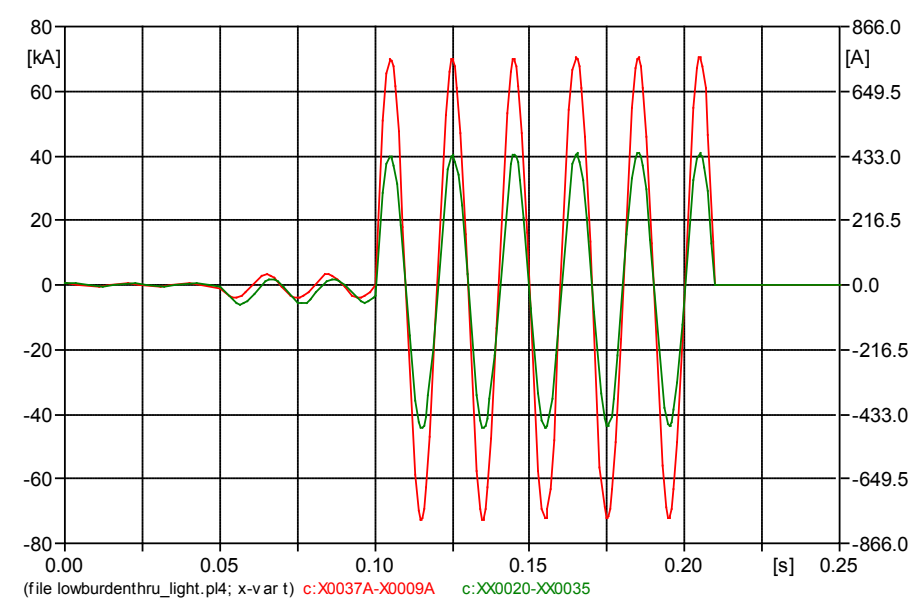

Figure G.40: 290 MVA, $Z s=10^{-8} \Omega$, light load, $\mathrm{R}_{\mathrm{TOT}}=0.512 \Omega$ : Phase-A pri and sec CT currents. 


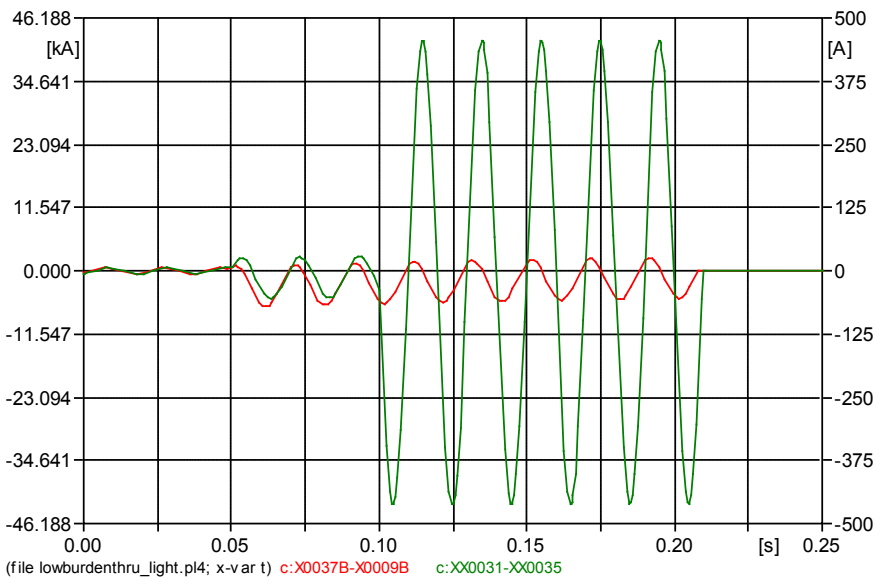

Figure G.41: 290 MVA, $Z s=10^{-8} \Omega$, light load, $\mathrm{R}_{\mathrm{TOT}}=0.512 \Omega$ : Phase-B pri and sec CT currents.

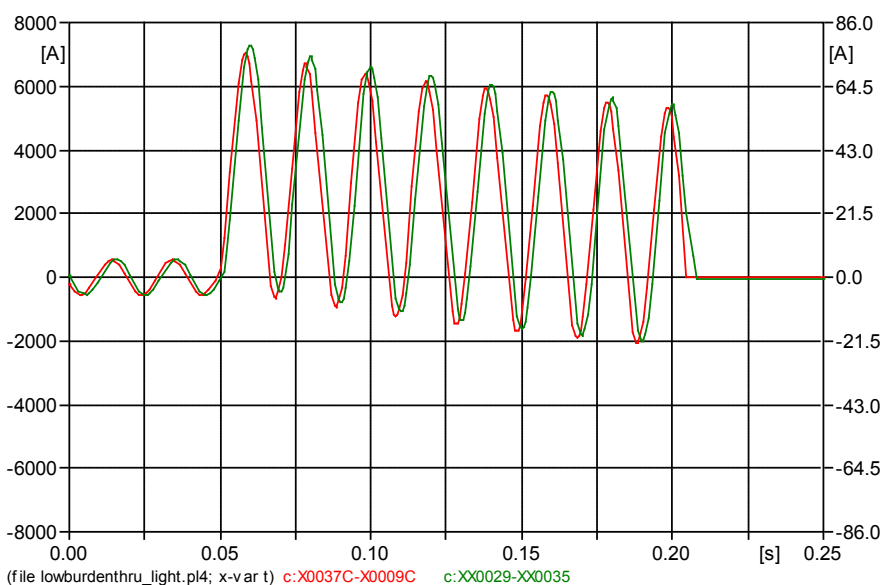

Figure G.42: $290 \mathrm{MVA}, \mathrm{Zs}_{\mathrm{s}}=10^{-8} \Omega$, light load, $\mathrm{R}_{\mathrm{TOT}}=0.512 \Omega$ : Phase-C pri and sec $\mathrm{CT}$ currents.

2. $\mathrm{R}_{\mathrm{TOT}}=0.932 \Omega$.

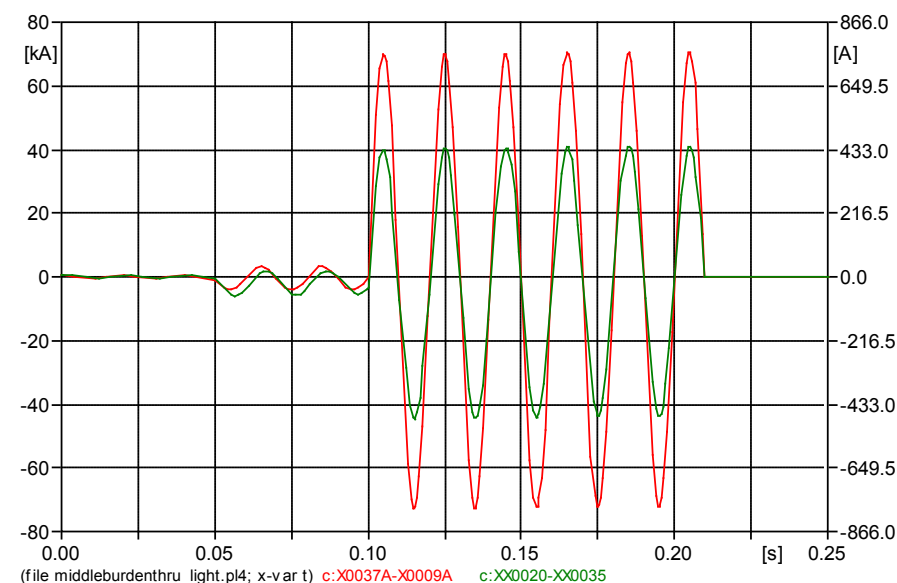

Figure G.43: 290 MVA, $Z s=10^{-8} \Omega$, light load, $\mathrm{R}_{\mathrm{TOT}}=0.932 \Omega$ : Phase-A pri and sec CT currents. 


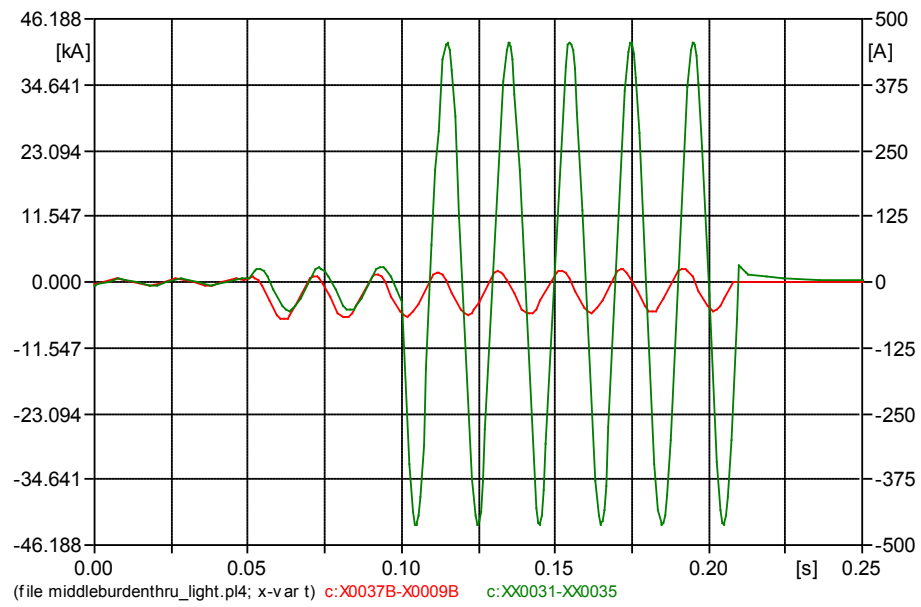

Figure G.44: 290 MVA, $Z s=10^{-8} \Omega$, light load, $\mathrm{R}_{\mathrm{TOT}}=0.932 \Omega$ : Phase- $\mathrm{B}$ pri and sec $\mathrm{CT}$ currents.

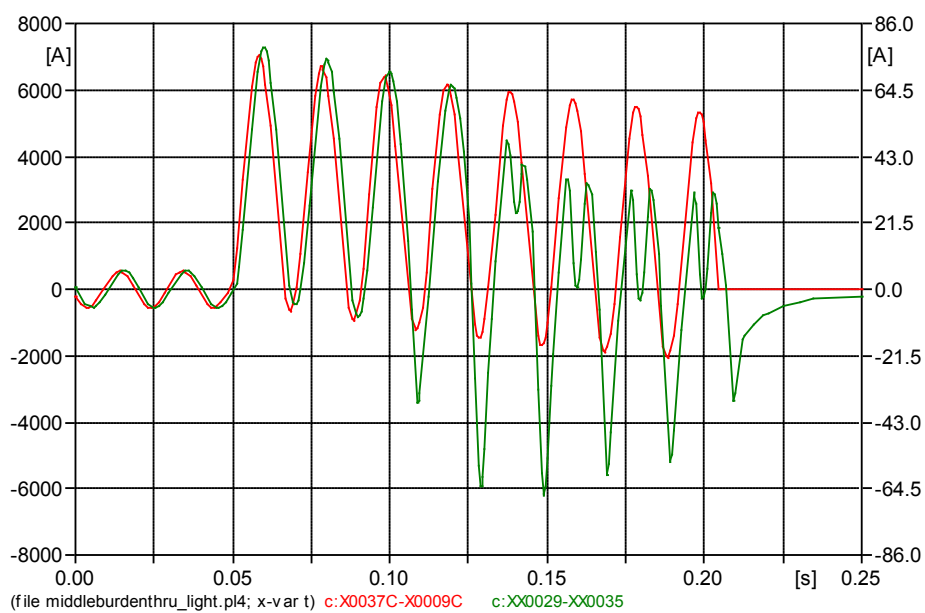

Figure G.45: 290 MVA, $Z_{s}=10^{-8} \Omega$, light load, $R_{\mathrm{TOT}}=0.932 \Omega$ : Phase-C pri and sec CT currents.

3. $\mathrm{R}_{\mathrm{TOT}}=1.652 \Omega$.

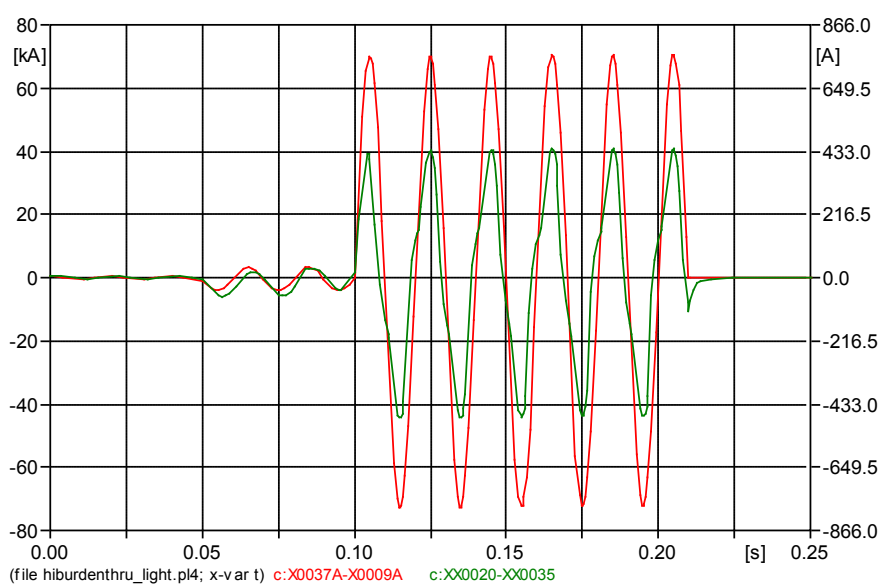

Figure G.46: 290 MVA, $Z s=10^{-8} \Omega$, light load, $\mathrm{R}_{\mathrm{TOT}}=1.652 \Omega$ : Phase-A pri and sec $\mathrm{CT}$ currents. 


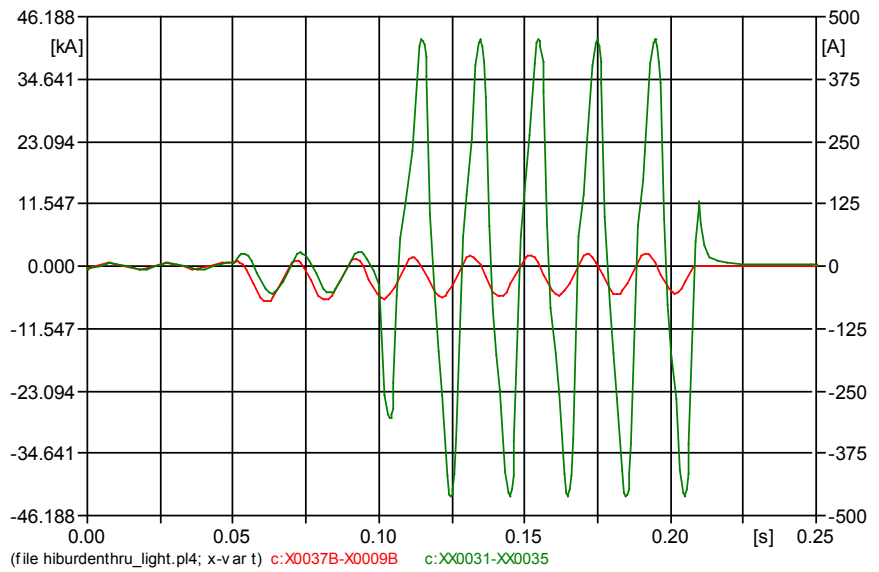

Figure G.47: 290 MVA, $Z s=10^{-8} \Omega$, light load, $\mathrm{R}_{\mathrm{TOT}}=1.652 \Omega$ : Phase-B pri and sec CT currents.

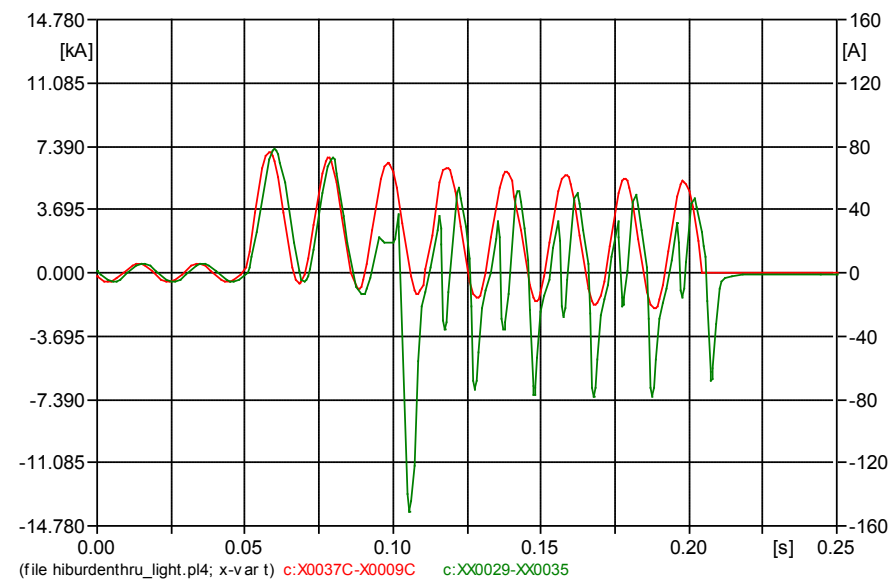

Figure G.48: 290 MVA, $Z s=10^{-8} \Omega$, light load, $\mathrm{R}_{\mathrm{TOT}}=1.652 \Omega$ : Phase-C pri and sec CT currents.

\section{G.2.2 Heavy load}

1. $\mathrm{R}_{\mathrm{TOT}}=0.512 \Omega$.

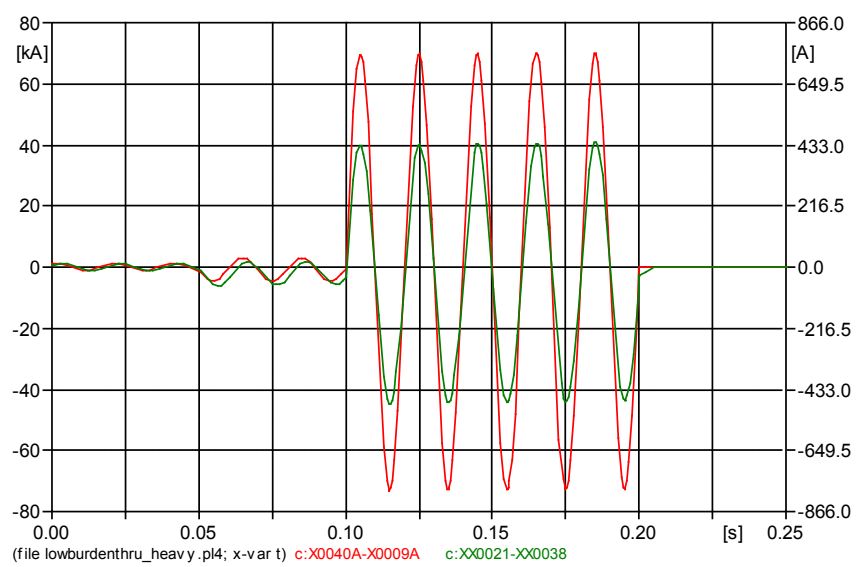

Figure G.49: 290 MVA, $Z s=10^{-8} \Omega$, heavy load, $\mathrm{R}_{\mathrm{TOT}}=0.512 \Omega$ : Phase-A pri and sec CT currents. 


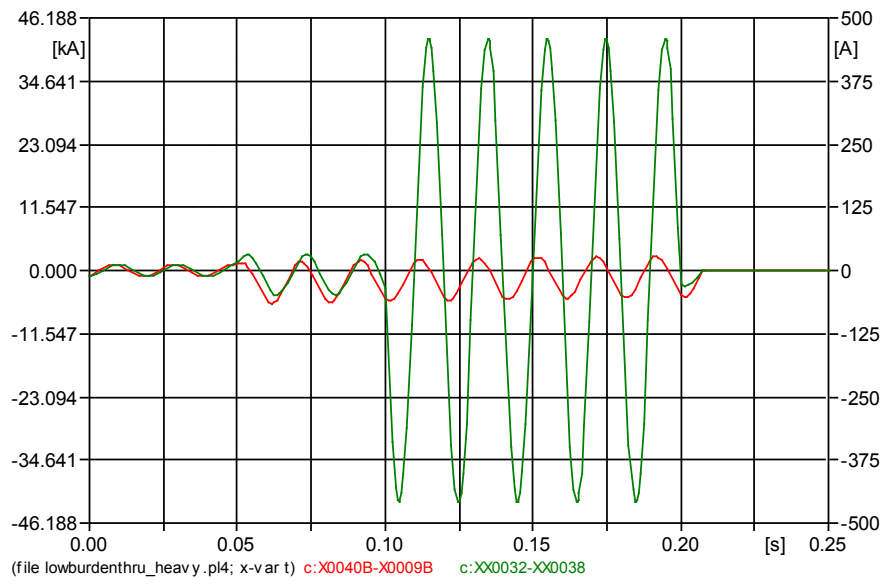

Figure G.50: 290 MVA, $Z_{s}=10^{-8} \Omega$, heavy load, $\mathrm{R}_{\text {TOT }}=0.512 \Omega$ : Phase-B pri and sec CT currents.

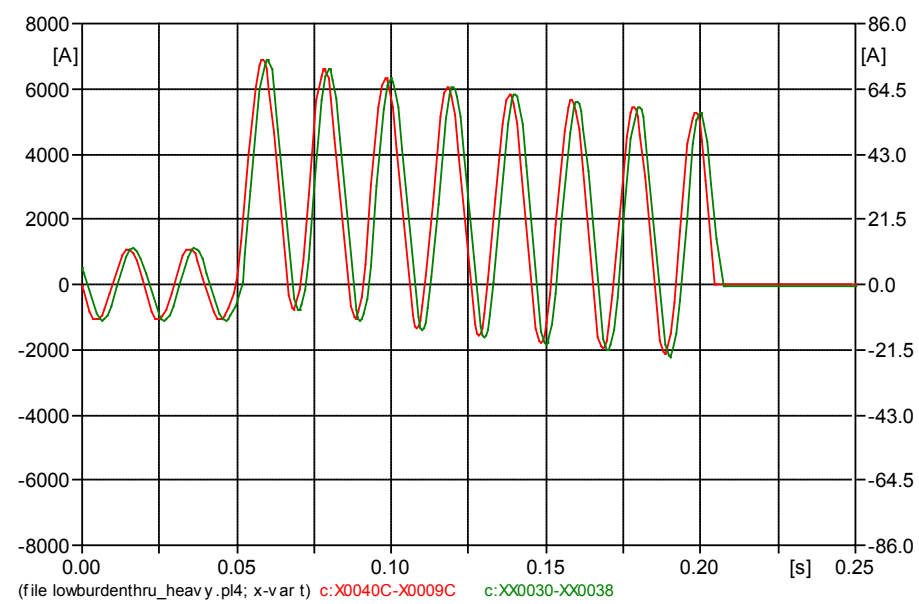

Figure G.51: 290 MVA, $Z_{s}=10^{-8} \Omega$, heavy load, $\mathrm{R}_{\text {TOT }}=0.512 \Omega$ : Phase-C pri and sec CT currents.

2. $\mathrm{R}_{\mathrm{TOT}}=0.932 \Omega$.

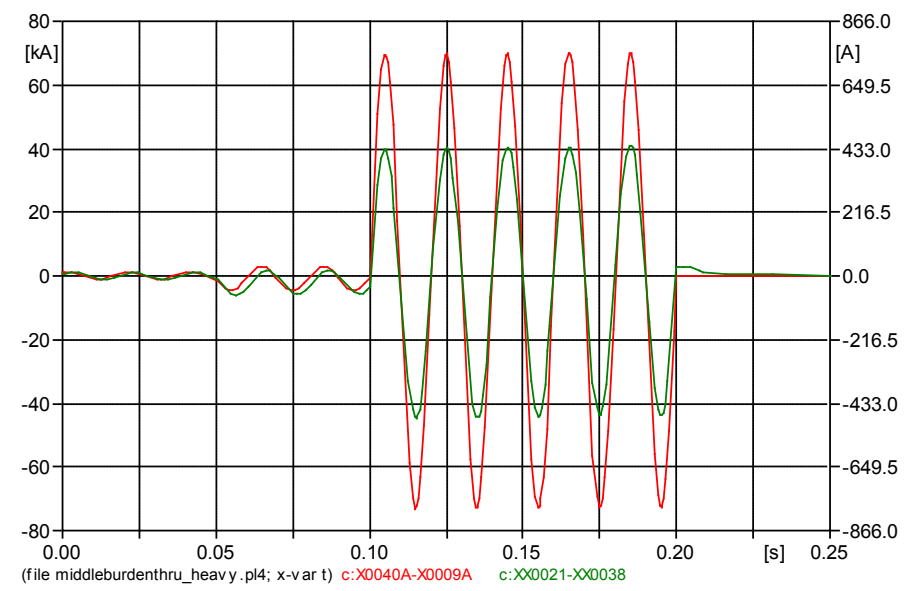

Figure G.52: 290 MVA, $Z s=10^{-8} \Omega$, heavy load, $\mathrm{R}_{\mathrm{TOT}}=0.932 \Omega$ : Phase-A pri and sec $\mathrm{CT}$ currents. 


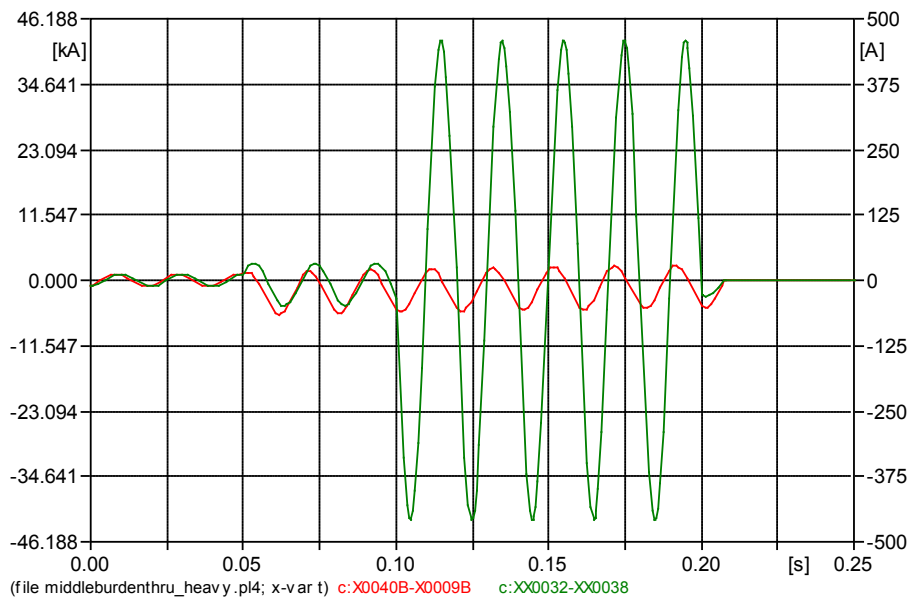

Figure G.53: 290 MVA, $Z_{s}=10^{-8} \Omega$, heavy load, $\mathrm{R}_{\mathrm{TOT}}=0.932 \Omega$ : Phase-B pri and sec CT currents.

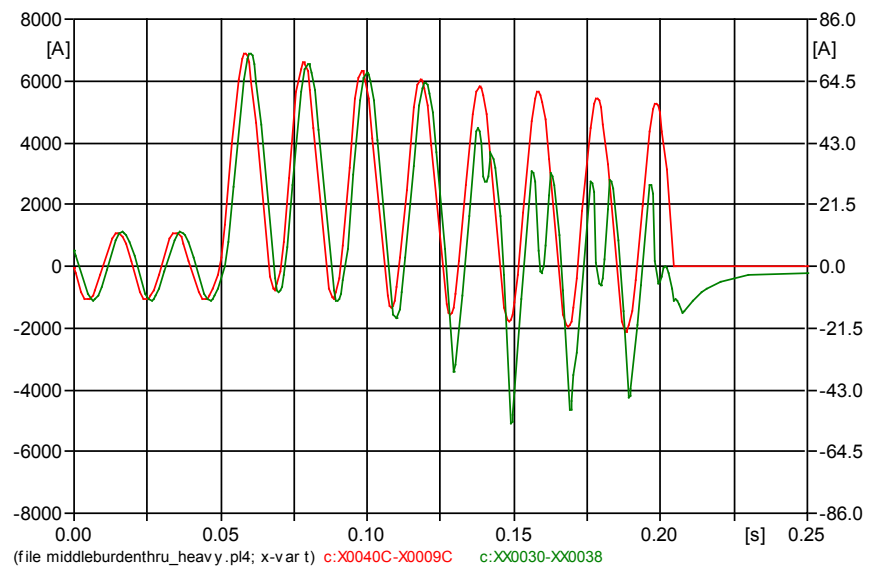

Figure G.54: 290 MVA, $Z_{s}=10^{-8} \Omega$, heavy load, $\mathrm{R}_{\mathrm{TOT}}=0.932 \Omega$ : Phase-C pri and sec CT currents.

3. $\mathrm{R}_{\mathrm{TOT}}=1.652 \Omega$.

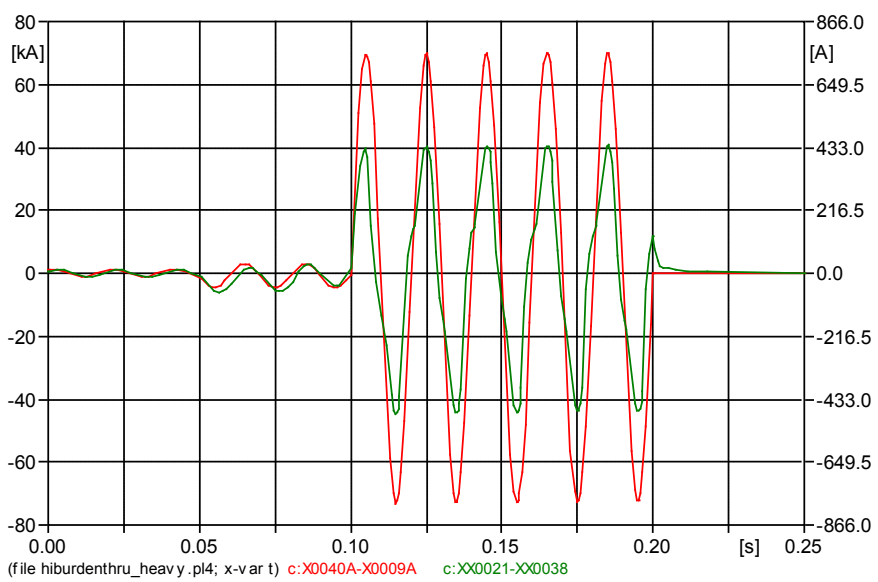

Figure G.55: 290 MVA, $Z s=10^{-8} \Omega$, heavy load, $\mathrm{R}_{\mathrm{TOT}}=1.652 \Omega$ : Phase-A pri and sec CT currents. 


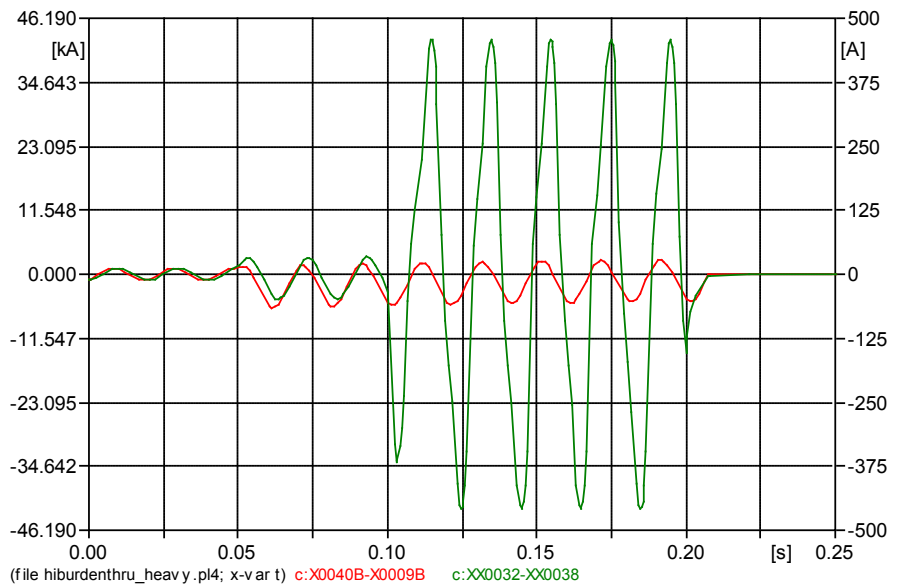

Figure G.56: $290 \mathrm{MVA}, \mathrm{Zs}=10^{-8} \Omega$, heavy load, $\mathrm{R}_{\mathrm{TOT}}=1.652 \Omega$ : Phase-B pri and sec CT currents.

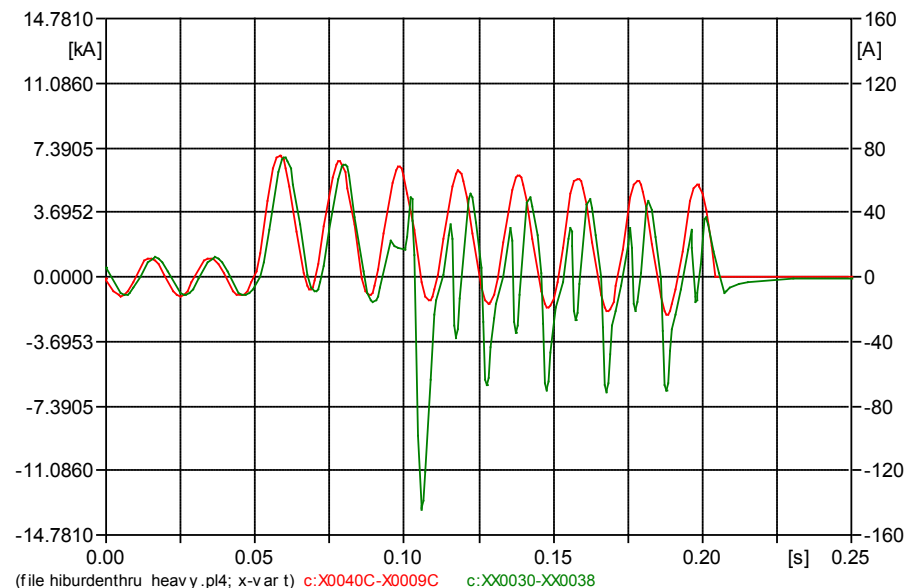

Figure G.57: 290 MVA, $Z s=10^{-8} \Omega$, heavy load, $\mathrm{R}_{\mathrm{TOT}}=1.652 \Omega$ : Phase-C pri and sec CT currents.

For the last case, currents in magnetizing branches of CTs are shown for phases A, B and C correspondingly.

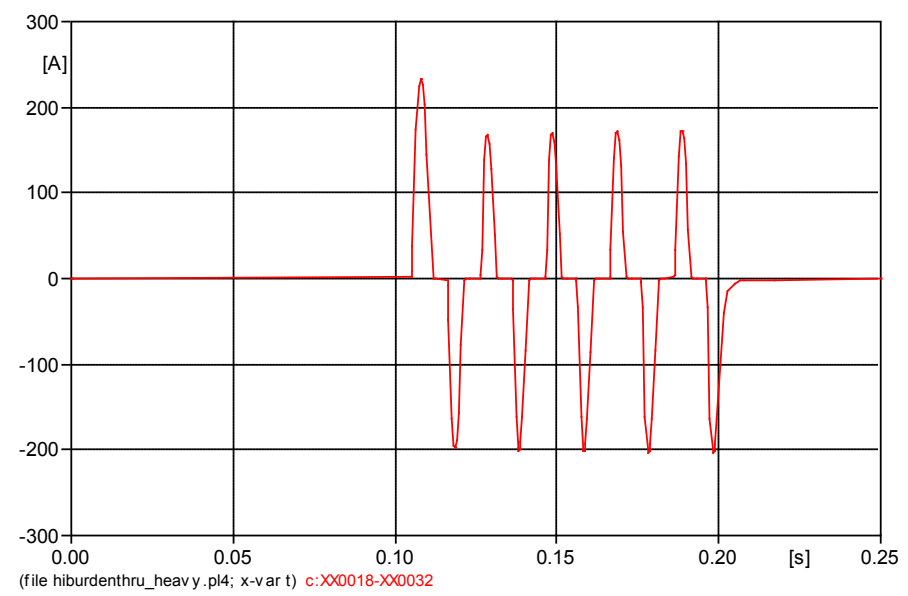

Figure G.58: $290 \mathrm{MVA}, \mathrm{Zs}=10^{-8} \Omega$, heavy load, $\mathrm{R}_{\mathrm{TOT}}=1.652 \Omega$ : magnetizing current of phase-A CT. 


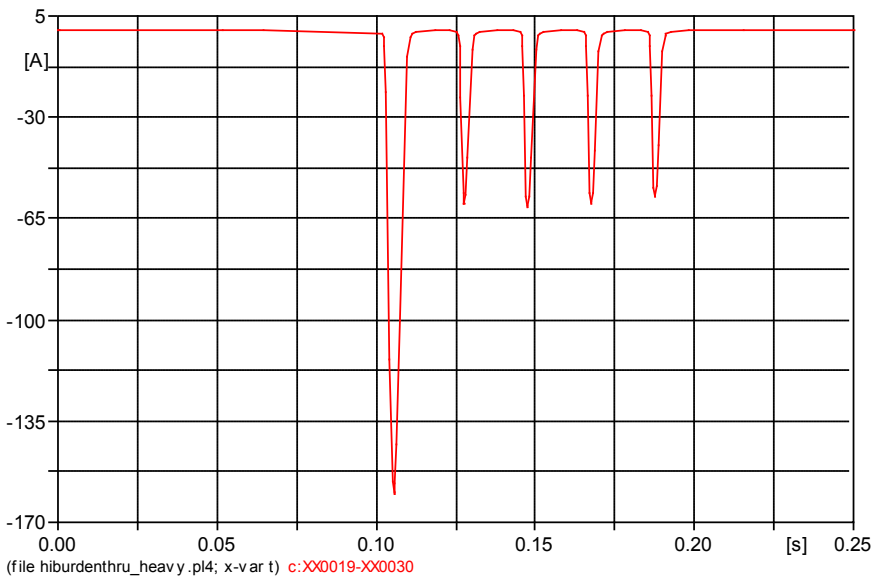

Figure G.59: $290 \mathrm{MVA}, \mathrm{Zs}=10^{-8} \Omega$, heavy load, $\mathrm{R}_{\mathrm{TOT}}=1.652 \Omega$ : magnetizing current of phase-B CT.

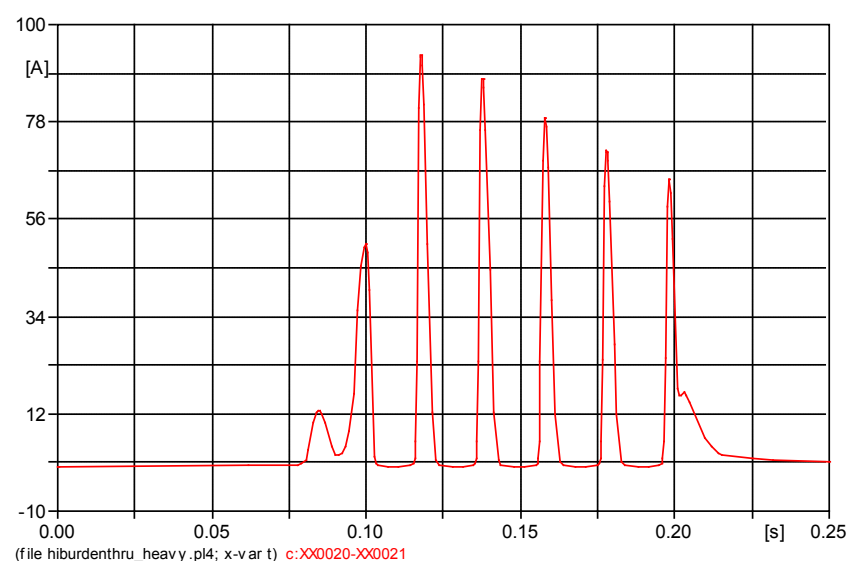

Figure G.60: 290 MVA, $\mathrm{Zs}_{\mathrm{s}}=10^{-8} \Omega$, heavy load, $\mathrm{R}_{\mathrm{TOT}}=1.652 \Omega$ : magnetizing current of phase-C CT. 



\section{Appendix H \\ Copyright permissions}

Zimbra Collaboration Suite

Re: copyright permission for a picture

Tuesday, August 10, 2010 1:25:20 PM

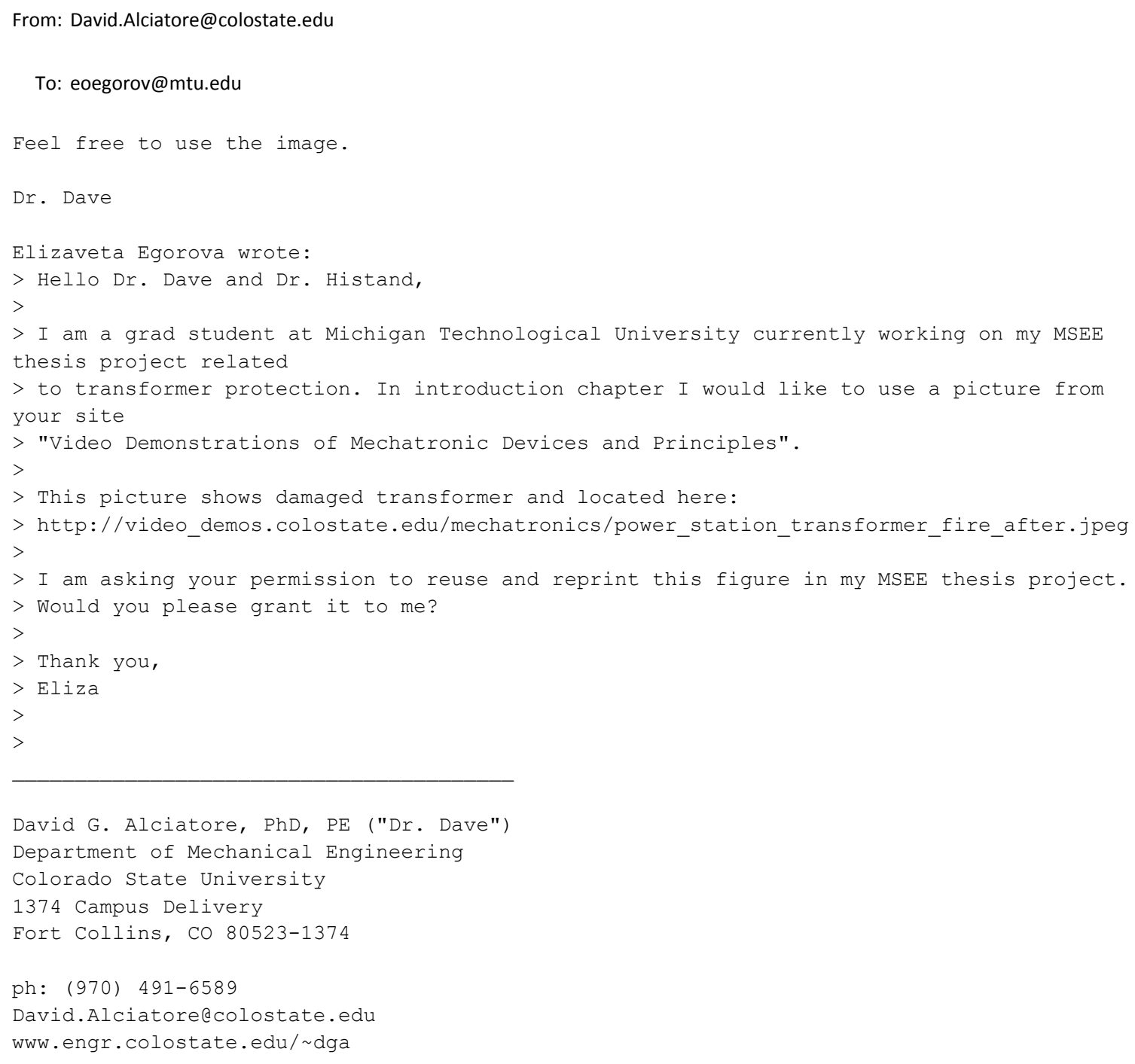




\begin{tabular}{|c|c|c|}
\hline $\begin{array}{l}\text { Confirmation Number: } 10104900 \\
\text { Order Date: } 01 / 13 / 2011\end{array}$ & & $\begin{array}{l}\text { Print citation information } \\
\text { (What's this?) }\end{array}$ \\
\hline \multicolumn{3}{|l|}{ Customer Information } \\
\hline \multicolumn{3}{|l|}{$\begin{array}{l}\text { Customer: Elizaveta Egorova } \\
\text { Account Number: } 3000331328 \\
\text { Organization: Michigan Technological } \\
\text { University } \\
\text { Email: eoegorov@mtu.edu } \\
\text { Phone: }+1 \text { (906)4871433 } \\
\text { Payment Method: Invoice }\end{array}$} \\
\hline Search order details by: Choose One & $\nabla$ & Go \\
\hline
\end{tabular}

Order Details

Protective relaying : principles and applications

Order detail ID: 49570770

ISBN: 978-1-57444-716-3

Publication year: 2007

Publication Book

Type:

TAYLOR \& FRANCIS GROUP LLC

Author/Editor: Figure 3 of IEEE 76-CH1130-4, PWR Transient Responce of Current

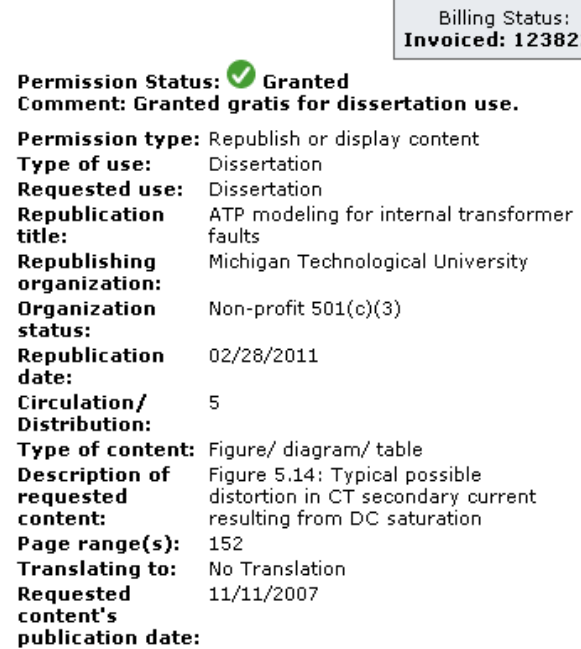

Organization Non-profit 501(c)(3) Republication $\quad 02 / 28 / 2011$

date:

Circulation/

Distribution:

Type of content: Figure/ diagram/table

Description of Figure 5.14: Typical possible

requested distortion in CT secondary current

content: 15 resultinge range(s): 152

Translating to: No Translation

Requested 11/11/2007

content's

publication date:

Your reference: Elizaveta Egorova's thesis, chapter 2 organization:

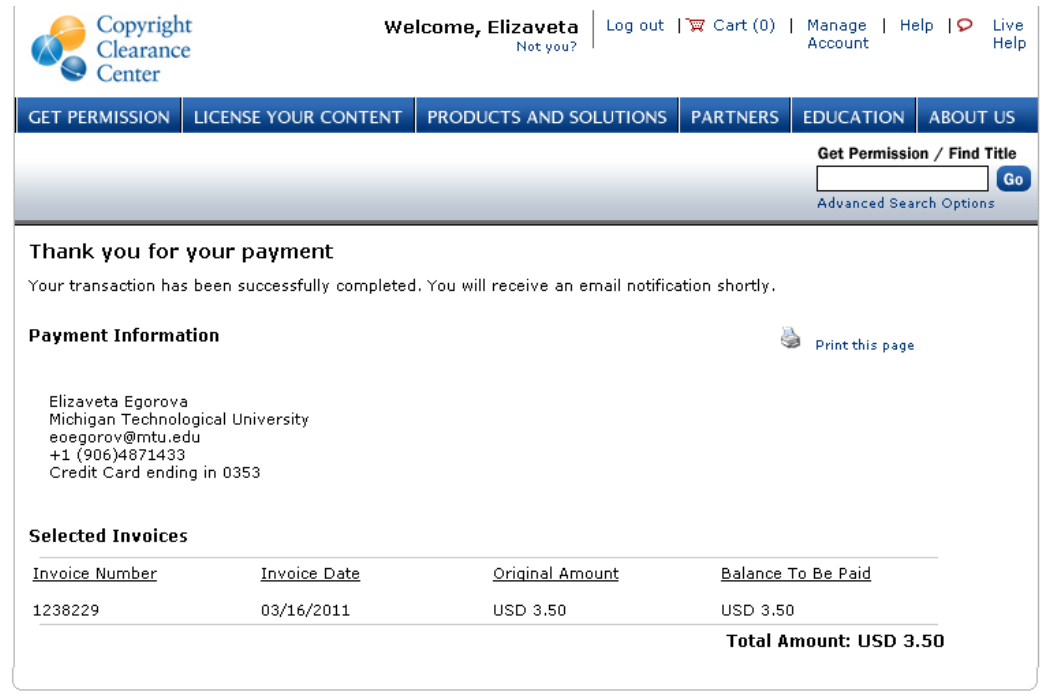




\section{GRANT OF COPYRIGHT LICENSE}

Effective 11 August 2010, Schweitzer Engineering Laboratories, Inc. ("SEL") grants to Elizaveta Olegovna Egorova, MSEE Candidate, Power and Energy Systems at Michigan Technological University, Department of Electric Power Engineering, 1400 Townsend Drive, EERC SB-27, Houghton, MI 49931 ("Licensee") a perpetual, non-exclusive, royalty-free license to reproduce and distribute the Licensed Works as defined herein, solely in connection with academic work with Michigan Technological University.

The Licensed Works include:

Figures 4.2, 4.9, and 4.19 from the publication "SEL-487E Relay, Current Differential and Voltage Protection, Instruction Manual", published by SEL on 7 April 2010; and

The front view of the SEL-487E relay available at

$<$ https://www.selinc.com/uploadedimages/Products/productImages/SEL487E/487E_600.jpg? $\mathrm{n}=5381>$ on 11 August 2010.

Each occurrence of the Licensed Works shall indicate that SEL owns the copyright to such by placing in the title for the License Work or in a footnote on the same page as the Licensed Work: "CC Schweitzer Engineering Laboratories, Inc. 2010".

No title or ownership interest in Licensed Works is transferred to Licensee.

SCHWEITZER ENGINEERING

LABORATORIES, INC.

Name: Nancy L. Hindman

Title: Chief Operating Officer

Date: August 23,2010 